UNIVERSIDADE DE BRASÍLIA

FACULDADE DE TECNOLOGIA DEPARTAMENTO DE ENGENHARIA ELÉTRICA

PROPOSTA E ANÁLISE DE INDICADORES ELETROMIOGRÁFICOS ESPECTRAIS E TEMPORAIS EM PROTOCOLOS DINÂMICOS COM INDUÇÃO DE FADIGA MUSCULAR LOCALIZADA

THIAGO RAPOSO MILHOMEM DE CARVALHO

ORIENTADOR: FRANCISCO ASSIS DE OLIVEIRA NASCIMENTO CO-ORIENTADOR: JAKE CARVALHO DO CARMO

TESE DE DOUTORADO EM ENGENHARIA DE SISTEMAS ELETRÔNICOS E AUTOMAÇÃO

PUBLICAÇÃO: PGEA.TD - 103/15

BRASÍLIA/DF: NOVEMBRO - 2015 
UNIVERSIDADE DE BRASÍLIA

FACULDADE DE TECNOLOGIA

DEPARTAMENTO DE ENGENHARIA ELÉTRICA

\section{PROPOSTA E ANÁLISE DE INDICADORES ELETROMIOGRÁFICOS ESPECTRAIS E TEMPORAIS EM PROTOCOLOS DINÂMICOS COM INDUÇÃO DE FADIGA MUSCULAR LOCALIZADA}

\section{THIAGO RAPOSO MILHOMEM DE CARVALHO}

TESE DE DOUTORADO SUBMETIDA AO DEPARTAMENTO DE ENGENHARIA ELÉTRICA DA FACULDADE DE TECNOLOGIA DA UNIVERSIDADE DE BRASÍLIA, COMO PARTE DOS REQUISITOS NECESSÁRIOS PARA A OBTENÇÃO DO GRAU DE DOUTOR.

APROVADA POR:

FRANCISCO ASSIS DE OLIVEIRA NASGIMENTO, Dr., ENE/UnB

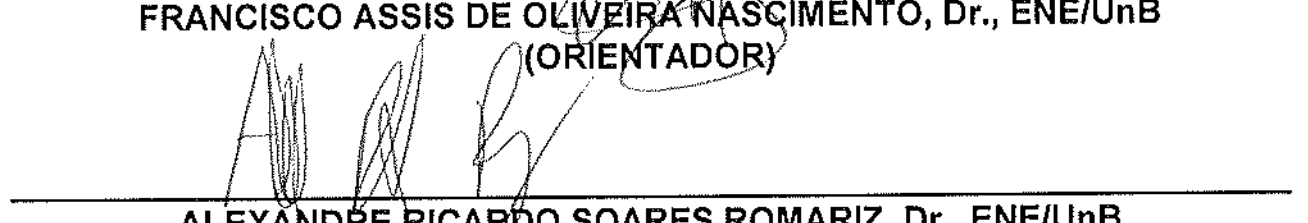

ALEXANDRE RICARPO SOARES ROMARIZ, Dr., ENE/UnB

(EXAMINADOR INTERNO)
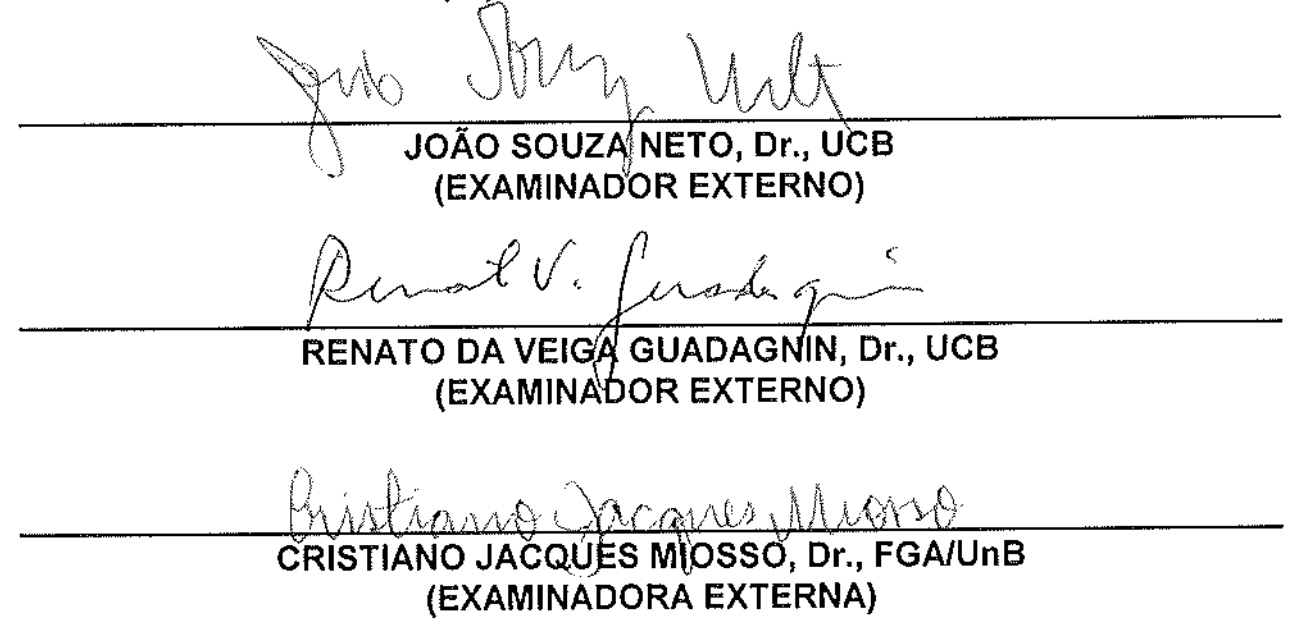

Brasília, 03 de novembro de 2015. 


\section{FICHA CATALOGRÁFICA}

CARVALHO, THIAGO RAPOSO MILHOMEM DE

Proposta e Análise de Indicadores Eletromiográficos Espectrais e Temporais em Protocolos

Dinâmicos com Indução de Fadiga Muscular Localizada [Distrito Federal] 2015.

xxvi, 203 p., 210 x 297 mm (ENE/FT/UnB, Doutor, Tese de Doutorado - Universidade de Brasília. Faculdade de Tecnologia.

Departamento de Engenharia Elétrica

1. Eletromiografia de Superfície 2. Fadiga Muscular

3. Contrações Dinâmicas 4. Wavelets

I. ENE/FT/UnB II. Título (série)

\section{REFERÊNCIA BIBLIOGRÁFICA}

Milhomem, T. R. (2015). Proposta e Análise de Indicadores Eletromiográficos Espectrais e Temporais em Protocolos Dinâmicos com Indução de Fadiga Muscular Localizada. Tese de Doutorado em Engenharia de Sistemas Eletrônicos e Automação, Publicação PGEA.TD-103/15, Departamento de Engenharia Elétrica, Universidade de Brasília, Brasília, DF, 203 p.

\section{CESSÃO DE DIREITOS}

AUTOR: Thiago Raposo Milhomem de Carvalho.

TÍTULO: Proposta e Análise de Indicadores Eletromiográficos Espectrais e Temporais em Protocolos Dinâmicos com Indução de Fadiga Muscular Localizada.

GRAU: Doutor

ANO: 2015

É concedida à Universidade de Brasília permissão para reproduzir cópias desta tese de doutorado e para emprestar ou vender tais cópias somente para propósitos acadêmicos e científicos. $\mathrm{O}$ autor reserva outros direitos de publicação e nenhuma parte dessa tese de doutorado pode ser reproduzida sem autorização por escrito do autor.

Thiago Raposo Milhomem de Carvalho

Rua 20 Sul, Lote 10, Apartamento 301, Águas Claras.

71.925-250 Brasília - DF - Brasil. 


\section{AGRADECIMENTOS}

Agradeço à minha esposa, amiga, parceira e namorada, Laura, por todo o amor, carinho, cumplicidade e dedicação; pelo que hoje sou e por dar sentido à minha vida. A insuficiência do vocabulário - e de todas as formas humanas de comunicação - não me permite expressar adequadamente minha gratidão, muito menos a saudade nos momentos de distância. Conhecemos tão bem um ao outro que não há melhor parceria neste mundo. Muito obrigado por tudo, sempre.

Aos meus pais, Paulo e Lucia, por todo o amor e carinho que recebo; e à minha avó, Terezinha, por todo o amor que me tem. Também agradeço aos meus avós que hoje não estão mais aqui (Wolney, Osório e Alzira). Agradeço a todos por tudo de bom que através das gerações foi passado.

Ao meu irmão, Paulinho, que, antes de mim, percorreu tantas trilhas, abrindo caminho para que, logo após, também eu o fizesse. Devo muitos dos meus acertos às pegadas familiares que reconheci ao longo dos caminhos que trilhei. Muito obrigado.

Agradeço novamente ao meu pai por todas as conversas, desde minha infância, durante idas e vindas da escola, durante as caminhadas com o King (nosso cachorro), durante os jogos de xadrez, entre tantos outros momentos. Agradeço por todo interesse que sempre demonstrou e por todos os conselhos, tendo sido o maior professor que já tive e terei. Enxergo-o como a tradução mais humana de toda a gentileza e paciência. Sempre foi, ainda é, e sempre será o meu herói.

À minha sogra, Wanja, por toda a sua presença na vida da minha esposa e na minha, das mais diversas formas, sempre boas; aos meus cunhados, João e Luiz, por tanto tempo de amizade e convívio; e ao meu sogro, Gilberto (em memória), pelas lembranças e otimismo ainda presente.

Aos meus orientadores, Francisco Assis e Jake do Carmo, por toda experiência compartilhada, orientação, apoio e gentileza. Sou grato por confiarem em meu julgamento na forma de conduzir as coisas, por toda a visão crítica que só a experiência possibilita e pelo quanto isso me fez crescer; levarei para sempre isto comigo. Muito obrigado pela parceria.

Um grande agradecimento ao Marcelino Andrade, que gentilmente aceitou compartilhar seus dados comigo. É com entusiasmo que vejo esta colaboração. Agradeço também ao Fabiano Soares e ao João Batista, que compartilharam seus dados com nosso grupo. Sem essas parcerias, este trabalho teria sido impossível.

Aos colegas de pesquisa, Valdinar - com quem sempre e inevitavelmente aprendo alguma coisa - e Ana Paula. Muito obrigado pela parceria e por todo o empenho. É sempre um prazer.

A todos os professores que tive, desde a infância até o doutorado. Um agradecimento especial aos professores João Carlos Nascimento de Pádua e Mauro Luiz Rabelo - tutores do grupo PET-MAT da UnB -, e Ricardo Fragelli, todos grandes incentivadores. Agradeço também àqueles que hoje são meus colegas de trabalho no IESB, especialmente à grande amiga Patrícia Moscariello, por toda a confiança e amizade.

Aos colegas e amigos da Engenharia e da Matemática, especialmente àqueles que sempre estiveram comigo, desde o início de tudo. Um grande abraço a todos.

Aos meus amigos do Dom Bosco e da Asa Norte, que deram significado à minha infância e adolescência. Que façam sempre parte da minha vida.

A todos os amigos que fiz ao longo da vida: àqueles ainda presentes e àqueles que ocupam um lugar especial em minhas lembranças. 


\section{DEDICATÓRIA}

À Laura, que sabe das coisas;

à minha família, que escuta as coisas;

aos meus amigos, que riem das coisas. 


\title{
RESUMO \\ PROPOSTA E ANÁLISE DE INDICADORES ELETROMIOGRÁFICOS ESPECTRAIS E TEMPORAIS EM PROTOCOLOS DINÂMICOS COM INDUÇÃO DE FADIGA MUSCULAR LOCALIZADA.
}

\section{Autor: Thiago Raposo Milhomem de Carvalho}

\author{
Orientador: Francisco Assis de Oliveira Nascimento
}

\section{Co-orientador: Jake Carvalho do Carmo}

\section{Programa de Pós-graduação em Engenharia de Sistemas Eletrônicos e Automação}

Brasília, mês de Novembro (2015)

Neste trabalho apresenta-se um estudo de parâmetros objetivos indicadores eletromiográficos de fadiga muscular utilizando eletromiografia de superfície (EMG-S). Esta avaliação compreende a proposição de seis novos indicadores de fadiga, sendo um calculado no domínio do tempo, um no domínio da frequência e quatro utilizando wavelets. O indicador no domínio do tempo proposto consiste na distância entre picos $e$ envoltória $\left(d_{P E}\right)$ do sinal de EMG-S, definida especialmente para o caso dinâmico; o indicador no domínio da frequência proposto é o estreitamento espectral $\left(s_{E}\right)$ do sinal; os indicadores utilizando wavelets são o deslocamento espectral $\left(K_{D E W}\right)$, a compressão espectral $\left(K_{C E W}\right)$, e suas versões adaptativas, o deslocamento espectral adaptativo $\left(K_{D E A}\right)$ e a compressão espectral adaptativa $\left(K_{C E A}\right)$. Estes dois últimos são calculados simultaneamente ao cálculo da transformada, adaptando-se a decomposição do sinal no banco de filtros. Os indicadores de fadiga propostos neste trabalho são avaliados e discutidos em conjunto com três indicadores tradicionais: raiz da média quadrática (RMS), frequência média (MNF) e frequência mediana (MDF). Além dos indicadores propostos, propõe-se avaliar parâmetros usualmente citados e sugeridos na literatura como possíveis indicadores de fadiga.

Como objetivos específicos, os indicadores de fadiga propostos nesta tese são avaliados quanto às suas características dispersivas para a inferência de sua reprodutibilidade, sendo comparados aos indicadores tradicionalmente utilizados na 
aferição da fadiga muscular. Faz-se um estudo do comportamento dos indicadores de fadiga em atividades de ciclismo em modalidades a carga constante (CL) e a carga crescente (IL), utilizando sinais de EMG-S dos músculos vasto lateral (VL) e vasto medial (VM), incluindo-se os efeitos da abordagem - isométrica ou dinâmica - para seu cálculo. O comportamento desses indicadores também é estudado em dinamometria isocinética para extensão de joelho (músculo VL), avaliando-se a monitoração da fadiga nas diferentes fases desse exercício. Apresenta-se uma proposta de instrumentação integrada para aquisição de sinais biomecânicos e eletromiográficos em ciclismo, definindo-se uma medida objetiva de desempenho biomecânico, que é discutido em conjunto com os indicadores eletromiográficos da fadiga muscular. Finalmente, os objetivos específicos deste trabalho também compreendem a proposição de um conjunto de técnicas de préprocessamento do sinal eletromiográfico, utilizando wavelets, para redução da interferência da rede elétrica e análise de desempenho da técnica de cancelamento de ruído invariante ao deslocamento.

As técnicas de pré-processamento propostas apresentaram desempenho satisfatório, reduzindo as interferências da rede elétrica no sinal de EMG-S, nas frequências de $60 \mathrm{~Hz}$ e harmônicos. Todos os indicadores de fadiga propostos apresentaram o padrão esperado com a fadiga muscular. Os indicadores espectrais propostos que estimam a compressão do espectro de amplitude do eletromiograma $\left(s_{E}, K_{C E W}\right.$ e $\left.K_{C E A}\right)$ apresentaram-se menos dispersos do que os demais - que estimam o deslocamento do centro de seu espectro -, incluindo-se as tradicionais MNF e MDF. As versões adaptativas dos indicadores utilizando wavelets $K_{D E A}$ e $K_{C E A}$ apresentaram comportamento menos disperso do que suas versões não adaptativas $K_{D E W}$ e $K_{C E W}$, assim como $s_{E}$, se comparado à MNF e à MDF. Entre os demais parâmetros citados na literatura, a assimetria do espectro de amplitude do sinal de EMG-S não apresentou padrão com a fadiga muscular, nem para o caso isométrico nem para o dinâmico. No caso dinâmico, o atraso da atividade mioelétrica e sua duração apresentaram padrão com a fadiga muscular localizada no músculo VL, mas não no VM. As abordagens dinâmica e isométrica permitiram a aferição objetiva da fadiga e, fixandose abordagem e modalidade, não se observaram diferenças entre a fadiga muscular localizada no VL e no VM. Em abordagem isométrica observou-se, em geral, um padrão crescente para a correlação entre os indicadores de fadiga do VL e do VM em função do aumento da duração dos trechos para seu cálculo. Verificou-se maior semelhança entre a atividade mioelétrica do VL e do VM ao exigir-lhes torque crescente, indicando uma 
aproximação funcional destes músculos nesta situação. Os indicadores temporais apresentaram maior correlação entre VL e VM se comparados aos indicadores espectrais, assim como maior sensibilidade ao incremento da carga. Os indicadores espectrais que aferem a diminuição da largura de banda do sinal de EMG-S apresentaram-se, em geral, mais sensíveis à carga se comparados àqueles que mensuram a fadiga a partir da posição do centro de seu espectro. Além disso, os resultados sugerem que, possivelmente, em ciclismo, o músculo VL seja mais sensível ao aumento da carga, se comparado ao VM. Apresenta-se a hipótese de que ciclistas que apresentam maior desempenho biomecânico estejam mais aptos a experimentar um processo relativamente mais intenso de fadiga. Em dinamometria isocinética, todos os indicadores eletromiográficos se comportaram de acordo com o esperado na fase concêntrica do exercício, mas não na excêntrica. Na fase de aceleração somente os indicadores temporais apresentaram o padrão esperado. 


\begin{abstract}
PROPOSAL AND ANALYSIS OF SPECTRAL AND TIME DOMAIN

ELECTROMYOGRAPHYC INDICATORS IN DYNAMIC PROTOCOLS WITH

LOCALIZED MUSCULAR FATIGUE INDUCTION.
\end{abstract}

Author: Thiago Raposo Milhomem de Carvalho

Supervisor: Francisco Assis de Oliveira Nascimento

Co-supervisor: Jake Carvalho do Carmo

Programa de Pós-graduação em Engenharia de Sistemas Eletrônicos e Automação

Brasília, month of November (2015)

This work consists in a study of localized muscle fatigue objective indicators using surface electromyography (EMG-S). This evaluation includes the proposition of six new fatigue indicators, one of them being computed in the time domain, one in the frequency domain and four using wavelets. The proposed indicator computed in time domain consists in the distance between spikes and envelope $\left(d_{P E}\right)$ from the electromyogram, defined specifically for the dynamic case; the proposed indicator in the frequency domain is the spectral narrowing $\left(s_{E}\right)$ of the electromyogram; the wavelet based indices are the spectral shift $\left(K_{D E W}\right)$, spectral compression $\left(K_{C E W}\right)$, and their adaptive versions, the adaptive spectral shift $\left(K_{D E A}\right)$ and adaptive spectral compression $\left(K_{C E A}\right)$. These last two are calculated simultaneously with the discrete wavelet transform, adapting the signal decomposition in the filter bank. The parameters proposed in this work are evaluated and discussed together with three traditional indicators: root mean square (RMS), mean frequency (MNF) and median frequency (MDF). In addition to the proposed indicators, the evaluation of parameters usually mentioned and suggested in the literature as possible fatigue indicators is proposed.

As specific goals, the dispersive features of the fatigue indicators proposed in this thesis are evaluated for their reproducibility inference, comparing them to the indicators traditionally used to assess muscular fatigue. The behavior of the fatigue indices is studied in cycling activity with constant and increasing load, using EMG-S signals obtained from 
vastus lateralis (VL) and vastus medialis (VM), including the effects of the approach isometric or dynamic - for computing them. The behavior of these indicators is also studied in isokinetic dynamometry, in knee extension exercise (VL muscle), evaluating the fatigue assessment in the different phases of this exercise. We present a proposal for an integrated instrumentation for acquisition of biomechanical and electromyographic signals in cycling, and an objective measure of biomechanical performance is defined, being such performance discussed jointly with electromyographic indicators of muscular fatigue. Finally, the specific goals of this work also include the proposal of a set of techniques for the pre-processing of the electromyographic signal using wavelets, aiming to reduce the interference from the electrical network; and a performance analysis of the shift invariant denoising technique.

The proposed preprocessing techniques showed satisfactory performance by reducing the interference from the electrical network in the EMG-S signal, on the $60 \mathrm{~Hz}$ frequency and its harmonics. All the proposed fatigue indicators showed the expected pattern with muscle fatigue. The proposed spectral indicators that assess the compression of the amplitude spectrum of the electromyogram $\left(s_{E}, K_{C E W}\right.$ and $\left.K_{C E A}\right)$ showed to be less scattered than the others - that assess the shift of its spectrum center -, including the traditional MNF and MDF. The wavelet based adaptive versions $K_{D E A}$ and $K_{C E A}$ showed a lower dispersion than their non-adaptive versions $K_{D E W}$ and $K_{C E W}$, and so did $s_{E}$, when compared to MNF and MDF. Among the other parameters mentioned in the literature, the asymmetry of the amplitude spectrum of the EMG-S signal did not present a pattern with muscle fatigue neither for the isometric case nor for the dynamic case. In the dynamic case, the delay of the myoelectric activity and its duration showed a pattern with muscular fatigue located in the VL muscle, but not in VM. The dynamic and isometric approaches were both suitable for muscular fatigue assess and, for each specific approach and modality, no differences between the fatigue localized in VL and in VM were observed. In isometric approach, in general, an increasing correlation pattern between VL and VM fatigue indicators was observed as a function of the length of the epochs. Greater similarity between myoelectric activity in VL and in VM was observed when increasing torque was demanded, indicating a functional approximation between these muscles in this situation. Time domain indicators showed greater correlation between VL and VM when compared to spectral indicators, as well as a greater sensitivity to load increment. The spectral indicators which assess the EMG-S signal bandwidth showed to be, generally, more 
sensitive to load when compared to those who assess fatigue by means of the position of the center of the amplitude of its spectrum. Moreover, results suggest that, possibly, in cycling, VL is more sensitive to load, when compared to VM. We hypothesize that cyclists who achieve greater biomechanical performance be more apt to experiment a relatively more intense fatigue. In isokinetic dynamometry, all the electromyographic indicators showed the expected behavior in the concentric phase of the exercise, but not in eccentric. In the acceleration phase only time domain indicators showed the expected pattern. 


\section{SUMÁRIO}

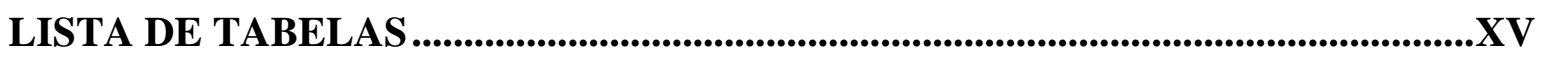

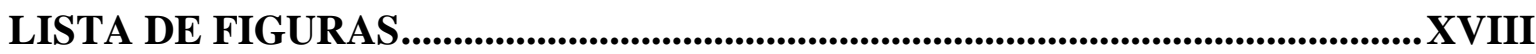

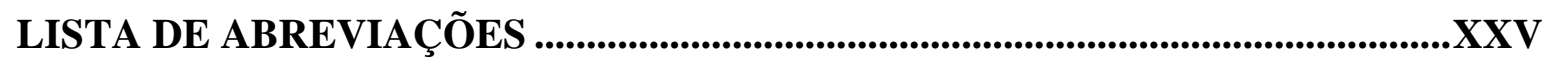

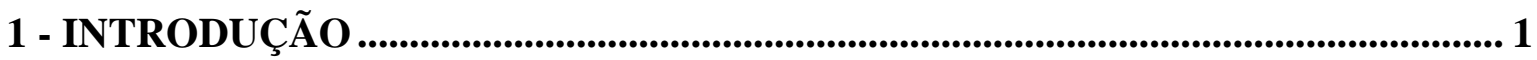

1.1 - POR QUE A ELETROMIOGRAIA? ............................................................................ 1

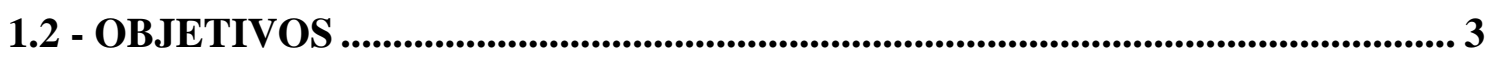

1.3 - JUSTIFICATIVA E CONTRIBUIÇÕES ............................................................... 6

1.4 - ORGANIZAÇÃO DO TRABALHO ........................................................... 9

2 - A ELETROMIOGRAFIA _.................................................................................... 11

2.1 - INTRODUÇÃ

2.2 - FORMAÇÃ̃ DO SINAL E DEFINIÇÕES ........................................................... 12

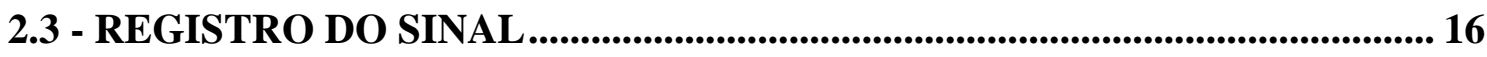

2.4 - CARACTERÍSTICAS DO SINAL E FADIGA MUSCULAR........................... 20

2.4.1 - Monitoração da fadiga .................................................................................. 20

2.4.2 - Relações entre os indicadores de fadiga e fatores que os influenciam... 25

2.4.3 - Distribuição do eletromiograma ..................................................................... 29

3 - PROTOCOLOS EXPERIMENTAIS E INSTRUMENTAÇÃO DEDICADA....... 32

3.1 - PROTOCOLO I: CICLISMO....................................................................... 32

3.1.1 - Protocolo experimental ......................................................................... 32

3.1.1.1 - Primeira seção ....................................................................................... 33

3.1.1.2 - Segunda seção ............................................................................................... 33

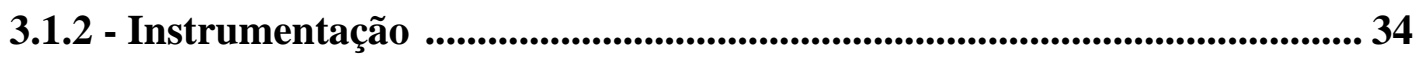

3.1.2.1 - Sinais biomecânicos .............................................................................. 34

3.1.2.2 - Sinais eletromiográficos ................................................................. 41

3.1.2.3 - Instrumentação integrada .................................................................................... 41

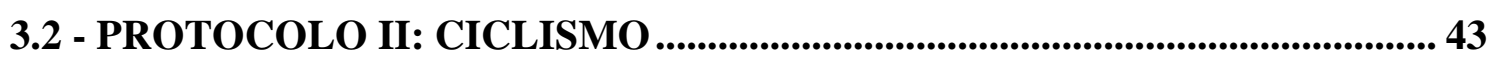

3.2.1 - Protocolo experimental .......................................................................43 
3.3 - PROTOCOLO III: ISOCINÉTICO

3.3.1 - Protocolo de aquisição e instrumentação .................................................. 44

3.4 - PROTOCOLO IV: ISOMÉTRICO ..................................................................... 45

3.4.1 - Protocolo de aquisição e instrumentação ............................................ 46

3.5 - CONSIDERAÇÕES FINAIS.................................................................................. 46

4 - TÉCNICAS DE PRÉ-PROCESSAMENTO ..................................................... 48

4.1 - RUÍDO BRANCO E ARTEFATOS DE MOVIMENTO ................................... 48

4.1.1 - Filtragem passa-faixa .................................................................................... 48

4.1.2 - Cancelamento de ruído invariante ao deslocamento: métodos e

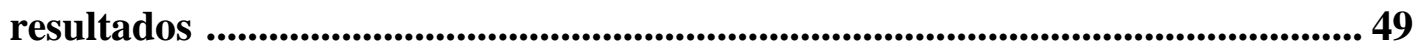

4.1.2.1 - Sinais dinâmicos de ciclismo ..................................................................... 49

4.1.2.2 - Sinais de outros protocolos experimentais ...................................................... 51

4.1.2.3 - Resultados e discussão ........................................................................5 52

4.2 - INTERFERÊNCIA DA REDE ELÉTRICA .................................................5 57

4.2.1 - Técnica proposta: formulação ........................................................................ 58

4.2.2 - Resultados e discussão.........................................................................62

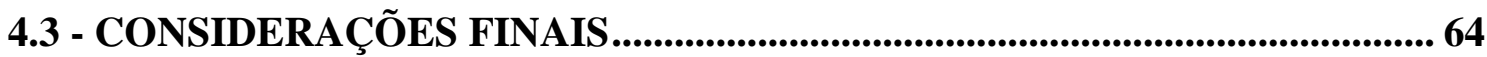

5 - TÉCNICAS PARA AVALIAÇÃO DA FADIGA .............................................. 65

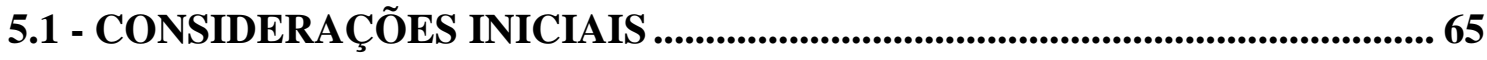

5.2 - TÉCNICAS CLÁSSICAS ................................................................................ 70

5.3 - TÉCNICAS PROPOSTAS ................................................................................. 71

5.3.1 - Deslocamento Espectral (Wavelets) ......................................................... 72

5.3.2 - Compressão Espectral (Wavelets) ...................................................... 79

5.3.3 - Deslocamento Espectral Adaptativo (Wavelets) ........................................ 81

5.3.4 - Compressão Espectral Adaptativa (Wavelets) ............................................. 86

5.3.5 - Estreitamento Espectral (Fourier) ..........................................................89

5.3.6 - Distância entre Picos e Envoltória (Tempo) ............................................... 91

5.3.7 - Outros parâmetros para análise ..............................................................93

5.4 - MÉTRICAS DE DISPERSÃO .................................................................................. 94

5.4.1 - Dispersão Polinomial .......................................................................... 96

5.4.2 - Dispersão Diferencial .................................................................................... 97 
6 - ANÁLISE DOS INDICADORES DE FADIGA ................................................... 102

6.1 - VALIDAÇÃO EXPERIMENTAL EM PROTOCOLO ISOMÉTRICO...... 102

6.1.1 - Resultados e discussão ........................................................................... 103

6.1.1.1 - Índices tradicionais e propostos ....................................................... 103

6.1.1.2 - Dispersão dos indicadores .................................................................... 106

6.1.1.3 - Outros parâmetros citados na literatura ........................................................... 107

6.1.2 - Considerações finais ................................................................................. 109

6.2 - VALIDAÇÃO EXPERIMENTAL EM PROTOCOLO DINÂMICO

(CICLISMO - II): ABORDAGEM DINÂMICA ...................................................... 110

6.2.1 - Resultados e discussão ................................................................... 114

6.2.1.1 - Índices tradicionais e propostos ........................................................... 114

6.2.1.2 - Dispersão dos indicadores ................................................................ 120

6.2.1.3 - Outros parâmetros citados na literatura ..................................................... 122

6.2.2 - Considerações finais ........................................................................................ 132

6.3 - PROTOCOLO DINÂMICO (CICLISMO - II): VARIAÇÃO DA CARGA E

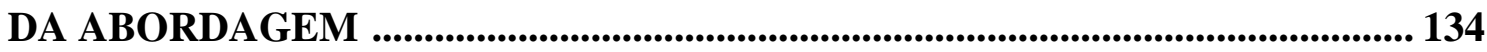

6.3.1 - Resultados e discussão ...................................................................... 137

6.3.2 - Considerações finais ............................................................................. 158

6.4 - PROTOCOLO DINÂMICO (CICLISMO - I): ELETROMIOGRAFIA E DESEMPENHO BIOMECÂNICO ..................................................................... 160

6.4.1 - Resultados e discussão ................................................................................... 161

6.4.2 - Considerações finais ........................................................................ 166

6.5 - PROTOCOLO DINÂMICO (ISOCINÉTICO) .................................................. 167

6.5.1 - Resultados e discussão ........................................................................... 171

6.5.2 - Considerações finais ......................................................................... 176

7 - CONCLUSÕES E RECOMENDAÇÕES ................................................................. 177

REFERÊNCIAS BIBLIOGRÁFICAS .............................................................................. 182 


\section{LISTA DE TABELAS}

Tabela 3.1 - Pesos utilizados na calibração dos pedais

Tabela 3.2 - Valores calculados de A e B - para a relação linear por partes entre tensão e

ângulo no goniômetro - em cada região da pedalada. 38

Tabela 5.1 - Dispersões das sequências de exemplo $f_{1}[n]$ e $f_{2}[n]$, de acordo com as métricas

$C o V, \mathrm{I}_{\text {Dpol }}$ e $\mathrm{I}_{\text {Ddif. }}$

Tabela 6.1 - Índices de fadiga definidos no domínio do tempo, valores $p$ do teste de

Shapiro-Wilk e do teste $\mathrm{t}$.

Tabela 6.2 - Índices de fadiga no domínio da frequência, valores $p$ do teste de Shapiro-

Wilk e do teste t.

Tabela 6.3 - Índices de fadiga utilizando wavelets, valores $p$ do teste de Shapiro-Wilk e do teste $\mathrm{t}$

Tabela 6.4 - Dispersão para os indicadores de fadiga no domínio do tempo. 106

Tabela 6.5 - Dispersão para os indicadores de fadiga no domínio da frequência. 106

Tabela 6.6 - Dispersão para os indicadores de fadiga no domínio da DWT. 106

Tabela 6.7 - Índices obtidos a partir da assimetria do espectro do eletromiograma em contrações isométricas.

Tabela 6.8 - Índices de fadiga (VL) definidos no domínio do tempo, valores $p$ do teste de

Shapiro-Wilk e do teste $t$. Teste a carga constante e velocidade constante.

Tabela 6.9 - Índices de fadiga (VL) definidos no domínio da frequência, valores $p$ do teste

de Shapiro-Wilk e do teste t. Teste a carga constante e velocidade constante.

Tabela 6.10 - Índices de fadiga (VL) utilizando wavelets, valores $p$ do teste de Shapiro-

Wilk e do teste t. Teste a carga constante e velocidade constante.

Tabela 6.11 - Índices de fadiga (VM) definidos no domínio do tempo, valores $p$ do teste de

Shapiro-Wilk e do teste t. Teste a carga constante e velocidade constante.

Tabela 6.12 - Índices de fadiga (VM) definidos no domínio da frequência, valores $p$ do

teste de Shapiro-Wilk e do teste t. Teste a carga constante e velocidade constante.

Tabela 6.13 - Índices de fadiga (VM) utilizando wavelets, valores $p$ do teste de Shapiro-

Wilk e do teste t. Teste a carga constante e velocidade constante.

Tabela 6.14 - Variabilidade dos índices (para VL e VM) obtidos para o conjunto dos sujeitos. Teste a carga constante e velocidade constante. 
Tabela 6.15 - Dispersão para os indicadores de fadiga no domínio do tempo (VL). Teste a carga constante e velocidade constante.

Tabela 6.16 - Dispersão para os indicadores de fadiga no domínio da frequência (VL).

Teste a carga constante e velocidade constante.

Tabela 6.17 - Dispersão para os indicadores de fadiga no domínio da frequência (VL).

Teste a carga constante e velocidade constante.

Tabela 6.18 - Dispersão para os indicadores de fadiga no domínio do tempo (VM). Teste a carga constante e velocidade constante.

Tabela 6.19 - Dispersão para os indicadores de fadiga no domínio da frequência (VM).

Teste a carga constante e velocidade constante.

Tabela 6.20 - Dispersão para os indicadores de fadiga no domínio da frequência (VM).

Teste a carga constante e velocidade constante.

Tabela 6.21 - Índices obtidos a partir da assimetria espectral do sinal de EMG-S em ciclismo (teste com carga e velocidade constantes) para os músculos VL e VM

Tabela 6.22 - Índices obtidos a partir do atraso absoluto da atividade mioelétrica em ciclismo (teste com carga e velocidade constantes) para os músculos VL e VM

Tabela 6.23 - Índices obtidos a partir do atraso normalizado da atividade mioelétrica em ciclismo (teste com carga e velocidade constantes) para os músculos VL e VM.

Tabela 6.24 - Índices obtidos a partir da duração absoluta das bulhas em ciclismo (teste com carga e velocidade constantes) para os músculos VL e VM.

Tabela 6.25 - Índices obtidos a partir da duração normalizada das bulhas em ciclismo (teste com carga e velocidade constantes) para os músculos VL e VM.

Tabela 6.26 - Correlação média geral - para todos os indicadores de todos os sujeitos - nas modalidades CL e IL, em função da abordagem.

Tabela 6.27 - Resultados do teste de Friedman. Comparação entre as correlações observadas - entre VL e VM - variando a duração do segmento do eletromiograma para cálculo dos indicadores (diferenças significativas destacadas em negrito).

Tabela 6.28 - Valores $p$ obtidos para as comparações entre os conjuntos de índices obtidos em CL e IL (diferenças significativas destacadas em negrito). Músculo VL

Tabela 6.29 - Valores $p$ obtidos para as comparações entre os conjuntos de índices obtidos em CL e IL (diferenças significativas destacadas em negrito). Músculo VM.

Tabela 6.30 - Desempenho fisiológico para os indicadores eletromiográficos no domínio do tempo. 
Tabela 6.31 - Desempenho fisiológico para os indicadores eletromiográficos no domínio da frequência.

Tabela 6.32 - Desempenho fisiológico para os indicadores eletromiográficos no domínio da DWT.

Tabela 6.33 - Desempenho biomecânico global (valor médio de $f_{\mathrm{d}}$ ) e variação média de $f_{\mathrm{d}}$ ao longo do teste em função de seu valor inicial. Todos os sujeitos.

Tabela 6.34 - Coeficientes de correlação entre valores de índice de fadiga e desempenho biomecânico global para o conjunto de todos os sujeitos. 165

Tabela 6.35 - Coeficientes de correlação entre valores de desempenho fisiológico e desempenho biomecânico global para o conjunto de todos os sujeitos 


\section{LISTA DE FIGURAS}

Figura 2.1 - Unidade motora. Modificado de Moritani et al. (2004).

Figura 2.2 - Propagação do potencial de ação na fibra muscular. Adaptado de Kamen e Gabriel (2010).

Figura 2.3 - Potencial da membrana e permeabilidade dos canais iônicos na ocorrência de um potencial de ação. Adaptado de Kamen e Gabriel (2010).

Figura 2.4 - Registro da soma dos potenciais de uma MU sobre a pele. Adaptado de Farina et al. (2004).

Figura 2.5 - Efeitos da localização do eletrodo no sinal de EMG-S: domínio do tempo e da frequência. Adaptado de DeLuca (1997).

Figura 2.6 - Representação de protocolos com indução de fadiga. Em (1), solicita-se a manutenção da força máxima. Em (2), realizam-se contrações repetidas a 45\% MVC. Modificado de Vøllestad (1997).

Figura 2.7 - Variação do torque e de indicadores eletromiográficos (RMS, CV e MNF) com a indução de fadiga. Adaptado de Merletti et al. (2004).

Figura 2.8 - Efeito do aumento gradual da força sobre a amplitude e o espectro (frequência média) do sinal de EMG-S, em contração isométrica (Moritani et al., 2004).......29

Figura 2.9 - Distribuição de probabilidade da amplitude do sinal de EMG obtido experimentalmente (linha sólida): entre a gaussiana (pontilhada) e a laplaciana (tracejada). Adaptado de Clancy e Hogan (1999).

Figura 3.1 - Pedal instrumentado utilizado no Protocolo I.

Figura 3.2 - Esquema ilustrando o ângulo do pedivela $\phi(t)$ e a localização do sensor magnético responsável pelo sinal do trigger (esq.) e seu uso no cicloergômetro (dir.).

Figura 3.3 - Referência para medição do ângulo $\theta(t)$ entre o pedal e o pedivela calculado a partir dos sinais das trilhas resistivas do goniômetro. Com este referencial para $\theta$, a pedalada acontece no sentido anti-horário..

Figura 3.4 - Exemplo de registro do ângulo do pedal em relação ao pedivela durante um ciclo de pedalada.

Figura 3.5 - Esquema ilustrando as forças e os ângulos medidos no pedal e no pedivela. ..... 40

Figura 3.6 - Esquema da instrumentação integrada para aquisição simultânea dos sinais biomecânicos e de EMG-S. 
Figura 3.7 - Sistema de dinamometria isocinética utilizado no protocolo III. Adaptado de Biodex (1998).

Figura 4.1 - Diagrama do algoritmo de cancelamento de ruído.

Figura 4.2 - Exemplo de trecho do sinal de EMG-S de um ciclo de contração: Sinal ruidoso (à esquerda) e sinal após aplicação da técnica de denoising (à direita).

Figura 4.3 - Faixa do espectro do sinal de EMG - de contração isométrica - utilizado para a estimação da potência do ruído.

Figura 4.4 - Resultados obtidos com denoising em função do limiar e $N_{\text {d. }}$ Técnica aplicada a trechos sucessivos de $250 \mathrm{~ms} . N_{\mathrm{d}}=12 k$.

Figura 4.5 - Resultados obtidos com denoising em função do limiar e $N_{\text {d. }}$ Técnica aplicada a trechos sucessivos de $250 \mathrm{~ms} . N_{\mathrm{d}}=10 k$.

Figura 4.6 - Resultados obtidos com denoising em função do limiar e $N_{\mathrm{d}}$. Técnica aplicada a trechos sucessivos de $500 \mathrm{~ms} . N_{\mathrm{d}}=12 k$.

Figura 4.7 - Resultados obtidos com denoising em função do limiar e $N_{\mathrm{d}}$. Técnica aplicada a trechos sucessivos de $500 \mathrm{~ms} . N_{\mathrm{d}}=10 \mathrm{k}$.

Figura 4.8 - Resultados obtidos com denoising em função do limiar e $N_{\mathrm{d}}$. Técnica aplicada a trechos sucessivos de $1 \mathrm{~s} . N_{\mathrm{d}}=12 \mathrm{k}$.

Figura 4.9 - Resultados obtidos com denoising em função do limiar e $N_{\mathrm{d}}=2^{\mathrm{k}}$. Técnica aplicada a trechos sucessivos de $250 \mathrm{~ms}$.

Figura 4.10 - Resultados obtidos com denoising em função do limiar e $N_{\mathrm{d}}=2^{\mathrm{k}}$. Técnica aplicada a trechos sucessivos de $500 \mathrm{~ms}$.

Figura 4.11 - Resultados obtidos com denoising em função do limiar e $N_{\mathrm{d}}=2^{\mathrm{k}}$. Técnica aplicada a trechos sucessivos de $1 \mathrm{~s}$.

Figura 4.12 - Espectro normalizado do sinal. De cima para baixo: a) EMG-S original, b) após adição da interferência, c) redução da interferência com o algoritmo proposto, d) redução com estimativa da amplitude da senoide a partir do valor RMS do trecho inicial do sinal, e e) utilizando filtros notch.

Figura 4.13 - Relações sinal/ruído obtidas - com a técnica proposta (azul), utilizando o valor RMS do trecho inicial (vermelho) e filtro notch (preto) - para diferentes números de harmônicos adicionados ao sinal. Valores obtidos para simulações com interferência de amplitude igual a) $10 \%$; b) $20 \%$; e c) $30 \%$ do desvio padrão do sinal eletromiográfico.

Figura 5.1 - Concatenação de trechos de bulhas consecutivas para abordagem isométrica..... 68 
Figura 5.2 - Variações abruptas, num trecho do sinal concatenado, resultantes da concatenação de segmentos de bulhas distintas do sinal de EMG-S. As descontinuidades ocorrem entre os (dois) pontos de concatenação destacados. ...69

Figura 5.3 - Distribuição dos coeficientes $\beta_{j}$ ao longo do espectro. Exemplo de um sinal decomposto pela DWT em 3 etapas.

Figura 5.4 - Cálculo da localização espectral por meio de banco de filtros (DWT). As saídas, após multiplicação pelos coeficientes $\beta_{j}$, são somadas, resultando no valor de $L_{E}$.

Figura 5.5 - Decomposição de uma sequência $\boldsymbol{x}$ em 3 estágios: abordagem tradicional descrita por Stéphane Mallat.

Figura 5.6 - Exemplo de decomposição adaptativa de uma sequência $\boldsymbol{x}$ em $j_{\text {máx }}=4$ níveis. Em destaque o caminho de maior energia relativa no banco de filtros: Neste exemplo, a energia de ${s_{H P}}^{[2]}$ é superior à de ${s_{L P}}^{[2]}$.

Figura 5.7 - Exemplo de curva de $\boldsymbol{S}_{\boldsymbol{E} A}$ e $\boldsymbol{I}_{\boldsymbol{S E A}}$ correspondente, obtidas para uma bulha em 7 estágios de cálculo. $\mathrm{O}$ valor de $C_{E A}$ é indicado pela área entre a curva de $\boldsymbol{I}_{S E A} \mathrm{e}$ seu valor máximo (área acima da curva). Por definição, quanto menor esta área for, maior deve ser o valor de $C_{E A}$.

Figura 5.8 - Estreitamento do espectro do sinal de EMG com a fadiga muscular. Exemplo de espectro de amplitude obtido nas fases inicial e final de exercício de contrações cíclicas em cicloergômetro.

Figura 5.9 - Exemplos de ciclos do sinal de EMG-S (azul) e envoltórias (vermelho) das fases inicial (à esquerda) e final (à direita). Em destaque, os picos que se distanciam significativamente da envoltória do sinal.

Figura 5.10 - Duas sequências $f_{1}[n]$ e $f_{2}[n]$ (e correspondentes ajustes lineares) e respectivas dispersões estimadas com o $\mathrm{CoV}$.

Figura 6.1 - Sequências descritoras de fadiga obtidas para cada indicador eletromiográfico (em azul) e respectivos ajustes lineares (em verde). Exemplo dos resultados obtidos para um dos sujeitos $\left(n^{\circ} 6\right)$.

Figura 6.2 - Assimetria do espectro de amplitude do eletromiograma ao longo do tempo (em azul) e respectivo ajuste linear (em verde). Todos os sujeitos. Eixo do tempo normalizado pela duração total do exercício.. 
Figura 6.3 - Exemplo de um ciclo do sinal de EMG-S após pré-processamento, com 1024 amostras. A amplitude é normalizada pelo desvio padrão do sinal de EMG-S completo.

Figura 6.4 - Padrão temporal de ativação muscular do VL e do VM. Adaptado de Hug e Dorel (2009).

Figura 6.5 - Atraso absoluto da atividade mioelétrica (AAM), definida como o intervalo $\Delta T$ indicado: tempo decorrido entre o acionamento do trigger (em verde) e início da atividade mioelétrica significativa no ciclo - definida como o trecho correspondente a $99 \%$ da energia do segmento do sinal eletromiográfico compreendido entre duas ativações consecutivas do trigger.

Figura 6.6 - Sequências descritoras de fadiga do músculo VL obtidas para cada indicador eletromiográfico (em azul) e respectivos ajustes lineares (em verde). Exemplo dos resultados obtidos para um dos sujeitos $\left(n^{\circ} 8\right)$.

Figura 6.7 - Sequências descritoras de fadiga do músculo VL obtidas para cada indicador eletromiográfico (em azul) e respectivos ajustes lineares (em verde). Exemplo dos resultados obtidos para um dos sujeitos $\left(n^{\circ} 8\right)$.

Figura 6.8 - Assimetria do espectro de amplitude do eletromiograma ao longo do tempo (em azul) e respectivo ajuste linear (em verde). Sinais do músculo vasto lateral em teste a carga e velocidade constantes. Todos os sujeitos. Eixo do tempo normalizado pela duração total do exercício.

Figura 6.9 - Assimetria do espectro de amplitude do eletromiograma ao longo do tempo (em azul) e respectivo ajuste linear (em verde). Sinais do músculo vasto medial em teste a carga e velocidade constantes. Todos os sujeitos. Eixo do tempo normalizado pela duração total do exercício.

Figura 6.10 - Comparação (Anova, $\alpha=0,05$ ) entre os dados obtidos para o VL e o VM para a variação da assimetria do espectro ao longo do teste. Não se observam diferenças significativas a partir destes resultados.

Figura 6.11 - Atraso absoluto da atividade mioelétrica ao longo dos ciclos (em azul) e respectivo ajuste linear (em verde). Sinais do músculo vasto lateral em teste a carga e velocidade constantes. Todos os sujeitos.

Figura 6.12 - Atraso absoluto da atividade mioelétrica ao longo dos ciclos (em azul) e respectivo ajuste linear (em verde). Sinais do músculo vasto medial em teste a carga e velocidade constantes. Todos os sujeitos. 
Figura 6.13 - Atraso absoluto da atividade mioelétrica ao longo dos ciclos. Retas normalizadas (com inclinação dividida pelo valor inicial) de todos os sujeitos sobrepostas, para os músculos VL (à esquerda) e VM (à direita).

Figura 6.14 - Comparação (Kruskal-Wallis, $\alpha=0$,05) entre os dados obtidos para o VL e o VM para a variação do atraso absoluto da atividade mioelétrica ao longo do teste. Não se observam diferenças significativas a partir destes resultados.

Figura 6.15 - Comparação (Kruskal-Wallis, $\alpha=0,05$ ) entre os dados obtidos para o VL e o VM para a variação do atraso normalizado da atividade mioelétrica ao longo do teste. Não se observam diferenças significativas a partir destes resultados.

Figura 6.16 - Duração absoluta das bulhas ao longo dos ciclos. Retas normalizadas (com inclinação dividida pelo valor inicial) de todos os sujeitos sobrepostas, para os músculos VL (à esquerda) e VM (à direita).

Figura 6.17 - Duração normalizada das bulhas ao longo dos ciclos. Retas normalizadas (com inclinação dividida pelo valor inicial) de todos os sujeitos sobrepostas, para os músculos VL (à esquerda) e VM (à direita).

Figura 6.18 - Comparação dos índices: VL versus VM em abordagem dinâmica, modalidade CL.

Figura 6.19 - Comparação dos índices: VL versus VM em abordagem isométrica (trechos de $500 \mathrm{~ms}$ ), modalidade CL.

Figura 6.20 - Comparação dos índices: VL versus VM em abordagem isométrica (trechos de 2,0 s), modalidade CL.

Figura 6.21 - Comparação dos índices: VL versus VM em abordagem dinâmica, modalidade IL.

Figura 6.22 - Comparação dos índices: VL versus VM em abordagem isométrica (trechos de $500 \mathrm{~ms}$ ), modalidade IL.

Figura 6.23 - Comparação dos índices: VL versus VM em abordagem isométrica (trechos de $2,0 \mathrm{~s}$ ), modalidade IL.

Figura 6.24 - Correlação média (coeficiente de Pearson) entre sequências descritoras de fadiga dos voluntários para o VL e VM. Indicadores no domínio do tempo. Carga constante (azul) e carga crescente (vermelho)..

Figura 6.25 - Correlação média (coeficiente de Pearson) entre sequências descritoras de fadiga dos voluntários para o VL e VM. Indicadores no domínio da frequência. Carga constante (azul) e carga crescente (vermelho). 
Figura 6.26 - Correlação média (coeficiente de Pearson) entre sequências descritoras de fadiga dos voluntários para o VL e VM. Indicadores no domínio da DWT. Carga constante (azul) e carga crescente (vermelho).

Figura 6.27 - Comparação (teste Anova) entre os valores médios de correlação entre VL e

VM nas modalidades CL e IL. Indicadores no domínio do tempo.

Figura 6.28 - Comparação (teste Anova) entre os valores médios de correlação entre VL e

VM nas modalidades CL e IL. Indicadores no domínio da frequência. 148

Figura 6.29 - Comparação (teste Anova) entre os valores médios de correlação entre VL e

VM nas modalidades CL e IL. Indicadores no domínio da DWT.

Figura 6.30 - Correlações médias entre VL e VM observadas para todos os indicadores em carga constante.

Figura 6.31 - Correlações médias entre VL e VM observadas para todos os indicadores em carga crescente.

Figura 6.32 - Diferenças significativas observadas para a correlação média geral entre os músculos VL e VM - para todos os indicadores de todos os sujeitos - obtida na modalidade CL e na modalidade IL.

Figura 6.33 - Comportamento dos indicadores eletromiográficos ao longo do teste - em função dos ciclos de pedalada - para todos os sujeitos. (Sujeitos 1, 2, 3 e 4 em azul, vermelho, preto e lilás, respectivamente.)

Figura 6.34 - Evolução de $f_{\mathrm{d}}$ (azul) e respectivos ajustes lineares (verde) ao longo dos ciclos de pedalada do exercício completo para todos os sujeitos. 163

Figura 6.35 - Exemplo de torque efetivo num ciclo de pedalada completo (suj. 2). 164

Figura 6.36 - Exemplo de $f_{\mathrm{d}}$ num ciclo de pedalada completo (suj. 2).

Figura 6.37 - Fases concêntrica (FC), excêntrica (FE) e de aceleração (FA) em dinamometria isocinética (adaptado de Milhomem et al., 2014e).

Figura 6.38 - Representação da velocidade angular normalizada (azul) e torque normalizado (verde) em um ciclo de contração durante a FC. Observa-se que o pico de torque ocorre durante esta fase, na região em que o exercício é mantido isocinético com imposição da carga pelo dinamômetro. Trecho dos sinais de um dos voluntários.

Figura 6.39 - Sequências descritoras de fadiga por série de contração. Sujeito 1. Indicadores no domínio do tempo. 
Figura 6.40 - Sequências descritoras de fadiga por série de contração. Sujeito 1. Indicadores no domínio da frequência. ............................................................... 172

Figura 6.41 - Sequências descritoras de fadiga por série de contração. Sujeito 1. Indicadores no domínio da DWT.

Figura 6.42 - Fase do exercício em torno da posição angular mínima: região contida na FA. 


\section{LISTA DE ABREVIAÇÕES}

$\mathrm{A} / \mathrm{D}$

AAM

ANM

Anova

Arma

ARV

$\mathrm{BF}$

$\mathrm{CV}$

CWT

DFT

DWT

ECG

EEC

EMG

EMG-S

ENM

FA

FC

FE

FEF

FFT

FIR

fMRI

GM

GMax

GL

IIR

MDF

MNF

MVC
- Analógico/Digital

- Atraso absoluto da atividade mioelétrica

- Atraso normalizado da atividade mioelétrica

- Analisys of Variance ou Análise de Variância

- Autoregressive moving average ou média móvel autorregressiva

- Average rectified value ou Valor retificado médio

- Bíceps femoral cabeça longa

- Conduction velocity ou velocidade de condução

- Continuous Wavelet Transform ou Transformada de Wavelets Contínua

- Discrete Fourier Transform ou Transformada Discreta de Fourier

- Discrete Wavelet Transform ou Transformada de Wavelets Discreta

- Eletrocardiografia

- Eletroencefalograma

- Eletromiografia

- Eletromiografia de superfície

- Eficiência neuromuscular

- Fase de aceleração

- Fase concêntrica

- Fase excêntrica

- Faculdade de Educação Física da Universidade de Brasília

- Fast Fourier Transform ou Transformada Rápida de Fourier

- Finite Impulse Response ou Resposta ao Impulso Finita

- functional magnetic resonance imaging ou imageamento por ressonância magnética funcional

- Gastrocnêmio medial

- Glúteo máximo

- Gastrocnêmio lateral

- Infinite Impulse Response ou Resposta ao Impulso Infinita

- median frequency ou frequência mediana

- mean frequency ou frequência média

- Contração máxima voluntária 
- Unidade motora

Muap

- Motor unit action potential ou Potencial de ação da unidade motora

PAR-Q

- Physical Activity Readiness Questionnaire

PF

- Percentile frequency ou frequência percentil

PSD

- Power spectral density ou Densidade espectral de potência

PT

- Pico de torque

$\mathrm{RF}$

- Reto femoral

RMS

- root mean square ou raiz da média quadrática

RPM

- rotações por minuto

Seniam

- Surface EMG for non-invasive assessment of muscles

SM

- Semimembranáceo

SNR

- signal-to-noise ratio ou relação sinal-ruído

SOL

- Sóleo

ST

- Semitendinoso

STFT

- Short-Time Fourier Transform ou Transformada de Fourier de Tempo Curto (ou, ainda, Transformada Janelada de Fourier)

TA - Tibial anterior

TD-MDF - Time-Dependent MDF ou MDF dependente do tempo

TD-MNF - Time-Dependent MDF ou MDF dependente do tempo

TVAR - Time varying autoregressive model ou modelo autorregressivo variante no tempo

UnB - Universidade de Brasília

VL - Vasto lateral

VM - Vasto medial

ZCR - Zero-crossing rate ou taxa de cruzamento de zeros 


\section{1 - INTRODUÇÃO}

De elementares e essenciais que são, listar as relevâncias do estudo das capacidades motoras torna-se uma longa e difícil tarefa. A avaliação das funções musculares e a aferição objetiva dos fenômenos envolvidos na contração muscular constituem etapas essenciais ao entendimento do movimento humano e dos processos fisiológicos nele envolvidos. Neste sentido, a eletromiografia é uma importante técnica para a monitoração da atividade muscular, por meio da medição dos sinais elétricos emanados pelo músculo (Merletti e Parker, 2004).

Em geral, as aplicações da eletromiografia estendem-se desde sua aplicação como ferramenta auxiliar para observação da atividade muscular - incluindo-se finalidades clínicas e diagnósticas - até seu estudo como principal objeto de investigação. Conforme relatado por Kamen e Gabriel (2010), a quantidade de artigos científicos envolvendo a eletromiografia publicados anualmente atingiu, a partir da segunda metade do século XX, a ordem de milhares, permanecendo até este momento em pleno crescimento. Assim, a eletromiografia tem encontrado cada vez mais espaço em pesquisa básica e aplicada, sendo hoje difícil dissociá-la do estudo das funções musculares, como se verá a seguir.

\section{1 - POR QUE A ELETROMIOGRAFIA?}

A interpretação, decomposição e extração de características de sinais biológicos, envolvendo suas aplicações, em especial a eletromiografia (EMG), têm sido objeto de pesquisa e ferramenta de auxílio em diversos campos das ciências da saúde e do esporte (Merletti e Parker, 2004). Suas recorrentes aplicações incluem a monitoração da fadiga muscular (DeLuca, 1984) e da recuperação muscular após a fadiga localizada (Larivière et al., 2002), treinamento associado à eletroestimulação (Molina et al., 1997), avaliação das capacidades motoras (Larivière et al., 2008 e 2009), quantificação da eficiência neuromuscular (Milner et al., 1986; David et al., 2008; Arabadzhiev et al., 2010), aplicações diversas à neurologia (Zwarts et al., 2004), observação de padrões e diferenças entre os gêneros durante exercícios fatigantes (Clark et al., 2005), técnicas não invasivas e automação de sistemas para predição e detecção da fadiga muscular localizada (Al-Mulla et al., 2011a e 2011b), controle de próteses (Parker et al., 2004), neurorreabilitação (Jiang et al., 2010), reabilitação motora (Rainoldi et al., 2004), monitoração indireta de 
parâmetros biomecânicos (Cifrek et al., 2009), ergonomia (Hägg et al., 2004), detecção automática de zonas de inervação utilizando eletromiografia de superfície (EMG-S) (Ullah et al., 2014), estudo de relações entre funções neuromusculares e postura (Boyas et al., 2013), de padrões de recrutamento de unidades motoras em diferentes fases da contração muscular (Kay et al., 2000), de biofeedback (Cram, 2004), de parâmetros associados às lesões musculares (Thiebaud et al., 2013), de causas de distúrbios associados ao controle motor (Bottas et al., 2005), da fisiologia do exercício (Felici et al., 2004), dos efeitos da fadiga sobre as ações agonista e antagonista na ação motora (Hassani et al., 2006), da fadiga de longo prazo após esforços prolongados (Søgaard et al., 2003), análise de postura e movimento (Frigo e Shiavi, 2004), entre outras.

Diversos autores têm utilizado a eletromiografia em estudos envolvendo contrações dinâmicas - associadas ao movimento (e.g. atividade de ciclismo) - e padrões da atividade mioelétrica dos músculos envolvidos (Ericson, 1986; Jorge e Hull, 1986; Mirka, 1991; Ryan e Gregor, 1992; Marsh e Martin, 1995; Hodges e Bui, 1996; Takaishi et al., 1998; Burden e Bartlett, 1999; Li e Caldwell, 1999; Hunter et al., 2002; Hug et al., 2004a, 2004b e 2006a; Laplaud et al., 2006; Chapman et al., 2006 e 2007; Rouffet e Hautier, 2007; Duc et al., 2008; Dorel et al., 2008). Em geral, os músculos estudados são: glúteo máximo (GMax), reto femoral (RF), vasto lateral (VL) vasto medial (VM), semimembranáceo (SM), semitendinoso (ST), bíceps femoral cabeça longa (BF), gastrocnêmio lateral (GL) e gastrocnêmio medial (GM), tibial anterior (TA), e sóleo (SOL). Por exemplo, Ericson (1986) utilizou eletromiografia para mostrar que os músculos extensores de joelho (VL e VM) são os mais exigidos na produção de torque durante a atividade de ciclismo, sendo estes mais ativos em ciclismo do que em caminhada.

A EMG-S, por sua vez, tem-se consolidado como ferramenta válida $\mathrm{e}$ recomendável ao estudo das funções musculares. Por exemplo, Ryan e Gregor (1992) verificaram, utilizando EMG-S, que os músculos monoarticulares (incluindo-se VL e VM) desempenham funções relativamente invariantes como geradores de torque durante ciclismo, em contraste com os músculos biarticulares, que apresentam maior variabilidade (Ryan e Gregor, 1992; Hug et al., 2004a). Ainda, vários autores concluem que a EMG-S pode ser utilizada para diferenciação funcional dos músculos e avaliação de suas propriedades intrínsecas (Sadoyama et al., 1988; Rainoldi et al., 2008).

Em meio às diversas linhas de pesquisa que utilizam a EMG-S como objeto principal de estudo ou como ferramenta auxiliar, muitas abordam o fenômeno da fadiga 
muscular como tema central (Lo Conte e Merletti, 1996; Rainoldi et al., 1999; Karlsson et al., 2000; Korosec, 2000; Bonato et al., 2001; Carmo, 2003; Zaman et al., 2005; JungYong et al., 2005; Clancy et al., 2005; Andrade, 2006; Cao et al., 2007; Andrade et al., 2008; Coorevits et al., 2008; Dimitrova et al., 2009; Schwartz, 2010; Thongpanja et al., 2012; Milhomem, 2014d e 2014e). Este contexto tem motivado o estudo de suas causas, efeitos e fenômenos correlatos em diferentes situações e modalidades de contrações musculares e, naturalmente, de métodos e técnicas para sua monitoração. Em geral, tais métodos e técnicas envolvem ferramentas matemáticas a serem aplicadas ao eletromiograma, associadas a protocolos experimentais que descrevem o exercício proposto e as condições de contorno. Este trabalho insere-se nesse contexto, abordando a avaliação da fadiga muscular localizada a partir do eletromiograma em protocolos dinâmicos, sendo este o escopo desta tese.

\section{2 - OBJETIVOS}

O objetivo geral deste trabalho é a avaliação de parâmetros objetivos indicadores eletromiográficos de fadiga muscular localizada. Esta avaliação compreende a proposição de seis novos indicadores, sendo um calculado no domínio do tempo, um no domínio da frequência e quatro utilizando wavelets. O indicador no domínio do tempo proposto é a distância entre picos e envoltória $\left(d_{P E}\right)$, definida especialmente para o caso dinâmico; o indicador no domínio da frequência proposto é o estreitamento espectral $\left(s_{E}\right)$ do eletromiograma; os indicadores utilizando wavelets são o deslocamento espectral $\left(K_{D E W}\right)$, a compressão espectral $\left(K_{C E W}\right)$, e suas versões adaptativas: o deslocamento espectral adaptativo $\left(K_{D E A}\right)$ e a compressão espectral adaptativa $\left(K_{C E A}\right)$. Estes dois últimos são calculados simultaneamente ao cálculo da transformada de wavelets discreta (DWT), adaptando-se a decomposição do sinal no banco de filtros. Os indicadores de fadiga propostos neste trabalho são avaliados e discutidos em conjunto com três indicadores tradicionais: o valor RMS (raiz da média quadrática), no domínio do tempo; e as frequências média (MNF) e mediana (MDF), no domínio da frequência. Além dos indicadores propostos, propõe-se avaliar parâmetros usualmente citados e sugeridos na literatura como possíveis indicadores de fadiga: 1) a assimetria do espectro de amplitude do eletromiograma; 2) o atraso do início da atividade mioelétrica; e 3) a duração da atividade mioelétrica. Os dois últimos parâmetros serão avaliados exclusivamente em 
protocolos dinâmicos de contrações cíclicas, para os quais apresentam uma definição coerente. São abordados 4 (quatro) protocolos experimentais envolvendo a aquisição de sinais de EMG-S de voluntários:

- Protocolo I (contrações dinâmicas em ciclismo) - este protocolo envolve a aquisição de sinais biomecânicos (curvas de forças sobre os pedais) e de EMGS do músculo VL de ciclistas pedalando em cicloergômetro até a exaustão, além da proposição de instrumentação dedicada para integração de dados biomecânicos e de EMG-S para avaliação conjunta;

- Protocolo II (contrações dinâmicas em ciclismo) - este protocolo envolve a aquisição de sinais de EMG-S dos músculos VL e VM de voluntários pedalando até a exaustão e proposição de estudo da avaliação da fadiga muscular em cicloergômetro em duas modalidades: carga constante (CL) e carga crescente (IL);

- Protocolo III (contrações dinâmicas em dinamometria isocinética) - neste protocolo coletaram-se sinais de EMG-S do músculo VL de voluntários realizando séries múltiplas de extensões isocinéticas de joelho;

- Protocolo IV (contração isométrica de bíceps) - neste protocolo os voluntários realizaram contração isométrica de bíceps braquial, músculo do qual se coletou sinal de EMG-S.

Os sinais de protocolo isométrico são utilizados neste trabalho somente com os objetivos de validar experimentalmente os parâmetros propostos neste trabalho como indicadores eletromiográficos de fadiga muscular e estudar o comportamento dispersivo dos indicadores abordados nesta tese. Posterior validação experimental é feita para o caso dinâmico, utilizando-se os sinais do Protocolo II.

Como objetivos específicos, os indicadores de fadiga propostos nesta tese são avaliados - em conjunto com os tradicionais - quanto às suas características dispersivas para a inferência de sua reprodutibilidade. São propostas neste trabalho duas métricas para avaliação da dispersão, os índices de dispersão polinomial $\left(I_{D_{p o l}}\right)$ e diferencial $\left(I_{D_{\text {dif }}}\right)$. Estas serão utilizadas em conjunto com a métrica tradicionalmente utilizada: o coeficiente de variação $(\mathrm{CoV})$. Objetiva-se avaliar, dentre os indicadores aqui estudados, quais apresentam comportamento menos dispersos; os indicadores propostos que se calculam utilizando wavelets com abordagem adaptativa visam reduzir tais características dispersivas e de imprevisibilidade. Junto a isto, estuda-se a possibilidade de que, ao propor 
a aferição da largura de banda - a partir do parâmetro $s_{E}$ aqui proposto - em vez do deslocamento do centro do espectro do sinal de EMG-S - a partir das tradicionais frequências média e mediana -, se obtenha um parâmetro menos disperso e, possivelmente, mais previsível e adequado à avaliação da fadiga muscular no domínio da frequência.

Com os sinais do Protocolo II, propõe-se estudar o comportamento dos indicadores eletromiográficos com a indução da fadiga a partir de duas abordagens: 1) dinâmica, em que os indicadores são calculados sobre os ciclos do eletromiograma (correspondentes às pedaladas) separadamente; e 2) isométrica, em que trechos de ciclos sucessivos são concatenados de forma a obter um sinal eletromiográfico semelhante ao caso de contração isométrica. Juntamente, faz-se um estudo do comportamento dos indicadores de fadiga nas modalidades CL e IL. Este estudo em protocolo de ciclismo compreende a investigação dos seguintes itens:

- Verificar se há diferenças significativas entre os índices obtidos para o VL e para o VM, em cada situação em particular (modalidade e abordagem para cálculo dos indicadores);

- Investigar a existência de padrões para a correlação calculada entre os indicadores eletromiográficos do VL e do VM em função da duração das janelas adotadas em abordagem isométrica; e, em caso positivo, avaliar quais indicadores são mais sensíveis à escolha da duração da janela. Assim busca-se avaliar com quais indicadores - e sob quais abordagens para seu cálculo obtêm-se maior similaridade ao escolher entre avaliar a fadiga a partir do VL ou a partir do VM;

- Avaliar se há maior aproximação entre atividade mioelétrica do VL e do VM em alguma das modalidades: CL ou IL;

- Avaliar qual dos músculos possivelmente apresenta maior sensibilidade ao incremento da carga e, em caso positivo, quais indicadores melhor devem-na refletir;

- Verificar quais indicadores melhor dissociam os efeitos da fadiga muscular localizada dos efeitos do incremento gradual da carga;

- Verificar em qual modalidade a janela adotada em abordagem isométrica exerce maior influência sobre a correlação entre os indicadores eletromiográficos calculados para o VL e para o VM;

As análises resultantes destes questionamentos conduzirão a um conjunto de 
recomendações sobre quais indicadores devem ser preferivelmente utilizados em quais situações.

Apresenta-se uma proposta de instrumentação integrada dedicada à avaliação conjunta de sinais biomecânicos e eletromiográficos. A partir desta proposição, intencionase gerar hipóteses acerca de possíveis relações entre desempenho biomecânico - cuja definição objetiva é oportunamente apresentada - e fadiga muscular. Desta maneira, estes aspectos direcionam-se, em grande parte, a proposições para trabalhos futuros.

O comportamento dos indicadores eletromiográficos também é estudado em dinamometria isocinética para extensões repetidas de joelho - a partir dos sinais de EMG-S do VL -, objetivando-se avaliar o efeito de se aferir a fadiga muscular nas diferentes fases do ciclo de contração desse exercício. Neste mesmo protocolo experimental, avalia-se se a eficiência neuromuscular (ENM) apresenta algum padrão com a fadiga muscular localizada induzida pelas extensões isocinéticas do joelho.

Finalmente, os objetivos específicos deste trabalho também compreendem a proposição de um conjunto de técnicas de pré-processamento do sinal eletromiográfico, utilizando wavelets, para redução da interferência da rede elétrica; e análise de desempenho da técnica de cancelamento de ruído invariante ao deslocamento. Para esta última técnica, fazem-se algumas recomendações para sua aplicação ao tratamento de sinais de EMG-S.

\section{3 - JUSTIFICATIVA E CONTRIBUIÇÕES}

Especialmente nas duas últimas décadas, a aplicabilidade de descritores espectrais em sinais de EMG-S de protocolos dinâmicos tem sido discutida na literatura científica, sendo estes citados, ao mesmo tempo, como padrão ouro e como ponto de controvérsias (Hug e Dorel, 2009). Além disso, a característica mais adequada a ser observada no espectro de amplitude do eletromiograma em atividades fatigantes ainda é bastante debatida, vistas as diversas propostas de indicadores espectrais para esta finalidade (Davies e Reisman, 1994; Ranniger e Akin, 1997; Ismail e Asfour, 1998; Karlsson et al., 2000; Sparto et al., 2000; Bonato et al., 2001; Clancy et al., 2005; Cao et al., 2007; Andrade et al., 2008; Coorevits et al., 2008; Dimitrova et al., 2009; Yochum et al., 2012). A esta discussão soma-se a carência de recomendações sobre quais tipos de indicadores melhor se aplicam a diferentes protocolos experimentais que induzem o indivíduo à fadiga, como, por 
exemplo, contrações realizadas à carga constante ou à carga crescente; juntamente à necessidade de verificar-se de que maneira a metodologia para uso dos indicadores afeta a avaliação objetiva da fadiga. Portanto, como contribuições deste trabalho podem-se listar:

- Proposição de seis novos indicadores eletromiográficos de fadiga muscular e metodologias para sua aplicação - dos quais três indicadores propõem-se a reduzir a dispersão da estimativa; inclui-se a definição de métricas de dispersão visando quantificar a qualidade dos indicadores eletromiográficos;

- Análise conjunta dos indicadores propostos e indicadores tradicionais da literatura científica;

- Proposição de indicador eletromiográfico que explora o gradual distanciamento entre os picos do eletromiograma e seu perfil suavizado $\left(d_{P E}\right)$;

- Proposição de indicadores eletromiográficos, baseados em decomposição adaptativa do sinal em wavelets, que promovam estimativas menos dispersas e imprevisíveis para a fadiga - visto que a fadiga muscular é um fenômeno previsível, é razoável e justificada a proposição e análise de indicadores que também o sejam -, e estudo das características dispersivas dos indicadores espectrais que abordam dois diferentes fenômenos do espectro de amplitude do sinal de EMG: deslocamento de sua frequência central e diminuição de sua largura de banda;

- Avaliação da hipótese de parâmetros eletromiográficos - relacionados ao padrão de ativação da atividade mioelétrica e à assimetria de seu espectro de amplitude - citados na literatura apresentarem padrão com a fadiga muscular;

- Análise comparativa entre os índices obtidos para o VL e para o VM em cada modalidade e abordagem para cálculo dos indicadores;

- Estudo de quais indicadores - e sob quais abordagens para seu cálculo apresentam comportamento significativamente mais semelhante ao escolher entre avaliar a fadiga em ciclismo a partir do VL ou a partir do VM; inclui-se uma investigação dos padrões de similaridade entre os indicadores eletromiográficos do VL e do VM em função da duração das janelas adotadas em abordagem isométrica;

- Avaliação da existência de maior (ou menor) aproximação entre atividade mioelétrica do VL e do VM - nos casos de impor-se ou não o incremento da carga - ao induzir o indivíduo à fadiga; 
- Avaliação sobre qual dos músculos - e a partir de quais indicadores eletromiográficos - possivelmente apresenta maior sensibilidade ao incremento da carga;

- Verificação de quais indicadores melhor dissociam os efeitos da fadiga muscular localizada dos efeitos do incremento gradual da carga sobre o sinal de EMG-S;

- Verificação de qual modalidade apresenta maior sensibilidade ao janelamento escolhido na abordagem isométrica, no que se refere às semelhanças entre fadiga localizada no VL e no VM;

- Estudo das relações entre os parâmetros eletromiográficos dos músculos VL e VM em ciclismo a carga crescente e constante e recomendações a cada protocolo experimental;

A observação destes fatores deve afetar a escolha do parâmetro eletromiográfico a ser utilizado em cada situação. Portanto, estas etapas da análise conjunta da fadiga localizada no VL e no VM - em cada modalidade, a partir de cada indicador e sob qual abordagem são necessárias para que se encontre apoio a conclusões mais assertivas sobre a monitoração da atividade mioelétrica em atividades fatigantes. Por fim, também constituem contribuições deste trabalho:

- Proposta de instrumentação integrada e metodologia para avaliação objetiva de desempenho biomecânico em ciclismo em conjunto com a fadiga muscular; por suas razões de caráter prático, um plausível e encorajado questionamento é se ciclistas que apresentam, em média, maior desempenho biomecânico, também apresentam maior aptidão a experimentar um processo mais intenso de fadiga muscular localizada;

- Estudo sobre a adequação da avaliação de fadiga muscular em cada fase de contração em dinamometria isocinética; os resultados deste estudo devem fornecer informações úteis, por exemplo, à aplicação em protocolos fisioterápicos nos quais a fadiga muscular é um aspecto relevante a ser monitorado; ressalte-se o crescente uso da dinamometria isocinética em tais situações;

- Conjunto de ferramentas para pré-processamento dos sinais de EMG-S.

A seguir, descreve-se brevemente a organização deste trabalho. 


\section{4 - ORGANIZAÇÃO DO TRABALHO}

Esta tese está organizada em sete capítulos. Neste primeiro capítulo apresentou-se o problema a ser estudado, a justificativa e os objetivos do trabalho, listando-se suas principais contribuições.

No segundo capítulo são abordados os fundamentos da eletromiografia, envolvendo a formação do sinal, sua captação e as características que este apresenta com a indução da fadiga muscular e em função de outros fatores. Ao longo desse capítulo faz-se uma revisão bibliográfica dos pontos mais importantes a serem abordados nesta tese. Considerações teóricas relacionadas aos protocolos experimentais e situações específicas ou pontuais abordadas neste trabalho serão discutidas quando conveniente. Por exemplo, uma revisão bibliográfica envolvendo especificamente a atividade de ciclismo é apresentada na respectiva seção do trabalho que lhe corresponde, e assim por diante.

No terceiro capítulo descrevem-se todos os protocolos experimentais abordados nesta tese, além de instrumentação dedicada para aquisição dos sinais e a proposta para a análise conjunta de desempenho biomecânico e indicadores eletromiográficos em ciclismo.

No quarto capítulo apresenta-se o conjunto de ferramentas de pré-processamento e condicionamento do sinal eletromiográfico. Os resultados obtidos com sua aplicação são apresentados e discutidos nesse mesmo capítulo.

No quinto capítulo são discutidas as técnicas para avaliação da fadiga muscular, apresentando-se os indicadores de fadiga definidos neste trabalho e as métricas de dispersão para avaliação conjunta. Nesse capítulo faz-se, inicialmente, uma breve revisão das técnicas propostas nos últimos anos e apresentam-se as abordagens - estudadas neste trabalho - para a aplicação dessas técnicas a sinais eletromiográficos obtidos durante contrações cíclicas.

No sexto capítulo as técnicas para avaliação de fadiga são estudadas. Nesse capítulo são apresentados e discutidos os resultados obtidos neste trabalho em cada protocolo experimental, separadamente. Primeiramente, na seção 6.1, faz-se a validação experimental dos parâmetros propostos neste trabalho - e os demais da literatura aqui abordados - como indicadores eletromiográficos de fadiga muscular utilizando sinais de EMG-S de contração isométrica de bíceps. Logo após, na seção 6.2, estes parâmetros são validados experimentalmente em protocolo dinâmico (sinais de ciclismo) e estudados em conjunto nos protocolos a carga constante e crescente para os músculos VL e VM, 
discutindo-se os padrões observados. Após estas validações experimentais e estudos citados, na seção 6.3 os indicadores são avaliados em conjunto com o desempenho biomecânico em ciclismo, a partir da instrumentação dedicada proposta. Por fim, apresenta-se o estudo destes parâmetros eletromiográficos em dinamometria isocinética na seção 6.4. O leitor perceberá que os aspectos metodológicos desta tese não foram apresentados em sua totalidade num único capítulo. Objetivando-se minimizar a possível densidade excessiva de informações ao longo do texto - além de eventuais descontinuidades na apresentação dos contextos e propostas da tese - estes aspectos estão distribuídos entre os capítulos 3 e 6 , sendo oportunamente apresentados.

Finalmente, no sétimo capítulo, as conclusões e recomendações para futuras pesquisas são feitas à luz dos resultados obtidos. Apresenta-se uma visão geral e crítica deste trabalho, baseada nas análises objetivas realizadas e direcionada às perspectivas nos campos de estudo nesta tese envolvidos. 


\section{2 - A ELETROMIOGRAFIA}

Neste capítulo serão examinados os fundamentos e princípios dos sinais tratados neste trabalho - sinais eletromiográficos. Tratar-se-á de sua origem, suas características básicas, principais formas de captação, condicionamento, seu comportamento sob a influência da fadiga muscular e demais fatores que afetam a estimação de parâmetros que os descrevem.

\section{1 - INTRODUÇÃO}

Considera-se o trabalho de Piper (1912) como pioneiro no estudo dos sinais elétricos associados às funções musculares, ou sinais mioelétricos. Adrian e Bronk (1929) desenvolveram o eletrodo de agulha, ferramenta até hoje utilizada em eletromiografia (EMG). Após algumas décadas de contribuições de vários pesquisadores no estudo e caracterização dos potenciais de ação das unidades motoras (Muaps), em 1962 J. V. Basmajian publica seu livro "Muscles Alive", referência utilizada até hoje em diversos campos de estudo que envolvem a eletromiografia, contando com várias reedições (Basmajian, 1978; Basmajian e DeLuca, 1985). Autores como LeFever, DeLuca e McGill, com o advento da computação em meados da década de 1980, investigaram o problema da decomposição do eletromiograma num trem de Muaps (LeFever e DeLuca, 1982a e 1982b; McGill, 1985).

Outro marco foi o trabalho de De Luca (1979), que apresenta, de forma pioneira, um estudo conjunto das propriedades matemáticas e fisiológicas da atividade mioelétrica. Dimitrova (1974) e Lindström (1977) apresentaram os primeiros avanços na modelagem dos fenômenos mioelétricos.

Nas três últimas décadas, a eletromiografia de superfície tem sido extensivamente empregada e discutida como ferramenta válida no estudo das funções musculares, havendo debates e propostas de padronização em seu uso (Merletti, 2000; Merletti e Hermens, 2000).

Assim, muitos dos fatores básicos que constituem e influenciam as características do eletromiograma são hoje razoavelmente bem documentados, sendo a eletromiografia corriqueiramente utilizada como ferramenta auxiliar em procedimentos de monitoração da 
atividade muscular, terapêuticos e diagnósticos (Kamen e Gabriel, 2010). A seguir, serão apresentados os conceitos básicos sobre eletromiografia e a formação do sinal eletromiográfico.

\section{2 - FORMAÇÃO DO SINAL E DEFINIÇÕES}

Basmajian (1978) define a eletromiografia como o estudo das funções musculares a partir dos sinais elétricos que estes músculos emanam - a atividade mioelétrica. Assim, o eletromiograma, ou sinal eletromiográfico, consiste no registro dos potenciais de unidades motoras (MUs) do músculo estudado. Uma unidade motora é formada por um neurônio motor e pelas fibras musculares por este inervadas (Basmajian e DeLuca, 1985), conforme ilustrado na figura 2.1:

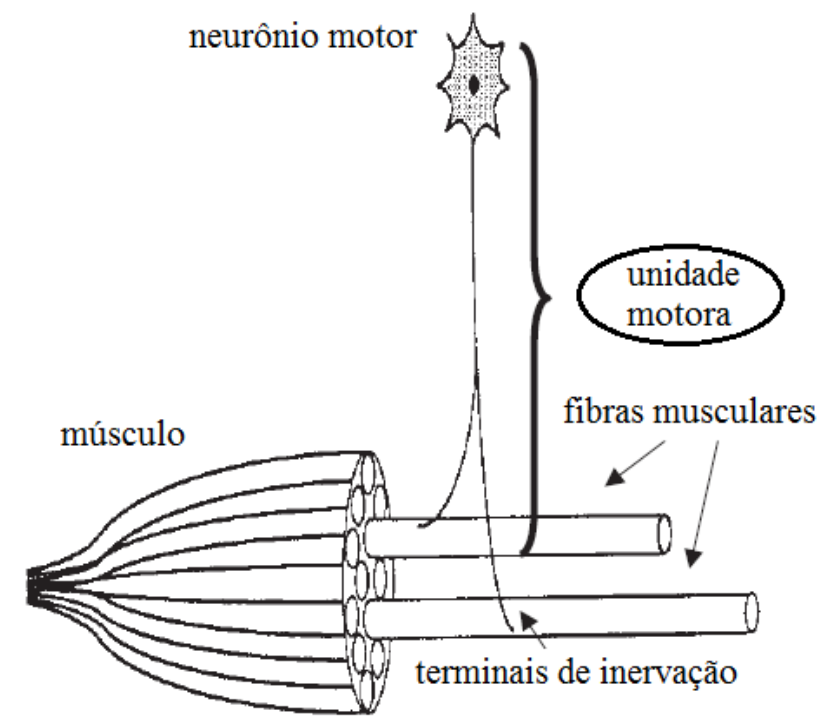

Figura 2.1: Unidade motora. Modificado de Moritani et al. (2004).

Fibras musculares são as células constituintes do músculo, responsáveis pela contração muscular (Burke, 1981). São tradicionalmente classificadas em 3 tipos (Moritani et al., 2004): tipo I (fibras de contração lenta e resistentes à fadiga); tipo IIa (de contração rápida e resistentes à fadiga); e tipo IIb (de contração rápida e fadigáveis). Ainda, fibras do tipo IIb não necessitam de quantidades significativas de oxigênio (atividade anaeróbia) se comparadas às do tipo I e IIa. Fibras de tipo I, IIa e IIb apresentam, respectivamente, diâmetros e MUs pequenas, médias e grandes. Fibras maiores, em geral, são recrutadas 
para contrações mais rápidas e intensas, normalmente em atividades físicas em que se necessita maior produção de torque (Burke, 1981; Moritani et al., 2004). Assim, músculos com diferentes funcionalidades exibem diferentes proporções de fibras de cada tipo.

A membrana da fibra muscular constitui-se de uma bicamada de moléculas fosfolipídicas e proteínas. O interior da membrana apresenta característica hidrofóbica, caracterizando sua impermeabilidade, o que impede a entrada e saída de íons. No entanto, as macromoléculas de proteínas presentes na membrana funcionam como canais iônicos, permitindo sua passagem quando abertos (Brown, 1984).

O comportamento de fibras musculares sob estímulos elétricos é razoavelmente mais complexo do que o de fibras nervosas. Um trabalho clássico envolvendo a descrição quantitativa destes fenômenos foi o modelo eletrofisiológico da membrana da fibra muscular, proposto por Hodgkin e Huxley (1952).

Uma contração muscular é acionada por impulsos nervosos conduzidos pelos axônios das MUs às suas respectivas fibras musculares, produzindo os potenciais de ação que trafegam ao longo destas fibras (Basmajian e DeLuca, 1985; Bear et al., 2008). Durante o repouso de uma fibra muscular, há uma alta concentração de $\mathrm{Na}+$ no exterior da célula e de $\mathrm{K}+$ em seu interior. Nestas condições, o potencial interno (potencial de repouso) da membrana da fibra muscular pode apresenta-se entre -65 e $-70 \mathrm{mV}$ em relação ao terra, ou entre -85 e $-90 \mathrm{mV}$ em relação ao exterior da membrana - fibras de contração rápida, em geral, com potencial mais próximo do zero -, encontrando-se esta polarizada (Kamen e Gabriel, 2010). Um potencial de ação é caracterizado, portanto, por uma despolarização da fibra, quando o potencial da MU a que pertence ultrapassa o limiar de ativação, caracterizando-se um potencial de ação da unidade motora (Muap). Durante um potencial de ação, canais iônicos de $\mathrm{Na}^{+}$e $\mathrm{K}^{+}$da membrana da fibra abrem-se permitindo a entrada e saída destes íons, devido à alteração no equilíbrio entre as cargas dos fluidos intra e extracelulares (despolarização) (Bear et al., 2008). A combinação destes fatores ocasiona uma corrente detectável ao longo da fibra muscular, como indicado na figura 2.2. 


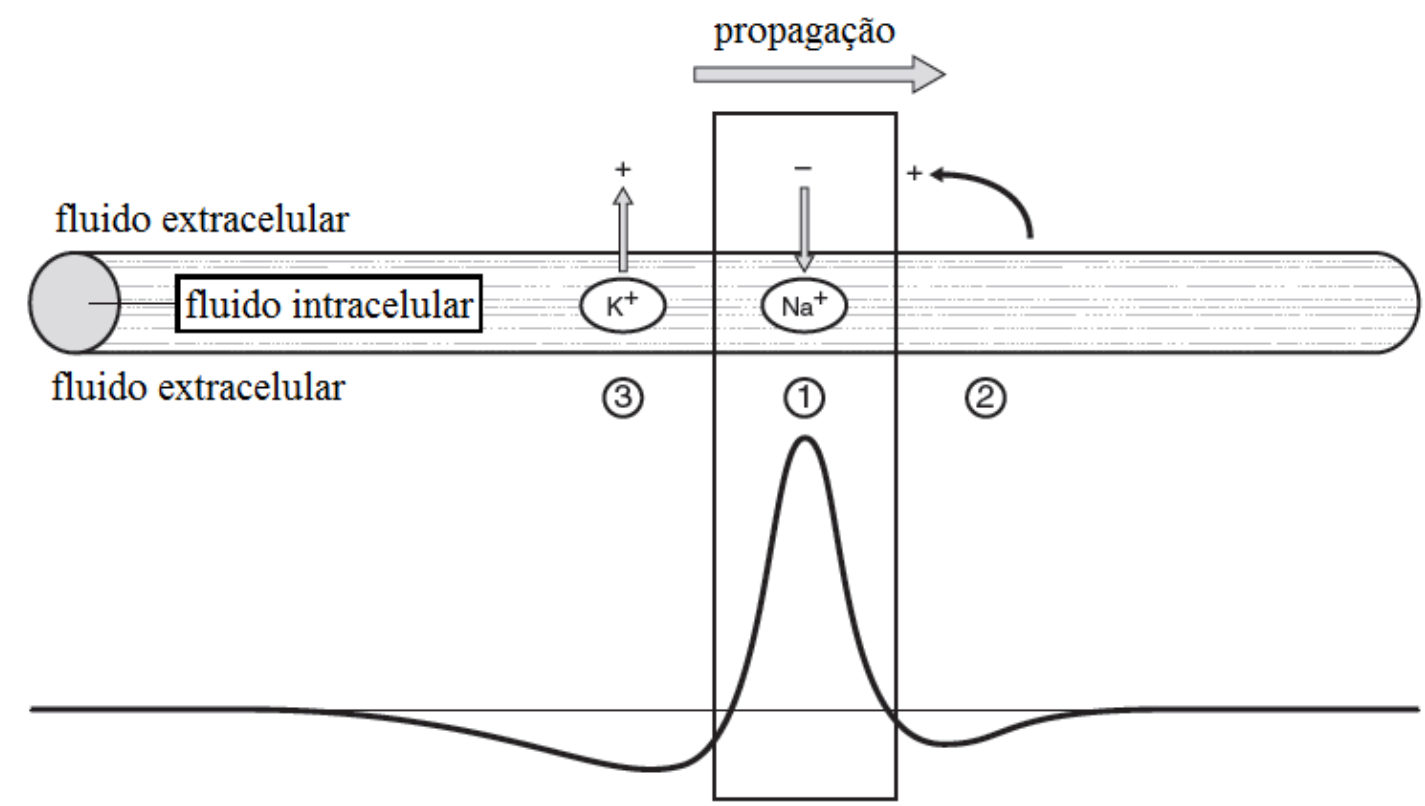

Figura 2.2: Propagação do potencial de ação na fibra muscular. Adaptado de Kamen e Gabriel (2010).

Primeiramente, com a abertura de canais de $\mathrm{Na}^{+}$e a entrada destes íons, o fluido extracelular torna-se negativamente carregado e registra-se uma despolarização (1) numa porção da fibra. Devido à despolarização, íons positivos são atraídos próximo à área em que a despolarização ocorre, registrando-se um pequeno potencial de sinal contrário (2). Assim, o movimento de $\mathrm{K}^{+}$para o exterior da fibra gera a repolarização (3) (Dumitru 2000; Loeb e Gans 1986). Completadas todas estas etapas, um potencial de ação dura aproximadamente $2 \mathrm{~ms}$ (Bear et al., 2008). A figura 2.3 mostra mais detalhadamente a sequência destes eventos ocorridos e a permeabilidade relativa da membrana aos íons $\mathrm{Na}^{+}$ e $\mathrm{K}^{+}$durante a propagação do potencial de ação, ilustrando-se o padrão temporal da influência da abertura de cada canal iônico e seu respectivo potencial sobre o potencial registrado na membrana. 


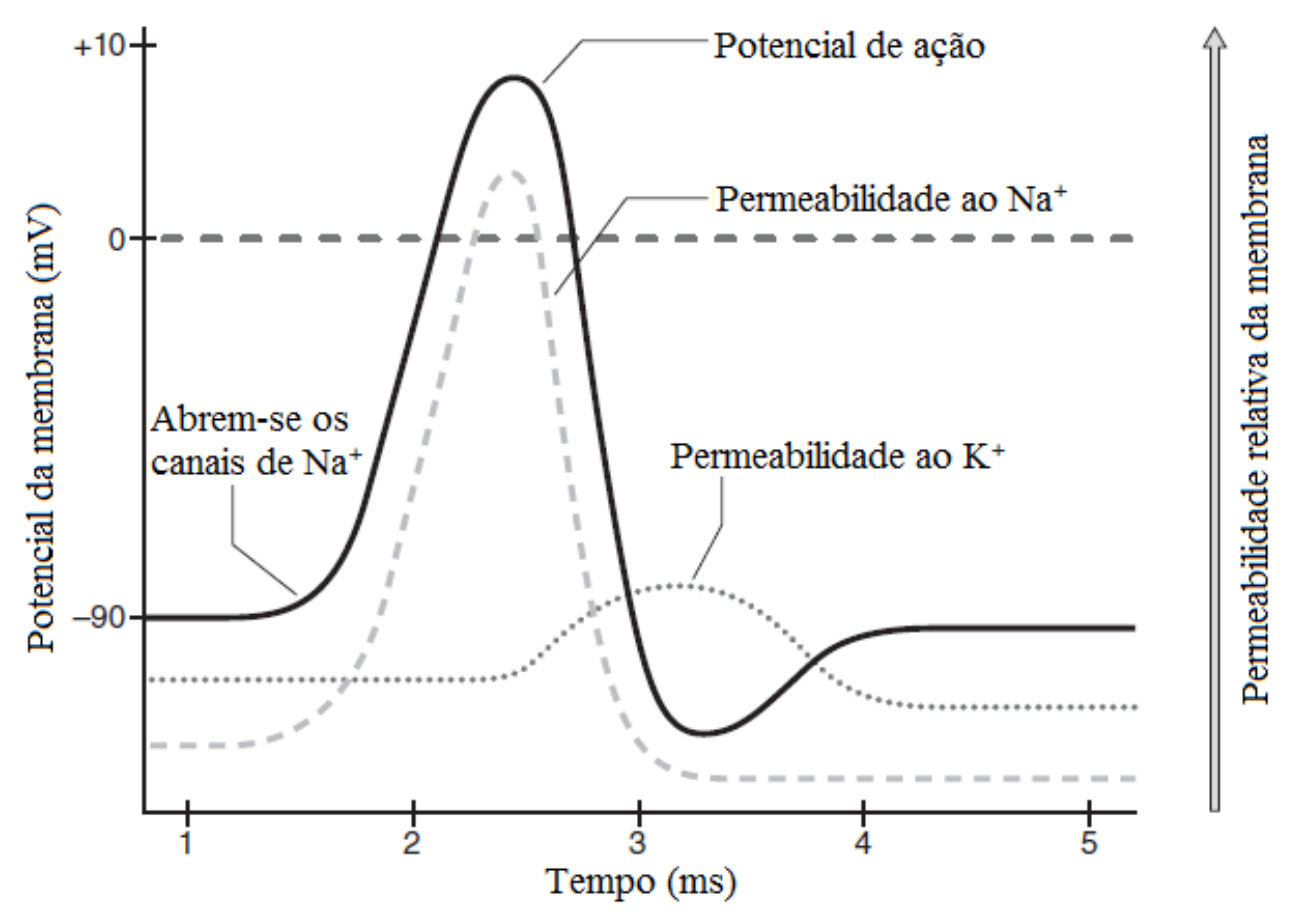

Figura 2.3: Potencial da membrana e permeabilidade dos canais iônicos na ocorrência de um potencial de ação. Adaptado de Kamen e Gabriel (2010).

Diferentes unidades motoras podem apresentar diferentes limiares de ativação. Em geral, aquelas que apresentam maiores valores de limiar exibem maiores amplitudes e velocidades de condução (CV) em seus potenciais de ação. Unidades motoras contendo maior proporção de fibras do tipo I são recrutadas a limiares mais baixos com menores valores de CV. Unidades motoras contendo mais fibras do tipo IIa são recrutadas a limiares médios com CV intermediária e do tipo IIb a limiares altos e CV alta (Moritani et al., 2004).

A força muscular é modulada pelo recrutamento de unidades motoras e pela frequência de disparos de potenciais de ação. Quanto maior a quantidade de MUs recrutadas e suas taxas de disparos, maior será a força produzida (Milner-Brown et al., 1973; Kukulka e Clamann, 1981; Moritani e Muro, 1987).

Em geral, o padrão de recrutamento das MUs está relacionado à maneira como a contração muscular é realizada (Moritani et al., 2004). São diversas as modalidades de contração muscular, sendo as principais classificadas por Silbernagl e Despopoulos (2003) em 3 (três) categorias: isométrica, em que o comprimento do músculo permanece constante; isotônica, em que a força exercida permanece constante; e auxotônica, em que ambos estes parâmetros podem variar. Assim, contrações dinâmicas englobam as isotônicas e auxotônicas. 
A atividade mioelétrica, quando detectada sobre a pele, representa a soma dos potenciais de ação de várias unidades motoras ativas durante a detecção (Farina et al., 2004). A seguir, a figura 2.4 ilustra a formação do eletromiograma quando registrado sobre a superfície da pele, como resultante da soma dos potenciais de diferentes fibras de uma unidade motora.

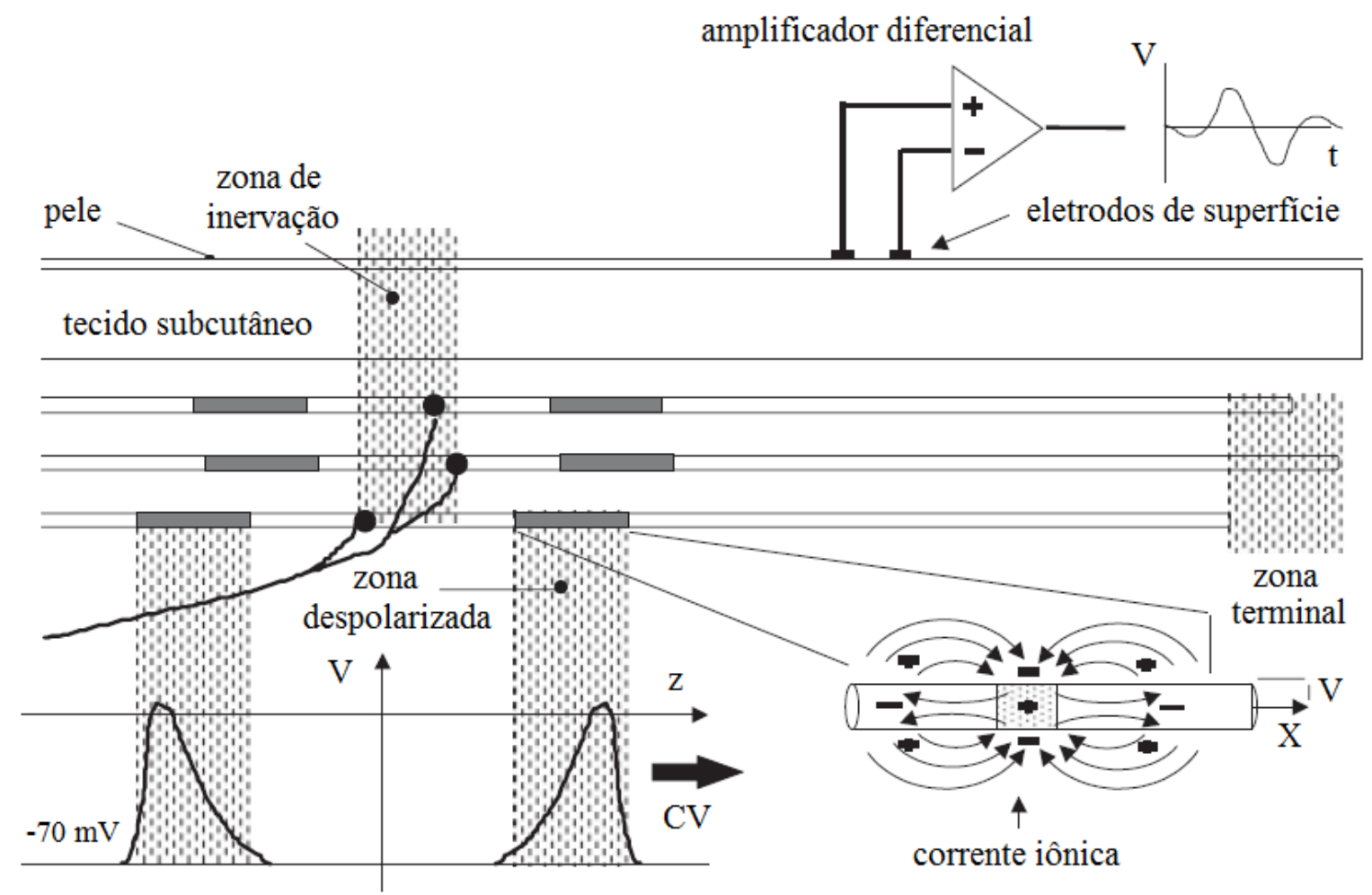

Figura 2.4: Registro da soma dos potenciais de uma MU sobre a pele. Adaptado de Farina et al. (2004).

Como sugerido na figura 2.4, o elemento básico utilizado na eletromiografia para a coleta do sinal é o eletrodo, sensor responsável por captar a atividade mioelétrica. As modalidades de captação serão discutidas a seguir.

\section{3 - REGISTRO DO SINAL}

As principais maneiras de se registrar a atividade mioelétrica são:

- Eletromiografia de superfície: os eletrodos são colocados sobre a pele, em regiões adequadamente escolhidas que proporcionem a melhor medição da atividade elétrica do músculo desejado. Considera-se este um método eficiente para estudos 
cinesiológicos e neurofisiológicos dos músculos superficiais, não sendo invasivo. Neste caso, obtém-se a soma dos potenciais de ação do músculo estudado - em sua forma global (Merletti e Hermens, 2004).

- Eletromiografia de profundidade ou intramuscular: é um método invasivo no qual são inseridos os eletrodos no músculo. Atualmente é um método utilizado somente quando justificado por necessidades específicas, como a monitoração de características musculares locais ou finalidades diagnósticas (Trontelj et al., 2004; Merletti e Parker, 2004).

A eletromiografia de superfície é um procedimento não invasivo já amplamente difundido na comunidade científica para aferição das funções musculares (Ollivier et al., 2005). Comparada aos métodos invasivos, como a eletromiografia de profundidade, mostra-se um procedimento indolor e reprodutível, permitindo estudos de longo prazo e aplicações terapêuticas (Jonsson e Bagga, 1968; Komi e Buskirk, 1970; Giroux e Lamontagne, 1990; Krivickas et al., 1996). Farina e Merletti (2004) incluem, entre os principais fatores que afetam a estimativa dos parâmetros do eletromiograma obtido por EMG-S:

- Inclinação das fibras em relação às placas do eletrodo, dimensões e formato do eletrodo e filtragem espacial;

- Distância entre fibras musculares e eletrodos, entre os eletrodos e movimento dos eletrodos sobre a pele;

- Espessura dos tecidos subcutâneos, heterogeneidades do tecido e interface eletrodopele e variações da impedância deste acoplamento;

- Localização dos eletrodos ao longo das fibras (zonas de inervação etc.) e comprimento das fibras;

- Ruídos aditivos e interferências eletromagnéticas (e.g. rede de alimentação), além dos ruídos internos do eletromiógrafo (componentes eletrônicos de alto ganho);

- Cross-talk (interferência de outras unidades motoras que não as de interesse) e terminais das fibras;

Os efeitos destes fatores citados podem ser significativamente reduzidos pelo adequado posicionamento dos eletrodos. Vários autores (Gydikov et al., 1976b e 1979; Sadoyama et al,.. 1985; Mesin et al., 2009) sugerem procedimentos para a correta localização e posicionamento dos eletrodos sobre a pele. Em geral, a inteligibilidade do sinal de EMG-S é comprometida se a captação é realizada próxima aos terminais das fibras (Gydikov et al., 
1976b e 1979). Ao posicionar os eletrodos entre a zona de inervação e terminais das regiões tendíneas, minimiza-se a sensibilidade a estes artefatos e aos potenciais que se propagam na direção oposta (Dimitrov e Dimitrova, 1974; Gydikov et al., 1976). Sugerese, assim, identificarem-se estes pontos anatômicos previamente à fixação dos eletrodos (Masuda et al., 1985; Mesin et al., 2009). DeLuca (1997) sugere eletroestimulação ou mapeamento elétrico de superfície para a localização das zonas de inervação. Realizada esta identificação, o eletrodo deve ser posicionado na direção das fibras musculares (Sadoyama et al. 1985; DeLuca, 1997; Farina e Merletti, 2004). Devem ser posicionados o mais próximo do centro do ventre muscular para se obter o máximo dos potenciais dos músculos fusiformes (Zuniga et al., 1970). A figura 2.5 ilustra os efeitos da localização do eletrodo no sinal de EMG-S captado e sua densidade espectral de potência (PSD).
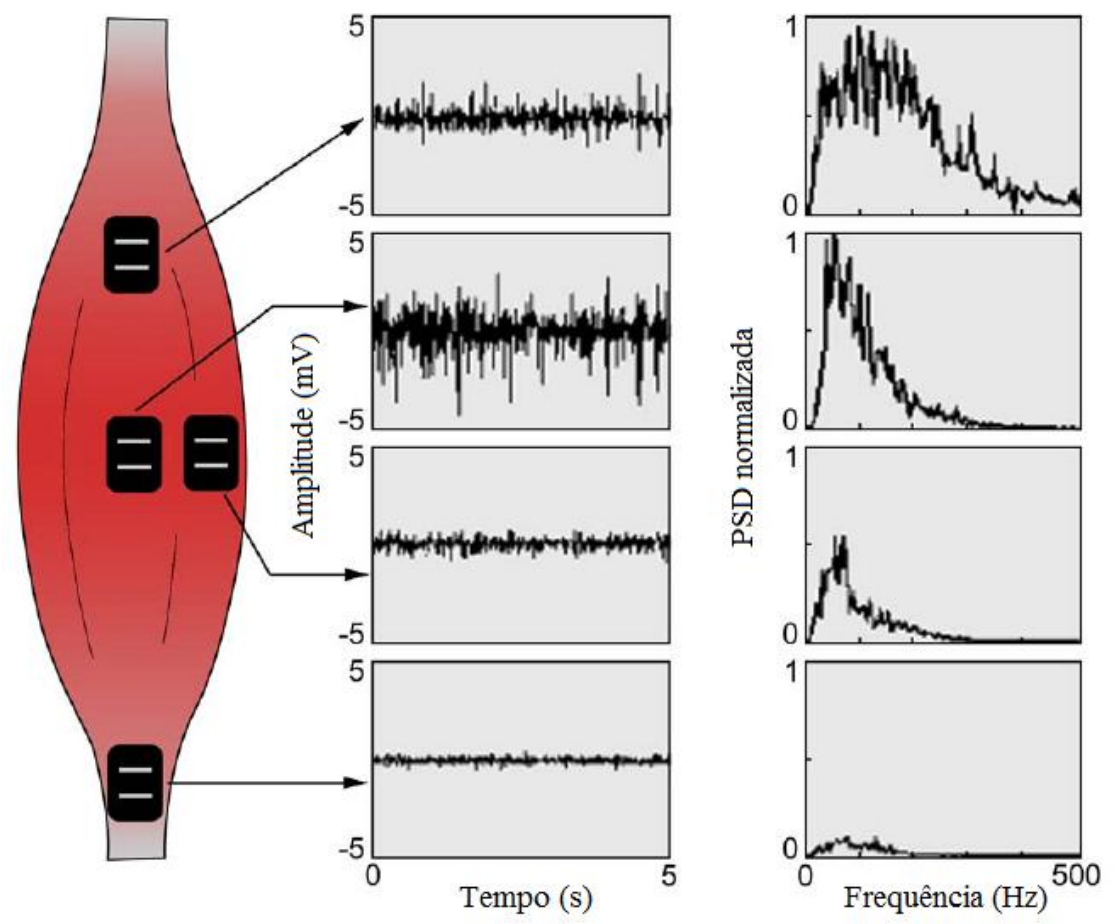

Figura 2.5. Efeitos da localização do eletrodo no sinal de EMG-S: domínio do tempo e da frequência. Adaptado de DeLuca (1997).

Algumas recomendações são feitas por DeLuca (1997) para a captação de EMG-S com eletrodos em configuração diferencial:

- Superfícies de detecção devem consistir em duas barras paralelas (1,0 cm x 1,0 a 2,0 $\mathrm{mm}$ ) afastadas em 1,0 cm;

- Banda passante de 20 a $500 \mathrm{~Hz}$ e roll-off de, no mínimo, 12 dB/oitava; 
- Razão de modo de rejeição comum superior a 80 dB;

- Ruído com amplitude inferior a $2 \mu \mathrm{V}$ RMS na faixa de 20 a $400 \mathrm{~Hz}$;

- Impedância de entrada superior a $100 \mathrm{M} \Omega$.

Tais fatores, assim como as técnicas escolhidas para estimação dos parâmetros do sinal de EMG, afetam a avaliação de fenômenos fisiológicos a partir do eletromiograma (e.g. fadiga muscular) além da reprodutibilidade intra-sujeito das estimativas (Farina e Merletti, 2004).

Wittek et al. (2001) mostram que, em casos dinâmicos mais extremos (e.g. reflexo muscular a um evento abrupto), pode ser necessária a filtragem passa-alta do sinal de EMG à frequência de corte de, ao menos, $50 \mathrm{~Hz}$. Em seu estudo, simularam com voluntários o reflexo prévio de um motorista à colisão de um veículo. Avaliam que, em casos semelhantes, a eletromiografia de profundidade é mais adequada à monitoração dos reflexos motores.

Ollivier et al. (2005) compararam os métodos de EMG-S utilizando as configurações laplaciana e bipolar e seus efeitos na reprodutibilidade das estimativas dos parâmetros de amplitude, espectrais e velocidade de condução dos Muaps. Verificaram que ambas as configurações apresentam reprodutibilidade aceitável, contudo, a configuração bipolar apresenta reprodutibilidade maior para todos os parâmetros aferidos. Atribuem estas observações à menor seletividade da configuração bipolar, o que faz com que forneça uma visão global da atividade muscular e, portanto, menos sensível a fatores locais.

Rainoldi et al. (2008) abordam o problema da diferenciação funcional entre os músculos vasto lateral e porções do vasto medial (longo e oblíquo) a partir da eletromiografia de superfície em contrações isométricas. Concluem que a EMG-S pode ser utilizada como método não invasivo para a diferenciação funcional destes músculos.

Assim, a EMG-S tem-se consolidado como uma técnica confiável para o acompanhamento da atividade muscular, desaconselhando-se o uso de ferramentas intramusculares para a monitoração global da atividade mioelétrica, especialmente para estudos ocupacionais (Christensen et al., 1995).

Alguns autores já exploram o tema da observação de atividades musculares não superficiais através da EMG-S. McGill et al. (1996), por exemplo, verificam que, para alguns músculos (coluna lombar), posicionando-se os eletrodos adequadamente, pode-se utilizar a eletromiografia de superfície para monitorar a atividade muscular profunda. 


\section{4 - CARACTERÍSTICAS DO SINAL E FADIGA MUSCULAR}

\subsection{1 - Monitoração da fadiga}

A fadiga é um fenômeno corriqueiro, sendo extensivamente abordada em estudos e induzida em protocolos experimentais. Sua definição, porém, é complexa, não é única, e comumente está sujeita a controvérsias (Merletti et al., 2004).

Para a identificação da fadiga muscular a partir de critérios biomecânicos, propõese defini-la como incapacidade na manutenção da força requisitada ou esperada (Edwards, 1981) ou como qualquer redução - induzida por exercício - na capacidade de gerar a força solicitada (Vøllestad, 1997). Tal disparidade explica-se, parcialmente, pela imensa variedade de modelos de exercício, protocolos experimentais e métodos aplicados ao seu estudo (Vøllestad, 1997).

O termo fadiga muscular localizada foi estabelecido por Chaffin (1973) para referir-se às manifestações da fadiga num único músculo ou grupo de músculos atuando em conjunto para uma mesma função. De acordo com a definição das manifestações mioelétricas da fadiga muscular, os músculos envolvidos tornam-se continuamente fadigados, a partir do início da contração (Bonato et al., 2001; Zazula et al., 2004).

A rapidez com que a fadiga ocorre depende das propriedades dos músculos solicitados na tarefa, da força da contração e se as contrações são contínuas ou intermitentes. A fadiga pode manifestar-se no sistema nervoso central ou no periférico, caracterizando a fadiga central e a periférica (Zazula et al., 2004). A fadiga central é causada, em geral, por alterações nos caminhos neurais e a periférica por alterações nas fibras musculares e nas junções neuromusculares (Merletti et al., 2004 ; Zazula et al., 2004; Bear et al., 2008). Neste sentido, a fadiga central não se relaciona diretamente com os fatores periféricos, não implicando na diminuição da força máxima evocável (e.g. eletroestimulação) (Vøllestad, 1997).

$\mathrm{O}$ estado da arte, no que se refere à fadiga periférica, está bastante avançado se comparado ao que se conhece sobre a fadiga central (Zazula et al., 2004). Vários fatores fisiológicos são já documentados e aceitos na comunidade científica, como o aumento na concentração de lactato, decréscimo no pH e modificações nas concentrações iônicas. Porém, a contribuição relativa de cada um destes fatores ainda é alvo de debates (Vøllestad, 1997; Zazula et al., 2004). 
De acordo com a definição de Vøllestad (1997), a fadiga muscular implica na incapacidade temporária em produzir a contração máxima voluntária (MVC). Sendo esta redução um processo gradual, o ponto de quebra, em exercícios realizados a menores porcentagens da MVC (\% MVC) a força constante, ocorre quando a redução na capacidade de gerar a força máxima é tal que esta se torne inferior à força solicitada, como ilustrado a na figura 2.6. O ponto de quebra (exaustão) ocorre quando a curva de controle (capacidade de produzir 100\% MVC) intercepta a curva correspondente à \%MVC solicitada. Neste sentido, o ponto de quebra - referente ao instante da exaustão - e a fadiga muscular são conceitos distintos, sendo o primeiro uma consequência do segundo.

(1)

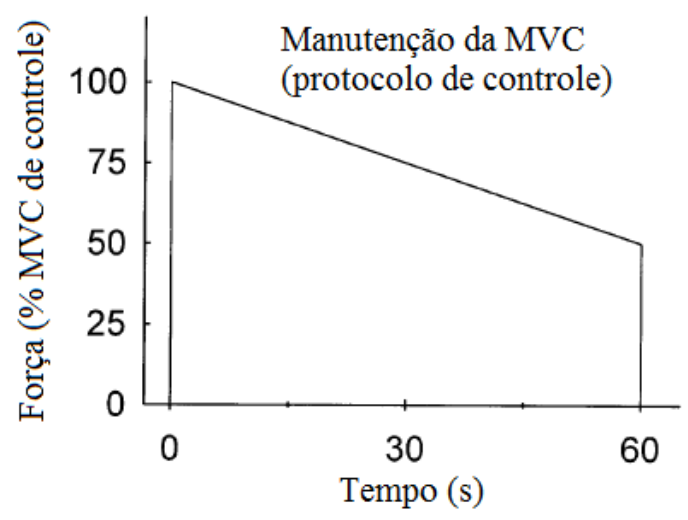

(2)

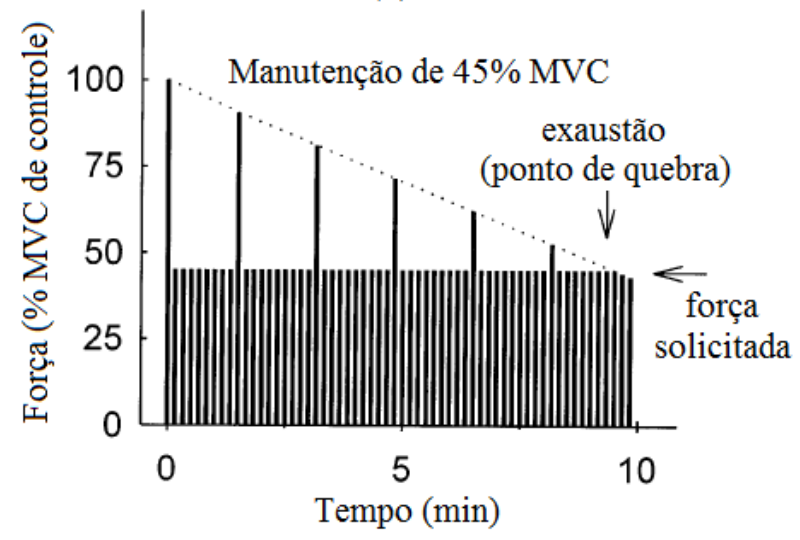

Figura 2.6: Representação de protocolos com indução de fadiga. Em (1), solicita-se a manutenção da força máxima. Em (2), realizam-se contrações repetidas a 45\% MVC. Modificado de Vøllestad (1997).

A eletromiografia representa, portanto, um método indireto de monitorar-se a fadiga muscular a partir de suas causas fisiológicas. Em geral, observam-se os efeitos dos padrões - de amplitude, redução da velocidade de condução (CV) e forma - dos Muaps sobre o eletromiograma ao longo da fadiga (DeLuca, 1984; Vøllestad, 1997). Entre os principais indicadores no domínio do tempo para a monitoração da fadiga estão a raiz da média quadrática (RMS) e o valor retificado médio (ARV). Para um sinal $x(t)$, em torno de um instante $t=t_{0}$ qualquer e intervalo de duração $T$, o valor RMS é dado por:

$$
x_{R M S}=\sqrt{\frac{1}{T} \int_{t_{0}-\frac{T}{2}}^{t_{0}+\frac{T}{2}}|x(t)|^{2} d t}
$$


e o valor retificado médio é dado por:

$$
x_{A R V}=\frac{1}{T} \int_{t_{0}-\frac{T}{2}}^{t_{0}+\frac{T}{2}}|x(t)| d t .
$$

Quando aplicados sobre o eletromiograma, estão positivamente correlacionados com a fadiga muscular, apresentando um aumento gradual em função desta. Tal aumento ocorre em função do recrutamento de novas unidades motoras para a manutenção do exercício (DeLuca, 1984). Além de sua duração e forma, o aumento gradual do sincronismo dos Muaps influencia as variáveis espectrais, de maneira que um decréscimo na frequência central do sinal de EMG seja observado, simultaneamente ao aumento da amplitude de seu espectro (Hermens e Bruggen, 1988; Bonato et al., 2001). Esses autores colocam estes três fatores (i.e. duração, forma e sincronismo dos Muaps) entre os principais no deslocamento do centro do espectro para as baixas frequências que se observa durante a fadiga muscular. Os indicadores espectrais tradicionalmente utilizados na monitoração da fadiga são a frequência média (MNF) e frequência mediana (MDF). A MNF de um sinal $x(t)$ é dada (em rad/s) por:

$$
\omega_{\text {média }}=\frac{\int_{0}^{\infty} \omega|X(\omega)|^{2} d \omega}{\int_{0}^{\infty}|X(\omega)|^{2} d \omega}
$$

em que $X(\omega)$ é a transformada de Fourier de $x(t)$. A MDF deste sinal, também em rad/s, é dada pelo valor $\omega_{\text {mediana }}$ tal que:

$$
\int_{0}^{\omega_{\text {mediana }}}|X(\omega)|^{2} d \omega=\int_{\omega_{\text {mediana }}}^{\infty}|X(\omega)|^{2} d \omega=\frac{1}{2} \int_{0}^{\infty}|X(\omega)|^{2} d \omega .
$$

Assim, a MDF deste sinal corresponde à frequência que separa seu espectro em dois segmentos de iguais energias. Na última década, frequências percentis também têm sido utilizadas na monitoração da fadiga (e.g. Lowery et al. (2002)). A frequência percentil 
(PF), para o percentil $p(0 \leq p \leq 1)$ do espectro, é o valor $\omega_{P F}$ tal que

$$
\int_{0}^{\omega_{P F}}|X(\omega)|^{2} d \omega=p \int_{0}^{\infty}|X(\omega)|^{2} d \omega .
$$

Desta maneira, $\omega_{P F}$ representa a frequência que acumula a $p$-ésima porcentagem da potência total no espectro de $x(t)$. Assim, a MDF é um caso específico de PF, em que $p=0,5\left(50^{\circ}\right.$ percentil $)$.

Alguns autores (Clancy et al., 2004; Merletti et al., 1984 e 1990; DeLuca, 1985; Arendt-Nielsen e Mills, 1985 e 1988) afirmam que o deslocamento espectral como parâmetro de monitoração da fadiga muscular oferece medida mais objetiva se comparada às técnicas clínicas baseadas em suas manifestações mecânicas. A seguir, a figura 2.7 ilustra os padrões típicos de torque e indicadores eletromiográficos em contração isométrica com indução da fadiga muscular:

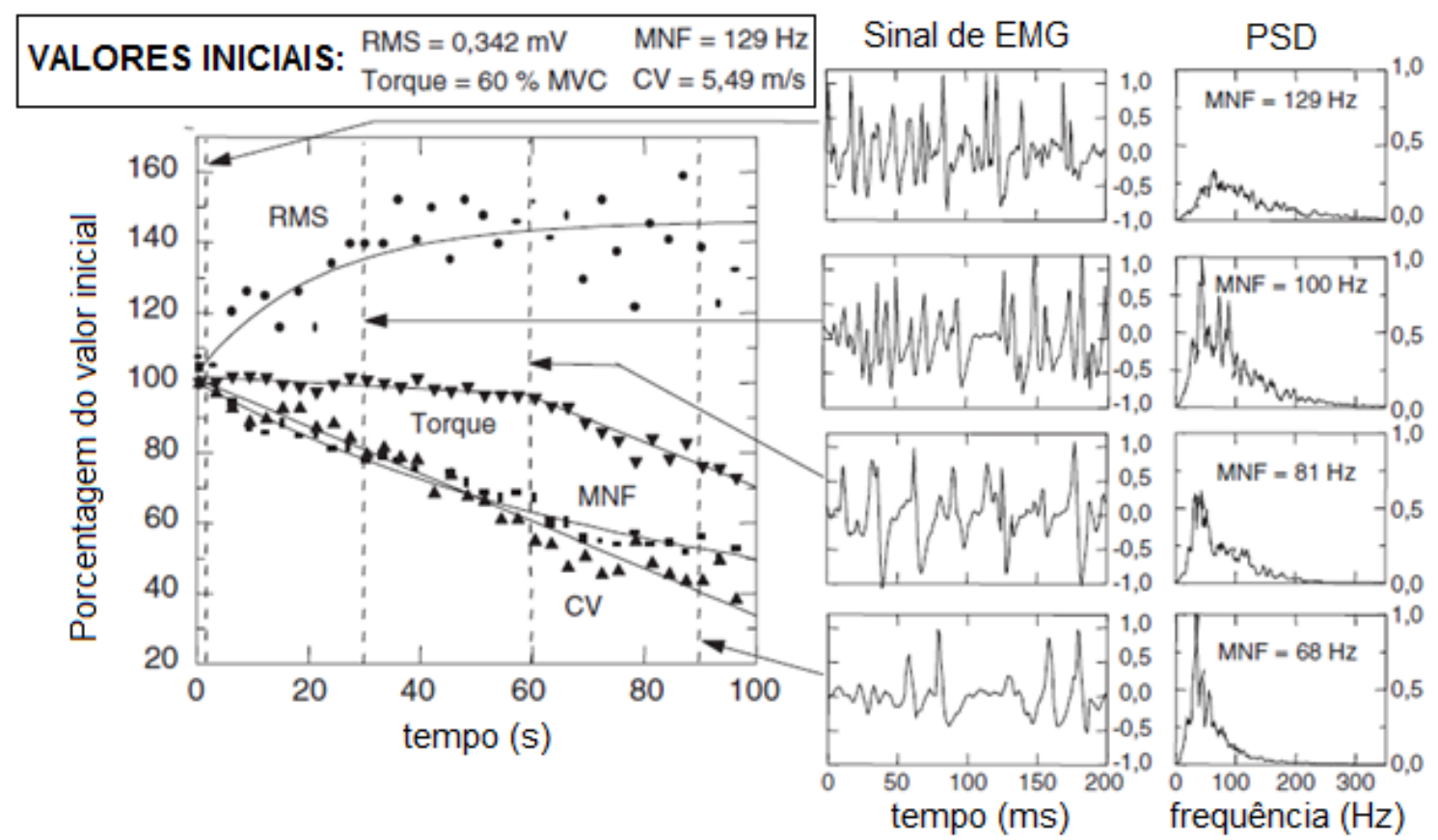

Figura 2.7: Variação do torque e de indicadores eletromiográficos (RMS, CV e MNF) com a indução de fadiga. Adaptado de Merletti et al. (2004).

Merletti et al. (1989) afirmam que, para a estimação da MDF e MNF, o uso de janela retangular é aceitável e, em alguns casos, preferível às demais janelas. Concluem que o viés da estimativa do periodograma torna-se inaceitável para trechos com duração 
inferior a $250 \mathrm{~ms}$. Verificam que a sobreposição de janelas (método de Welch) fornece diminuição desprezível no viés da estimativa, aumentando-se significativamente o custo computacional, não sendo, portanto, recomendável. A MDF mostra-se mais influenciável pela resolução espectral, podendo ser necessária a interpolação. O viés teórico da MDF é menor em comparação ao da MNF, possuindo a MNF menor variância em sua estimativa. Para propósitos práticos, o viés da MNF é insensível à janela escolhida e à duração do trecho (Balestra et al., 1988). Por outro lado, Hollman et al. (2013) afirmam que, apesar de a duração da janela para o cálculo da MDF influenciar em sua variabilidade, o decréscimo percentual médio ao longo do exercício observado para este parâmetro não varia significativamente com a duração escolhida (janelas de 100, 500, 1000, 2000 e 5000 ms com EMG-S em de contrações isométricas).

De acordo com Duchene e Goubel (1990), os padrões das variáveis de amplitude (aumento gradual) e espectrais (deslocamento para as baixas frequências) do eletromiograma são altamente correlacionadas com a fadiga muscular em esforços isométricos, especialmente em contrações máximas ou submáximas próximas a 100\% MVC. Nestas condições, consideram-se válidos e reprodutíveis os parâmetros da EMG (Larsson et al., 1999).

Vários autores abordaram, nas últimas décadas, o problema da avaliação dos indicadores espectrais do sinal de EMG em contrações dinâmicas (Bouissou et al., 1989; Duchene e Goubel, 1993; Christensen et al., 1995; Ament, et al., 1996; Potvin, 1997; Bonato et al., 2001; Carmo, 2003; Andrade, 2006; Schwartz, 2010; Milhomem, 2011, 2014d e 2014e). Komi e Tesch (1979) e Gerdle e Fugl-Meyer (1992) observaram que, em contrações máximas isocinéticas, as variáveis biomecânicas (e.g. pico de torque) decrescem acentuadamente; em média, durante as primeiras 40-60 contrações. Após este período, verificaram valores constantes de pico de torque (PT). Assim, referem-se à fase inicial como fase de fadiga e à fase após esta como fase de resistência. De maneira semelhante a do caso isométrico, verificou-se o deslocamento do espectro para as baixas frequências (Fugl-Meyer, 1985; Gerdle et al., 1987). A amplitude do eletromiograma, sob estas condições, apresentou resultados controversos (aumento, diminuição ou sem variações significativas) (Gerdle et al., 1987; Gerdle e Langström, 1987; Gerdle e Elert, 1989; Wretling et al., 1997).

Gerdle et al. (2000) estudaram a validade de descritores eletromiográficos (RMS e MNF) como indicadores de fadiga muscular em contrações dinâmicas repetidas. Em 
exercício isocinético de extensão de joelho, coletaram sinais de EMG-S dos músculos vasto lateral, vasto medial e reto femoral. Para a validação dos descritores de EMG como indicadores da fadiga, avaliaram a correlação entre estes parâmetros e os valores de PT registrados. Verificam em seu estudo que a MNF apresentou maior correlação com o PT do que o valor RMS, sendo, em geral, ambas as correlações (MNF com PT e RMS com PT) positivas (ambos os descritores de EMG decrescem com a diminuição do PT). Os autores sugerem que a MNF, mais do que o valor RMS, seja um bom parâmetro indicador da fadiga muscular em contrações máximas dinâmicas.

\subsection{2 - Relações entre os indicadores de fadiga e fatores que os influenciam}

Assumia-se comumente que CV e variáveis espectrais, como MNF e MDF, eram diretamente relacionadas (Lindström et al., 1970, 1971, 1977; Lindström e Magnusson, 1977). O modelo relacionando a velocidade $v$ de um potencial de ação com o espectro de potência $P(f)$ é dado por

$$
P(f)=\frac{1}{v^{2}} G\left(\frac{f}{v}\right)
$$

em que $G\left(\frac{f}{v}\right)$ representa a forma do espectro do potencial de ação detectado por EMG-S, incluindo-se fatores geométricos (Clancy et al., 2004). Assim, um deslocamento no espectro do eletromiograma poderia ser diretamente determinado a partir da mudança observada na CV e vice-versa (Farina e Merletti, 2004).

Outros autores também abordaram o problema da relação entre CV e variáveis espectrais, em geral, propondo técnicas para estimação da $\mathrm{CV}$ a partir do espectro (Lindström et al., 1970, 1971 e 1977; Stulen e DeLuca, 1981; Lo Conte el al., 1994; Muhammad el al., 2003). Nestes casos, as razões da proposição de tais técnicas eram, principalmente, o problema do uso de eletrodos monopolares ou bipolares para estimação da CV. Spinelli et al. (2001) também abordam esta questão, porém, propondo um método baseado em autocorrelação.

Solomonow et al. (1990) concluem, sob condições simplificadas em esforços isométricos, que se pode observar relação linear entre indicadores espectrais (MNF e MDF) e a velocidade de condução. Tal observação é refutada por Dimitrova e Dimitrov 
(2003), que mostram que, apesar de poderem correlacionar-se, estes parâmetros não apresentam relação linear entre si. Farina et al. (2002) também fazem observações semelhantes, verificando que a correlação entre MNF (ou MDF) e CV pode ser menor que a esperada (coeficiente de correlação entre 0,41 e 0,81). Verificam, a partir de dados simulados e experimentais, que eventualmente, durante o recrutamento de novas unidades motoras, as variáveis espectrais podem decrescer simultaneamente ao aumento da velocidade de condução, especialmente em contrações de torque variável. Os autores atribuem estas observações, possivelmente, à distribuição espacial particular das unidades motoras para diferentes sujeitos, à área da superfície de contato sobre o músculo para aquisição da EMG-S e padrões de recrutamento relacionados a critérios geométricos. A influência destes fatores (geometria e posição do eletrodo) no espectro do eletromiograma já havia sido anteriormente proposta por Lindström (1970) e reforçada por Lindström e Petersén (1981). Farina et al. (2002) argumentam ainda que indicadores baseados em MNF ou MDF não refletem fenômenos relacionados ao controle pelo sistema nervoso central e que, assim como indicadores baseados na amplitude do sinal, são mais sensíveis ao recrutamento de novas unidades motoras. Já a velocidade de condução tende a ser insensível à localização da MU e mais sensível à taxa de disparos dos potenciais de ação que não afeta significativamente o espectro do eletromiograma (Solomonow et al., 1990). Com isso, a CV mostra-se sensível ao torque; em geral, como função crescente deste. Portanto, não se aconselha a assunção de que a MNF (ou frequências percentis, como a MDF) e CV sejam globalmente correlacionadas (Farina et al., 2002). Em geral, todos estes parâmetros são sensíveis à \%MVC com a indução da fadiga muscular (Masuda et al., 1996; Farina et al., 2002). Öberg et al. (2002) atentam para o problema do movimento dos eletrodos sobre a pele ao utilizar a EMG-S e sua influência sobre o eletromiograma como um potencial fator a confundir-se com a fadiga.

Masuda et al. (1999) também avaliam CV, MDF e amplitude do eletromiograma em contrações isométricas e dinâmicas isotônicas (50\% MVC, vasto lateral). MDF e CV mostraram-se, em média, significativamente maiores no caso dinâmico. No caso das contrações estáticas, como outros estudos houveram concluído, MDF e CV estão positivamente correlacionadas (aumento da duração dos Muaps), e a MDF decresce mais acentuadamente do que a $\mathrm{CV}$. Verificaram que, no caso das contrações dinâmicas, não houve variações significativas da CV (mesmo havendo para MDF e amplitude). Assim, argumentam que, como o fluxo sanguíneo é mantido durante as contrações, a CV deve ser 
afetada pelo estado metabólico e que as variações na MDF não se explicam somente por mudanças na CV. No caso dinâmico, a prolongação dos Muaps pode ser independente da CV e influenciar a MDF. A força resistida do exercício e temperatura do músculo não são determinantes para a diferença observada entre CV e MDF e, em seu estudo, afirmam não haver relações entre diferenças na amplitude e na CV. Tampouco a diferença na amplitude deve refletir a dissociação entre CV e MDF observadas no caso dinâmico.

Após a exaustão, a MDF deve retornar gradualmente ao estado inicial com a recuperação, porém, não necessariamente a CV. Assim, constata-se que o fluxo sanguíneo influencia na relação entre CV e espectro, em que sua obstrução parcial diminui a correlação entre estes parâmetros. No caso dinâmico, o fluxo sanguíneo é aumentado devido à alteração na geometria do músculo, removendo-se os metabólitos e contribuindo para a inibição da diminuição do pH intracelular (Masuda et al., 1999).

Lowery et al. (2002) definem outra estimativa para a compressão do espectro da EMG-S baseada em frequências percentis (em que a MDF se inclui) e verifica que, para exercícios de contrações isométricas do músculo braquiorradial (30\%, 50\% e $80 \%$ MVC), tal estimativa apresenta maior correlação com a CV nas fibras musculares do que a MDF que consiste na $50^{a}$ frequência percentil. Neste caso, seus resultados indicam que o uso de maior quantidade de percentis do espectro do eletromiograma - considerando-se a média destes, obtém-se melhor estimativa da CV.

Waly et al. (2003) estudaram o efeito do tamanho da janela para a estimação dos parâmetros espectrais no sinal de EMG-S em contrações isométricas a 25, 50 e 100\% MVC. Utilizando janelas com duração de 64 a 4096 ms, concluem que o efeito desta variação sobre as variáveis espectrais é significativo, sugerindo a duração mínima de $0,5 \mathrm{~s}$ para sua estimação. Também observam que a variação da carga afeta significativamente os indicadores calculados no domínio da frequência. Frequências abaixo do $75^{\circ}$ percentil mostraram comportamento crescente em função da carga. Frequências acima desta mostraram comportamento inverso com a aproximação da MVC, sugerindo-se que em contrações isométricas a forma do espectro de amplitude é alterada com o aumento da carga. Os autores concluem que o uso de um único parâmetro espectral, como a MDF, pode não ser suficiente para avaliar todas as modificações do espectro do eletromiograma.

Dimitrova e Dimitrov (2003) sugerem que as variáveis de amplitude do potencial das unidades motoras observadas na EMG-S são influenciadas não somente pela amplitude do potencial de ação intracelular, mas também por sua duração e pela distância entre 
eletrodo e fonte. Os autores mostram que a amplitude do sinal de EMG-S pode aumentar mesmo com uma simultânea atenuação dos potenciais de ação intracelulares. Indicam ainda a possibilidade de que as variações do potencial de ação intracelular não sejam causas da fadiga muscular, mas consequências desta.

Karlsson e Gerdle (2001) utilizam a EMG-S dos músculos vasto lateral, reto femoral e vasto medial em extensões de joelho a torque crescente (até 100\% MVC) para avaliar a correlação entre parâmetros de EMG e torque. Verificam, para os músculos em estudo, que a MNF, assim como o valor RMS, correlaciona-se positivamente com o torque. Também observam que a morfologia muscular (proporção e área das fibras) do vasto lateral influencia significativamente a estimativa da MNF. Os autores concluem que técnicas baseadas em distribuições tempo-frequência podem ser utilizadas para a análise do eletromiograma em rápidas contrações dinâmicas em que há alto grau de nãoestacionariedade. O comportamento inverso havia sido anteriormente observado para baixos valores da \%MVC. Por exemplo, Ogino e Kozak (1983) haviam verificado um decréscimo na frequência central do espectro com o aumento da carga em músculo flexor do antebraço. Já os autores Cechetto et al. (2001) afirmam que a modificação da quantidade unidades motoras (MUs) ativas e da taxa de disparos, apesar de contribuírem para a não-estacionariedade do sinal de EMG, não afetam a MNF significativamente. Em seu estudo, concordam com as observações de Karlsson e Gerdle (2001), no sentido de que a geometria muscular influencia a MNF, porém, sugerem que a força afeta tal parâmetro pouco significativamente. Atualmente, é consenso que, em contrações isométricas, com o aumento gradual da força, ocorre o aumento da amplitude e das variáveis espectrais do sinal de EMG (Moritani et al., 2004). O aumento das variáveis espectrais explica-se, ao menos parcialmente, o recrutamento de MUs superficiais com limiares de ativação mais altos, produzindo-se picos mais altos e estreitos no sinal de EMG-S, influenciando as altas frequências do seu espectro de potência (Komi e Buskirk, 1970). A figura 2.8 ilustra estas relações: 

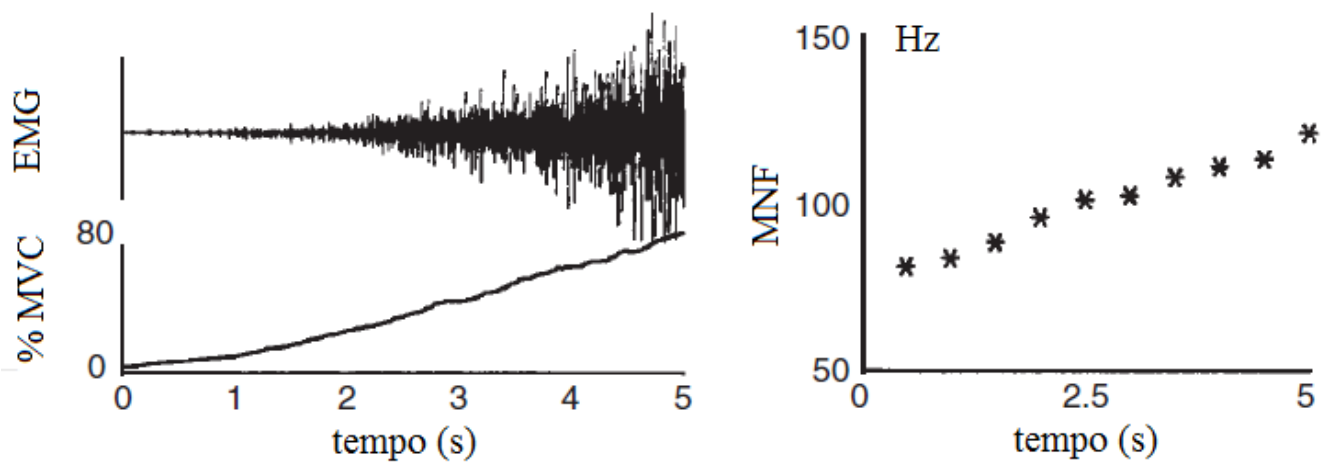

Figura 2.8: Efeito do aumento gradual da força sobre a amplitude e o espectro (frequência média) do sinal de EMG-S, em contração isométrica (Moritani et al., 2004).

Maïsettia et al. (2002) realizaram experimentos com voluntários em exercícios de contrações isométricas (extensão de joelho) a 50\% MVC e concluem que as manifestações mioelétricas da fadiga muscular - a partir de indicadores espectrais e temporais - não dependem do conhecimento prévio da duração do teste pelos voluntários. Sugere, portanto, que tal característica de invariância ao protocolo permite que parâmetros eletromiográficos sejam utilizados na predição do ponto de quebra e duração do teste.

Em geral, esses autores concluem sugerindo o uso dos estimadores espectrais de EMG-S em aplicações clínicas e diagnósticas. Tais aplicações e propostas já são recorrentes há algumas décadas. Inbar e Noujaim (1984), por exemplo, discutem a aplicação de parâmetros espectrais à classificação diagnóstica baseada em EMG-S.

Mills (1982) comparou as variações do espectro do eletromiograma voluntário com os potenciais de ação induzidos por estimulação supramáxima - estimulação na qual se espera que todas as fibras nervosas do nervo estudado sejam estimuladas, despolarizandose todas as fibras musculares por estas inervadas (Nobrega e Manzano, 2013). As comparações foram feitas durante a indução da fadiga e a durante a recuperação. Conclui em seu estudo que os valores de MNF dos sinais voluntário e estimulado mostram-se similares durante a fadiga; assim como a taxa de recuperação da força e da amplitude dos Muaps, ambas recuperando-se em $50 \%$ do total após 30 s. O autor sugere que a recuperação das variáveis espectrais depende do estado metabólico do músculo fadigado.

\subsection{3 - Distribuição do eletromiograma}

Considera-se que o sinal de EMG obtido de contrações isométricas estáticas a força constante consiste num processo estacionário no sentido amplo, quando observado em 
janelas temporais de duração entre 0,5 s e 2,0 s (Bonato et al., 2001; Zazula et al., 2004).

Frequentemente assume-se que sinais de EMG-S, especialmente para maiores valores de \%MVC, apresentam amplitude com distribuição gaussiana de média nula, conforme corroborado por Roesler (1974) e Clancy e Hogan (1994). Todavia, outros autores afirmam que tal distribuição mostra-se mais estreita em torno da média do que a gaussiana (Milner-Brown e Stein, 1975; Hunter et al., 1987; Bilodeau et al., 1997). Principalmente a valores mais baixos de \%MVC, intervalos entre os Muaps tornam-se claramente detectáveis, de forma que a distribuição se torne mais concentrada em torno do zero. Afirma-se que estas características também podem ser observadas com a fadiga muscular (Clancy et al., 2002). Clancy e Hogan (1999) propuseram modelo alternativo para a distribuição da EMG, assumindo-se distribuição laplaciana, que apresenta estas características discutidas. Clancy et al. (2002) observam experimentalmente que, para contrações isométricas a força e postura constantes em que não há indução de fadiga muscular localizada, a distribuição do eletromiograma encontra-se entre a gaussiana e a laplaciana, como ilustra a figura 2.9:

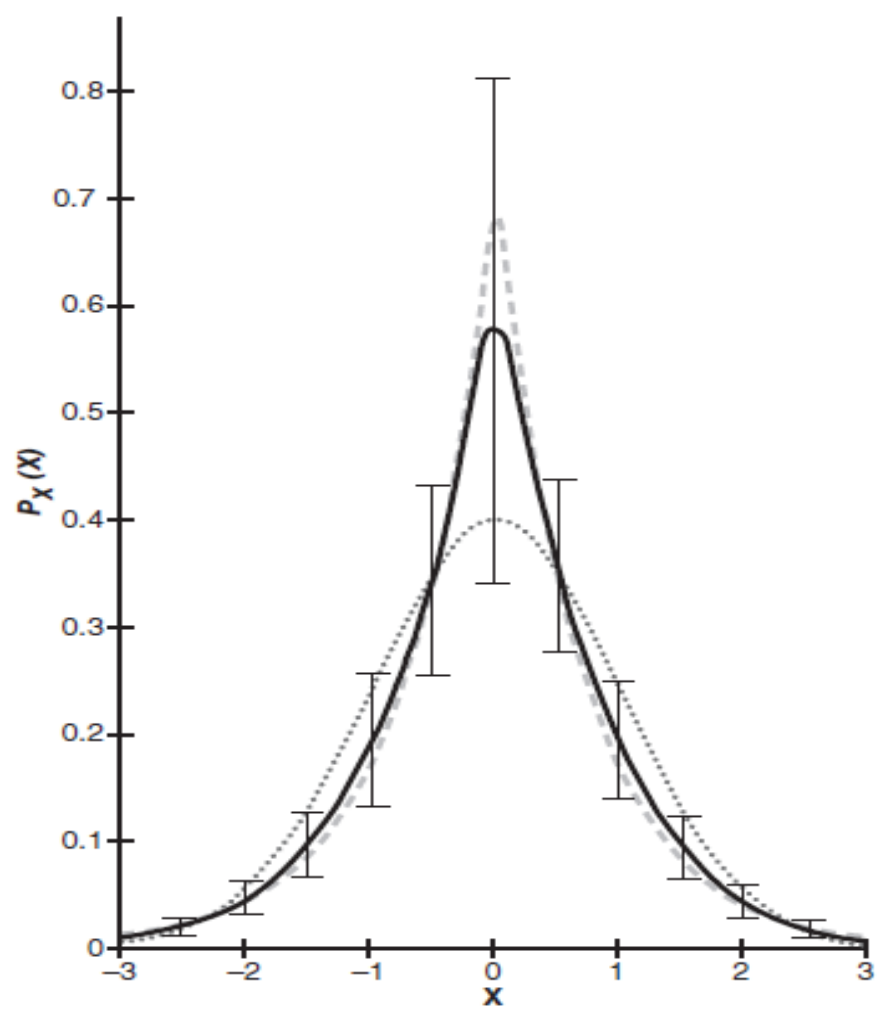

Figura 2.9. Distribuição de probabilidade da amplitude do sinal de EMG obtido experimentalmente (linha sólida): entre a gaussiana (pontilhada) e a laplaciana (tracejada). Adaptado de Clancy e Hogan (1999). 
Outros estudos verificam, ainda, que a distribuição da EMG-S afasta-se da gaussiana com o aumento da força (Hussain et al., 2009; Hussain e Mamun, 2012). Além disso, Cooverits et al. (2009) sugerem que a duração do intervalo de tempo no qual se pode considerar o sinal EMG-S de contração isométrica como um processo estacionário no sentido amplo decresce com o aumento da força exercida.

Os fatores que contribuem para não-estacionariedades rápidas do sinal de EMG-S são, em sua maioria, relacionados à biomecânica do exercício, como movimento dos eletrodos sobre a pele e variação da força e comprimento do músculo durante a contração. Não-estacionariedades lentas, em geral, decorrem de processos graduais, como a fadiga muscular e modificações da impedância da pele em virtude, por exemplo, da sudorese (Clancy e Hogan, 1999; Bonato et al., 2001; DeLuca et al., 2010).

Para a análise destes processos não-estacionários, distribuições tempo-frequência são necessárias e diversas são propostas na literatura (por exemplo, Bonato et al., 2001; Andrade et al., 2008; Cooverits et al., 2009). No capítulo 5, as técnicas para avaliação da fadiga muscular serão discutidas em maiores detalhes. No próximo capítulo serão apresentados os protocolos experimentais de aquisição abordados no trabalho, incluindo-se instrumentação integrada para digitalização dos sinais. 


\section{3 - PROTOCOLOS EXPERIMENTAIS E INSTRUMENTAÇÃO DEDICADA}

Neste capítulo serão descritos os protocolos de aquisição e instrumentação utilizados para a aquisição dos sinais. Todas as coletas foram realizadas no laboratório da Faculdade de Educação Física da Universidade de Brasília (FEF/UnB).

\section{1 - PROTOCOLO I: CICLISMO}

Este protocolo envolve a aquisição de sinais de EMG-S e biomecânicos (de pedais instrumentados) de ciclistas em cicloergômetro. Envolve também a definição de um parâmetro objetivo de desempenho biomecânico, proposto neste trabalho. Assim, descrever-se-á o protocolo experimental, a instrumentação biomecânica e seu uso para o cálculo de ângulos e forças sobre o pedal, a definição de desempenho biomecânico proposta, a instrumentação para a coleta de EMG-S e a integração da instrumentação, nesta ordem.

\subsection{1 - Protocolo experimental}

Foram utilizados sinais de 4 voluntários do sexo masculino $(26,3 \pm 4,0$ anos, $77,0 \pm$ $6,5 \mathrm{~kg}$ e 176,5 $\pm 6,3 \mathrm{~cm}$ de altura) pedalando até a exaustão. O estudo foi aprovado pelo Comitê de Ética da Faculdade de Ciências da Saúde da Universidade de Brasília (parecer $\left.n^{\circ} 069 / 10\right)$.

Ao serem realizadas atividades físicas até a exaustão, com durações típicas de 3 minutos, o corpo necessita do máximo de reservas anaeróbicas disponíveis, gerando, portanto, uma quantidade significativa de ácido lático (Medbo e Tabata, 1993). Como o exercício de pedalar até a exaustão é uma atividade de característica anaeróbica lática, sugere-se considerar este tempo como mínimo e o máximo sendo o seu dobro, havendo assim a certeza da ocorrência da fadiga no sujeito sendo submetido ao experimento (Carmo et al., 2001). São realizadas então duas seções de exercícios, separados em dois dias consecutivos, a ciclistas profissionais. A primeira não possui duração definida, e tem a finalidade de determinar a carga a ser utilizada por cada sujeito na segunda seção de 
exercícios, na qual são coletados os sinais eletromiográficos e biomecânicos destes ciclistas.

\subsubsection{1 - Primeira seção}

No primeiro dia, inicialmente, são explicados ao sujeito voluntário a participar do projeto todos os procedimentos e protocolos para a aquisição dos dados, de acordo com a aceitação dos termos do convite. Registram-se os dados do participante, como peso, altura, idade etc. antes de inicializar-se o exercício no cicloergômetro. Após assinar termo de esclarecimento e consentimento do protocolo experimental, o sujeito realizava aquecimento no cicloergômetro sem resistência por 3 minutos. Imediatamente após o aquecimento, realizava-se um teste com velocidade fixa de $35 \mathrm{~km} / \mathrm{h}$. A potência de resistência do cicloergômetro iniciava a $150 \mathrm{~W}$ e era incrementada em $50 \mathrm{~W}$ a cada minuto até a exaustão. Fixou-se então $70 \%$ deste valor de potência resistida para realizarem-se os testes do segundo dia (Milhomem et al., 2012 e 2014d).

\subsubsection{2 - Segunda seção}

No segundo dia, 48 h após a primeira seção de exercícios, são coletados os sinais eletromiográficos e biomecânicos. Antes do início das coletas, os pedais são calibrados segundo o método proposto por Carmo et al. (2001). A calibração dos pedais permite que as forças tangenciais e normais ao pedal sejam medidas. São registrados também os sinais de trigger e ângulo do pedal em relação ao pedivela.

Para a colocação do eletrodo do eletromiógrafo, mede-se o comprimento entre a porção lateral da patela e a cabeça do fêmur da perna esquerda, tomando-se um terço deste valor medido, a partir do joelho. Faz-se a tricotomia e higieniza-se a pele do ciclista com algodão e álcool nesta região para a fixação do eletrodo. Passam-se os fios que ligam o eletrodo ao eletromiógrafo por dentro da bermuda do ciclista, de modo a evitar deslocamentos e movimentações abruptas durante o experimento, reduzindo-se os efeitos devidos a artefatos de movimento (Milhomem, 2011).

Após serem conectados todos os aparelhos, o sujeito realiza um leve aquecimento, pedalando em baixa potência, durante aproximadamente 5 minutos. O aquecimento é realizado visando evitarem-se lesões no atleta durante o exercício, sendo realizado por não 
mais de 5 minutos, de modo a não induzir a fadiga antecipadamente. Durante o aquecimento pode-se verificar a qualidade dos sinais captados pelos pedais $\mathrm{e}$ eletromiógrafo, corrigindo-se eventuais falhas antes de realizarem-se as coletas. Terminado o aquecimento, inicia-se a coleta dos sinais, com o sujeito pedalando a $35 \mathrm{~km} / \mathrm{h}$, com a potência de resistência do cicloergômetro que foi definida em seu primeiro teste, no dia anterior. Os dados são então coletados até a ocorrência do ponto de quebra, com a exaustão do indivíduo.

\subsection{2 - Instrumentação}

Nesta subseção será descrita a instrumentação utilizada para a coleta dos sinais biomecânicos e eletromiográficos, respectivamente. Então se mostrará como a instrumentação foi integrada para o registro dos sinais para seu posterior processamento.

\subsubsection{1 - Sinais biomecânicos}

Nesta seção será apresentada a proposta de instrumentação dedicada para a aquisição dos sinais biomecânicos dos ciclistas. Tomou-se como ponto de partida a abordagem utilizada por Carmo (2001) do problema com adaptações e modificações propostas para as medições de ângulos e torques (Milhomem et al., 2012 e 2014d).

Para o registro das forças aplicadas aos pedais durante a execução do protocolo proposto, devem-se utilizar instrumentos capazes de medir as forças aplicadas em, pelo menos, duas dimensões - que definem o plano de giro do pedivela, e leves o suficiente para não interferirem na prática ciclística (os instrumentos presos aos pedais não devem prejudicar nem auxiliar o ciclista na atividade de pedalar). Para isto, podem ser usados sistemas mais modernos que utilizam cristais piezelétricos, os quais apresentam vantagens em relação aos strain gauges (instrumentos convencionais utilizados) por permitirem calibrações mais simples, maior resposta em frequência e menor interferência cruzada (Broker e Gregor, 1996). Entretanto, strain gauges são consideravelmente mais acessíveis e apresentam resultados bastante satisfatórios (Hull e Davis, 1981; Bontempo et al., 1997; Carmo et al., 1998; Neto et al, 2001; Carmo et al., 2001; Milhomem, 2011).

Especificações foram propostas por Hull e Davis (1981) para os requisitos a serem cumpridos por um sistema de sensoriamento mecânico de forças, devendo o sistema 
apresentar uma acurácia de \pm 0,5\% para a medição das forças; não interferir na atividade de pedalar; ser de fácil instalação, não dependendo do modelo específico da bicicleta ou cicloergômetro; fornecer dados em formato adequado para posterior processamento; pedais com frequência fundamental superior a $35 \mathrm{~Hz}$ e com precisão de 0,1 N.m para medida dos momentos $M_{x}$ e $M_{y}, 1 \mathrm{~N}$ para as forças $F_{x}$ e $F_{y}$ e $5 \mathrm{~N}$ para a força $F_{z}$ (direção normal ao plano de giro do pedal).

O sistema utilizado consiste de um cicloergômetro vertical da marca ErgoFit, onde foi acoplado o pedal baseado no modelo proposto por Carmo (2001), com adaptações. Utilizou-se uma base de pedal de mercado, onde foi acoplada uma peça em forma de ' $U$ '. Essa peça em forma de 'U' possui quatro strain gauges, da marca Koya modelo KFG 5350-C1-11, formando meias pontes de Wheatstone, duas em sua parte superior e duas em sua parte anterior. Essas pontes, fixadas simetricamente na parte externa e interna da peça em 'U', são responsáveis por determinar as forças aplicadas ao pedal, pela transdução das forças em sinais elétricos em dois eixos ortogonais. Para completar o pedal foi utilizada uma carcaça de um pedal de mercado para o encaixe da sapatilha. Para a determinação da direção das forças aplicadas foi fixado ao pedal - acompanhando o movimento da base e com eixo fixo ao eixo do pedal - um potenciômetro de duas trilhas resistivas lineares. Este sistema que compõe o pedal foi, então, fixado ao pedivela esquerdo do cicloergômetro. Há a possibilidade de movimentação dos pedais no plano horizontal, com uma variação de aproximadamente 15 graus. Tal movimentação visa evitar lesões nos ciclistas, que podem ocorrer caso os pedais estejam fixados de forma rígida, sem permitir uma movimentação do pé no plano tangente ao pedal (Broker e Gregor, 1996). O pedal instrumentado é mostrado na figura 3.1 a seguir:

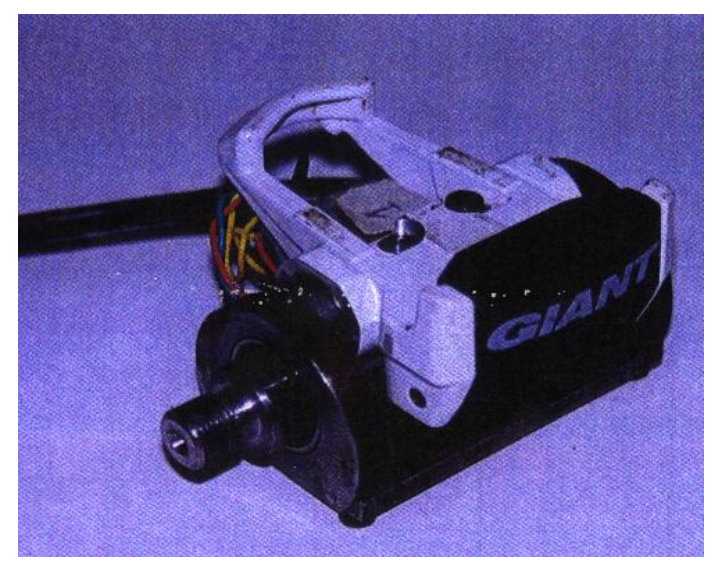

Figura 3.1: Pedal instrumentado utilizado no Protocolo I. 
Antes de cada bateria de coleta de dados os sistemas de sensores de força dos pedais são calibrados usando conjuntos fixos de pesos, que, combinados entre si, resultavam nas forças-peso - aplicadas nas direções normal e tangencial ao plano de piso do pedal - descritas na tabela 3.1 a seguir, sendo os pesos utilizados sequencialmente nesta ordem:

Tabela 3.1 - Pesos utilizados na calibração dos pedais.

\begin{tabular}{|c|c|}
\hline Força normal (N) & Força tangencial (N) \\
\hline 21,29 & 59,64 \\
\hline 44,24 & 116,05 \\
\hline 65,53 & 165,69 \\
\hline 80,84 & 216,60 \\
\hline 111,83 & 266,24 \\
\hline 133,22 & 307,05 \\
\hline 154,02 & 356,69 \\
\hline
\end{tabular}

A estes pesos foram acrescidos os pesos dos respectivos ganchos que os suspendem. Utilizou-se o método de calibração proposto por Carmo et al. (2001). Uma descrição mais detalhada dos cálculos de calibração pode ser encontrada em Carmo (2003). Nesse trabalho podem ser apreciados todos os cálculos e curvas de calibração geradas, utilizadas pelo autor para seu protocolo experimental.

Para a marcação das pedaladas, foi adaptado ao cicloergômetro um sensor magnético utilizado como trigger (gatilho). O trigger foi fixado no ponto mais alto alcançado pelo pedal num ciclo de pedalada, de modo a ser ativado no momento em que o pedal cruzasse a extremidade superior do ciclo, emitindo um pulso cada vez que o pedal o cruzasse. Como a velocidade do teste foi aproximadamente constante, em que a ação conjunta das pernas funciona como um volante e a taxa de amostragem de todos os sinais é fixa (todos os sinais foram digitalizados à taxa de $2,4 \mathrm{kHz}$ ), o ângulo $\phi(t)$ do pedivela num instante qualquer é considerado proporcional à quantidade de amostras capturadas neste intervalo de tempo. O ângulo $\phi(t)$ do pedivela é tomado em relação à vertical, como ilustrado a seguir na figura 3.2 : 

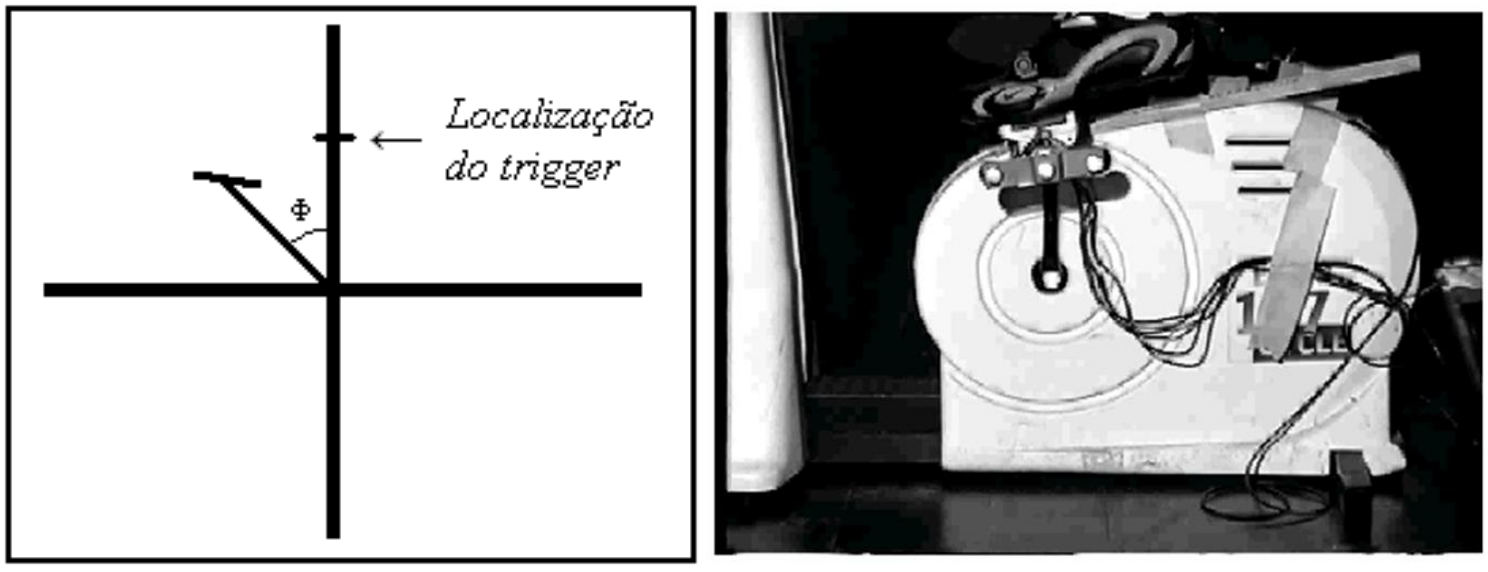

Figura 3.2: Esquema ilustrando o ângulo do pedivela $\phi(t)$ e a localização do sensor magnético responsável pelo sinal do trigger (esq.) e seu uso no cicloergômetro (dir.).

Para medir a inclinação do pedal em relação ao pedivela utilizou-se o goniômetro construído a partir de um potenciômetro com duas trilhas resistivas acopladas. Este goniômetro foi fixado ao suporte interno do pedal (à carcaça e ao eixo do pedal), de modo que sua posição fosse rígida em relação ao pedivela, porém, girasse em relação ao plano de piso do pedal. O par de trilhas resistivas constitui de uma interna e outra externa. As trilhas são selecionadas alternadamente, de forma a contornar o efeito da descontinuidade causada pela existência de uma lacuna ( $g a p$ ) em cada trilha resistiva. Para isto, as trilhas foram fixadas de forma que os gaps da trilha interna e o da externa ficassem em posições opostas, permitindo que, para o cálculo do ângulo, apenas o segmento de comportamento mais próximo ao linear de cada trilha fosse considerado. Assim, determina-se o ângulo entre pedal e pedivela a partir das tensões no potenciômetro por uma relação linear por partes (Milhomem, 2011; Milhomem et al., 2012). A seleção das trilhas resistivas é feita a cada 1/4 (um quarto) de pedalada completado, como descrito a seguir:

1) Do início (ativação do trigger) até $1 / 4$ da pedalada completada: trilha interna.

2) De $1 / 4$ até $1 / 2$ da pedalada completada: trilha externa.

3) De $1 / 2$ até $3 / 4$ da pedalada completada: trilha externa.

4) De $3 / 4$ da pedalada completada até o fim desta: trilha interna.

A transformação do sinal $V(t)$ de tensão (em Volts) medido sobre o goniômetro para o sinal de ângulo $\theta(t)$ do pedal em relação ao pedivela segue - devido à linearidade das regiões selecionadas em cada trilha - uma relação simples: 


$$
V(t)=A_{i} \cdot \theta(t)+B_{i}
$$

em que os valores de $A_{i}$ (em Volts/graus) e $B_{i}$ (em Volts) são determinados experimentalmente para cada uma das quatro regiões (quadrantes em que o pedivela se encontra) no ciclo $(i=1,2,3,4)$. Para o goniômetro construído, foram obtidos os valores indicados na tabela 3.2 a seguir.

Tabela 3.2 - Valores calculados de A e B - para a relação linear por partes entre tensão e ângulo no goniômetro - em cada região da pedalada.

\begin{tabular}{|c|c|c|c|}
\hline$i$ & Região da pedalada & $A_{i}(\mathrm{mV} /$ graus $)$ & $B_{i}(\mathrm{~V})$ \\
\hline 1 & De 0\% a 25\% do ciclo completado & 1,1391 & 0,14161 \\
\hline 2 & De 25\% a 50\% do ciclo completado & 1,0266 & $-0,023602$ \\
\hline 3 & De 50\% a 75\% do ciclo completado & 1,0266 & $-0,023602$ \\
\hline 4 & De 75\% a 100\% do ciclo completado & 0,8948 & $-0,18053$ \\
\hline
\end{tabular}

Se os sinais medidos, obtidos do goniômetro, pela trilha externa e interna, são, respectivamente $V_{\text {ext }}(t)$ e $V_{\text {int }}(t)$, então:

$$
\left\{\begin{array}{lr}
\theta(t)=\frac{\left(V_{\text {int }}(t)-B_{1}\right)}{A_{1}} & \text { se } 0<\phi(t) \leq 90^{\circ} \\
\theta(t)=\frac{\left(V_{\text {ext }}(t)-B_{2}\right)}{A_{2}} & \text { se } 90^{\circ}<\phi(t) \leq 180^{\circ} \\
\theta(t)=\frac{\left(V_{\text {ext }}(t)-B_{3}\right)}{A_{3}} & \text { se } 180^{\circ}<\phi(t) \leq 270^{\circ} \\
\theta(t)=\frac{\left(V_{\text {int }}(t)-B_{4}\right)}{A_{4}} & \text { se } 270^{\circ}<\phi(t) \leq 360^{\circ}
\end{array}\right.
$$

Assim, obtém-se o ângulo do pedal em relação ao pedivela, ilustrado a seguir na figura 3.3: 


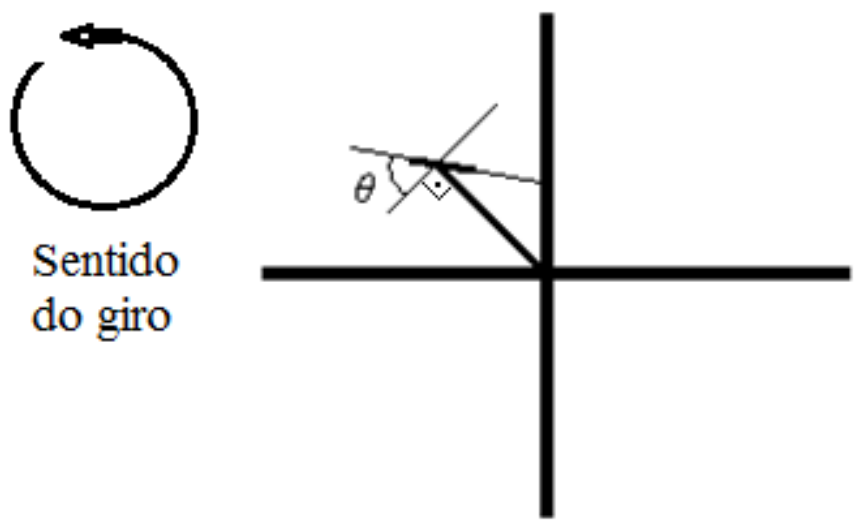

Figura 3.3: Referência para medição do ângulo $\theta(t)$ entre o pedal e o pedivela calculado a partir dos sinais das trilhas resistivas do goniômetro. Com este referencial para $\theta$, a pedalada acontece no sentido anti-horário.

Este procedimento - restringindo o registro do sinal de tensão aos segmentos das trilhas com comportamento aproximadamente linear e evitando-se as regiões dos gaps permitiu o registro do ângulo $\theta(t)$ de maneira relativamente suave, como ilustra a figura 3.4:

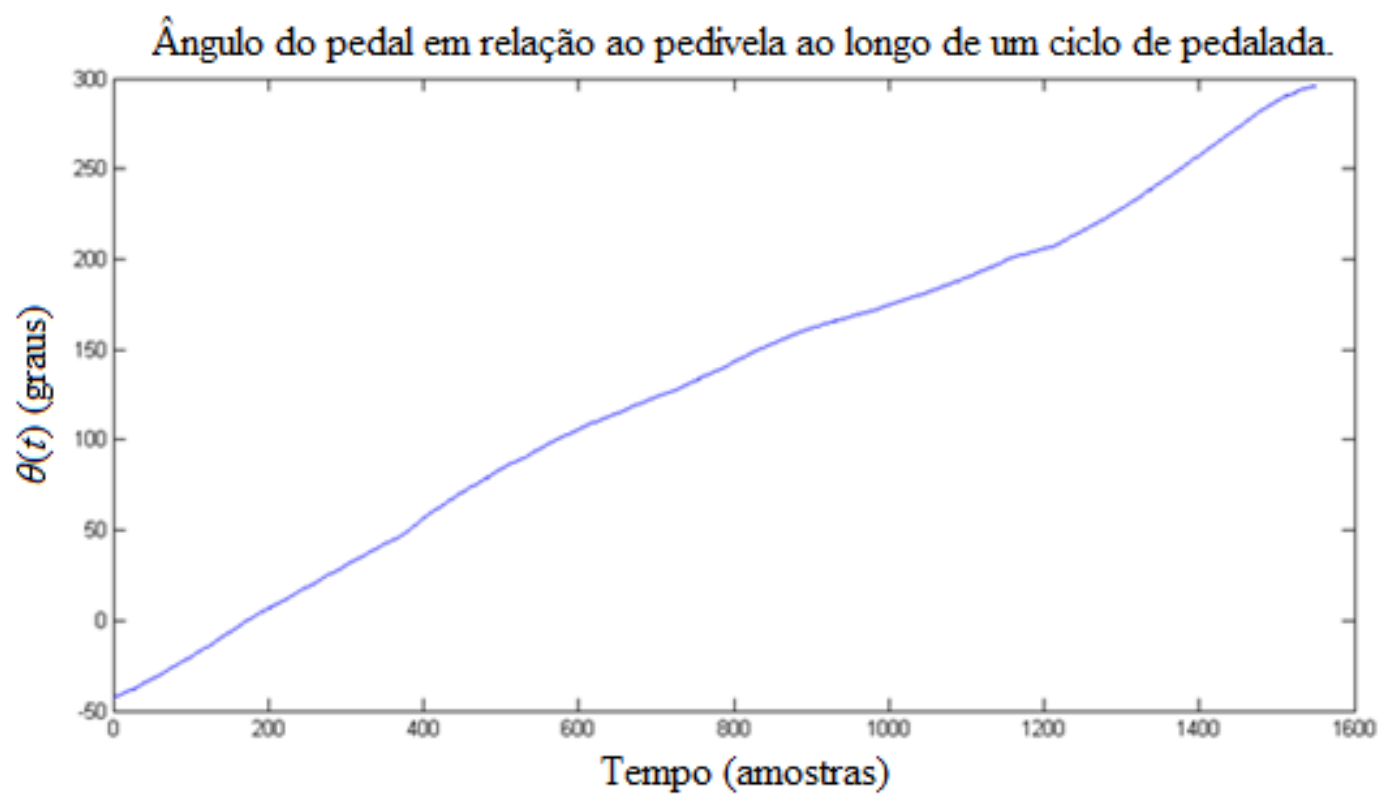

Figura 3.4: Exemplo de registro do ângulo do pedal em relação ao pedivela durante um ciclo de pedalada.

Observa-se nesta figura que a transição entre as trilhas foi feita sem gerar descontinuidades perceptíveis. A partir de combinações entre os ângulos $\theta$ e $\Phi$ calculados, obtém-se uma descrição completa da localização e inclinação do pedal em qualquer 
instante do experimento.

Para a medição das forças aplicadas ao pedal, foram utilizados os strain gauges que lhe foram acoplados, registrando-se a força normal ao pedal e a tangencial (valendo-se da fixação da sapatilha) para obtenção dos sinais de torque. A figura 3.5 ilustra um esquema com todas as variáveis biomecânicas medidas:

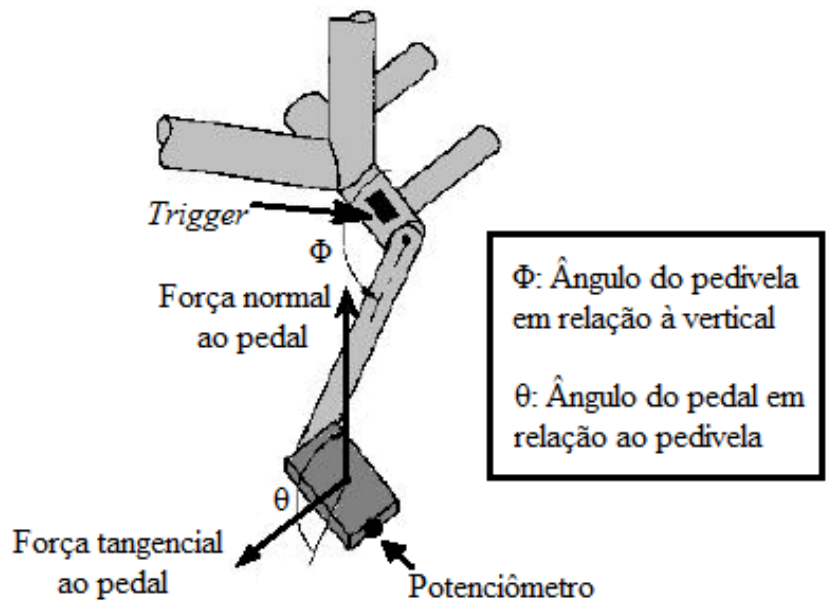

Figura 3.5: Esquema ilustrando as forças e os ângulos medidos no pedal e no pedivela.

O cálculo do torque resultante é feito a partir da decomposição das forças nas direções perpendicular e paralela ao pedivela. Desta maneira pode-se definir um parâmetro biomecânico objetivo de desempenho, no que diz respeito ao aproveitamento das forças aplicadas no pedal. Assim, define-se como fator de desempenho biomecânico $\left(f_{d}\right)$ o valor adimensional definido pela razão

$$
f_{d}=\frac{F_{P}}{F_{T}}
$$

na qual $F_{P}$ é a parcela da força aplicada sobre o pedal na direção perpendicular ao pedivela e $F_{T}$ é a força total aplicada sobre o pedal. Obtém-se, portanto, um coeficiente tal que $-1 \leq f_{d} \leq 1$. Por exemplo, no caso em que $f_{d}=1$, ter-se-ia o máximo aproveitamento da força aplicada. $\mathrm{O}$ valor $f_{d}=-1$ indicaria que a força aplicada é totalmente oposta ao sentido do giro do pedivela, e $f_{d}=0$ indicaria que a força está sendo aplicada na direção paralela ao pedivela, não contribuindo positivamente nem negativamente com torque resultante. Consiste, portanto, numa medida instantânea do desempenho, tendo-se um parâmetro objetivo para a observação da eficiência da pedalada de um ciclista. Variando-se 
a técnica, em geral, varia-se $f_{d}$ (Milhomem et al., 2014d). Esta definição mostra-se interessante no treinamento de ciclistas de alto desempenho e na identificação de posturas indesejadas ao pedalar (Milhomem et al., 2012; Telles et al., 2012; Carmo et al., 2014).

\subsubsection{2 - Sinais eletromiográficos}

O sinal eletromiográfico foi captado no músculo vasto lateral utilizando um eletromiógrafo comercial da marca Delsys (modelo Bagnoli 2). Este equipamento fornece eletrodos bipolares com pré-amplificação e filtro passa-faixa embutido (faixa de $20 \mathrm{~Hz}$ a $400 \mathrm{~Hz} \mathrm{a}-3 \mathrm{~dB}$ ) o qual, além de reduzir os artefatos de movimento do eletrodo, funciona como filtro anti-aliasing. A distância entre os contatos do eletrodo é de 1,0 cm, com áreas de contato retangulares de $1,0 \mathrm{~cm}$ x $0,1 \mathrm{~cm}$. Este eletromiógrafo possui também um comutador, através do qual seu ganho pode ser ajustado para os valores de 100, 1000 ou 10000. Utilizou-se um ganho total de 1000. Além de realizar a pré-amplificação do sinal de EMG nos eletrodos, este equipamento conta com amplificação diferencial com rejeição de modo comum. Assim, reduzem-se as interferências que se encontram na faixa de $60 \mathrm{~Hz}$, em geral, oriundas das instalações elétricas locais. Para sua alimentação, o aparelho utiliza uma bateria de 9,0 V e, durante a coleta, o sujeito é mantido conectado ao terra do aparelho. O equipamento fornece, ainda, um sistema de segurança contra falhas do aterramento, composto por um isolamento através de um transformador. As recomendações de assepsia e posicionamento de eletrodos do Seniam foram observadas (Hermens et al., 2000). Antes do processamento dos sinais de EMG-S, foram-lhes aplicadas as ferramentas de pré-processamento a serem descritas no Cap. 4.

\subsubsection{3 - Instrumentação integrada}

Todos os sinais - biomecânicos e de EMG-S - foram digitalizados com um conversor A/D de 12 bits da marca National Instruments, modelo PCI 6024E (Austin-TX, USA) à taxa de 2,4 kHz, utilizando-se 6 (seis) canais distintos - um para cada sinal, separadamente. A figura 3.6 ilustra a integração da instrumentação para aquisição simultânea dos sinais: 


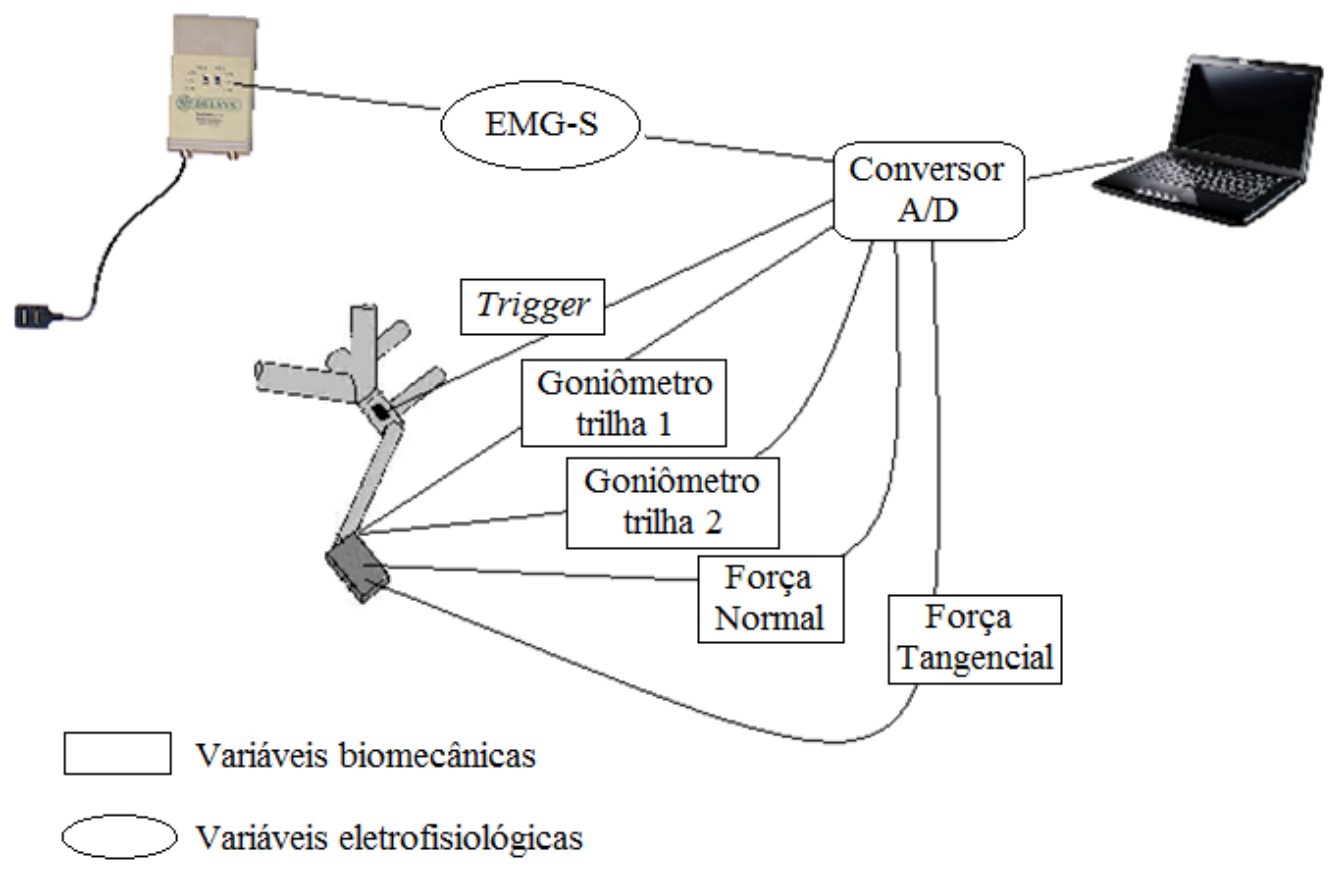

Figura 3.6: Esquema da instrumentação integrada para aquisição simultânea dos sinais biomecânicos e de EMG-S.

O software utilizado para a coleta dos sinais, tanto biomecânicos como eletromiográficos, foi o LabView, que permite visualizar todos os sinais no momento em que estão sendo coletados. Assim, no caso de observar-se qualquer irregularidade durante a coleta, esta era interrompida e iniciada novamente. Utilizou-se a interface gráfica deste software, que permitia que todos fossem observados simultaneamente. Tal facilidade permitia, por exemplo, a verificação de sincronia dos sinais e sua coerência com a atividade do ciclista no momento de seu registro. Este mesmo software foi utilizado para o registro dos dados de calibração dos pedais. O software utilizado - tanto para gerar as curvas de calibração como para o processamento dos sinais - foi o Matlab. Executa-se primeiramente a rotina de calibração dos sinais, pois há uma curva de calibração resultante para cada dia de coleta (no início de cada dia, calibravam-se os pedais com os pesos da tabela 3.1). Com a execução desta rotina, são gerados os arquivos de calibração, os quais são utilizados pelo Matlab para a obtenção correta das forças aplicadas nos pedais. Além dos sinais de calibração, são fornecidos como entrada no algoritmo desenvolvido em Matlab, no momento do processamento, os seis sinais obtidos pelos canais separados (EMG, forças tangenciais ao pedal, forças normais ao pedal, trigger, trilha interna do goniômetro e trilha externa), todos armazenados numa só variável, para cada ciclista voluntário. 


\section{2 - PROTOCOLO II: CICLISMO}

Este protocolo envolve a aquisição de sinais de EMG-S de ciclistas em cicloergômetro. Foram utilizados os mesmos equipamentos - cicloergômetro e eletromiógrafo - do Protocolo I. Foram utilizados sinais de EMG-S do vasto lateral e do vasto medial de 8 ciclistas voluntários com idade de $26 \pm 4,3$ anos, todos previamente examinados e classificados como saudáveis por um especialista em atividades físicas, assinando um termo de esclarecimento e consentimento. Estes sinais foram coletados e utilizados no estudo de Andrade (2006) e cedidos pelo autor.

\subsection{1 - Protocolo experimental}

Este protocolo experimental consiste de 3 (três) etapas de coletas de sinais, em que os ciclistas voluntários pedalaram até a exaustão, com intervalos entre si de aproximadamente $48 \mathrm{~h}$. A primeira coleta era realizada a velocidade constante e carga crescente, a segunda coleta com velocidade crescente e carga constante, e a terceira coleta com velocidade e carga constantes, como detalhado adiante. Antes de cada coleta, fazia-se a tricotomia e higienização da pele nas regiões de fixação dos eletrodos e explicavam-se os procedimentos aos voluntários.

No primeiro dia de coleta, os sujeitos realizavam breve aquecimento no cicloergômetro durante menos que 4 minutos à velocidade constante de $30,0 \mathrm{~km} / \mathrm{h}$ e carga resistida de $30 \mathrm{~W}$. Após aquecimento, iniciava-se o registro dos sinais. Os sujeitos pedalavam à mesma velocidade constante de $30 \mathrm{~km} / \mathrm{h}$ com carga inicial de $150 \mathrm{~W}$, sendo incrementada em $50 \mathrm{~W}$ a cada $30 \mathrm{~s}$ até a exaustão. No segundo dia, após aquecimento idêntico ao do primeiro dia, a coleta era realizada com os voluntários pedalando com carga constante, definida como $70 \%$ da carga máxima atingida na primeira coleta. A velocidade inicial era de $30 \mathrm{~km} / \mathrm{h}$, sendo incrementada em $3 \mathrm{~km} / \mathrm{h}$ a cada $30 \mathrm{~s}$, até a exaustão. No terceiro dia, após o mesmo aquecimento realizado antes das coletas anteriores, a coleta era realizada com os sujeitos pedalando à velocidade constante de $70 \%$ da máxima atingida na coleta anterior e com carga constante, também igual a $70 \%$ da carga máxima da primeira coleta e já utilizada na segunda. Utilizou-se o mesmo sistema de trigger descrito no Protocolo I para identificação das pedaladas. 


\section{3 - PROTOCOLO III: ISOCINÉTICO}

Este protocolo experimental envolve a aquisição de sinal de EMG-S e sinais biomecânicos (torque, posição angular e velocidade) durante exercício isocinético de extensão de joelho. O sinal eletromiográfico foi captado no vasto lateral durante um protocolo tradicional de exercício: 6 séries de 10 repetições com velocidade angular de $60 \%$ na fase concêntrica e $180 \%$ s na fase excêntrica (Milhomem et al., 2014a, 2014b e 2014e). Os procedimentos serão detalhados a seguir.

\subsection{1 - Protocolo experimental e instrumentação}

Neste protocolo experimental utilizaram-se sinais coletados de 7 (sete) indivíduos do sexo masculino $(23,9 \pm 5,9$ anos, $92,5 \pm 10,4 \mathrm{~kg}$ e $180,5 \pm 5,8 \mathrm{~cm}$ de altura). $\mathrm{O}$ experimento foi aprovado pelo Comitê de Ética da Universidade de Brasília (parecer $\mathrm{n}^{\circ}$ 71484/12). Os voluntários preencheram um questionário de prontidão para atividade física (Physical Activity Readiness Questionnaire - PAR-Q), sendo considerados aptos para a realização dos procedimentos experimentais. A atividade consistia na realização de 6 séries de 10 repetições de extensão e flexão do joelho. A fase concêntrica (FC) era realizada a $60 \%$ e a fase excêntrica (FE) a $180 \%$ s. Entre cada série de repetições, havia 1 minuto de repouso. Para a realização do exercício, foi utilizado um dinamômetro isocinético da marca Biodex, modelo System 3 (Biodex Medical, Inc., Shirley, NY, EUA), que impõe resistência variável, de modo a manter a velocidade constante. Os sujeitos foram posicionados confortavelmente, com uma faixa em volta de tronco e pélvis para minimizar movimentos indesejáveis e com fêmur alinhado de forma a permitir movimentação livre da extensão total à posição angular de $80^{\circ}$ (limite concêntrico, tomando como referência de $0^{\circ}$ o repouso, em ângulo reto). Contrações com interrupções ou incompletas foram descartadas. A calibração do dinamômetro foi feita de acordo com o manual do fabricante, e a acomodação dos sujeitos de acordo com os procedimentos descritos por Bottaro et al. (2012). A figura 3.7 ilustra o sistema de dinamometria isocinética e a posição do voluntário na realização do exercício proposto. 


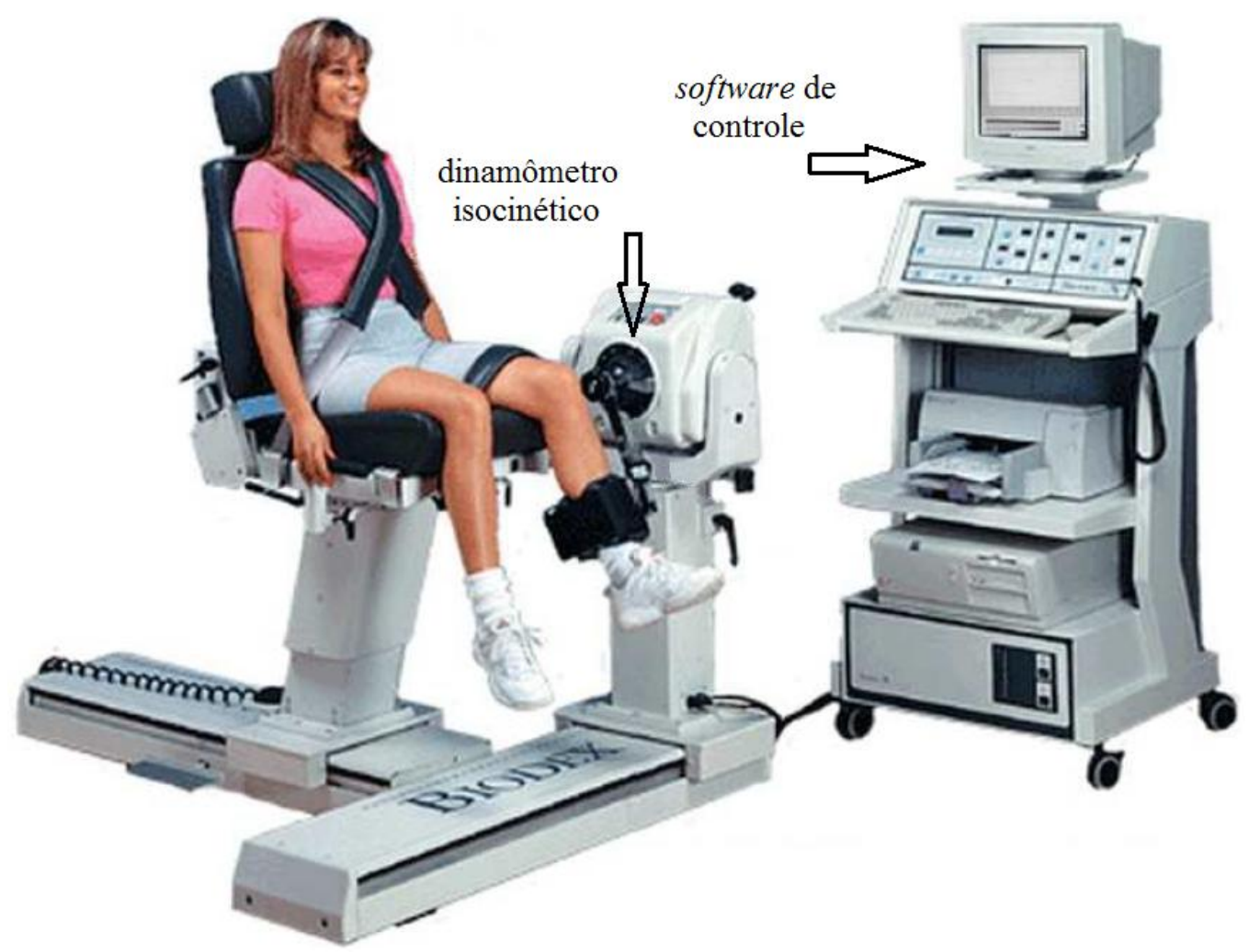

Figura 3.7: Sistema de dinamometria isocinética utilizado no Protocolo III. Adaptado de Biodex (1998).

O sinal de EMG-S foi captado no músculo vasto lateral utilizando eletrodos bipolares ativos com $15 \mathrm{~mm}$ de diâmetro e distância de $20 \mathrm{~mm}$ entre polos. Os sinais foram digitalizados à taxa de 2,0 kHz por um eletromiógrafo da marca Miotec, modelo Miotool, com ganho total de $2000 \mathrm{~V} / \mathrm{V}$ e modo de rejeição comum a $110 \mathrm{~dB}$. Observaram-se as recomendações de assepsia e posicionamento de eletrodos do Seniam (Hermens et al., 2000). Os dados de torque, velocidade e posição angular obtidos do dinamômetro foram sincronizados com o sinal de EMG-S pela interface do eletromiógrafo, sendo também processados utilizando o software MATLAB. Antes do processamento dos sinais de EMGS, estes foram filtrados com o procedimento a ser descrito no Cap. 4.

\section{4 - PROTOCOLO IV: ISOMÉTRICO}

Este protocolo experimental envolve a aquisição de sinal de EMG-S em contração isométrica do bíceps braquial (cabeça curta). A análise foi conduzida com os sinais de 8 homens $(26,9 \pm 4,0$ anos; 71,5 \pm 7,5 $\mathrm{kg}$ e 179,0 \pm 7,3 $\mathrm{cm}$ de altura). Todos os sujeitos assinaram termo de consentimento livre e esclarecido e o questionário PAR-Q. O protocolo 
foi aprovado pelo Comitê de Ética em Pesquisa da Universidade de Brasília (022/07).

Os sinais deste protocolo foram somente utilizados para a prévia validação experimental dos indicadores de fadiga propostos nesta tese para posterior aplicação em protocolos dinâmicos. Estes foram coletados para os estudos de Soares (2007) e Salomoni (2008) e cedidos pelos autores.

\subsection{1 - Protocolo experimental e instrumentação}

Os sujeitos realizaram contração isométrica (40\% MVC) durante $90 \mathrm{~s}$. O valor da MVC foi registrado em prévias contrações de $3 \mathrm{~s}$ utilizando-se estímulo verbal. Os mesmos procedimentos de assepsia dos protocolos anteriores foram empregados.

Para realizar a contração, o sujeito segurava uma empunhadura de madeira presa a uma célula de carga. A célula de carga era fixada à base da cadeira em que o sujeito permanecia sentado. Para a manutenção da posição, o cotovelo do sujeito era apoiado sobre um suporte fixo da cadeira de forma a manter um ângulo de $90^{\circ}$ entre braço e antebraço, permanecendo o braço alinhado ao corpo. A carga mantida durante as contrações foi medida com uma célula de carga modelo TS - AEPH (SP, Brasil) com carga máxima de $50 \mathrm{kgf}$. A aquisição do sinal de EMG-S foi realizada com um arranjo linear flexível biadesivo de 8 eletrodos (LISiN Politecnico di Torino - SPES Medica, Milão, Itália). Os eletrodos consistiam em barras retangulares $(5,0 \mathrm{~mm}$ por $1,0 \mathrm{~mm})$ espaçadas em $5,0 \mathrm{~mm}$ e eram preenchidos com gel condutor. Os sinais foram captados com ganho de $2000 \mathrm{~V} / \mathrm{V}$ e filtragem analógica passa-faixa $(10 \mathrm{~Hz}-500 \mathrm{~Hz}$ a $-3 \mathrm{~dB})$. A digitalização foi realizada com a mesma placa A/D utilizada nos protocolos I e II, à taxa de $2048 \mathrm{~Hz}$. Apenas um par de canais do arranjo linear foi utilizado para processamento e análise, escolhendo-se aquele que apresentava maior SNR, de acordo com a estimativa de SNR a ser definida - para sinais de contração isométrica - na seção 4.1.2.1. Antes do processamento, esses sinais também foram filtrados com o procedimento que será descrito no Cap. 4.

\section{5 - CONSIDERAÇÕES FINAIS}

Neste capítulo foram apresentados os protocolos experimentais abordados nesta 
tese e suas correspondentes instrumentações para aquisição. Inclui-se, para o Protocolo I, uma proposta de instrumentação dedicada à avaliação conjunta de parâmetros eletromiográficos e biomecânicos em ciclismo, definindo-se um indicador objetivo de desempenho biomecânico, a partir do aproveitamento das forças aplicadas sobre os pedais instrumentados.

No próximo capítulo tratar-se-á do conjunto de ferramentas de pré-processamento dos sinais eletromiográficos proposto neste trabalho, envolvendo técnicas clássicas e técnicas utilizando wavelets. 


\section{4 - TÉCNICAS DE PRÉ-PROCESSAMENTO}

Neste capítulo descreve-se o conjunto de técnicas de pré-processamento implementadas para o tratamento dos sinais eletromiográficos utilizados no trabalho. Tais técnicas objetivam a redução do ruído branco aditivo, dos artefatos de movimento e da interferência da rede elétrica, nas frequências de $60 \mathrm{~Hz}$ e harmônicos.

\section{1 - RUÍDO BRANCO E ARTEFATOS DE MOVIMENTO}

Para a redução dos artefatos de movimento do eletrodo e do ruído branco aditivo foram utilizadas duas técnicas tradicionais: filtragem passa-faixa e algoritmo de cancelamento de ruído invariante ao deslocamento (denoising) utilizando wavelets.

\subsection{1 - Filtragem passa-faixa}

A sequência $\boldsymbol{y}=\{y[n]\}_{n=1}^{L}$ de $L$ amostras do sinal de EMG-S digitalizado é processada - obtendo-se sua versão filtrada $\boldsymbol{y}_{f i l t}$ - da seguinte maneira:

i) Aplica-se um filtro passa-faixa de Butterworth de $4^{\mathrm{a}}$ ordem sobre $\boldsymbol{y}$, resultando numa sequência $\boldsymbol{w}=\{w[n]\}_{n=1}^{L}$.

ii) Aplica-se novamente este mesmo filtro sobre a versão refletida $\boldsymbol{w}^{\prime}=$ $\{w[L-n+1]\}_{n=1}^{L}$ do sinal obtido anteriormente, obtendo-se uma versão refletida $\boldsymbol{y}_{\text {filt }}^{\prime}=\left\{y_{\text {filt }}[L-n+1]\right\}_{n=1}^{L}$ do resultado desejado.

iii) Refletindo-se este resultado, tem-se um sinal $\boldsymbol{y}_{\text {filt }}^{\prime \prime}=\boldsymbol{y}_{\text {filt }}=\left\{y_{\text {filt }}[n]\right\}_{n=1}^{L}$ filtrado sem distorção de fase. Desta maneira, utiliza-se um filtro passa-faixa equivalente de $8^{\mathrm{a}}$ ordem para o sinal eletromiográfico.

Esta técnica resulta num filtro com distorção de fase nula e reduz os artefatos de movimento contidos nas frequências inferiores a $20 \mathrm{~Hz}$, além dos ruídos que contaminam o sinal de EMG-S nas frequências superiores a $500 \mathrm{~Hz}$ (DeLuca et al., 2010). Especialmente em situações nas quais se deve filtrar o sinal de EMG-S coletado para posterior cálculo de velocidade de condução (CV) é interessante o uso de filtros com distorção de fase nula (Merletti e Parker, 2004). 


\subsection{2 - Cancelamento de ruído invariante ao deslocamento: métodos e resultados}

Para o cancelamento de ruído do sinal eletromiográfico, utilizou-se uma técnica empregando transformada de wavelets, o denoising de $2^{a}$ geração. Esta técnica envolve a aplicação sucessiva do denoising de $1^{\text {a }}$ geração - que consiste no truncamento dos coeficientes menos significativos (hard tresholding) do sinal no domínio da transformada a versões do sinal ruidoso obtidas por deslocamento circular. Após realizar, no domínio da transformada, o truncamento de todas as versões circularmente deslocadas do sinal ruidoso, faz-se a promediação dos sinais reconstruídos, de forma que ruídos e artefatos sejam suprimidos (Donoho, 1995; Coifman e Donoho, 1995). A realização do truncamento sobre várias versões deslocadas contribui para que o método seja aproximadamente invariante ao deslocamento. Em geral, quanto mais versões são promediadas, mais próxima de invariante torna-se a técnica (Coifman e Donoho, 1995; Antoniadis et al., 1995). Este método está fortemente relacionado ao comportamento relativamente suave do sinal eletromiográfico, devido à sua limitação em banda. Assim, espera-se que os coeficientes da DWT - do sinal de EMG-S ruidoso - correspondentes às frequências mais altas representem, predominantemente, o ruído que contamina o sinal. O uso do denoising de $2^{\mathrm{a}}$ geração deve, ainda, atenuar os artefatos causados pelo fenômeno de Gibbs, presente nas vizinhanças das descontinuidades do sinal, reduzindo este efeito (Coifman e Donoho, 1995).

\subsubsection{1 - Sinais dinâmicos de ciclismo}

Em atividades de ciclismo, em geral, apresentam-se padrões de atividade muscular de maneira tal que a atividade mioelétrica significativa ocorra durante uma fase bem definida de cada ciclo (Carmo, 2003; Andrade, 2006; Milhomem, 2011). Fora desta fase considera-se que o sinal de EMG-S resultante seja composto, além do tônus muscular, predominantemente por ruído. Este fato foi utilizado para a estimação da potência do ruído e escolha do limiar no algoritmo de denoising. Assim, a potência do ruído foi estimada a partir do trecho silencioso (em que não há contração muscular) mais próximo ao segmento a ser processado, no qual se assume que não há atividade mioelétrica significativa.

Devido à não-estacionariedade do sinal de EMG-S, esta técnica foi aplicada, separadamente, a cada ciclo de contração - em todos os protocolos experimentais 
abordados no trabalho. A família de wavelets utilizada foi a Daubechies-4, utilizando-se sempre a quantidade máxima possível de níveis no banco de filtros para a decomposição do sinal. A figura 4.1 a seguir ilustra o procedimento:

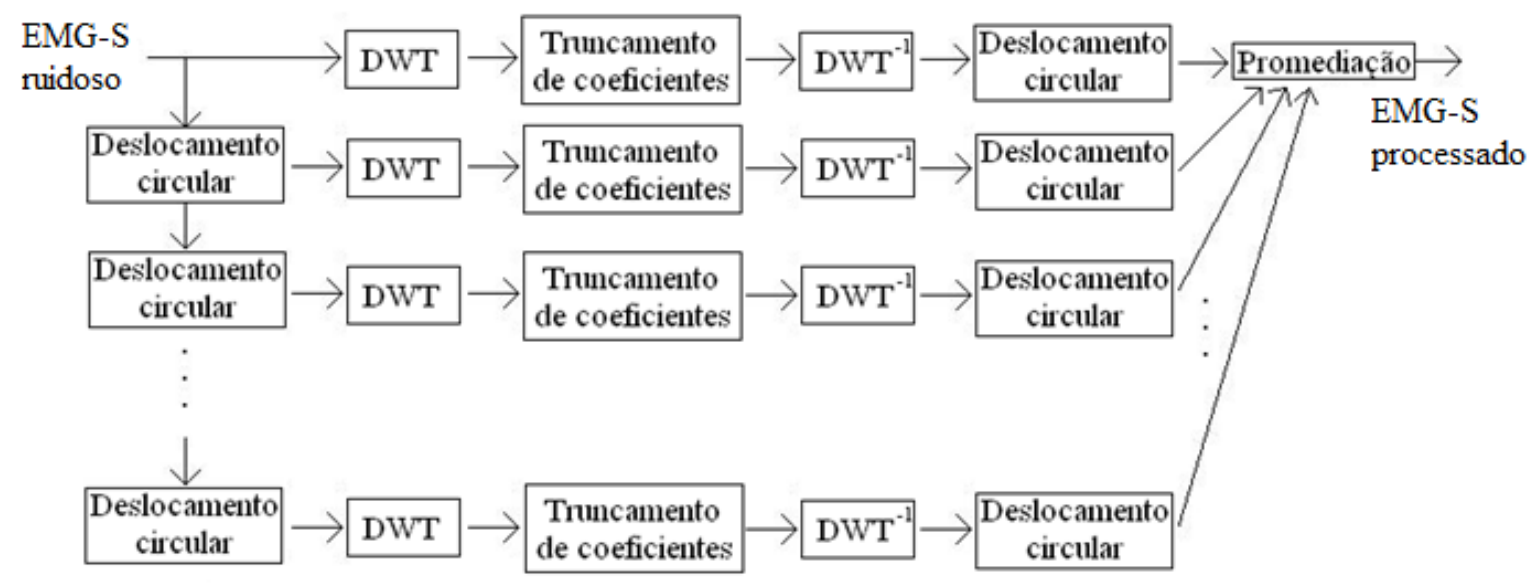

Figura 4.1: Diagrama do algoritmo de cancelamento de ruído.

Este método mostra-se útil por, possivelmente, atenuar a potência do ruído presente na faixa de $20 \mathrm{~Hz}$ a $500 \mathrm{~Hz}$, a qual, idealmente, não é alterada na filtragem passa-faixa tradicional. Além disso, suprimem-se os artefatos aparentes na reconstrução do sinal, em que são evidenciadas as funções base escolhidas nos trechos de menor amplitude. A promediação de diferentes versões reduz estes efeitos, descorrelacionando-se tais artefatos dos trechos silenciosos do sinal (Donoho, 1995; Coifman e Donoho, 1995). A figura 4.2 exemplifica a aplicação do método sobre um trecho de sinal de EMG-S, de contrações dinâmicas cíclicas (ciclismo), correspondente a um ciclo de contração. Para o truncamento dos coeficientes, o limiar utilizado foi de seis vezes o desvio-padrão do ruído estimado a partir do trecho silencioso: 

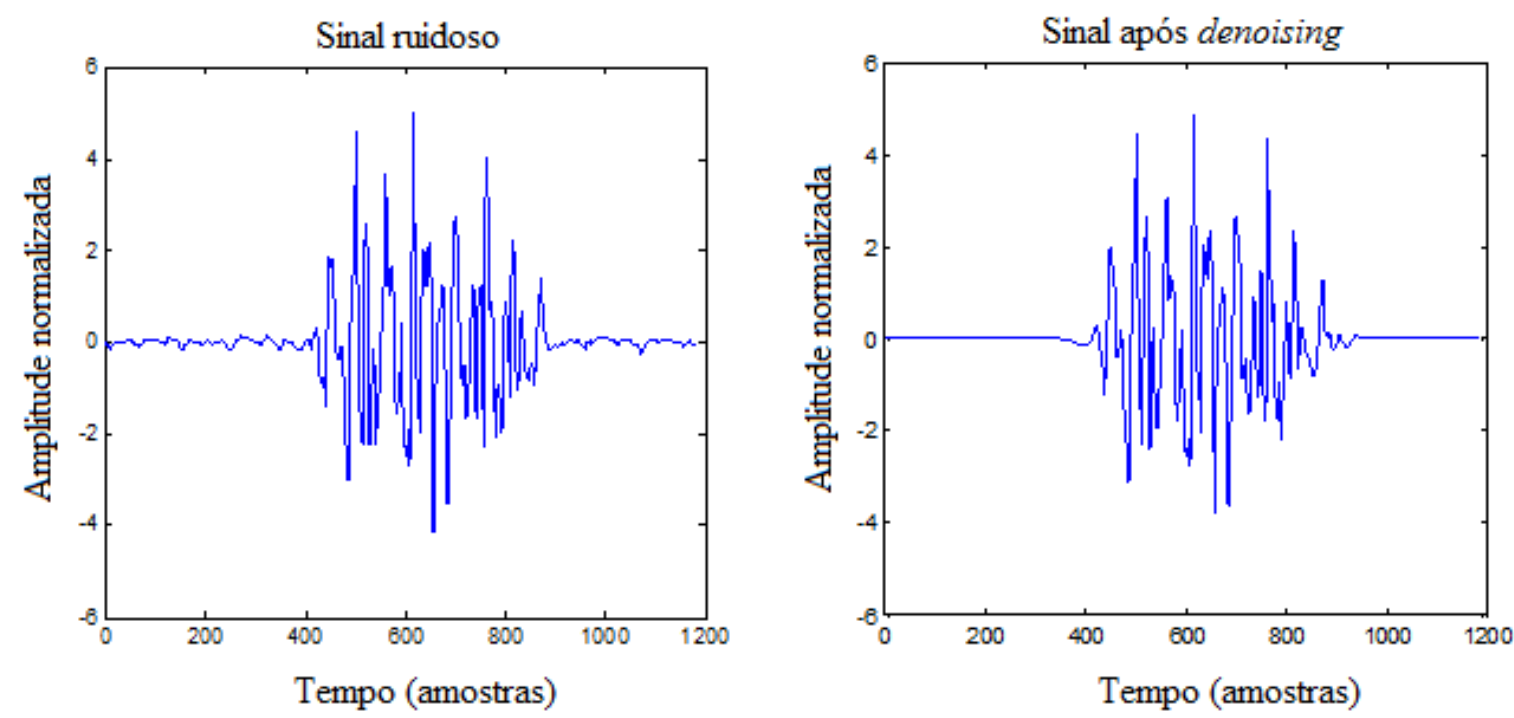

Figura 4.2: Exemplo de trecho do sinal de EMG-S de um ciclo de contração: Sinal ruidoso (à esquerda) e sinal após aplicação da técnica de denoising (à direita).

\subsubsection{2 - Sinais de outros protocolos experimentais}

Para a aplicação do denoising aos demais sinais, coletados em outros protocolos experimentais, como o de contrações isométricas, não se conta com a facilidade do trecho silencioso bem definido próximo ao segmento a ser processado. Deve-se, portanto, estimar a potência do ruído de outra maneira. Em tais casos utilizou-se o espectro de amplitude do sinal de EMG-S contaminado pelo ruído. Como a atividade mioelétrica possui seu espectro restrito a frequências inferiores a $500 \mathrm{~Hz}$, as coletas em todos os protocolos eram realizadas a taxas de amostragem de, no mínimo, 2,0 kHz, de forma que a metade superior do espectro após a amostragem - correspondente à faixa de $500 \mathrm{~Hz}$ a $1,0 \mathrm{kHz}$ - não contenha informações significativas de eletromiografia, assumindo-se que tal faixa seja ocupada, essencialmente, pelo ruído branco. Como este ruído, em média, afeta o espectro uniformemente, utiliza-se a faixa $500 \mathrm{~Hz}-1,0 \mathrm{kHz}$ para estimar a potência do ruído branco aditivo. Para isto, pondera-se a relação de Parseval, de acordo com o comprimento do espectro considerado para estimação da potência do ruído $\left(P_{\text {ruído }}\right)$, isto é:

$$
P_{\text {ruído }} \cong \frac{1}{N\left(k_{\text {máx }}-k_{\text {mín }}-1\right)} \sum_{k=k_{\text {mín }}}^{k_{\text {máx }}}|X[k]|^{2}
$$


Em que $N$ é o comprimento, em amostras, do trecho do sinal de EMG-S a ser processado, $X[k]$ é o $k$-ésimo harmônico da transformada discreta de Fourier (DFT) deste trecho, $k_{\text {mín }}$ é o índice de $X[k]$ correspondente à frequência de $500 \mathrm{~Hz}$ e $k_{\text {máx }}$ o índice correspondente a 1,0 kHz. A figura 4.3 ilustra a faixa do espectro sobre o qual se estima a potência do ruído.

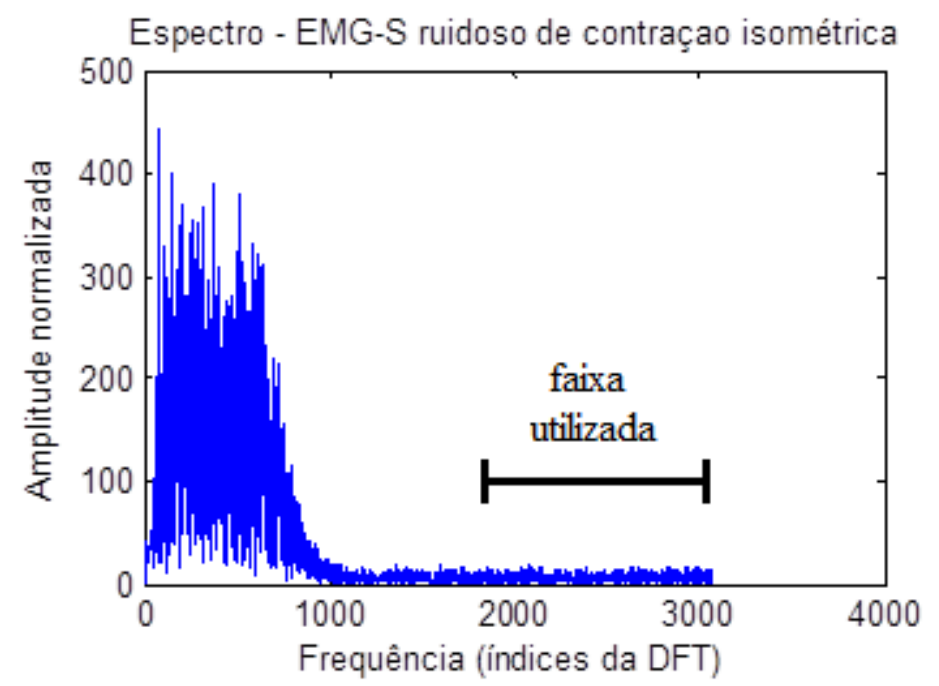

Figura 4.3. Faixa do espectro do sinal de EMG - de contração isométrica - utilizado para a estimação da potência do ruído.

Estimada a potência do ruído, os demais procedimentos para o denoising são os mesmos descritos para o caso de sinais de ciclismo. A seguir, apresentam-se os resultados obtidos com a técnica de denoising com a potência do ruído branco estimada de acordo com o método descrito.

\subsubsection{3 - Resultados e discussão}

Apresentam-se a seguir os resultados obtidos com sinais de EMG-S simulados com o modelo de Farina e Merletti (2001). Estes sinais simulam uma contração isométrica com duração de $3 \mathrm{~s}$ com CV constante. Para a avaliação da técnica, esta foi empregada com diferentes limiares - em múltiplos do desvio padrão do ruído -, números de deslocamentos $\left(N_{d}\right)$ para a promediação e durações dos trechos sucessivos. Em todos os casos, foi imposta uma SNR inicial de $10 \mathrm{~dB}$. As figuras 3.4 e 3.5 mostram os resultados obtidos com a técnica, quando aplicada a trechos sucessivos de $250 \mathrm{~ms}$. No primeiro caso, a simulação foi realizada com $N_{d}=10 k(1 \leq k \leq 6)$ e no segundo com $N_{d}=6$ e $12 k(1 \leq k \leq 5)$. 


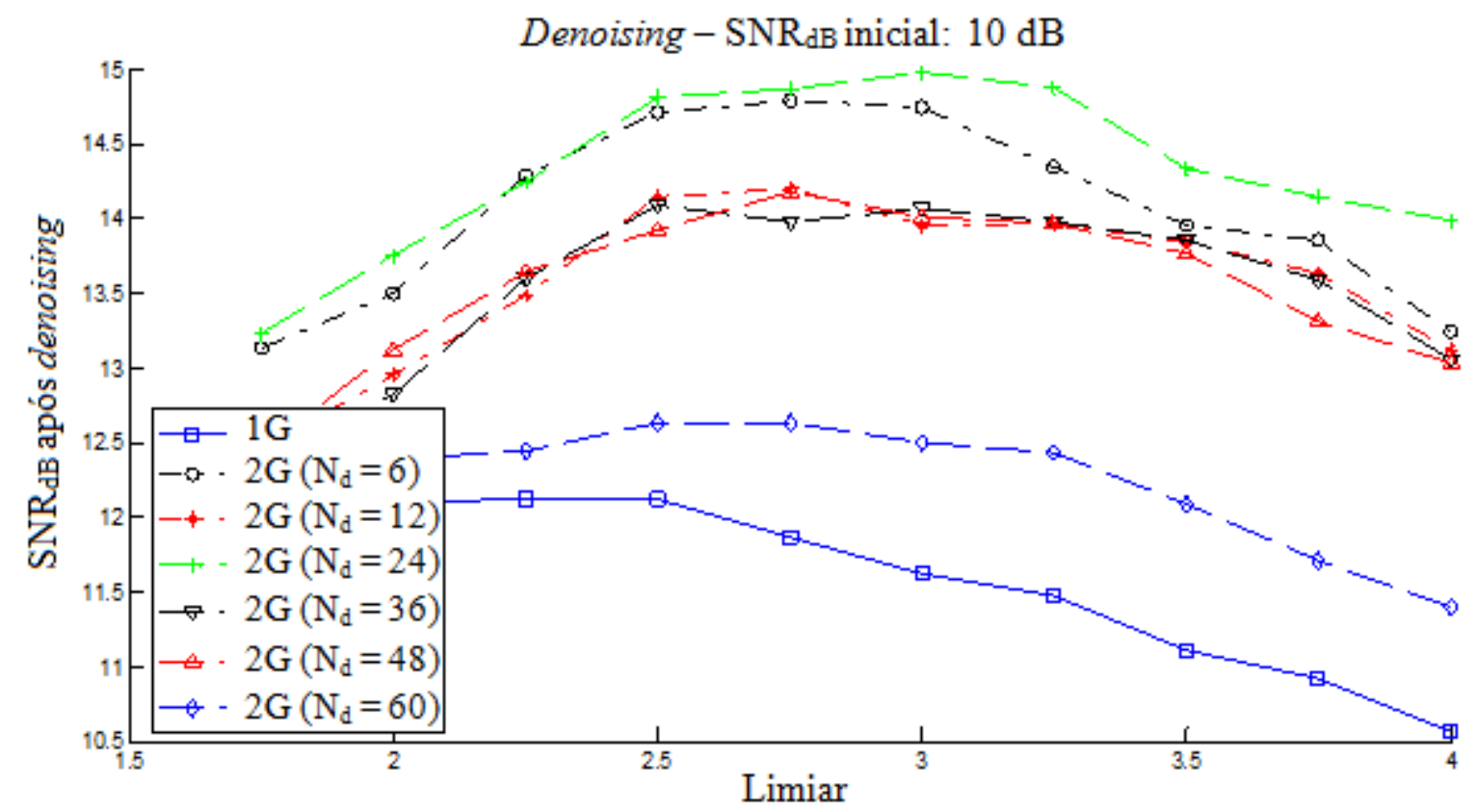

Figura 4.4: Resultados obtidos com denoising em função do limiar e $N_{d}$. Técnica aplicada a trechos sucessivos de $250 \mathrm{~ms} . N_{d}=12 k$.

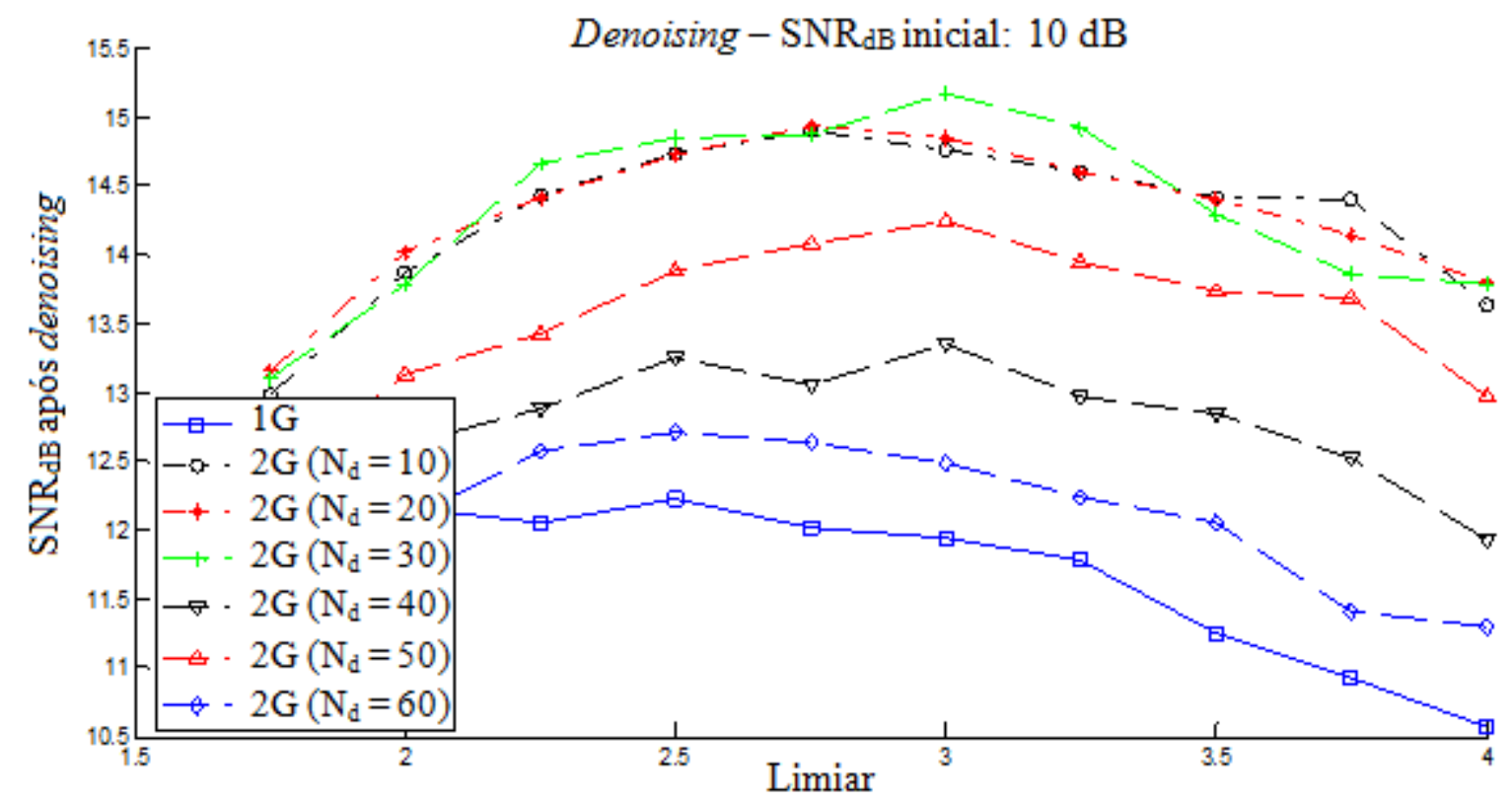

Figura 4.5: Resultados obtidos com denoising em função do limiar e $N_{d}$. Técnica aplicada a trechos sucessivos de $250 \mathrm{~ms} . N_{d}=10 \mathrm{k}$.

Obtiveram-se, para $N_{d} \leq 30$, aumentos iguais ou superiores a 5,0 dB na SNR inicial. As figuras 4.6 e 4.7 a seguir mostram os resultados para as mesmas simulações, quando realizadas considerando-se trechos sucessivos de $500 \mathrm{~ms}$. E, por último, a figura 4.8 mostra os resultados obtidos ao considerar trechos sucessivos de $1 \mathrm{~s}$. 


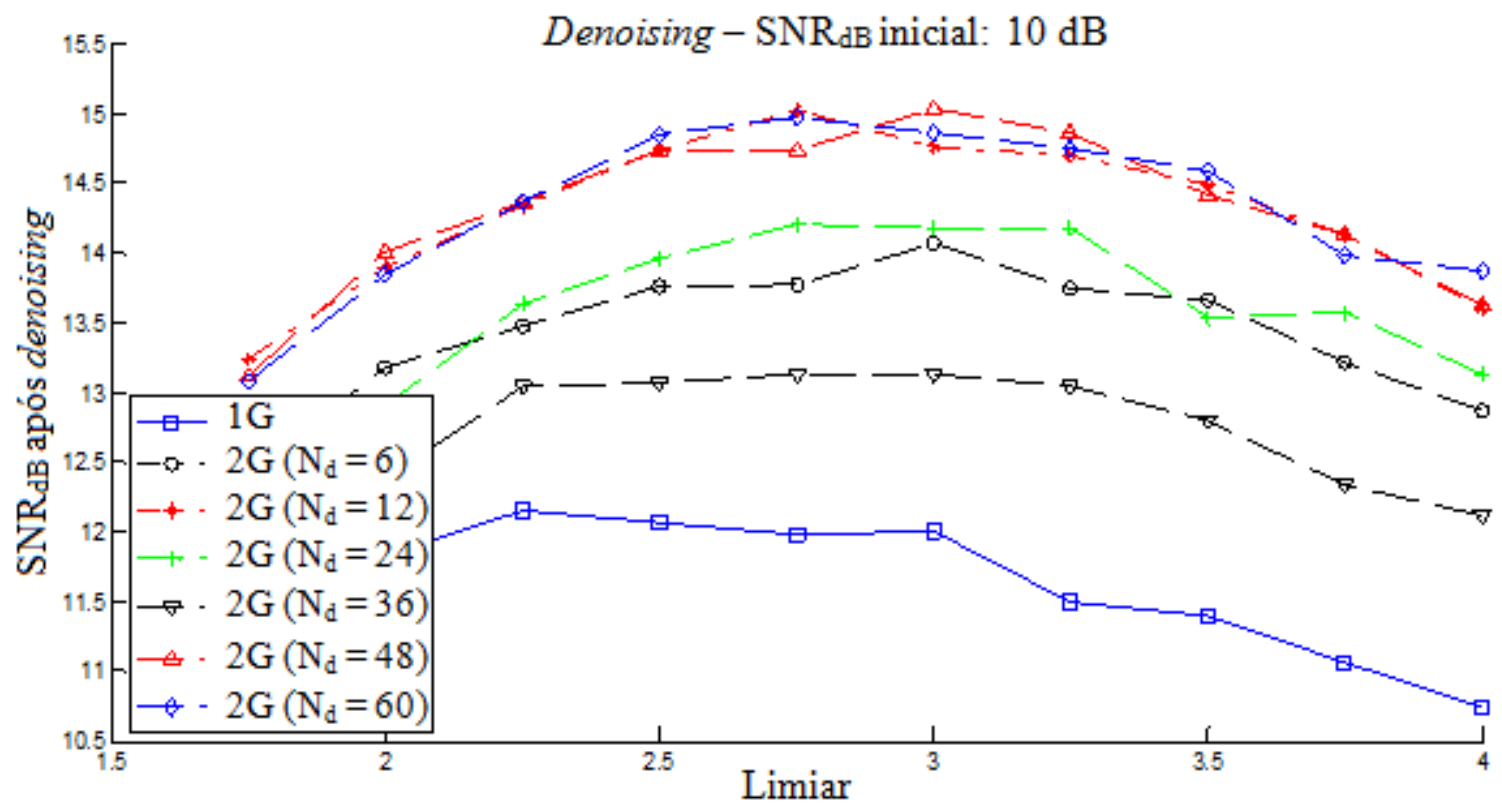

Figura 4.6: Resultados obtidos com denoising em função do limiar e $N_{d}$. Técnica aplicada a trechos sucessivos de $500 \mathrm{~ms} . N_{d}=12 k$.

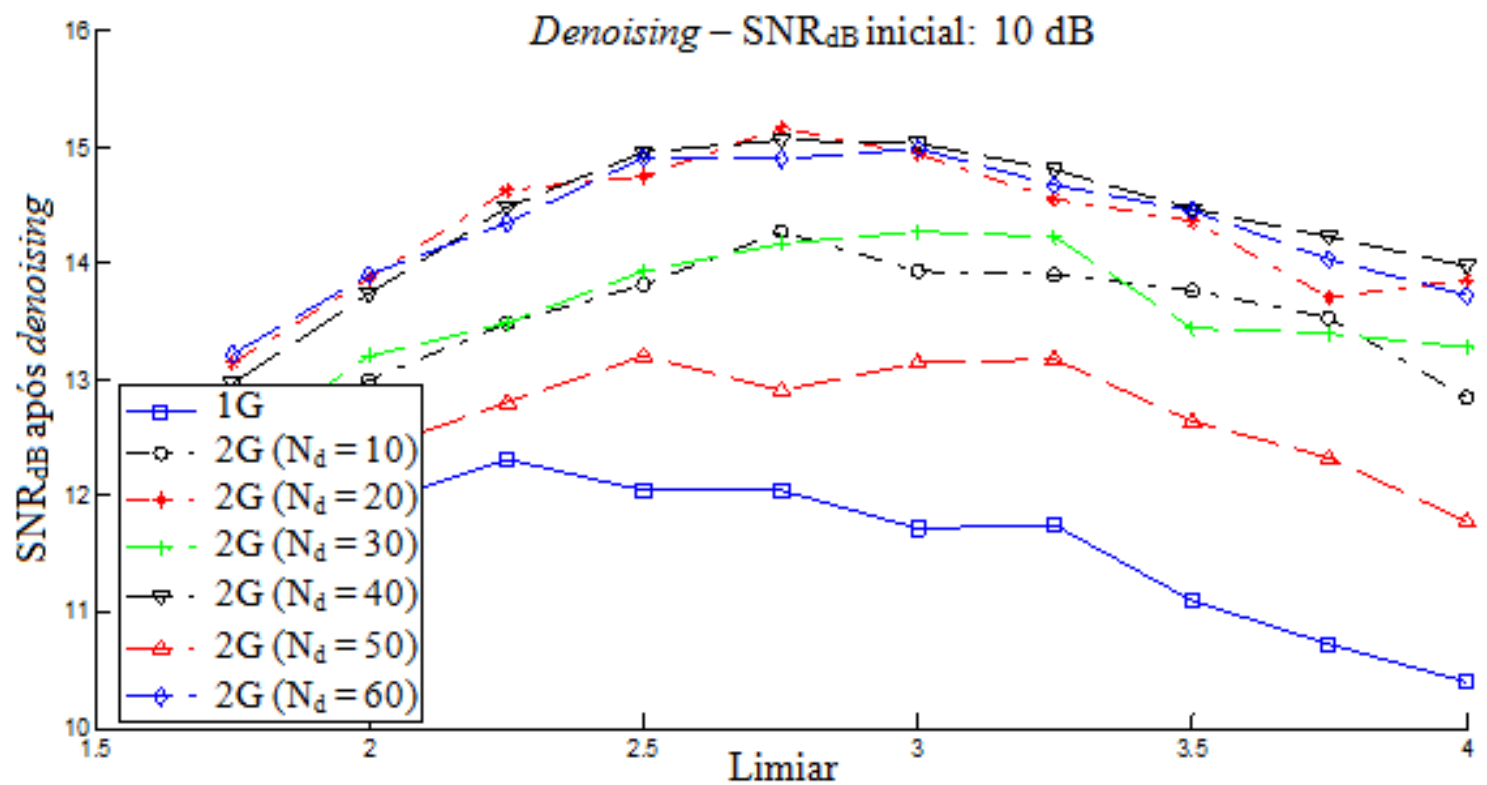

Figura 4.7: Resultados obtidos com denoising em função do limiar e $N_{d}$. Técnica aplicada a trechos sucessivos de $500 \mathrm{~ms} . N_{d}=10 k$. 


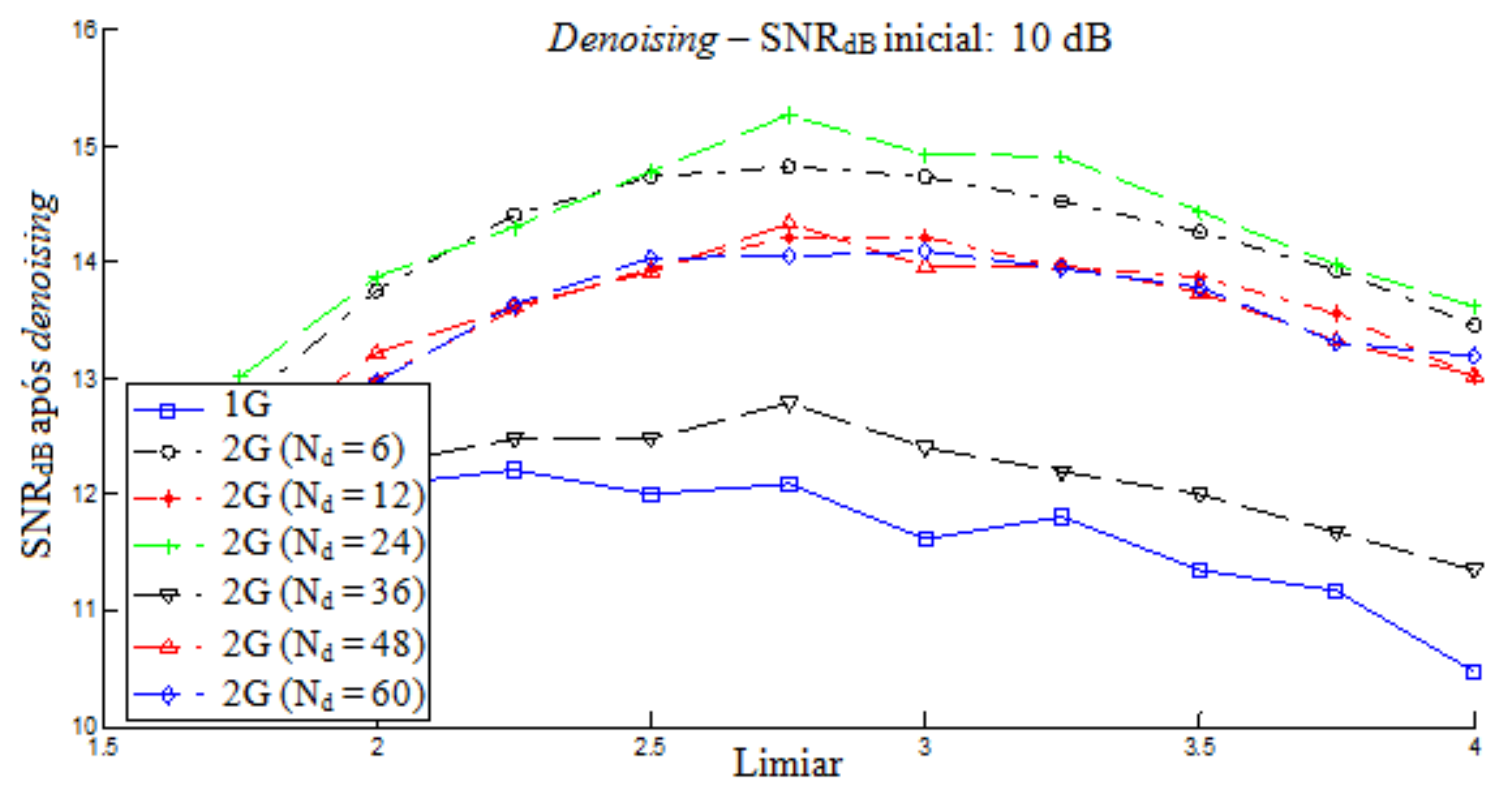

Figura 4.8: Resultados obtidos com denoising em função do limiar e $N_{d}$. Técnica aplicada a trechos sucessivos de 1 s. $N_{d}=12 k$.

Observa-se que, em geral, foi possível obter aumento ligeiramente superior a 5,0 dB na relação sinal/ruído após a técnica. Em todas as situações, o denoising de segunda geração apresentou melhores resultados em relação ao denoising simples. As figuras 4.9, 4.10 e 4.11 a seguir mostram os resultados ao considerarem-se somente potências de 2 para $N_{d}$, para trechos de 250,500 e $1000 \mathrm{~ms}$, respectivamente.

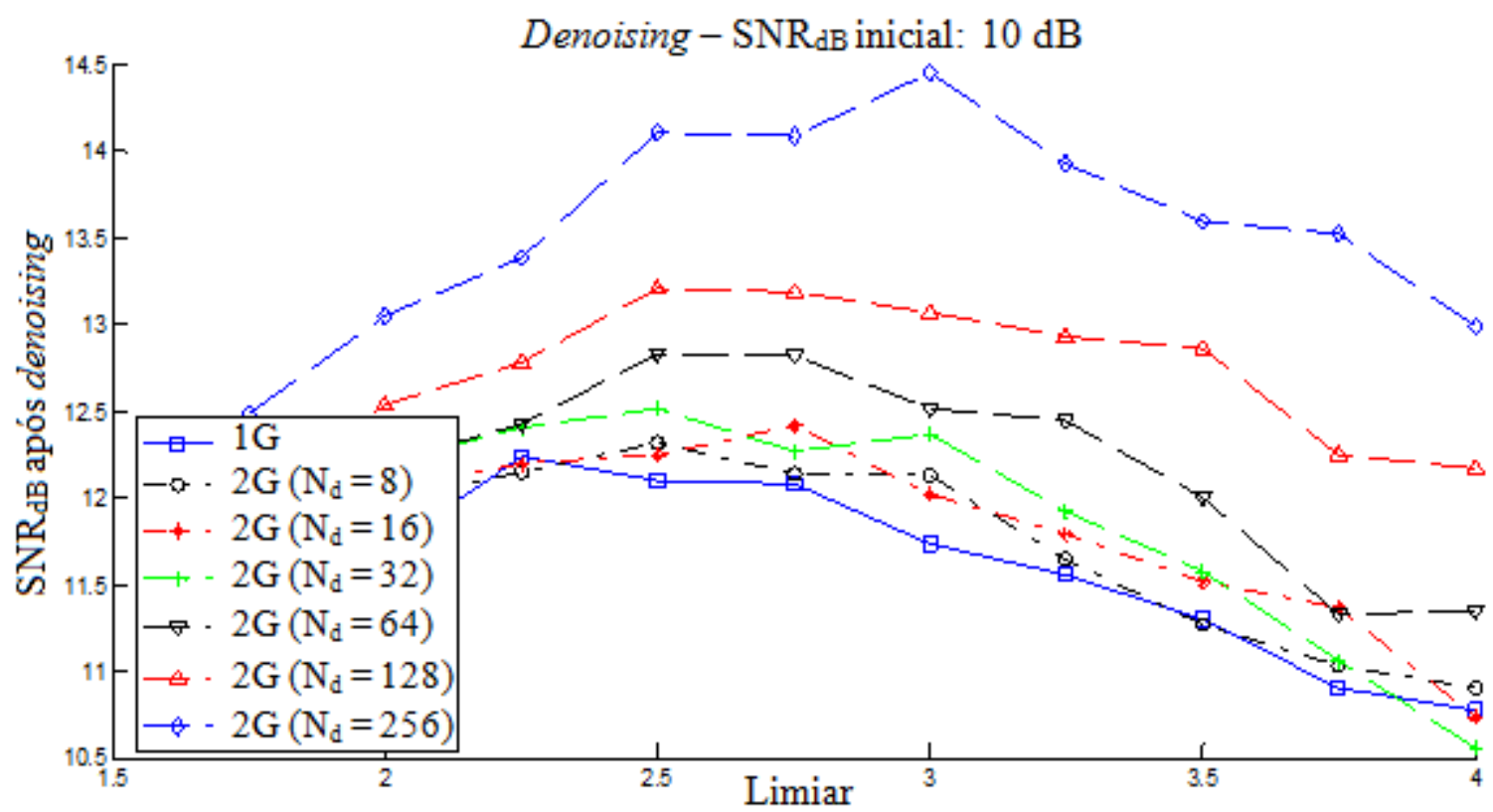

Figura 4.9: Resultados obtidos com denoising em função do limiar e $N_{d}=2^{k}$. Técnica aplicada a trechos sucessivos de $250 \mathrm{~ms}$. 


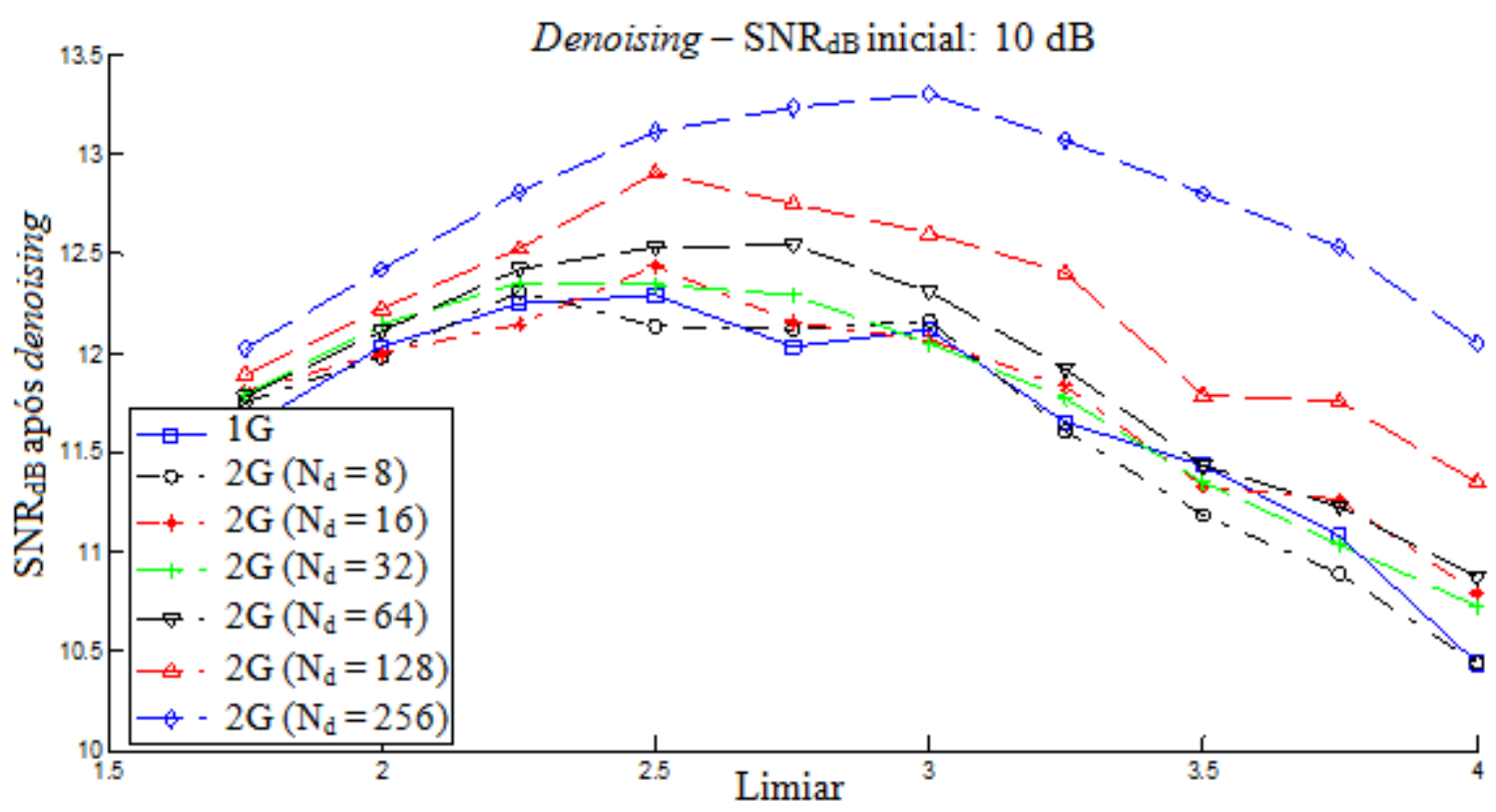

Figura 4.10: Resultados obtidos com denoising em função do limiar e $N_{d}=2^{k}$. Técnica aplicada a trechos sucessivos de $500 \mathrm{~ms}$.

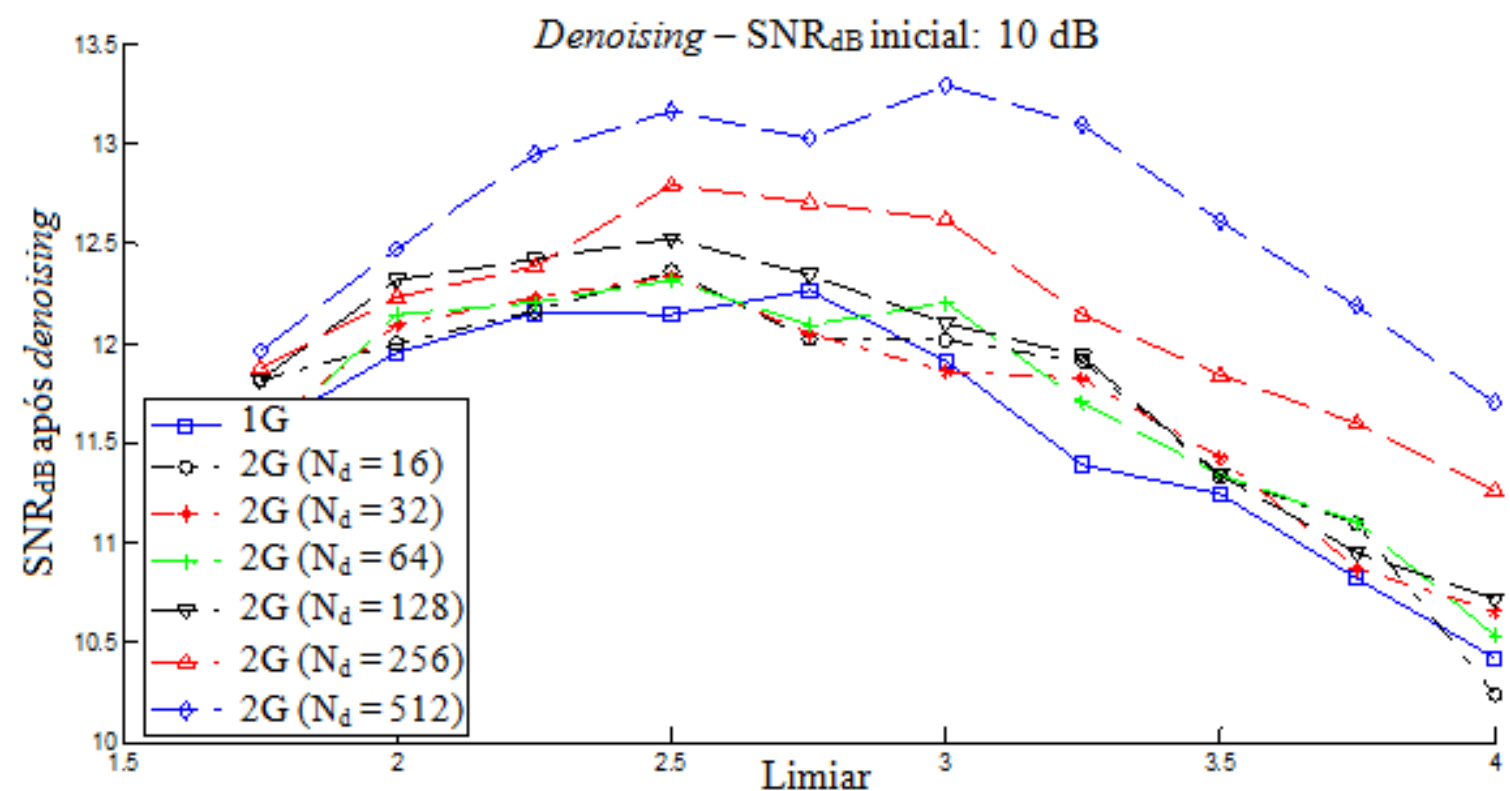

Figura 4.11: Resultados obtidos com denoising em função do limiar e $N_{d}=2^{k}$. Técnica aplicada a trechos sucessivos de $1 \mathrm{~s}$.

A restrição $N_{d}=2^{k}$, em todos os casos, promoveu aumentos inferiores na relação sinal/ruído comparando-se aos primeiros casos. Note-se o crescimento praticamente monotônico, em função de $N_{d}$, dos valores obtidos de SNR. Ainda, evidencia-se a necessidade de valores $N_{d}=256$ ou $N_{d}=512$ para que se aproxime - ainda por valores inferiores a $15 \mathrm{~dB}$ - o desempenho obtido anteriormente. Estes resultados constatam a vantagem em não utilizar potências de 2 para a quantidade de deslocamentos circulares na 
técnica de denoising de $2^{a}$ espécie. Como a decomposição da DWT já é diática, as versões promediadas com $N_{d}=2^{k}$ deslocamentos são bastante semelhantes às promediadas com $N_{d}=2^{k+1}$. Assim, quantidades que não sejam potências de 2 para as versões promediadas parecem descorrelacionar melhor os artefatos gerados na reconstrução do sinal, suprimindo-os. Estas observações estão de acordo com Burrus et al. (1998), que sugere que, para um sinal com $L$ amostras, $N_{d}=\log _{2} L$ versões circularmente deslocadas são suficientes para que a DWT detecte todas as características significativas do sinal.

Outros autores (Soares et al., 2008) também utilizaram a família de wavelets de Daubechies para a técnica de denoising, comparando o desempenho entre os diversos tipos de limiar, entre eles o hard, soft, semi-soft, super-soft e sigmoidal tresholding. Esses autores argumentam que as modalidades hard e sigmoidal tresholding apresentam melhor desempenho para o tratamento de sinais cuja energia se concentra nas baixas frequências, situação à qual a EMG-S se aproxima (DeLuca, 1979; Basmajian e DeLuca, 1985). A aplicação do hard tresholding foi, portanto, escolhida por sua relativa simplicidade.

Este procedimento - envolvendo a promediação a partir de deslocamentos cíclicos - pode também ser realizado com outras transformadas, como a transformada cosseno ou a de Fourier. Nestes casos, refere-se também a estas técnicas como invariantes à modulação (Coifman e Donoho, 1995).

A técnica de denoising baseada em wavelets também tem sido utilizada em outros contextos, como o reconhecimento de padrões em eletromiografia (Phinyomark et al., 2011) e, na última década, a técnica tem sido razoavelmente difundida. Por exemplo, Fopaku et al. (2001) a aplicam em sinais de EMG e ECG para a monitoração de animais de pequeno porte em experimentos de ressonância magnética.

\section{2 - INTERFERÊNCIA DA REDE ELÉTRICA}

Inevitavelmente, o sinal obtido por eletromiografia de superfície pode ser contaminado por - além dos diversos ruídos e artefatos originados na interface entre pele e eletrodo nos estágios de amplificação - interferências de fontes externas (Merletti e Parker, 2004). Apesar de relativamente imunes a vários tipos de ruído, equipamentos modernos em geral são suscetíveis a interferências da rede elétrica (Clancy et al., 2002; DeLuca et al., 2010). Desta maneira, a análise de sinais eletromiográficos de superfície pode ser 
comprometida, especialmente no caso de exercícios associados a sinais eletromiográficos de baixa amplitude (Yacoub et al., 2008).

Um método para redução de artefatos de eletroencefalograma (EEG) em imagens por ressonância magnética funcional (fMRI) é apresentado no estudo de Allen et al. (2000), em que é proposta a subtração da forma de onda correspondente ao artefato, obtida por promediação, seguida de cancelamento adaptativo de ruído aplicado aos artefatos residuais. Nesse estudo, os autores ainda concluem que é possível o estudo simultâneo de EEG e fMRI, em que a aquisição é realizada de forma combinada. No caso de sinais de obtidos por EMG-S, frequentemente as interferências periódicas - devidas ao aterramento inadequado, por exemplo - se somam a artefatos de movimento do eletrodo sobre a superfície da pele (Mewett et al., 2001; Clancy et al., 2002; DeLuca et al., 2010).

DeLuca et al. (2010) estudaram os efeitos dos artefatos de movimento sobre o sinal eletromiográfico, que distorcem as baixas frequências no espectro de potência do sinal. $\mathrm{O}$ autor recomenda, como uso geral, filtro passa-faixa de Butterworth, com frequência de corte inferior de $20 \mathrm{~Hz}$ e decréscimo de $12 \mathrm{~dB} /$ oitava em sua resposta em frequência. Mewett et al. (2001) propõem a eliminação da componente espectral onde se localiza a interferência da rede elétrica para posterior interpolação do espectro, supondo inicialmente um comportamento suave do espectro de amplitude do sinal de EMG-S. Nesse trabalho, os autores ainda comparam o método utilizando interpolação do espectro com a aplicação direta de filtros notch sobre os harmônicos onde se localiza a interferência. Concluem, em seu estudo, que tal prática (aplicação de filtros notch) deve ser evitada sempre que possível, pois parte significativa da potência do sinal de EMG-S está localizada em torno da frequência fundamental da interferência da rede de alimentação. Nesta seção, descrevese um modelo proposto (Milhomem et al., 2014c) de estimativa e subtração da interferência utilizando transformadas de wavelets discreta (DWT), como descrito a seguir.

\subsection{1 - Técnica proposta: formulação}

A técnica proposta consiste em i) estimar a senoide que contamina o sinal de EMG$\mathrm{S}$; ii) subtrair a senoide estimada do sinal de EMG-S completo; e iii) repetir o procedimento até o último harmônico desejado.

Para realizar a predição da componente senoidal, devem ser estimadas sua fase e 
sua amplitude. A fase pode ser determinada a partir da correlação cruzada entre uma senoide - com a frequência escolhida - sem atraso com um trecho inicial do sinal de EMGS - onde ainda não há contração muscular, tomando-se o argumento máximo desta correlação. Para dois sinais $x[n]$ e $y[n]$ quaisquer, sua correlação cruzada é dada pela equação a seguir:

$$
R_{x, y}[n]=\sum_{k} x^{*}[k] y[n+k]
$$

onde $x^{*}[k]$ é o complexo conjugado de $x[k]$.

Portanto, seja $e m g_{0}[n]$ a sequência que representa o trecho inicial do sinal eletromiográfico e $s_{M}[n]=\operatorname{sen}\left(M \omega_{0} n-\varphi_{M}\right)(\mathrm{M}=1,2,3, \ldots)$ a sequência representando a senoide com frequência $f=60 \mathrm{M}[\mathrm{Hz}]$ (M-ésima harmônica), com fase correspondente $\varphi_{M}$, interferindo sobre o sinal. A interferência periódica total $I_{\text {total }}[n]$ da rede elétrica sobre o sinal de EMG-S é dada por

$$
I_{\text {total }}[n]=\sum_{M} A_{M} \operatorname{sen}\left(M \omega_{0} n-\varphi_{M}\right)
$$

Assim, se $s_{M, 0}[n]=\operatorname{sen}\left(M \omega_{0} n\right)$ é a senoide com fase nula, o valor da fase $\varphi_{M}$ é determinada pelo argumento máximo da correlação entre $e m g_{0}[n]$ e $s_{M, 0}[n]$. Obtém-se, assim, uma estimativa $\overline{\varphi_{M}}$ para a fase, dada por:

$$
\overline{\varphi_{M}}=M \omega_{0} \operatorname{argmax}\left\{R_{e m g_{0}, s_{M, 0}}[n]\right\}
$$

A amplitude correspondente $A_{M}$ é estimada utilizando a DWT, da seguinte maneira:

1) Define-se uma senoide com fase determinada a partir da equação (4.4) e variância igual à do trecho inicial do sinal de EMG-S;

2) Toma-se a raiz quadrada do valor absoluto do produto, no domínio da DWT, entre a senoide criada e o trecho inicial do sinal de EMG-S, mantendo o sinal da DWT do trecho inicial do sinal de EMG-S, isto é:

$$
Y[k]=\sqrt{\left|S_{M}[k] E M G_{0}[k]\right|} \operatorname{sign}\left(E M G_{0}[k]\right),
$$

em que $S_{M}[k]$ e $E M G_{0}[k](k=0,1,2, \ldots)$ são, respectivamente, os coeficientes da 
DWT da senoide $s_{M}[n]$ e da DWT do trecho inicial $e m g_{0}[n]$, e sign(.) é a função sinal (+1 ou -1 caso o argumento seja positivo ou negativo, respectivamente).

3) Calcula-se a transformada inversa $y[n]=\mathrm{DWT}^{-1}(Y[k])$ do sinal obtido no passo anterior, e a amplitude $A_{M}$ da interferência senoidal é estimada a partir do valor RMS do sinal $y[n]$ resultante, obtendo-se uma estimativa $\overline{A_{M}}$, dada por

$$
\overline{A_{M}}=y_{R M S}=\sqrt{\frac{1}{N} \sum_{n=0}^{N-1}|y[n]|^{2}}
$$

onde $\mathrm{N}$ é a quantidade de amostras das sequências $\operatorname{emg}_{0}[n], s_{M}[n]$ e $y[n]$.

Como emg $_{0}[n]$ representa o trecho inicial do sinal de EMG-S sem contração, este consiste na soma $e m g_{0}[n]=I_{\text {total }}[n]+\eta[n]$ da interferência da rede elétrica $\left(I_{\text {total }}[n]\right)$ com a soma dos demais ruídos $(\eta[n])$ do processo de aquisição do sinal. Como estes ruídos possuem, em geral, sua potência espalhada ao longo do espectro (Basmajian e DeLuca, 1985; Clancy et al., 2002), espera-se que seus coeficientes no domínio da DWT também tenham sua potência diluída ao longo do escalograma. Assim, sejam $D W T_{I_{\text {total }}}[k] \mathrm{e}$ $D W T_{\eta}[k]$, respectivamente, os coeficientes no domínio da DWT de $I_{\text {total }}[n]$ e $\eta[n]$. Verifica-se que, nas regiões onde se concentram os coeficientes de maior energia, tem-se $\left|D W T_{I_{\text {total }}}[k]\right|^{2} \gg\left|D W T_{\eta}[k]\right|^{2}$. Portanto, espera-se que em tais regiões, a igualdade dada por

$$
\left|S_{M}[k] E M G_{0}[k]\right|=\left|S_{M}[k]\left(D W T_{I_{\text {total }}}[k]+D W T_{\eta}[k]\right)\right|,
$$

em que, nestas condições, tem-se

$$
\left|S_{M}[k] . D W T_{I_{\text {total }}}[k]\right| \gg\left|S_{M}[k] D W T_{\eta}[k]\right|,
$$

permita a aproximação

$$
\sqrt{\left|S_{M}[k] E M G_{0}[k]\right|} \cong \sqrt{\mid S_{M}[k] D W T_{I_{\text {total }}[k] \mid}}
$$

Assim, espera-se que o produto entre os coeficientes, no domínio da DWT, da 
senoide com o trecho inicial do sinal de EMG-S, forneça uma medida de similaridade entre o ruído da fase silenciosa do sinal eletromiográfico e a senoide com frequência especificada (60 Hz e harmônicos) e fase estimada.

A senoide com fase e amplitude estimadas com este procedimento é, então, subtraída do sinal de EMG-S completo. Este procedimento é realizado iterativamente, até o máximo harmônico especificado. Como critério, subtrai-se a senoide estimada caso sua potência seja igual ou superior a $1 \%$ da potência do eletromiograma.

Como a senoide estimada é subtraída do sinal completo, a técnica se limita a interferências senoidais com amplitude e fase constantes ao longo do exercício, sendo, portanto, aplicável a protocolos experimentais onde não ocorram deslocamentos do indivíduo ao longo da aquisição, não havendo variação da distância entre o eletrodo e a fonte da interferência (Mewett et al., 2001, Milhomem et al., 2014c). Em casos em que estejam previstos tais deslocamentos, o procedimento pode ser aplicado a trechos consecutivos do sinal.

Como a estimativa da interferência é feita a partir de um trecho silencioso do sinal, espera-se reduzir somente as parcelas das componentes em $60 \mathrm{~Hz}$ e seus harmônicos que se devem às interferências da rede de alimentação, diferentemente do uso de filtros notch, que anulam também as informações do sinal contidas nestas frequências.

Para a decomposição do sinal em wavelets, foi utilizada também a família Daubechies-4. Estudos prévios abordando a compressão de sinais eletromiográficos (Berger et al., 2006) sugerem que esta família de wavelets é adequada para sinais de EMG$\mathrm{S}$, no sentido de que concentra a energia do sinal em poucos coeficientes no domínio da DWT. Isto deve permitir que, no domínio da transformada, os coeficientes correspondentes ao sinal eletromiográfico puro estejam razoavelmente separados daqueles correspondentes a outros fenômenos.

Para comparação com outros métodos, a estimativa da amplitude da interferência também foi feita, alternativamente, diretamente pelo valor RMS do período silencioso do sinal de EMG-S. Por último, também foram aplicados filtros notch de Butterworth sobre o espectro, com rejeição localizada nos harmônicos da interferência, como feito no estudo de Mewett et al. (2001).

As técnicas foram implementadas em Matlab e para realizar os testes foram utilizados sinais eletromiográficos simulados com o modelo desenvolvido por Farina e Merletti (2001). Ao sinal gerado, foi adicionado ruído branco gaussiano com $10 \%$ do 
desvio padrão do sinal eletromiográfico. Para a simulação da interferência da rede elétrica, foram somadas senoides de $10 \%, 20 \%$ e $30 \%$ do desvio padrão do sinal eletromiográfico, com número de harmônicos variando entre 1 e 6 . As fases das senoides foram definidas aleatoriamente, com distribuição uniforme.

\subsection{2 - Resultados e discussão}

Na figura 3.12 mostra-se o espectro de amplitude original normalizado do sinal EMG-S simulado, após adição da interferência e os resultados obtidos com o uso da técnica proposta - utilizando wavelets; com a estimativa da amplitude da senoide realizada diretamente a partir do valor RMS do trecho inicial do sinal; e ao aplicar o filtro notch localizado nos harmônicos onde ocorre a interferência da rede de alimentação.
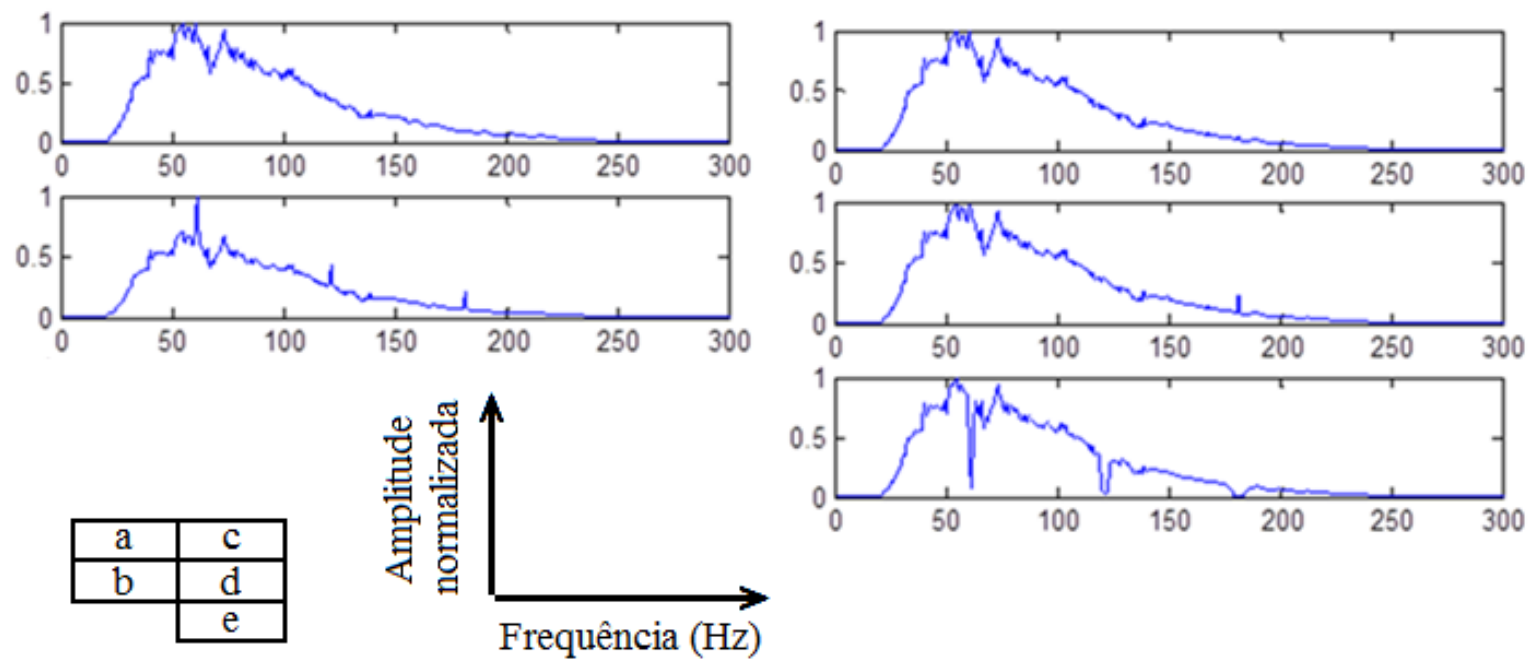

Figura 4.12. Espectro normalizado do sinal. De cima para baixo: a) EMG-S original, b) após adição da interferência, c) redução da interferência com o algoritmo proposto, d) redução com estimativa da amplitude da senoide a partir do valor RMS do trecho inicial do sinal, e e) utilizando filtros notch.

A figura 4.13 as relações sinal/ruído obtidas para as diferentes amplitudes de interferência, variando-se a quantidade de harmônicos, para os 3 métodos descritos. A relação sinal/ruído foi obtida segundo a relação

$$
S N R_{d B}=20 \log _{10}\left(\frac{\sigma_{x}}{\sigma_{x-y}}\right)
$$


em que $\sigma_{x}$ é o desvio padrão do sinal original (sinal de EMG-S simulado) e $\sigma_{x-y}$ é o desvio padrão da diferença entre sinal original e sinal obtido após aplicação da técnica.
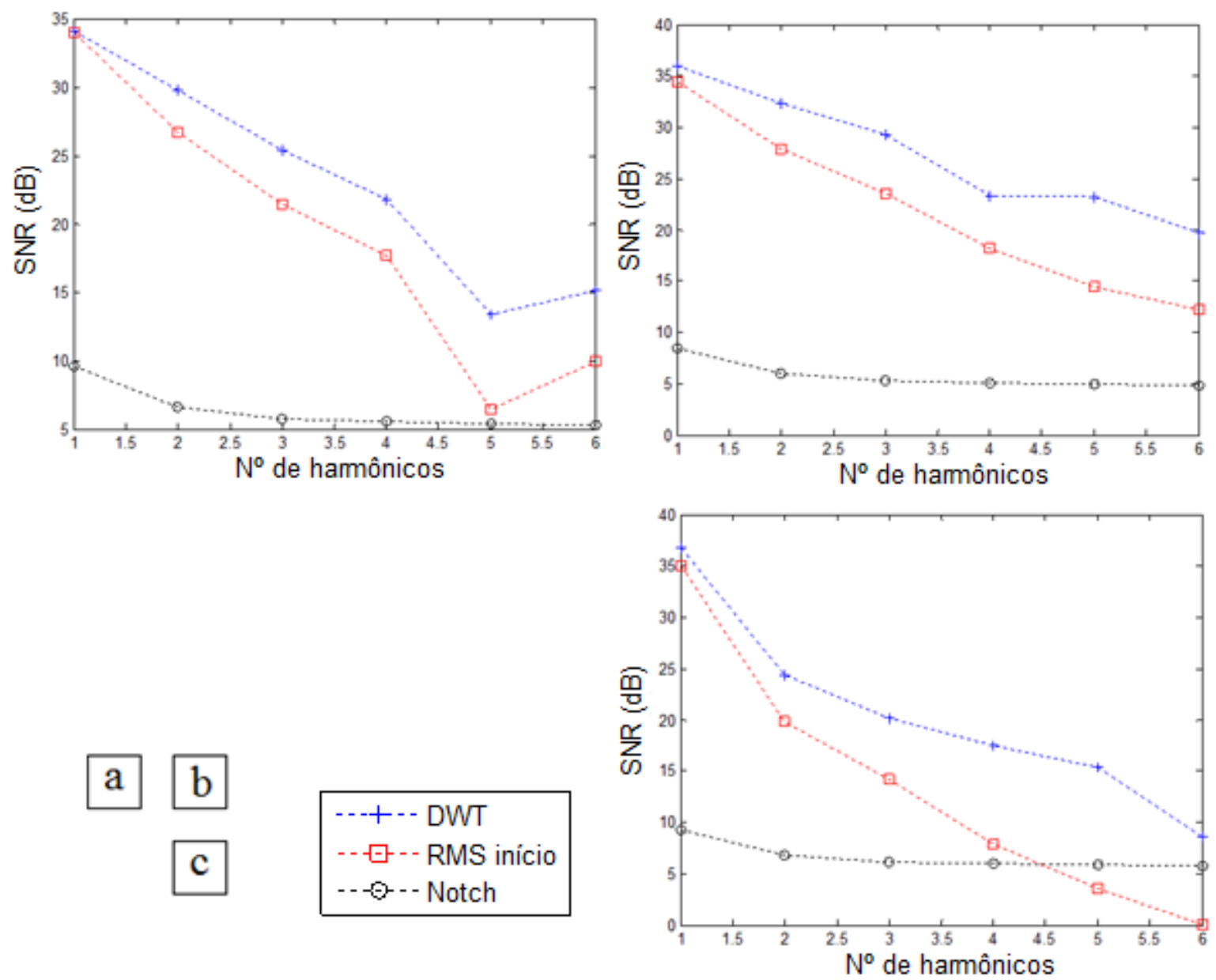

Figura 4.13: Relações sinal/ruído obtidas - com a técnica proposta (azul), utilizando o valor RMS do trecho inicial (vermelho) e filtro notch (preto) - para diferentes números de harmônicos adicionados ao sinal. Valores obtidos para simulações com interferência de amplitude igual a) $10 \%$; b) $20 \%$; e c) $30 \%$ do desvio padrão do sinal eletromiográfico.

A partir da observação destes resultados, reforça-se a recomendação de não utilizar filtros notch sobre sinais eletromiográficos de superfície (DeLuca et al., 2010), especialmente na frequência de $60 \mathrm{~Hz}$, onde se concentra parte significativa da potência do sinal. Para interferências de amplitude relativamente baixa, constata-se que pode ser preferível mantêla a utilizar tais filtros. Apesar da variedade de técnicas propostas, em geral é preferível a aquisição do sinal de EMG-S com o mínimo de artefatos possível (Basmajian e DeLuca, 1985). Com a aplicação da técnica proposta, verifica-se que o conteúdo em $60 \mathrm{~Hz}$ (e harmônicos) do sinal EMG-S não foi eliminado, reduzindo-se, predominantemente, somente parcela da potência - localizada nestas frequências - relativa à interferência da 
rede elétrica de alimentação. Ainda, para a estimativa da amplitude da interferência a partir de um trecho de $N$ pontos do sinal de EMG-S, a técnica envolve o cálculo da DWT deste trecho, com complexidade $\mathcal{O}(N)$, o produto ponto a ponto pela senoide de fase previamente estimada e a transformada inversa, obtendo-se, ainda complexidade $\mathcal{O}(N)$ não envolvendo, portanto, a promediação de várias versões após o cálculo da DWT e da $\mathrm{DWT}^{-1}$.

\section{3 - CONSIDERAÇÕES FINAIS}

Neste capítulo foi apresentado o conjunto de técnicas proposto para a redução dos principais ruídos e artefatos possivelmente presentes nos sinais de EMG-S. A técnica proposta, utilizando a DWT, permite o uso de algoritmos rápidos existentes para a decomposição do sinal ruidoso e estimação da interferência - em contraste com algoritmos de mínimos quadrados em geral, possibilitando seu tratamento com custo computacional relativamente baixo.

Com o conjunto de técnicas proposto, pode-se evitar o uso de filtros notch em frequências nas quais a fadiga muscular se manifesta, reduzindo a susceptibilidade dos indicadores espectrais às interferências de fontes externas. No próximo capítulo será apresentada a fundamentação dos indicadores de fadiga utilizados neste trabalho. 


\section{5 - TÉCNICAS PARA AVALIAÇÃO DA FADIGA}

Neste capítulo, serão descritas e discutidas as técnicas para avaliação da fadiga muscular utilizadas neste trabalho; as clássicas, as principais propostas na literatura nas últimas décadas e as propostas nesta tese.

\section{1 - CONSIDERAÇÕES INICIAIS}

Para avaliação da fadiga muscular, várias técnicas de processamento do sinal de EMG-S têm sido utilizadas. As técnicas mais comuns são baseadas em variações de parâmetros do domínio do tempo ou da frequência e distribuições tempo-frequência (Basmajian e DeLuca, 1985; DeLuca, 1979; DeLuca, 1984; Bonato et al., 1996; Masuda et al., 1999; Merletti et al., 1999; Merletti e Parker, 2004). Entre os parâmetros tradicionais que podem ser encontrados na literatura, estão: raiz da média quadrática (RMS), valor retificado médio (ARV), frequência de potência média (MDF), frequência de potência mediana (MNF), frequência instantânea (IF) e velocidade de condução (CV) (Sakurai et al., 2010; Georgakis et al., 2003; Kiryu et al., 1995; Gamet et al., 1993; Jansen et al., 1997; Moritani et al., 1986; Christensen et al., 1995; Kiryu et al., 1998; Maïsettia et al., 2002; Sbriccoli et al., 2003; Farina et al., 2004; Ollivier et al., 2005; Hedayatpour et al., 2008; Shaw e Huang, 2010; Lowery et al., 2000; Zaman et al., 2011; Roman-Liu e Konarska, 2009; Mesin et al., 2009; Melchiorri e Rainoldi, 2011). Outra estimativa é proposta por Lowery et al. (2002), a partir da compressão do espectro de amplitude acumulado entre os $60^{\circ}$ e o $90^{\circ}$ percentis - calculando-se a média dos deslocamentos de todas as frequências percentis (PF) nesta faixa. Korosec (2000) propõe o uso de um modelo baseado em média móvel autorregressiva (Arma) para a caracterização suave do espectro da EMG-S ao longo do tempo, na ocorrência de variações lentas, como as observadas durante a fadiga muscular. Zaman et al. (2005) descrevem uma proposta similar, com um modelo autorregressivo variante no tempo (TVAR) em cascata com estimação de frequência instantânea, para a análise de sinais de EMG-S de contrações isométricas. Segundo o autor, este parâmetro mostra-se adequado para longos intervalos de tempo em sinais não-estacionários. Jung-Yong et al. (2005) também propõem um modelo autorregressivo, comparando sua reprodutibilidade e sensibilidade à fadiga com 
indicadores clássicos, além da taxa de cruzamento de zeros (ZCR). Clancy et al. (2005) comparam vários indicadores espectrais em protocolo dinâmico com força variável, concluindo que estimadores baseados na STFT e em modelos autorregressivos produzem resultados semelhantes. Dimitrova et al. (2009) definem um índice de fadiga a partir do momento normalizado do espectro do sinal de EMG, com o momento calculado em diferentes ordens, afirmando que este índice definido em seu estudo é mais sensível para a detecção de fadiga muscular durante contrações isométricas voluntárias, em comparação com os índices clássicos MNF e MDF. Nesse estudo ainda se afirma que uma baixa sensibilidade dos índices de fadiga pode ocorrer devido à fixação do eletrodo na pele em posição longitudinal.

Thongpanja et al. (2012) afirmam que uma das desvantagens dos parâmetros MNF e MDF é a sua relação não linear com a carga utilizada na contração, propondo versões modificadas destes parâmetros, definindo TD-MDF e TD-MNF ("Time-Dependent MDF" e "Time-Dependent MNF"), obtendo-se uma relação mais direta com a carga. Para sinais de EMG-S de contrações dinâmicas, técnicas utilizando diferentes distribuições tempofrequência foram propostas, com métodos baseados em classe de Cohen, especialmente distribuições de Choi-Williams, Wigner-Ville, Born-Jordan (Bonato et al., 2001; Karlsson et al., 2000). Davies e Reisman (1994), por exemplo, aplicaram a STFT e as distribuições de Wigner-Ville e de Choi-Williams para visualização do espectro de EMG-S de contração isométrica. Avaliaram que a STFT permitiu uma eficiente caracterização da compressão do espectro, porém, os requisitos de suporte no domínio do tempo e da frequência definidos em seu trabalho não foram satisfeitos. Como distribuições de Wigner-Ville possuem, intrinsecamente, termos cruzados, desaconselham seu uso como representação tempofrequência do eletromiograma na ocorrência de fadiga, em virtude das nãoestacionariedades que esta lhe impõe. Sugerem, por fim, que a distribuição de ChoiWilliams é mais sensível às características locais - e.g. as impulsivas, que geram espalhamentos instantâneos no espectro - e à gradual compressão do espectro, em conformidade com a proposta de Choi e Williams (1989).

Autores têm proposto o uso de wavelets para avaliação de fadiga, com a transformada de wavelets contínua (CWT), pelo cálculo da frequência mediana - ou escala mediana - no escalograma, do valor RMS de diferentes escalas na representação tempoescala e pelo índice de amplitude máxima no escalograma (Ranniger e Akin, 1997; Sparto et al., 2000; Cao et al., 2007; Andrade et al., 2008; Coorevits et al., 2008; Yochum et al., 
2012). Ismail e Asfour (1998), por exemplo, utilizaram a CWT para identificar os padrões de recrutamento das fibras lentas e rápidas para suprir as demandas em protocolo isométrico (músculos tibial anterior, gastrocnêmio, quadríceps e isquiotibiais) em diferentes posturas. Cao et al. (2007), além de utilizar a CWT, propuseram a análise de ciclo-estacionariedade como índice de fadiga para contrações dinâmicas, observando que o valor deste parâmetro tende a crescer com a ocorrência da fadiga muscular. Moshou et al. (2005) utilizam wavelets e redes neurais para a monitoração da fadiga. Afirmam que os coeficientes de aproximação mostram-se correlacionados com a fadiga muscular. Propõem o uso de mapas auto-organizáveis para avaliar se houve recuperação temporária dos músculos. Andrade et al. (2008) sugeriram ainda a aplicação do espectro de Hilbert para a análise de sinais de EMG-S. Cooverits et al. (2008) fazem uma análise comparativa da transformada de Fourier de tempo curto (STFT) com a CWT para o sinal de EMG na análise de fadiga localizada de contrações isométricas por extensão da coluna. Os autores calcularam a frequência de potência mediana com a STFT e a frequência de potência mediana instantânea com a CWT, e concluíram que, sob suas condições de análise descritas, as técnicas fornecem informações similares. Yochum et al. (2012) definiram um índice de fadiga a partir do máximo local sobre os coeficientes do escalograma obtido com a CWT, aplicando a técnica a sinais de EMG-S de eletroestimulações e sinais de EMG-S sintéticos, fazendo uma análise comparativa da robustez da técnica à ruídos e truncamentos do sinal com índices clássicos, como MDF e RMS, concluindo que o uso de wavelets apresentou a maior robustez a estes fatores. Em comum, todas estas técnicas citadas utilizando wavelets são aplicadas a sinais de contrações isométricas e, em geral, quando aplicadas a sinais de contrações dinâmicas, são calculadas sobre segmentos concatenados do sinal eletromiográfico, de forma que se aproxime da situação isométrica. Ainda, em todos estes estudos, utiliza-se a CWT, realizando-se procedimentos semelhantes àqueles envolvendo a análise de Fourier para a estimação dos parâmetros espectrais.

Knaflitz e Bonato (1999) afirmam que, em sinais de EMG obtidos de contrações cíclicas, há duas abordagens aceitáveis para monitorar a fadiga muscular ao longo do experimento:

i) Segmentar trechos - de cada ciclo - correspondentes à mesma fase da contração, de forma que as propriedades biomecânicas, localização do eletrodo sobre o músculo e comprimento das fibras sejam aproximadamente as mesmas. Estes trechos são então concatenados, de maneira que o sinal 
resultante seja similar ao obtido de uma contração isométrica; e assim este é tratado. Desta maneira, a técnica para a avaliação de fadiga é aplicada sobre segmentos consecutivos - com ou sem sobreposição - de comprimento tal que apresentem comportamento estacionário no sentido amplo. Desta forma, apesar de ser o sinal originalmente dinâmico, tal abordagem ainda é, essencialmente, isométrica. Nesta tese, referir-se-á a este procedimento como abordagem isométrica. A figura 4.1 a seguir ilustra este processo:

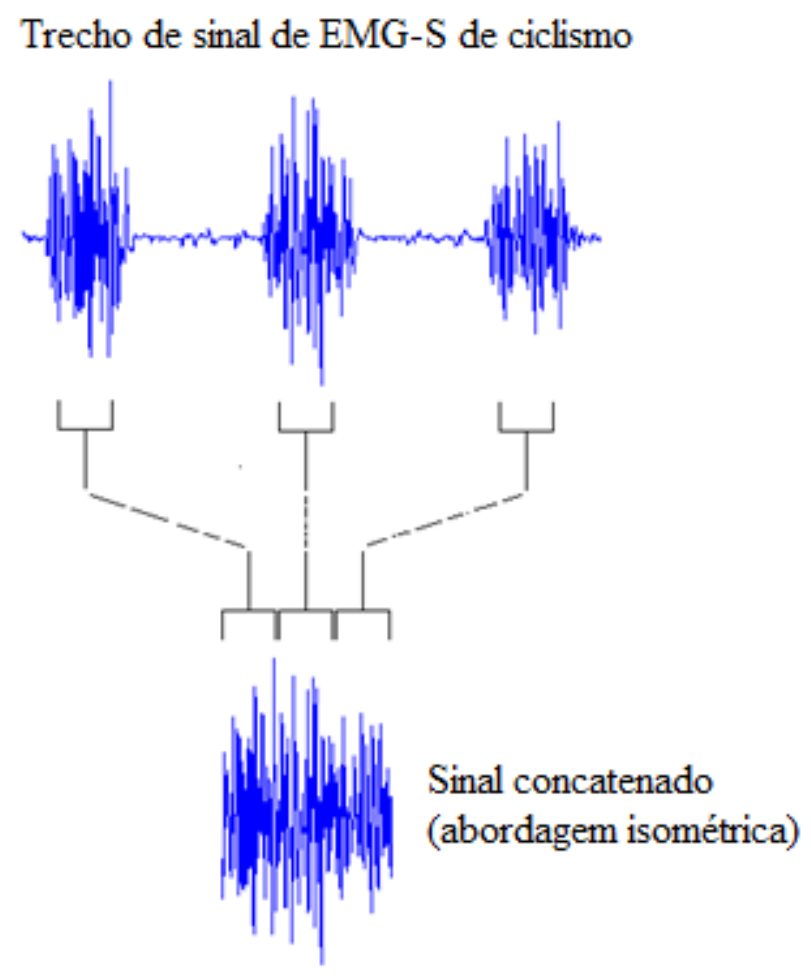

Figura 5.1: Concatenação de trechos de bulhas consecutivas para abordagem isométrica.

ii) Aplicação da técnica sobre cada ciclo separadamente, assumindo a cicloestacionariedade ou quasi-cicloestacionariedade do processo. De fato, mesmo em alguns processos que não podem ser assim considerados, argumenta-se que este procedimento pode ser utilizado, como em protocolos experimentais que envolvam a repetição de um mesmo movimento ou em que a identificação das fases de contração pode ser feita de forma relativamente precisa (Knaflitz e Bonato, 1999). Assim, tal procedimento será identificado nesta tese como abordagem dinâmica.

Por um lado, a abordagem isométrica permite flexibilidade na definição das janelas 
para cálculo dos indicadores, contando-se com o comportamento aproximadamente estacionário já observado para contrações isométricas em trechos de duração próxima a 1 segundo, conforme discutem Bonato et al. (2001). Por outro lado, entre os fatores já considerados para a abordagem dinâmica, esta abordagem permite obter indicadores parciais de fadiga correspondentes a cada ciclo de contração. Assim, os ciclos de contração definem, naturalmente, as etapas de interesse para o cálculo dos indicadores, ao contrário de protocolos isométricos, em que, a princípio, não há fases pré-determinadas no sinal de EMG. Para os sinais de ciclismo, possibilita-se também reduzir os artefatos de oscilação na frequência, ocorridos quando se concatenam segmentos distintos inicialmente separados no domínio do tempo, devido a variações abruptas entre amostra final de um trecho e amostra inicial do próximo. A figura 5.2 a seguir ilustra um exemplo desta situação, para o caso da concatenação de trechos de ciclos do sinal de EMG-S obtidos durante contrações cíclicas em cicloergômetro.

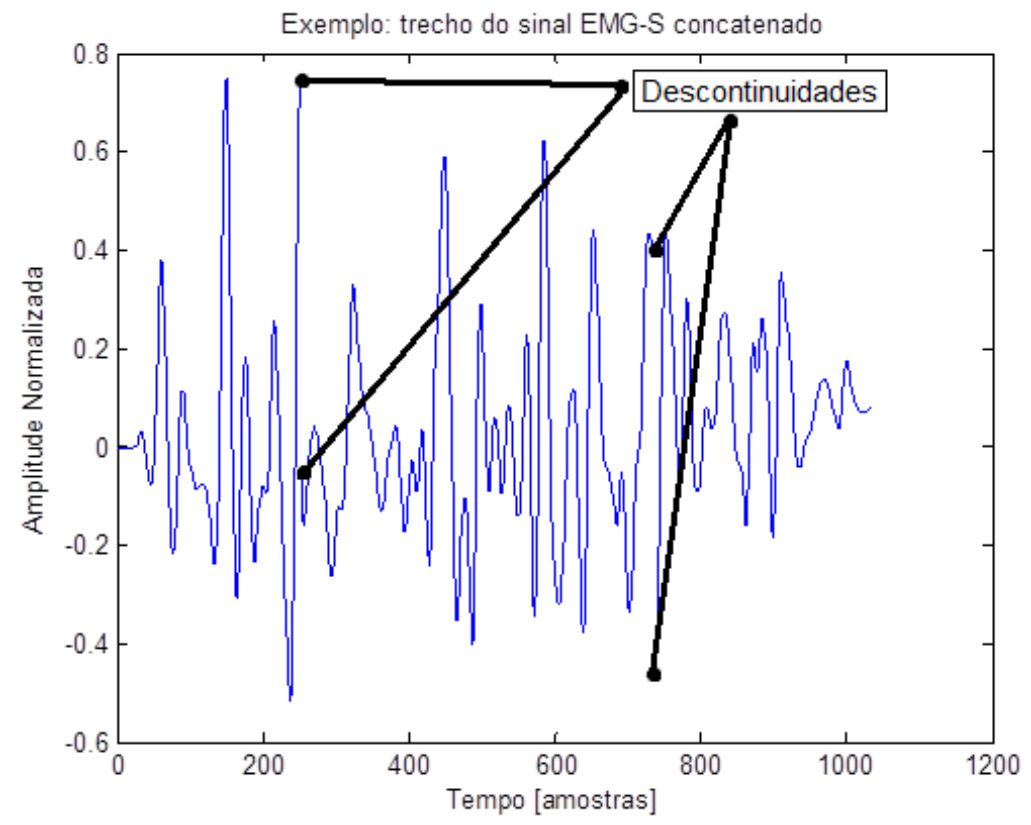

Figura 5.2: Variações abruptas, num trecho do sinal concatenado, resultantes da concatenação de segmentos de bulhas distintas do sinal EMG-S. As descontinuidades ocorrem entre os (dois) pontos de concatenação destacados.

Estas descontinuidades no domínio do tempo podem gerar espalhamento no espectro de amplitude do trecho selecionado para cálculo de indicadores de fadiga, possivelmente influenciando os indicadores espectrais. Tais efeitos podem ser especialmente problemáticos em casos de concatenação de trechos muito curtos. Neste trabalho serão utilizadas ambas as abordagens, isométrica e dinâmica, para os protocolos envolvendo 
contrações cíclicas em atividade de ciclismo.

A seguir, serão descritas as ferramentas clássicas e as propostas neste trabalho para a observação da fadiga muscular. Após a apresentação destes indicadores de fadiga, serão definidas métricas para avaliar sua dispersão, um dos fatores utilizados para estimar a reprodutibilidade e previsibilidade da técnica. Em geral, indicadores menos dispersos tendem a se apresentar melhor relacionados com o fenômeno da fadiga (Lo Conte e Merletti, 1996; Rainoldi et al., 1999; Arnall et al., 2002; Zaman et al., 2011).

\section{2 - TÉCNICAS CLÁSSICAS}

Dentre os indicadores clássicos, tradicionalmente utilizados na monitoração da fadiga a partir do eletromiograma, foram implementados neste trabalho, no domínio do tempo, o valor RMS e, no domínio da frequência, os valores de MDF e MNF. Neste caso, são utilizadas suas versões em tempo discreto, apresentadas a seguir.

Dada uma sequência $\boldsymbol{x}=\{x[n]\}_{n=1}^{N}$ de $N$ amostras, seu valor RMS é dado por

$$
x_{R M S}=\sqrt{\frac{1}{N} \sum_{n=1}^{N}|x[n]|^{2}} .
$$

Quando calculado sobre trechos de sinais EMG-S coletados durante contrações isométricas prolongadas, ou em contrações cíclicas com indução de fadiga, tende a apresentar comportamento crescente (DeLuca, 1984). Ainda, para esta sequência $\boldsymbol{x}$, o índice $k_{M N F}$ correspondente à sua MNF é dada por

$$
k_{M N F}=\sum_{k=0}^{M} k|X[k]|^{2} / \sum_{k=0}^{M}|X[k]|^{2},
$$

onde $X[k]$ é a $k$-ésima componente da transformada de Fourier discreta (DFT) de $x[n]$ de $N$ amostras, $M$ é o índice correspondente à metade da frequência de amostragem $(M=$ $N / 2-1)$. Ainda com as mesmas notações, o índice correspondente à MDF é definido pelo valor $k_{M D F}$ tal que 


$$
\sum_{k=0}^{k_{M D F}}|X[k]|^{2}=\sum_{k=k_{M D F}}^{M}|X[k]|^{2}=\frac{1}{2} \sum_{k=0}^{M}|X[k]|^{2} .
$$

Assim, $k_{M D F}$ é o índice correspondente ao harmônico que separa o espectro em dois segmentos de energias iguais. Frequentemente o valor que satisfaz esta relação pode não resultar num inteiro, tomando-se, neste caso o inteiro mais próximo. Tendo-se conhecimento da taxa de amostragem do sinal analógico $x(t)$ que resulta na sequência $\boldsymbol{x}=\{x[n]\}_{n=1}^{N}$, obtêm-se os valores de MDF e MNF em Hertz. Quando calculados sobre trechos de sinais EMG-S coletados durante contrações isométricas prolongadas, ou em contrações cíclicas com indução de fadiga, tendem a apresentar comportamento semelhante e decrescente (DeLuca, 1984; Vollestad, 1997). Para aplicações envolvendo a monitoração da fadiga a partir da eletromiografia de superfície, em geral, há preferência pela MDF, por apresentar menor sensibilidade aos ruídos que contaminam o sinal, além de maior correlação com o processo da fadiga (Stulen e DeLuca, 1981; Clancy et al., 2004). Contudo, a MNF mostra-se um estimador espectral de variância inferior à da MDF (Stulen e DeLuca, 1982; Clancy et al., 2004).

\section{3 - TÉCNICAS PROPOSTAS}

Apresentam-se nesta seção as técnicas propostas neste trabalho como parâmetros indicadores de fadiga a partir da EMG-S. São, ao todo, seis: quatro utilizando a transformada de wavelets discreta (DWT), uma utilizando a transformada de Fourier e uma no domínio do tempo, sendo apresentadas nesta ordem citada (Milhomem et al., 2014d; Milhomem et al., 2014e). Os indicadores utilizando wavelets são o deslocamento espectral $\left(K_{D E W}\right)$, a compressão espectral $\left(K_{C E W}\right)$, e suas versões adaptativas: o deslocamento espectral adaptativo $\left(K_{D E A}\right)$ e a compressão espectral adaptativa $\left(K_{C E A}\right)$. Os dois últimos são calculados simultaneamente ao cálculo da DWT, adaptando-se a decomposição do sinal no banco de filtros de acordo com a forma local do espectro de amplitude do eletromiograma. O indicador no domínio da frequência proposto é o estreitamento espectral $\left(s_{E}\right)$ do eletromiograma. O indicador no domínio do tempo proposto é a distância entre picos e envoltória $\left(d_{P E}\right)$, definida especialmente para o caso dinâmico. Os 
indicadores de fadiga propostos neste trabalho são avaliados e discutidos em conjunto com os parâmetros tradicionais RMS, MNF e MDF. Os parâmetros espectrais propostos que abordam compressão ou estreitamento do espectro visam obter uma descrição menos dispersa do processo de fadiga muscular ao longo do tempo, assim como as versões adaptativas daqueles baseados em wavelets, se comparadas às versões não adaptativas. Ainda, os indicadores utilizando wavelets aproveitam-se do relativamente baixo custo computacional da DWT se comparada a métodos baseados em análise de Fourier, além de evitar as redundâncias obtidas com sua versão contínua - CWT - no procedimento de decomposição do sinal (Burrus et al., 1998). Note-se, além disso, que a localização típica do conteúdo espectral significativo de sinais eletromiográficos sugere que abordagens mais eficientes para a avaliação da fadiga possam ser obtidas a partir de métodos baseados em resolução variável no domínio tempo-frequência, como obtido com a DWT.

Assim como os indicadores tradicionais, os indicadores propostos são calculados sobre segmentos sucessivos do sinal de EMG-S, obtendo-se uma sequência descritora de fadiga $\boldsymbol{f}=\{f[i]\}_{i=1}^{N_{\text {ciclos }}}$ para uma quantidade $N_{\text {ciclos }}$ de contrações realizadas (ou segmentos consecutivos considerados).

\subsection{1 - Deslocamento Espectral (Wavelets)}

A seguir será apresentada a formulação matemática para o cálculo dos descritores espectrais utilizando DWT. Os fundamentos discutidos nesta subseção serão os mesmos para todos os descritores que utilizam wavelets propostos neste trabalho.

Sejam $c[k]$ e $d_{j}[k]$ os coeficientes de aproximação e de detalhes, respectivamente, da DWT de um segmento (ciclo) $x(t)$ do sinal EMG-S. Isto é, $c[k]$ é o $k$-ésimo coeficiente de aproximação, correspondente à função de escala deslocada $\varphi_{k}(t)=\varphi(t-k)$ e $d_{j}[k]$ o $k$-ésimo coeficiente dos detalhes na escala $j$, correspondente à wavelet $\psi_{j, k}(t)$. Assume-se que $x(t) \in \mathbb{L}^{2}(\mathbb{R})$, isto é:

$$
\int|x(t)|^{2} d t<\infty
$$

Assim, $x(t)$ pode ser decomposto na forma: 


$$
x(t)=\sum_{k} c[k] \varphi_{k}(t)+\sum_{j} \sum_{k} d_{j}[k] \psi_{j, k}(t) .
$$

Como $x(t)$ representa um ciclo de contração, então $x(t)$ possuirá suporte compacto, de maneira que $c[k]$ e $d_{j}[k]$ serão não nulos somente para um conjunto finito de valores de $k$. Além disso, como $x(t) \in \mathbb{L}^{2}(\mathbb{R})$, o nível inicial de aproximação (menor nível de detalhes de $x(t)$ ) pode ser escolhido arbitrariamente (Burrus et al., 1998). Para uma representação inicial numa escala de aproximação $j_{0}$, as funções de escala para a aproximação neste nível são $\varphi_{j_{0} k}(t)=\varphi_{j_{0}}(t-k)=\varphi\left(2^{j_{0}} t-k\right)$. Portanto, se $j_{0}$ é o nível inicial de decomposição de $x(t)$ escolhido, tem-se

$$
x(t)=\sum_{k=-\infty}^{\infty} c[k] \varphi_{j_{0}, k}(t)+\sum_{j=j_{0}}^{\infty} \sum_{k=-\infty}^{\infty} d_{j}[k] \psi_{j, k}(t) .
$$

Outra forma de se representar $x(t)$ é como a soma

$$
x(t)=x_{0}(t)+\sum_{j=j_{0}}^{\infty} x_{j}(t)
$$

onde

$$
x_{0}(t)=\sum_{k=-\infty}^{\infty} c[k] \varphi_{j_{0}, k}(t)
$$

é a representação aproximada de $x(t)$ reconstruída somente com as funções de escala, e

$$
x_{j}(t)=\sum_{k=-\infty}^{\infty} d_{j}[k] \psi_{j, k}(t)
$$

é a representação dos detalhes de $x(t)$ no j-ésimo nível de decomposição. Ou seja, $x_{j}(t)$ é uma versão reconstruída de $x(t)$ composta somente com wavelets $\psi_{j, k}(t)$ na escala $j$. Então, se $x(t)$ é o segmento do sinal sob análise, define-se como energia relativa de $x(t)$ 
na escala $j$ o valor $E R_{j}$ dado pela razão

$$
E R_{j}=\frac{\int\left|x_{j}(t)\right|^{2} d t}{\int|x(t)|^{2} d t}=\frac{E_{x_{j}}}{E_{x}}
$$

em que $E_{x_{j}}=\int\left|x_{j}(t)\right|^{2} d t . E R_{j}$ representa a contribuição do $j$-ésimo nível de detalhes para a energia de $x(t)$. Tem-se da definição de $x_{j}(t)$ que $0 \leq E R_{j} \leq 1$. Além disso, se $x(t)$ é decomposta utilizando-se uma família ortogonal de wavelets, tem-se uma partição da energia de $x(t)$ nas representações $x_{j}(t)$ dos detalhes de $x(t)$, de forma que

$$
E_{x}=\sum_{j} E_{x_{j}}
$$

(incluindo-se na soma a parcela $E_{f_{0}}$ ). Em especial, se $x(t)$ é decomposta utilizando-se uma família ortonormal de wavelets, pode-se calcular $E R_{j}$ de maneira eficiente, pois, segue da ortonormalidade que

$$
\int\left|x_{j}(t)\right|^{2} d t=\int\left|\sum_{k=-\infty}^{\infty} d_{j}[k] \psi_{j, k}(t)\right|^{2} d t=\sum_{k=-\infty}^{\infty}\left|d_{j}[k]\right|^{2} \int\left|\psi_{j, k}(t)\right|^{2} d t=\sum_{k=-\infty}^{\infty}\left|d_{j}[k]\right|^{2},
$$

tendo-se, portanto

$$
E R_{j}=\frac{1}{E_{f}} \sum_{k=-\infty}^{\infty}\left|d_{j}[k]\right|^{2}
$$

Obtém-se, portanto, uma relação de Parseval, com uma partição da energia de $x(t)$ na escala $j$ a partir dos coeficientes $d_{j}[k]$. Pela mesma razão, segue que

$$
E R_{0}=\frac{1}{E_{f}} \sum_{k=-\infty}^{\infty}|c[k]|^{2}
$$


Note-se que, como a convergência de $E_{f}$ segue diretamente de $x(t) \in \mathbb{L}^{2}(\mathbb{R})$, as energias relativas $E R_{0}$ e $E R_{j}$ serão, em geral, não nulas.

Definem-se como coeficientes de escala um conjunto de valores $\alpha_{j}(j=0,1,2, \ldots)$ de forma que $\left\{\alpha_{j}\right\}_{j}$ seja uma sequência satisfazendo os seguintes requisitos:

i. $\quad\left\{\alpha_{j}\right\}_{j}$ é uma sequência decrescente;

ii. $\quad \alpha_{j}>0 \quad \forall j$;

iii. $\quad \sum \alpha_{j}<\infty$

Tais requisitos serão justificados mais adiante. (Note-se que (ii) e (iii) associados implicam em (i)). Define-se como coeficiente de escala normalizado o coeficiente $\beta_{j}$ dado por

$$
\beta_{j}=\frac{\alpha_{j}}{\sum_{l} \alpha_{l}}
$$

Assim, a localização espectral $\left(L_{E}\right)$ do trecho $x(t)$ do sinal eletromiográfico é definida como o valor dado pela soma

$$
L_{E}=\sum_{j} \beta_{j} E R_{j}
$$

das energias relativas $E R_{j}$ da escala $j$ ponderadas por $\beta_{j}$. Os requisitos (ii) e (iii), em conjunto, implicam que também $\beta_{j} \neq 0 \forall j$. Com isso, não se perdem informações do conteúdo de energia em quaisquer níveis da decomposição de $x(t)$. O requisito (iii) garante, ainda, que $\left\{\beta_{j}\right\}_{j}$ será uma sequência bem definida, pois em conjunto com (i) e (ii) garantem que a soma $\sum \alpha_{j}$ é absolutamente convergente, sendo, necessariamente, $\sum \beta_{j}$ também absolutamente convergente. Pela definição de $E R_{j}$ e pelos requisitos sobre $\beta_{j}$, espera-se que, com pesos $\beta_{j}$ mais baixos atribuídos aos níveis de detalhes $j$ mais altos, o valor de $L_{E}$ indique uma proximidade do espectro do sinal em relação às baixas frequências, de forma a obter-se uma medida de localização do espectro central deste sinal. A figura 5.3 ilustra a distribuição dos coeficientes $\beta_{j}$ ao longo do espectro normalizado de um sinal com DWT calculada em 3 estágios: 


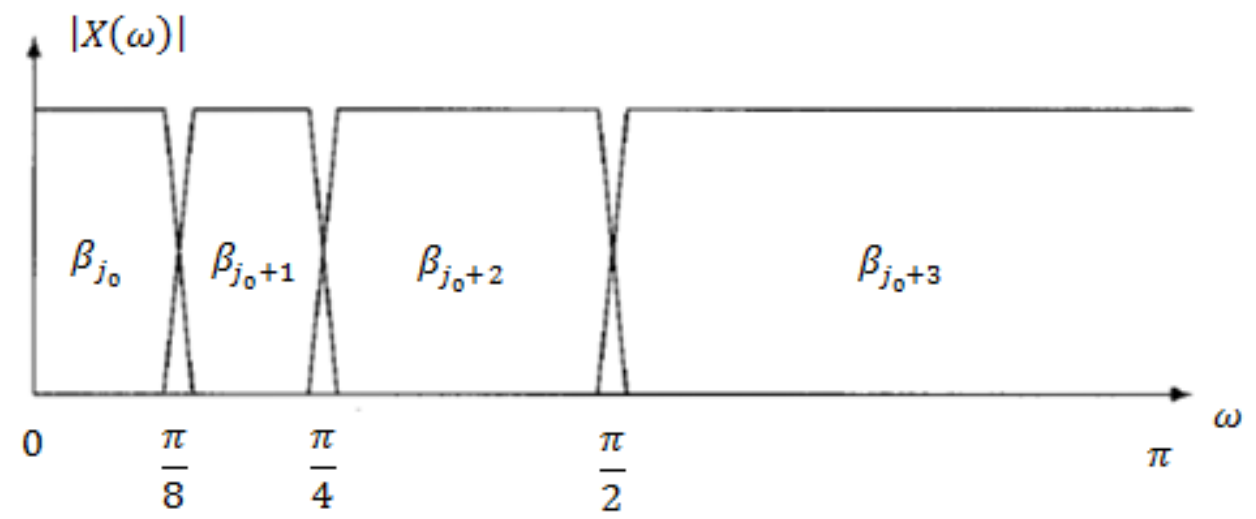

Figura 5.3: Distribuição dos coeficientes $\beta_{j}$ ao longo do espectro. Exemplo de um sinal decomposto pela DWT em 3 etapas.

Para uma escala arbitrária $J$ de decomposição, pode-se definir a soma parcial, a partir da escala $J$, dada por

$$
L_{E_{J}}=\sum_{j=j_{0}}^{J} \beta_{j} E R_{j}
$$

obtendo-se uma sequência $\left\{L_{E_{J}}\right\}_{J \geq j_{0}}$. Destas definições, segue que $L_{E}=\beta_{0} E R_{0}+L_{E_{\infty}}$. Como sinais EMG-S são limitados em frequência, assumindo-se que $x(t) \in \mathbb{L}^{2}(\mathbb{R})$, então

$$
\lim _{j \rightarrow \infty} d_{j}[k]=0 \quad \forall k,
$$

ou seja, coeficientes $d_{j}[k]$ devem se anular para valores de $j$ suficientemente altos, e, necessariamente, $E R_{j} \rightarrow 0$ se $j \rightarrow \infty$, de modo que em geral $L_{E_{\infty}}$ convirja. Para sinais amostrados, o nível máximo de decomposição será determinado pela taxa de amostragem do sinal. Será definido como coeficiente de deslocamento espectral - wavelets $\left(K_{D E W}\right)$ num trecho $x(t)$ qualquer do sinal de EMG o valor de $L_{E}$ calculado neste trecho dividido pelo valor de $L_{E}$ calculado num trecho inicial do sinal eletromiográfico. Assim, indica-se um deslocamento relativo do espectro do sinal de EMG-S em relação ao início do experimento. Espera-se que, em geral, valores mais altos de $K_{D E W}$ representem maior rapidez e intensidade no processo de fadiga muscular localizada, evidenciando-se as nãoestacionariedades lentas do fenômeno. 
Para o caso discreto, os coeficientes $c_{j}[k]$ na escala inicial $j=j_{0}$ podem ser aproximados pelas próprias amostras do sinal $x(k T)$. Isto ocorre porque, para taxas de amostragem acima da de Nyquist (Burrus et al., 1998), e sob algumas condições sobre as funções de escala $\varphi_{j, k}(t)$, tem-se que $c_{j}[k] \rightarrow x(k T)=x[k]$ (Daubechies, 1988; Graps, 1995; Mallat, 2009). As famílias de wavelets mais comumente utilizadas, em geral, satisfazem este critério. Para valores de escala arbitrariamente altos, a duração da função de escala $\varphi_{j, k}(t)$ é arbitrariamente pequena e sua amplitude é arbitrariamente alta. Isto é:

$$
\lim _{j \rightarrow \infty} \varphi_{j, k}(t)=\lim _{j \rightarrow \infty} 2^{j} / 2 \varphi\left(2^{j} t-k\right)=\delta(t)
$$

Ou seja, para taxas arbitrariamente altas, $\varphi_{j, k}(t) \rightarrow \delta(t)$ e a amostragem se aproxima da ideal, obtida pelo produto de um trem de impulsos $\sum_{k} \delta(t-k T)$ pelo sinal $x(t)$ em tempo contínuo (Daubechies, 1989; Daubechies, 1990). Assim, para escalas $j_{0}$ suficientemente altas

$$
x_{j_{0}}(t)=\sum_{k=-\infty}^{\infty} c[k] \varphi_{j_{0}, k}(t)=\sum_{k=-\infty}^{\infty} x(k T) \varphi_{j_{0}, k}(t)
$$

Para isto, é suficiente que $T<\frac{1}{2 f_{\max }}$, onde $f_{\max }$ é a máxima frequência, em Hertz, contida no sinal $x(t)$.

Sob o ponto de vista de tempo discreto, a localização espectral é calculada simultaneamente à decomposição do sinal no banco de filtros da DWT, de acordo com o algoritmo de Mallat. De acordo seu algoritmo para o cálculo da DWT, as funções de escala, em níveis subsequentes, apresentam a relação recursiva, a partir dos coeficientes de $h_{0}[k]$ (Mallat, 2009):

$$
\varphi\left(2^{j} t-k\right)=\sum_{m} h_{0}[m-2 k] \sqrt{2} \varphi\left(2^{2 j+1} t-m\right)
$$

Tal relação pode ser obtida a partir da condição 


$$
\varphi(t)=\sum_{n} h_{0}[n] \sqrt{2} \varphi(2 t-n)
$$

utilizada para a definição de funções de escala $\varphi(t)$ na escala $j$ a partir de versões comprimidas e deslocadas $\varphi(2 t-n)$ na escala $j+1$. O fator $\sqrt{2}$ garante que o espaço de funções de escala seja ortonormal, e não somente ortogonal. Wavelets $\psi(t)$ apresentam a relação com as funções de escala, a partir dos coeficientes de $h_{1}[n]$, dada por

$$
\psi(t)=\sum_{n} h_{1}[n] \sqrt{2} \varphi(2 t-n)
$$

Da mesma maneira, tem-se

$$
\psi\left(2^{j} t-k\right)=\sum_{m} h_{1}[m-2 k] \sqrt{2} \varphi\left(2^{2 j+1} t-m\right) .
$$

Como, para bases ortonormais tem-se

$$
c_{j}[k]=\left\langle x(t), \varphi_{j, k}(t)\right\rangle
$$

$\mathrm{e}$

$$
d_{j}[k]=\left\langle x(t), \psi_{j, k}(t)\right\rangle,
$$

então

$$
c_{j}[k]=\sum_{m} h_{0}[m-2 k] c_{j+1}[m]
$$

e

$$
d_{j}[k]=\sum_{m} h_{1}[m-2 k] c_{j+1}[m]
$$

Assim, ambos os coeficientes $c_{j}[k]$ e $d_{j}[k]$ podem ser obtidos a partir de $c_{j+1}[k]$, coeficientes da escala superior. Tais operações para obtenção de $c_{j}[k]$ e $d_{j}[k]$ podem ser vistas como a convolução de $c_{j+1}[k]$ com $h_{0}[-m]$ (e, respectivamente, $h_{1}[-m]$ ), seguida de subamostragem por um fator de 2, podendo ser implementadas por um banco de filtros 
de resposta ao impulso finita (FIR). Assim, o cálculo da localização espectral é feito simultaneamente ao cálculo da DWT, como ilustrado na figura 5.4:

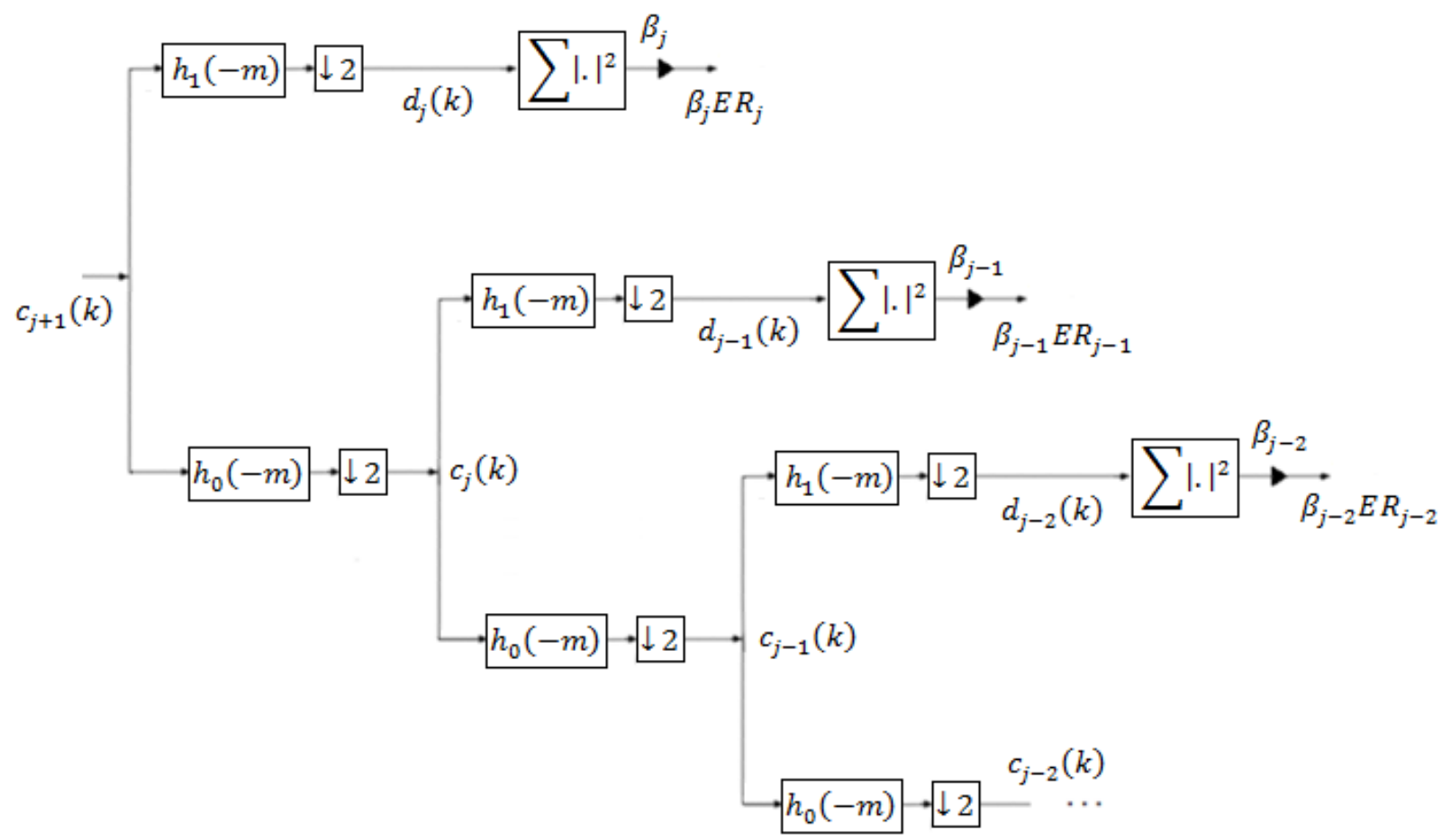

Figura 5.4: Cálculo da localização espectral por meio de banco de filtros (DWT). As saídas, após multiplicação pelos coeficientes $\beta_{j}$, são somadas, resultando no valor de $L_{E}$.

Assim, cada valor de $K_{D E W}$ calculado define um ponto da sequência descritora de fadiga $f=\{f[i]\}_{i=1}^{N_{\text {ciclos }}}$. As propriedades utilizadas para a definição de $K_{D E W}$ são as mesmas para o descritor apresentado na subseção a seguir.

\subsection{2 - Compressão Espectral (Wavelets)}

Utilizando as mesmas notações usadas no cálculo de localização espectral, definese $E_{A_{J}}$, a energia acumulada até a escala $J$ da decomposição de $x(t)$, como:

$$
E_{A_{J}}=\sum_{j=j_{0}}^{J} E_{x_{j}} .
$$

Considere-se que $j_{\operatorname{Max}}$ seja a máxima escala na decomposição de $x(t)$. Isto é, 
$E_{A_{j_{M a x}}}$ representa a energia acumulada total (valor final da curva de energia acumulada). Define-se, portanto, como concentração espectral de $x(t)$ o valor $C_{E}$ dado por:

$$
C_{E}=1-\sqrt{\frac{1}{j_{M a x}\left(E_{A_{j_{M a x}}}\right)^{2}} \sum_{j=j_{0}}^{j_{\text {Max }}}\left(E_{A_{j_{M a x}}}-E_{A_{j}}\right)^{2}} .
$$

Este parâmetro consiste num valor normalizado, que mede a diferença entre curva de energia acumulada das escalas da DWT e a curva correspondente à maior concentração espectral possível - caso em que toda a energia está na escala de aproximação da DWT. Este valor deve se aproximar da unidade quando o espectro de potência do sinal sob análise estiver concentrado nas baixas frequências. Da maneira análoga à que se definiu o coeficiente de deslocamento espectral, define-se o coeficiente de compressão espectral wavelet $\left(K_{C E W}\right)$ de um trecho $x(t)$ do sinal de EMG-S como a razão entre o valor de $C_{E}$ calculado neste trecho e o valor de $C_{E}$ calculado no início do eletromiograma. Os valores sucessivos de $K_{C E W}$ calculados definirão a sequência descritora de fadiga $f=\{f[i]\}_{i=1}^{N_{\text {ciclos }}}$.

Em comparação a métodos baseados na transformada discreta de Fourier, têm-se descritores eletromiográficos que envolvem menor complexidade computacional em seus cálculos, sendo, para uma sequência de $N$ pontos, $\mathcal{O}(N)$ para a DWT e $\mathcal{O}(N \log (N))$ para os algoritmos clássicos de transformada rápida de Fourier (FFT) (Daubechies, 1988; Graps, 1995; Burrus et al., 1998; Mallat, 2009).

Devido à natureza recursiva da definição das funções ortogonais (wavelets e funções de escala), a DWT apresenta resolução variável em diferentes faixas de frequência. Para frequências maiores, a DWT possui maior resolução temporal e menor resolução em frequência. Para frequências menores, a DWT possui menor resolução temporal e maior resolução em frequência (Daubechies, 1988; Graps, 1995; Burrus et al., 1998; Mallat, 2009). Tal distribuição pode se mostrar adequada especialmente para análise de sinais eletromiográficos, cuja potência está concentrada nas frequências mais baixas, e que, com a produção da fadiga, tendem a aumentar esta característica (DeLuca, 1984; Vollestad, 1997; Knaflitz e Bonato, 1999). Neste sentido, a divisão uniforme em sub-bandas na análise de Fourier - se comparado à DWT - apresenta utilização dos coeficientes da transformada em prol de maior resolução temporal (e menor espectral) em baixas 
frequências e maior resolução espectral (e menor temporal) nas altas frequências. Portanto, o decréscimo da frequência central e a concentração da potência do sinal - com sua realocação não uniforme no espectro - sugerem que talvez esta não seja a abordagem ótima, motivando o uso de wavelets.

Comparada à sua versão contínua (CWT), a DWT não apresenta redundâncias em sua representação no domínio da transformada, permitindo algoritmos mais eficientes para o seu cálculo. Tal característica pode ser interessante para aplicações em tempo real onde houver maiores limitações de recursos computacionais (Burrus et al., 1998; Mallat, 2009).

A seguir, são descritas as próximas técnicas propostas utilizando wavelets, consistindo de descritores adaptativos visando à redução da dispersão na indicação de fadiga. Mais adiante tratar-se-á da dispersão em maiores detalhes.

\subsection{3 - Deslocamento Espectral Adaptativo (Wavelets)}

Para a definição dos próximos descritores baseados em wavelets, utilizar-se-á uma notação distinta para os coeficientes obtidos nas saídas dos bancos de filtros - aproximação e detalhes, visto que, em geral, não corresponderão aos mesmos utilizados para o cálculo de $K_{D E W}$ e $K_{C E W}$. Isto se deve à implementação de uma versão modificada da DWT tradicional, de maneira semelhante aos algoritmos de wavelet packets.

A modificação do cálculo da DWT é feita alterando-se o caminho no banco de filtros para o cálculo da transformada no algoritmo de Mallat. Tradicionalmente, considera-se a saída do filtro passa-baixa para o próximo nível de decomposição, como ilustra a figura 5.5. 

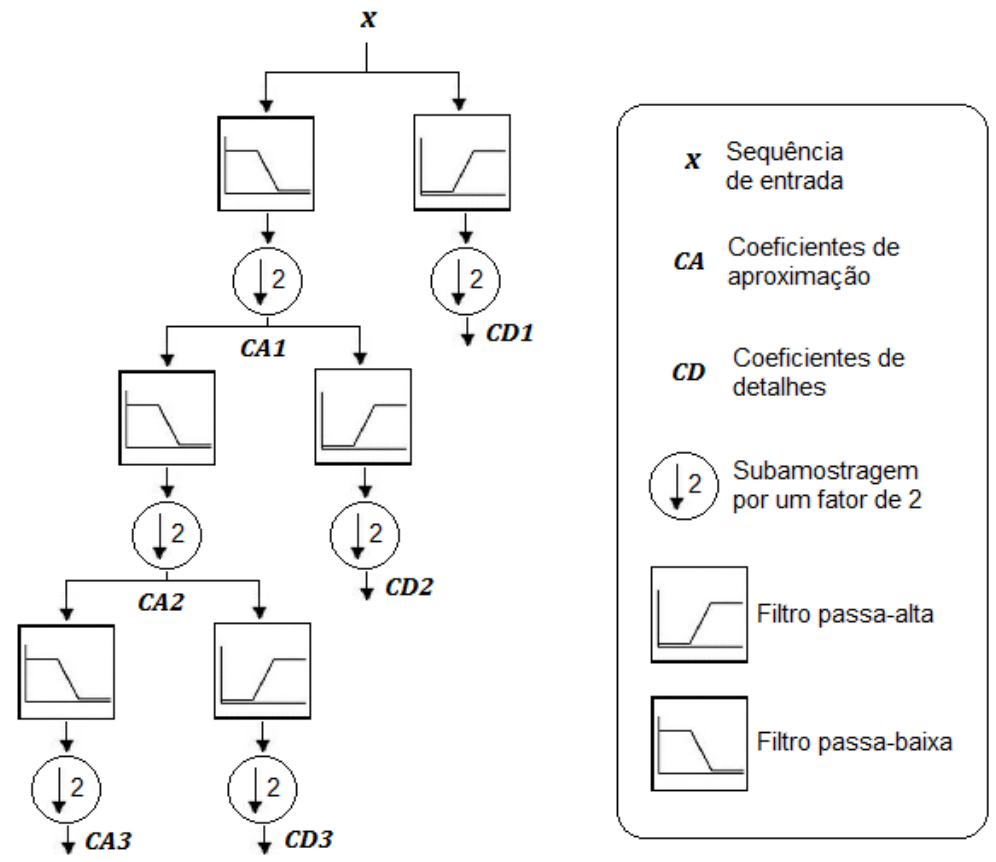

Figura 5.5: Decomposição de uma sequência $\boldsymbol{x}$ em 3 estágios: abordagem tradicional descrita por Stéphane Mallat.

Para as técnicas adaptativas propostas, decide-se entre considerar a saída do filtro passa-baixa ou passa-alta para a decomposição no nível $j+1$ observando em qual metade do espectro, no nível $j$, se concentra a maior parcela da energia. Caso a metade do espectro em baixas frequências possua energia superior à da metade nas altas frequências, considera-se a saída do filtro passa-baixa para o próximo nível da DWT. Caso contrário, considera-se a saída do passa-alta. Assim, o cálculo da $i$-ésima amostra da sequência descritora de fadiga é feito simultaneamente ao cálculo da transformada do respectivo trecho do sinal de EMG-S.

De maneira análoga à definição do coeficiente de deslocamento espectral $K_{D E W}$ (subseção 5.3.1), define-se primeiramente a localização espectral adaptativa $\left(L_{E A}\right)$ e, a partir desta, define-se o coeficiente de deslocamento espectral adaptativo $\left(K_{D E A}\right)$.

Sejam $s_{L P}^{[j]}[m]$ e $s_{H P}^{[j]}[m]$ os coeficientes obtidos, respectivamente, nas saídas dos filtros passa-baixa e passa-alta - após a subamostragem - no nível $j$ de decomposição da DWT $\left(j=1,2, \ldots, j_{\text {máx }}\right)$ de um segmento $\boldsymbol{x}=\{x[n]\}_{n=1}^{N}$ do sinal EMG-S sobre o qual se quer calcular um dos valores da sequência $\{f[i]\}_{i=1}^{N_{c i c l o s}}$. Isto é:

$$
s_{L P}^{[j]}[m]=\sum_{k} h_{0}[k-2 m] s^{[j]}[k]
$$


$\mathrm{e}$

$$
s_{H P}^{[j]}[m]=\sum_{k} h_{1}[k-2 m] s^{[j]}[k]
$$

Estas equações representam um nível de decomposição na DWT, em que $h_{0}[m]$ e $h_{1}[m]$ são ainda, respectivamente, a resposta ao impulso do filtro passa-baixa e do passa-alta correspondentes à wavelet escolhida para a decomposição de $\boldsymbol{x}$. Assim, as duas últimas equações representam a convolução de $s_{L P}^{[j]}[m]$ (e $s_{H P}^{[j]}[m]$ ) com as versões refletidas $h_{0}[-m]\left(\right.$ e $h_{1}[-m]$ ), seguidas de subamostragem por um fator de 2. Assim, no primeiro nível de decomposição $(j=1)$, têm-se duas sequências $\boldsymbol{s}_{L P}^{[1]}=\left\{s_{L P}^{[1]}[m]\right\}_{m=1}^{N / 2}$ e $\boldsymbol{s}_{H P}^{[1]}=$ $\left\{\boldsymbol{S}_{H P}^{[1]}[m]\right\}_{m=1}^{N / 2}$ e $\boldsymbol{S}^{[1]}=\boldsymbol{x}$. No nível $j$ de decomposição as sequências $\boldsymbol{s}_{\boldsymbol{L P}}^{[j]}$ e $\boldsymbol{S}_{\boldsymbol{H P}}^{[j]}$ possuem, portanto, $M=N / 2^{j}$ coeficientes. A figura 5.6 exemplifica este procedimento.
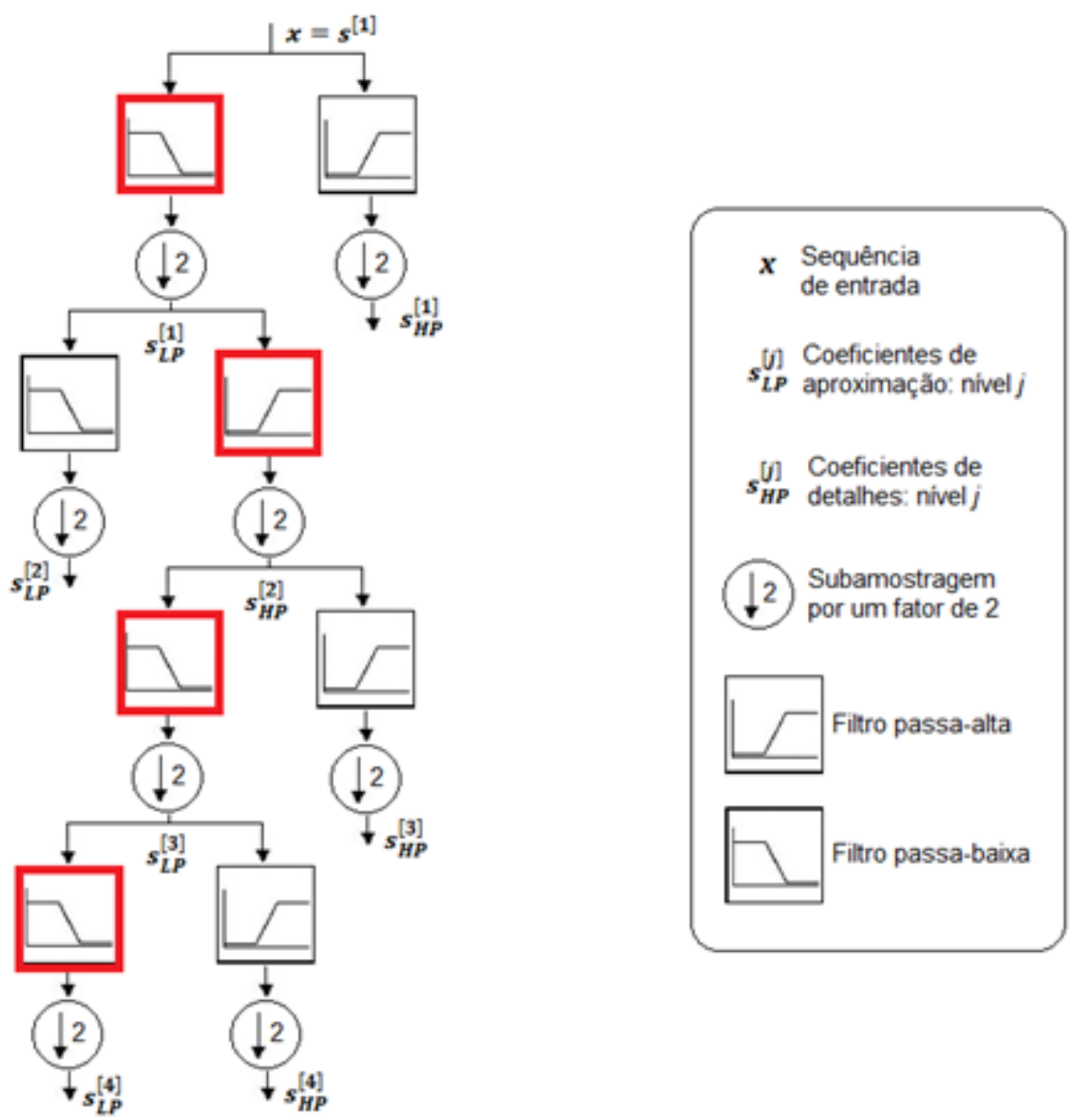

Figura 5.6: Exemplo de decomposição adaptativa de uma sequência $\boldsymbol{x}$ em $j_{\text {máx }}=4$ níveis. Em destaque o caminho de maior energia relativa no banco de filtros. Neste exemplo, a energia de $\boldsymbol{s}_{H P}^{[2]}$ é superior à de $\boldsymbol{s}_{L P}^{[2]}$. 
Agora, seja $\boldsymbol{y}=\{y[n]\}_{n=1}^{L}$ a sequência representando o sinal de EMG-S completo normalizado (de forma que sua variância seja igual à unidade) de comprimento $L$ e $Y[k]$ os coeficientes da transformada de Fourier discreta (DFT) de $\boldsymbol{y}$. O espectro do sinal de EMG$S$ é utilizado como informação auxiliar para determinar o valor de $L_{E A}$, simultaneamente ao cálculo da DWT adaptativa do $i$-ésimo ciclo de $\boldsymbol{y}$. Num nível $j$ qualquer, o cálculo de $L_{E A}$ é feito da seguinte forma:

i) Obtêm-se $\boldsymbol{s}_{\boldsymbol{L P}}^{[j]}$ (e $\boldsymbol{s}_{\boldsymbol{H P}}^{[j]}$ ), a partir de $\boldsymbol{s}^{[j]}$, com a filtragem passa-baixa (e passaalta) seguida de subamostragem.

ii) Calculam-se $E_{L P}^{[j]}$ e $E_{H P}^{[j]}$, as energias de $\boldsymbol{s}_{\boldsymbol{L P}}^{[j]}$ e $\boldsymbol{s}_{\boldsymbol{H P}}^{[j]}$, respectivamente:

$$
E_{L P}^{[j]}=\sum_{m=1}^{N / 2^{j}}\left|s_{L P}^{[j]}[m]\right|^{2}
$$

$\mathrm{e}$

$$
E_{H P}^{[j]}=\sum_{m=1}^{N / 2^{j}}\left|s_{H P}^{[j]}[m]\right|^{2}
$$

iii) O segmento do espectro neste nível $\boldsymbol{Y}^{[j]}=\left\{Y^{[j]}[k]\right\}_{k=k_{\min }^{[j]}}^{k_{\max }^{[j]}}$ é particionado em suas metades inferior e superior, de forma que

$$
\boldsymbol{Y}^{[j]}=\left[\left\{Y^{[j]}[k]\right\}_{k=k_{\min }^{[j]}}^{\left.k_{\text {máx }}^{[j]} / 2\right]} \quad\left\{Y^{[L]}[k]\right\}_{\left.k=\mid k_{\text {máx }} k^{[j]} / 2\right]+1}^{[j]}\right]
$$

onde $k_{\min }^{[j]}$ e $k_{\text {máx }}^{[j]}$ são, respectivamente, os índices inicial e final do segmento do espectro no nível $j$ de iteração do algoritmo e $[\lambda]$ é a função menor inteiro maior ou igual a $\lambda$.

iv) Calculam-se os pesos $\alpha_{L P}^{[j]}$ e $\alpha_{H P}^{[j]}$ relativos às metades inferior e superior do espectro neste nível de iteração, da seguinte forma

$$
\alpha_{L P}^{[j]}=\frac{1}{E_{x}} \sqrt{\frac{2}{k_{\text {máx }}^{[j]}-k_{\text {min }}^{[j]}+1} \sum_{k=k_{\text {min }}^{[j]}}^{\left\lfloor k_{\text {max }}^{[j]} / 2\right\rfloor}\left(Y^{[j]}[k]\right)^{2}}
$$

e 


$$
\alpha_{H P}^{[j]}=\frac{1}{E_{x}} \sqrt{\frac{2}{k_{\text {máx }}^{[j]}-k_{\text {min }}^{[j]}+1} \sum_{k=\left\lfloor k_{\text {máx }}^{[j]} / 2\right]+1}^{k_{\text {máx }}^{[j]}}\left(Y^{[j]}[k]\right)^{2}}
$$

Em que $E_{x}$ é a energia do trecho $\boldsymbol{x}$ do sinal EMG-S.

v) $\mathrm{O}$ valor de $L_{E A}^{[j]}$ na iteração $j$ é, então, definido como

$$
L_{E A}^{[j]}=L_{E A}^{[j-1]}+\alpha_{L P}^{[j]} \cdot E_{L P}^{[j]}+\alpha_{H P}^{[j]} \cdot E_{H P}^{[j]}
$$

vi) $\quad$ Se $E_{L P}^{[j]} \geq E_{H P}^{[j]}$, então:

$$
\begin{gathered}
\boldsymbol{s}^{[\boldsymbol{j}+\mathbf{1}]}=\boldsymbol{s}_{\boldsymbol{L P}}^{[j]} \\
\boldsymbol{Y}^{[\boldsymbol{j}+\mathbf{1}]}=\left\{Y^{[j]}[k]\right\}_{k=k_{\min }^{[j]}}^{\left.k_{\text {max }}^{[j]} / 2\right]}
\end{gathered}
$$

e

$$
k_{\text {máx }}^{[j+1]}=k_{\text {min }}^{[j]}+\left\lfloor\frac{k_{\text {máx }}^{[j]}-k_{\text {min }}^{[j]}}{2}\right\rfloor .
$$

Caso contrário (se $E_{L P}^{[j]}<E_{H P}^{[j]}$ ) faz-se:

$$
\begin{gathered}
\boldsymbol{S}^{[\boldsymbol{j}+\mathbf{1}]}=\boldsymbol{s}_{\boldsymbol{H P}}^{[\boldsymbol{j}]} \\
\boldsymbol{Y}^{[\boldsymbol{j}+\mathbf{1}]}=\left\{Y^{[L]}[k]\right\}_{\left.k=\mid k_{\text {máx }}^{[j]} / 2\right]+1}^{k_{\text {max }}^{[j]}}
\end{gathered}
$$

e

$$
k_{\min }^{[j+1]}=k_{\max }^{[j]}-\left\lfloor\frac{k_{\max }^{[j]}-k_{\min }^{[j]}}{2}\right\rfloor .
$$

vii) $\quad j \leftarrow j+1$.

viii) $\operatorname{Se} j \leq j_{\text {máx }}$ : retornar ao passo (i);

Senão: finalizam-se as iterações.

Finalizando-se este procedimento, o valor final de localização espectral $L_{E A}^{\left[j_{m} a ́ x\right]}$ obtido é atribuído a $L_{E A}$. Como parâmetros iniciais no nível de detalhes $j=1$, tomam-se $L_{E A}^{[0]}=0$, $\boldsymbol{S}^{[\mathbf{1}]}=\boldsymbol{x}, \boldsymbol{Y}^{[\mathbf{1}]}=\boldsymbol{Y}, k_{\min }^{[1]}=1$ e $k_{\text {máx }}^{[1]}=L / 2$ (índice correspondente à metade da frequência de amostragem no espectro $\boldsymbol{Y}$ do sinal de EMG-S completo). O coeficiente de deslocamento espectral adaptativo $K_{D E A}$ para o trecho $\boldsymbol{x}$ do sinal eletromiográfico é então definido como a razão entre o valor de $L_{E A}$ calculado neste trecho e o valor de $L_{E A}$ calculado num trecho inicial do eletromiograma. Assim como sua versão não adaptativa, 
esperam-se valores crescentes de $K_{D E A}$ como indicação da fadiga muscular.

$\mathrm{Na}$ próxima subseção será apresentado o coeficiente de compressão espectral adaptativa $K_{C E A}$, que segue passos semelhantes aos apresentados nesta subseção, a partir da decomposição adaptativa do trecho do sinal eletromiográfico.

\subsection{4 - Compressão Espectral Adaptativa (Wavelets)}

Como na subseção anterior será definido primeiramente o parâmetro concentração espectral adaptativa $\left(C_{E A}\right)$ e, a partir deste, o coeficiente de compressão espectral $\left(K_{C E A}\right)$. Utiliza-se no cálculo de $C_{E A}$ a variação na DWT pelo critério de máxima energia de uma das metades do segmento do espectro em cada etapa de decomposição de $\boldsymbol{x}=\{x[n]\}_{n=1}^{N}$. A descrição dos cálculos na $j$-ésima etapa de decomposição para determinar um dos valores de $C_{E A}$ é feita usando as mesmas notações para os parâmetros utilizados em ambos os métodos. Destaca-se, como diferença em relação à técnica anterior, o uso de uma sequência de energia acumulada $S_{E A}=\left\{S_{E A}[k]\right\}_{k=1}^{L / 2}$ com mesmo comprimento do espectro $\boldsymbol{Y}=Y[k]$ do sinal eletromiográfico completo. $\mathrm{O}$ algoritmo é definido nos passos a seguir:

i) Obtêm-se $\boldsymbol{s}_{\boldsymbol{L P}}^{[j]}\left(\right.$ e $\left.\boldsymbol{s}_{\boldsymbol{H} \boldsymbol{P}}^{[j]}\right)$, a partir de $\boldsymbol{s}^{[j]}$.

ii) Calculam-se $E_{L P}^{[j]}$ e $E_{H P}^{[j]}$.

iii) O segmento do espectro neste nível $\boldsymbol{Y}^{[j]}=\left\{Y^{[j]}[k]\right\}_{k=k_{\min }^{[j]}}^{k_{\max }^{[j]}}$ é particionado em suas metades inferior e superior.

iv) Calculam-se os pesos $\alpha_{L P}^{[j]}$ e $\alpha_{H P}^{[j]}$ relativos às metades inferior e superior do espectro neste nível de iteração.

v) Atribuem-se aos coeficientes da sequência de energia acumulada $S_{E A}$ contidos nos intervalos inferior $I_{\text {inf }}^{[j]}=\left[k_{\text {min }}^{[j]} ; k_{\text {min }}^{[j]}+\left[\left(k_{\text {máx }}^{[j]}-k_{\text {min }}^{[j]}\right) / 2\right]\right]$ e superior $\left.I_{\text {sup }}^{[j]}=\left[k_{\text {máx }}^{[j]}-\mid\left(k_{\text {máx }}^{[j]}-k_{\text {min }}^{[j]}\right) / 2\right\rfloor ; k_{\text {máx }}^{[j]}\right]$ seus valores atuais somados às energias ponderadas de $\boldsymbol{s}_{\boldsymbol{L P}}^{[j]}$ e $\boldsymbol{s}_{\boldsymbol{H P}}^{[j]}$, isto é:

$$
\left\{S_{E A}[k]\right\}_{k \in I_{i n f}^{[j]}} \leftarrow\left\{S_{E A}[k]\right\}_{k \in I_{i n f}^{[j]}}+E_{L P}^{[j]} \cdot \alpha_{L P}^{[j]}
$$

e 


$$
\left\{S_{E A}[k]\right\}_{k \in I_{\text {sup }}^{[j]}} \leftarrow\left\{S_{E A}[k]\right\}_{k \in I_{\text {sup }}^{[j]}}+E_{H P}^{[j]} \cdot \alpha_{H P}^{[j]}
$$

vi) $\quad$ Se $E_{L P}^{[j]} \geq E_{H P}^{[j]}$, então:

$$
\begin{gathered}
\boldsymbol{S}^{[\boldsymbol{j}+\mathbf{1}]}=\boldsymbol{s}_{\boldsymbol{L P}}^{[\boldsymbol{j}]} \\
\boldsymbol{Y}^{[\boldsymbol{j}+\mathbf{1}]}=\left\{Y^{[j]}[k]\right\}_{k=k_{\min }^{[j]}}^{\left.k_{\max }^{[j]} / 2\right]}
\end{gathered}
$$

e

$$
k_{m a ́ x}^{[j+1]}=k_{\min }^{[j]}+\left\lfloor\frac{k_{m a ́ x}^{[j]}-k_{m i n}^{[j]}}{2}\right\rfloor .
$$

Caso contrário (se $E_{L P}^{[j]}<E_{H P}^{[j]}$ ) faz-se:

$$
\begin{gathered}
\boldsymbol{s}^{[\boldsymbol{j}+\mathbf{1}]}=\boldsymbol{s}_{\boldsymbol{H P}}^{[\boldsymbol{j}]} \\
\boldsymbol{Y}^{[\boldsymbol{j}+\mathbf{1}]}=\left\{Y^{[L]}[k]\right\}_{\left.k=\mid k_{\text {máx }}^{[j]} / 2\right]+1}^{k_{\text {máx }}^{[j]}}
\end{gathered}
$$

e

$$
k_{\min }^{[j+1]}=k_{m a ́ x}^{[j]}-\left\lfloor\frac{k_{m a ́ x}^{[j]}-k_{\min }^{[j]}}{2}\right\rfloor .
$$

vii) $\quad j \leftarrow j+1$.

viii) $\quad$ Se $j \leq j_{\text {máx }}$ : retornar ao passo (i);

Senão: finalizam-se as iterações.

Inicialmente, toma-se $\left\{S_{E A}[k]\right\}_{k=1}^{L / 2}=0$. Todos os outros parâmetros têm seus valores iniciais definidos identicamente ao caso do cálculo de $K_{D E A}$. A partir da sequência $\boldsymbol{S}_{\boldsymbol{E} \boldsymbol{A}}$ resultante, define-se uma sequência integral de energia acumulada $\boldsymbol{I}_{\boldsymbol{S E A}}=\left\{I_{S E A}[k]\right\}_{k=1}^{L / 2}$ como a sequência integral discreta de $\boldsymbol{S}_{E A}$, isto é:

$$
I_{S E A}[k]=\sum_{m=1}^{k} S_{E A}[m] \quad k=1,2, \ldots, N / 2 .
$$

O valor de concentração espectral adaptativa do ciclo é definido, então, por:

$$
C_{E A}=1-\sqrt{\frac{2}{L \cdot\left(\max \left\{I_{S E A}\right\}\right)^{2}} \sum_{k=1}^{L / 2}\left(\max \left\{I_{S E A}\right\}-I_{S E A}[k]\right)^{2}},
$$


em que $\max \left\{I_{S E A}\right\}=I_{S E A}[L / 2]$, por ser a curva acumulada de $S_{E A}$. Este valor de $C_{E A}$ é, portanto, atribuído ao $i$-ésimo coeficiente $f[i]$ da sequência descritora de fadiga. A definição de $K_{C E A}$ a partir de $C_{E A}$ é idêntica à da última técnica descrita $\left(K_{D E A}\right)$.

Como $\boldsymbol{I}_{\boldsymbol{S E A}}$ representa a integral discreta da sequência de energia acumulada $\boldsymbol{S}_{\boldsymbol{E A}}$, o valor de $C_{E A}$ indica o quão próximo a curva acumulada $\boldsymbol{I}_{\boldsymbol{S E A}}$ está de seu valor máximo. A seguir, na figura 5.7, exemplificam-se curvas $\boldsymbol{S}_{\boldsymbol{E A}}$ e $\boldsymbol{I}_{\boldsymbol{S E A}}$ obtidas para um trecho de sinal eletromiográfico de contrações dinâmicas.
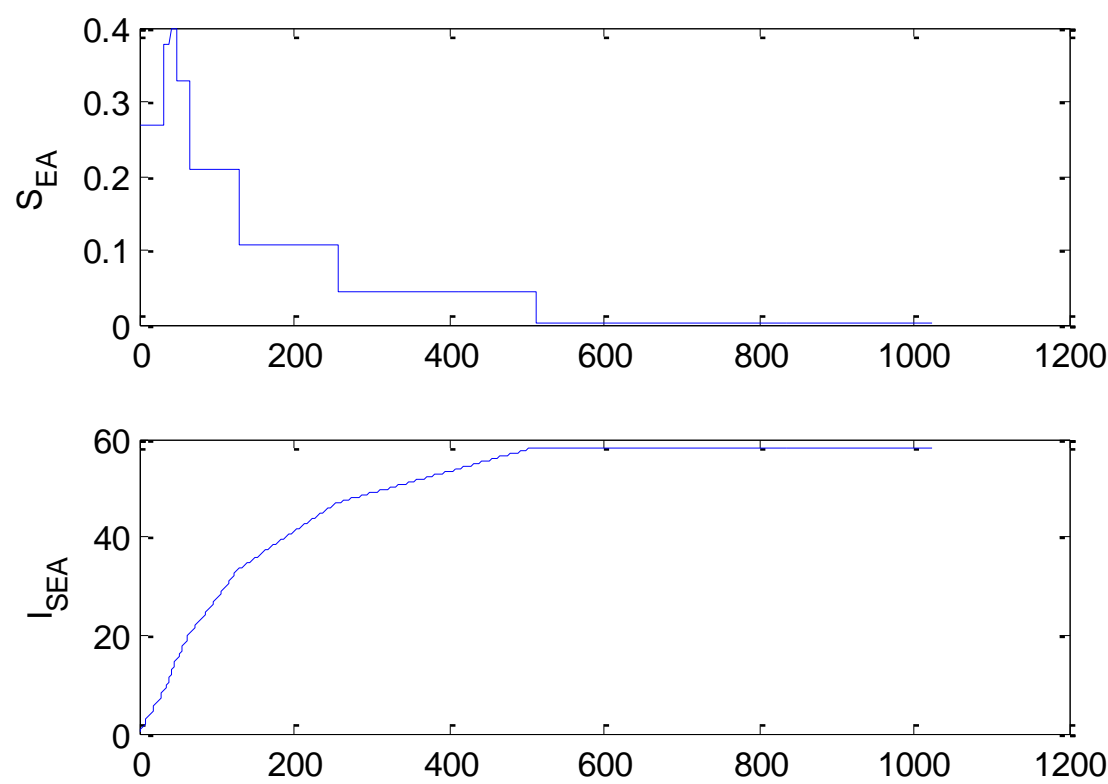

Figura 5.7: Exemplo de curva de $\boldsymbol{S}_{\boldsymbol{E} \boldsymbol{A}}$ e $\boldsymbol{I}_{\boldsymbol{S E A}}$ correspondente, obtidas para uma bulha em 7 estágios de cálculo. $\mathrm{O}$ valor de $C_{E A}$ é indicado pela área entre a curva de $\boldsymbol{I}_{\boldsymbol{S E A}}$ e seu valor máximo (área acima da curva). Por definição, quanto menor esta área for, maior deve ser o valor de $C_{E A}$.

Se o segmento do sinal de EMG-S sobre o qual se calcula $C_{E A}$ possui seu espectro de amplitude arbitrariamente concentrado nas baixas frequências, então $C_{E A} \rightarrow 1$. No caso extremo oposto, estando arbitrariamente concentrado numa vizinhança da metade da frequência de amostragem, tem-se $C_{E A} \rightarrow 0$.

Ambos os descritores adaptativos foram definidos de maneira a adaptar-se às características espectrais locais do eletromiograma. Desta maneira, espera-se obter indicadores de fadiga relativamente menos dispersos e, possivelmente, mais previsíveis e reprodutíveis (Lo Conte e Merletti, 1996; Zaman et al., 2011). Na subseção seguinte, 
propõe-se um indicador de fadiga baseado também no estreitamento do espectro de amplitude, utilizando a transformada de Fourier.

\subsection{5 - Estreitamento Espectral (Fourier)}

Os indicadores espectrais de fadiga muscular localizada comumente utilizados na literatura, em geral, consistem em parâmetros tradicionais como MNF, frequências percentis (incluindo-se a MDF) (Stulen e DeLuca, 1981; Stulen e DeLuca, 1982; DeLuca, 1984; Vollestad, 1997; Clancy et al., 2004), frequência instantânea (Lowery et al., 2002) e estimadores semelhantes, normalmente com pequenas variações ou utilizando distribuições tempo-frequência alternativas (Karlsson et al., 2000; Bonato et al., 2001; Andrade et al., 2008; Yochum et al., 2012). Um fenômeno pouco explorado é o estreitamento do espectro de amplitude do sinal ao longo do tempo, sem se considerar o deslocamento ou concentração do espectro nas baixas frequências. Neste sentido, a hipótese de este fenômeno apresentar-se durante o processo de fadiga muscular equivale a questionar se, durante contrações fatigantes, a potência do sinal torna-se mais desigualmente distribuída, concentrando-se em torno de alguma frequência central, independentemente de sua localização ou proximidade em relação às baixas frequências. A figura 5.8 ilustra este fenômeno, mostrando o espectro de amplitude de um trecho inicial do eletromiograma, com largura de banda $\Delta f^{\prime}$ e de um trecho final do sinal, com largura de banda $\Delta f^{\prime \prime}$. Observa-se que, independentemente de sua frequência central, a faixa ocupada pela parte significativa do espectro de amplitude é tal que $\Delta f^{\prime}>\Delta f^{\prime \prime}$. A observação de interesse baseia-se na evolução desta desigualdade durante a indução da fadiga. 

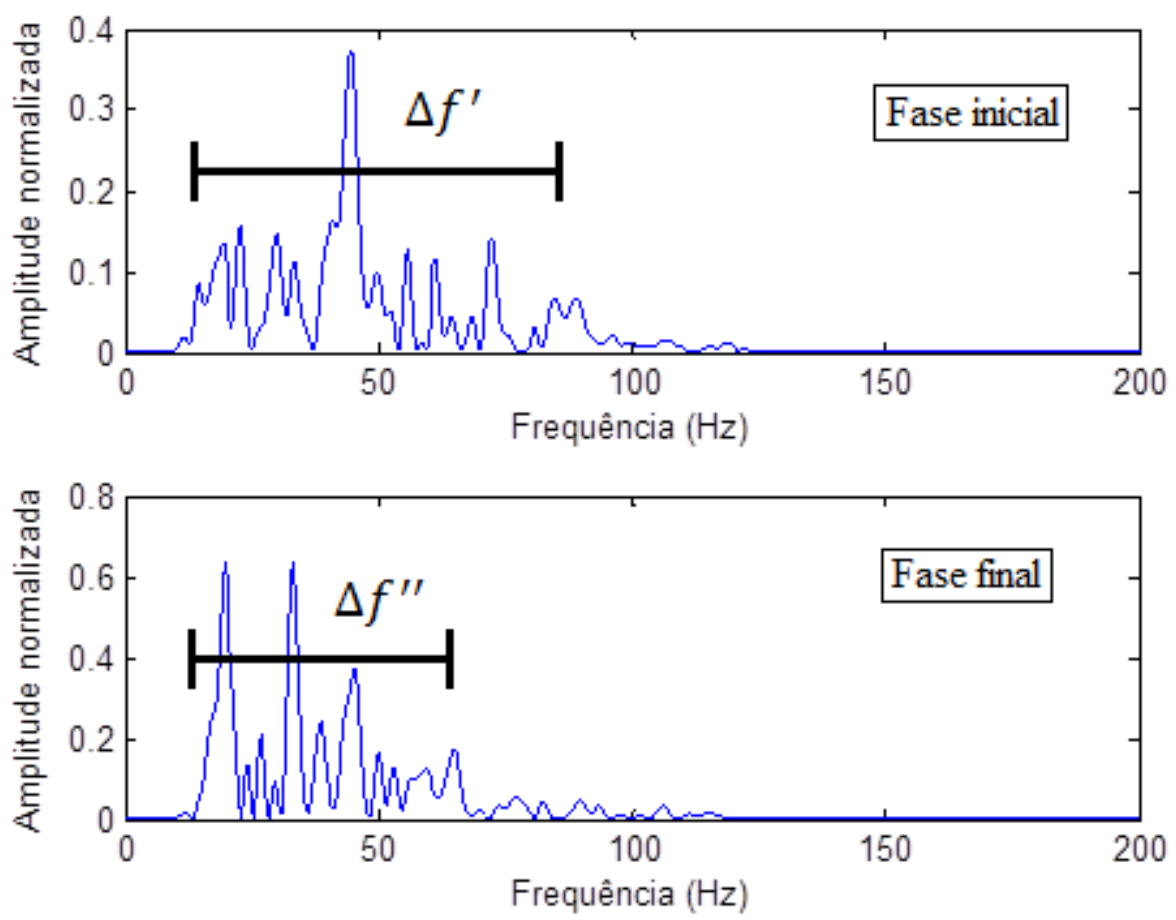

Figura 5.8: Estreitamento do espectro do sinal de EMG com a fadiga muscular. Exemplo de espectro de amplitude obtido nas fases inicial e final de exercício de contrações cíclicas em cicloergômetro.

O parâmetro descrito a seguir visa estimar tal estreitamento espectral. Seja $x[n]$ a sequência de comprimento $N$ par representando o trecho do eletromiograma sobre o qual se deseja estimar o estreitamento do espectro e $X[k]$, o $k$-ésimo harmônico de sua DFT. Define-se $Y[k]=|X[k]|^{2}$ para $k=0,1, \ldots, \frac{N}{2}-1$, isto é, a densidade espectral de energia até o último harmônico, correspondente à metade da frequência de amostragem. Então, ordena-se a sequência $Y[k]$, ordenando os seus coeficientes da maior amplitude à menor amplitude. Define-se então a sequência acumulada $S[k]\left(k=0,1, \ldots, \frac{N}{2}-1\right)$ da seguinte maneira:

$$
S[k]=\sum_{i=0}^{k} Y[i] .
$$

Assim, o valor máximo da sequência acumulada $S[k]$ é a amplitude de último coeficiente, isto é, $S\left[\frac{N}{2}-1\right]$. Seja $S_{m a ́ x}=S\left[\frac{N}{2}-1\right]$ este valor máximo. Neste contexto, a concentração espectral $\left(s_{W}\right)$ - no sentido de desigualdade ou não uniformidade da distribuição do 
espectro - do trecho $x[n]$ do sinal eletromiográfico amostrado é calculada pela relação:

$$
s_{W}=1-\frac{2}{(N / 2-1) S_{\text {máx }}} \sum_{k=0}^{N / 2-1}\left(S_{\text {máx }}-S[k]\right) \text {. }
$$

Assim, o estreitamento espectral $\left(s_{E}\right)$ do trecho do $x[n]$ do eletromiograma é definido como a razão entre o valor de $s_{W}$ calculado para este trecho e o valor de $s_{W}$ calculado num trecho inicial do sinal eletromiográfico. Para sinais cujo espectro de potência mostra-se estreito (e.g. sinais de comportamento próximo ao monocromático), $s_{W}$ assume valores próximos à unidade. Para sinais cujo espectro de potência mostra-se distribuído (e.g. sinais de comportamento impulsional), $s_{W}$ assume valores próximos de zero. Espera-se que este parâmetro reflita o comportamento do recrutamento das unidades motoras, o aumento de seu sincronismo, e/ou variações na propagação dos potenciais de ação em protocolos experimentais envolvendo a fadiga muscular induzida, exibindo padrões, assim como $\mathrm{MDF}, \mathrm{MNF}, \mathrm{CV}$, etc. Para o indicador $s_{E}$, espera-se verificar comportamento crescente com a ocorrência da fadiga.

Curiosamente, ideia semelhante - ao estreitamento do espectro - é aplicada à estimativa de distribuição de renda numa região ou país, conhecida como índice de Gini. Tal índice mede o quanto a renda total da população de uma região está concentrada em poucos habitantes (Gini, 1912; Ceriani e Verme, 2011). Aqui a ideia é desenvolvida e aplicada ao espectro de trechos do eletromiograma para observação da fadiga muscular localizada.

\subsection{6 - Distância entre Picos e Envoltória (Tempo)}

Nesta subseção apresenta-se um indicador de fadiga proposto, o qual é definido no domínio do tempo. Essencialmente, o parâmetro aqui definido deve estimar o quanto os picos do segmento retificado - correspondente a um trecho do eletromiograma distanciam-se de sua envoltória.

Dado o trecho $x[n]$ do sinal eletromiográfico, a primeira etapa do procedimento consiste em determinar a envoltória de $x[n]$. Isto é feito aplicando-se um filtro passa-baixa FIR com correção de fase sobre o trecho retificado $|x[n]|$. Isto é, se $x_{e n v}[n]$ representa a 
envoltória de $x[n]$, então:

$$
x_{\text {env }}[n]=h_{L P}[n] *|x[n]| .
$$

Para o filtro passa-baixa $h_{L P}[n]$ foi utilizada uma janela gaussiana com duração aproximada de $10 \mathrm{~ms}$, duração de aproximadamente uma ordem de grandeza acima do período refratário absoluto, intervalo mínimo entre a ocorrência de dois potenciais de ação consecutivos (correspondente à taxa máxima de disparos), e cerca de uma ordem de grandeza abaixo da duração de um ciclo de atividade mioelétrica no protocolo proposto em cicloergômetro, isto é, uma bulha (Bear et al., 2008; Costa Filho et al., 2012; Milhomem et $a l ., 2014$ d). Então, a parte positiva da diferença $x_{D P}[n]$ entre os picos do sinal retificado e sua envoltória é calculada como:

$$
x_{D P}[n]=\frac{|x[n]|-x_{e n v}[n]+|| x[n]\left|-x_{e n v}[n]\right|}{2} .
$$

Esta operação é responsável por estimar o quanto os picos de $x[n]$ distanciam-se de seu perfil suavizado $x_{e n v}[n]$. Sobre esta sequência assim definida, calcula-se o indicador temporal de fadiga distância entre picos e envoltória $\left(d_{P E}\right)$ pela norma- $p$, dada por:

$$
d_{P E}=\left\|x_{D P}[n]\right\|_{p}=\left(\sum\left|x_{D P}[n]\right|^{p}\right)^{\frac{1}{p}}
$$

Em geral, valores maiores de $p$ tendem a aproximar a média entre as maiores amplitudes de $\left|x_{D P}[n]\right|$. Isto é, quanto maior $p$, menor a faixa dinâmica de valores que contribuem significativamente para a média, sendo esta restringida aos picos mais altos desta sequência. Valores menores de $p$ tendem a diluir o cálculo da média, considerando-se uma maior faixa de amplitude da sequência $\left|x_{D P}[n]\right|$. Se $p=1$, por exemplo, considera-se a faixa dinâmica inteira uniformemente e tem-se simplesmente a soma de $\left|x_{D P}[n]\right|$. No caso extremo oposto, se $p=\infty$, tem-se $\left\|x_{D P}[n]\right\|_{\infty}=\sup _{n \in \mathbb{Z}}\left\{\left|x_{D P}[n]\right|\right\}$. Como, em geral, a quantidade de coeficientes não nulos de $x[n]$ é finita (duração finita do segmento), tem-se $\sup _{n \in \mathbb{Z}}\left\{\left|x_{D P}[n]\right|\right\}=\max _{n \in \mathbb{Z}}\left\{\left|x_{D P}[n]\right|\right\}$ e a norma $\left\|x_{D P}[n]\right\|_{\infty}$ corresponderá efetivamente a um valor de pico de $x[n]$. Se $p=2$, tem-se a norma euclidiana de $x_{D P}[n]$. Será adotado 
o valor $p=15$. Verifica-se experimentalmente que, para $15 \leq p \leq 30$, os valores de $d_{P E}$, quando utilizados como indicadores temporais, apresentem comportamento crescente com a ocorrência da fadiga muscular. Possivelmente, isto esteja correlacionado ao padrão ou ordem de recrutamento normal das unidades motoras em atividades fatigantes, de modo que unidades motoras produzindo potenciais de ação com maiores amplitudes são recrutadas para compensar as unidades já induzidas à fadiga em prol da manutenção da força solicitada (Moritani et al., 2004). Este fenômeno pode levar à produção de picos mais acentuados no eletromiograma, ocasionando o distanciamento entre os máximos locais do sinal e sua envoltória, de modo que $d_{P E}$ cresça com a indução da fadiga. A seguir, a figura 5.9 exemplifica esta observação:
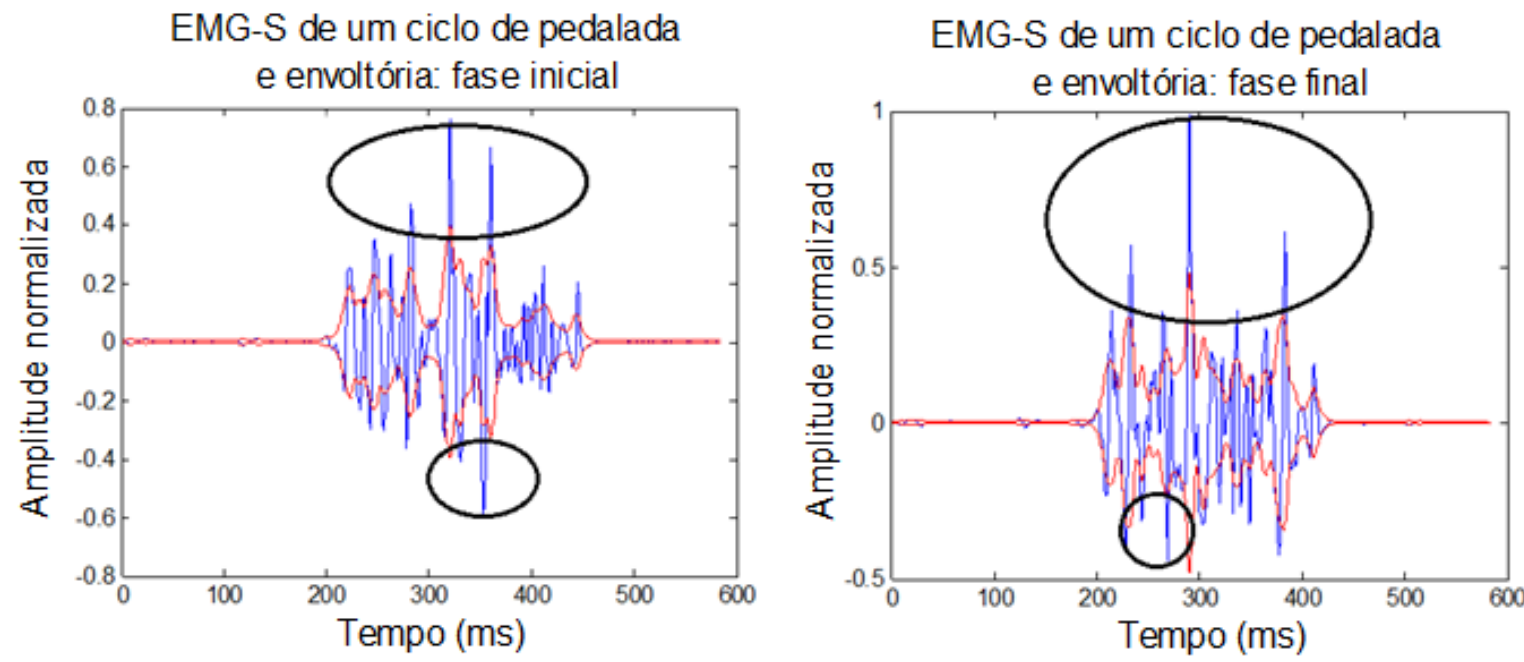

Figura 5.9: Exemplos de ciclos do sinal de EMG-S (azul) e envoltórias (vermelho) das fases inicial (à esquerda) e final (à direita). Em destaque, os picos que se distanciam significativamente da envoltória do sinal.

Assim como todos os outros indicadores definidos, define-se a sequência descritora de fadiga a partir dos valores de $d_{P E}$ calculados ao longo do experimento divididos pelo valor inicial de $d_{P E}$. Por sua definição, espera-se que apresente comportamento crescente. Pela natureza do sinal eletromiográfico, não se espera que este indicador apresente alguma vantagem em relação à previsibilidade ou comportamento local pouco disperso.

\subsection{7 - Outros parâmetros para análise}

Diversos estudos abordam outros parâmetros de interesse do sinal eletromiográfico, 
como, por exemplo, as relações entre MDF e MNF, em especial a razão MDF/MNF estimador que reflete uma assimetria do espectro (Clancy et al., 2004; Stulen e DeLuca, 1981 e 1982). Se esta razão é maior que a unidade, há um espalhamento do espectro nas baixas frequências, de modo que o centro da faixa ocupada pelo espectro se encontre à esquerda de seu valor de pico. Por outro lado, se esta razão é menor que a unidade, ocorre o oposto, isto é, um espalhamento à direita. Outros exemplos de parâmetros da eletromiografia frequentemente abordados são a duração e o momento da ativação muscular em protocolos dinâmicos, o que define o atraso eletromecânico - intervalo de tempo entre a ativação neural e a ativação muscular (Hodges e Rui, 1996; Bonato et al., 1998; Merlo et al., 2003; Lanyi e Adler, 2004; Vanozzi et al., 2010; Costa Filho et al., 2012). Este último parâmetro é em geral abordado em sinais de contrações cíclicas, em que a fase de ativação muscular é relativamente bem definida, não havendo atividade mioelétrica significativa fora deste intervalo, como em protocolos experimentais envolvendo sinais coletados - do vasto lateral, vasto medial, ou reto femoral - de ciclistas (Costa Filho et al., 2012). Não há, porém, na literatura disponível, quantidade significativa de estudos verificando se estes parâmetros - assimetria do espectro e atraso da ativação neural/muscular - apresentam algum padrão com a ocorrência da fadiga muscular localizada. Assim, propõe-se, além dos indicadores já discutidos, avaliar estas hipóteses.

\section{4 - MÉTRICAS DE DISPERSÃo}

Uma questão naturalmente posta, ao tratar de distintos indicadores de fadiga, é a definição de parâmetros que avaliem (comparem) estes indicadores, de modo a estimar sua reprodutibilidade e previsibilidade, visto que a própria fadiga localizada é um fenômeno previsível e reprodutível sob condições controladas (Basmajian e DeLuca, 1985; Vøllestad, 1997). Uma maneira de abordar este problema é por meio de aquisições de sinais de EMG de indivíduos repetidas vezes num mesmo protocolo experimental, comparando-se a variabilidade dos índices entre cada aquisição realizada, para cada indivíduo (Rainoldi et al., 1999; Arnall et al., 2002). Outra maneira, quando não se têm disponíveis coletas dos mesmos indivíduos em dias distintos, é a estimação da reprodutibilidade e previsibilidade através de parâmetros de dispersão aplicados às sequências indicadoras de fadiga, como o coeficiente de variação (Lo Conte e Merletti, 1996; Rainoldi et al., 1999; Arnall et al., 
2002; Zaman et al., 2011). O coeficiente de variação ( $\mathrm{OoV}$ ) de uma sequência positiva é dado pela razão $\sigma / \mu$ entre seu desvio padrão e sua média. Este valor representa a variação percentual da sequência em torno de seu valor médio. A partir desta definição, não se descartam, por exemplo, valores maiores de $\mathrm{CoV}$ para indicadores de MDF ou MNF em relação à velocidade de condução $(\mathrm{CV})$, devido ao decréscimo mais acentuado da MDF e MNF em relação à $\mathrm{CV}$ - e assim, possivelmente, maior valor de $\mathrm{CoV}$ - para várias porcentagens da contração voluntária máxima (\%MVC) (Lowery et al., 2000), o que sugeriria menor reprodutibilidade para os parâmetros MDF e MNF. Porém, em alguns estudos, como o de Rainoldi et al. (1999), sugere-se que a reprodutibilidade da MNF é superior à da CV para contrações isométricas a 10\% MVC, por exemplo. Outro caso em que o uso do $\mathrm{CoV}$ pode ser debatido é em contrações com carga crescente, em que os parâmetros de amplitude do sinal eletromiográfico podem crescer significativamente devido à carga e à fadiga localizada, simultaneamente - sem que estes parâmetros deixem de apresentar previsibilidade e reprodutibilidade, contudo (Andrade, 2006; Hug e Dorel, 2009). Desta maneira, uma limitação do $\operatorname{CoV}$ é sua interpretação quando aplicado a parâmetros que apresentam grande faixa dinâmica de variação - em conjunto com outros que não apresentem esta característica -, porém razoavelmente reprodutíveis, previsíveis, e não necessariamente dispersos. Esta situação pode ser brevemente verificada com o exemplo hipotético ilustrado na figura 5.10. Neste exemplo duas sequências de 10 pontos $f_{1}[n]$ e $f_{2}[n]$ são comparadas quanto à sua dispersão, de acordo com o $\mathrm{CoV}$. A sequência $f_{1}[n]$ consiste na soma de uma sequência linearmente crescente (de 1 a 10) com uma sequência aleatória normalmente distribuída (média nula e desvio padrão unitário). $f_{2}[n]$ é a soma de uma sequência linearmente crescente (de 5 a 50) com uma sequência aleatória normalmente distribuída (média nula e desvio padrão 0,5 ).
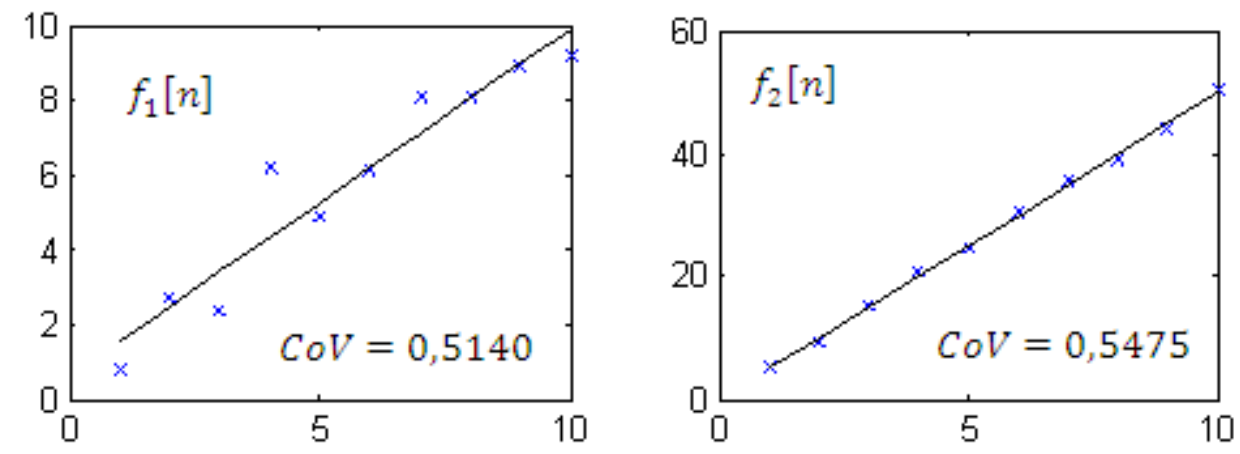

Figura 5.10: Duas sequências $f_{1}[n]$ e $f_{2}[n]$ (e correspondentes ajustes lineares) e respectivas dispersões estimadas com o $\mathrm{CoV}$. 
Apesar de relativamente mais dispersa - conforme mostrado pelos ajustes lineares,$- f_{1}[n]$ apresenta menor $\operatorname{CoV}$ do que $f_{2}[n]$, devido à maior faixa dinâmica da segunda. Tal interpretação pode não ser crítica em alguns contextos, porém, ao avaliar diferentes protocolos experimentais e parâmetros eletromiográficos em conjunto, esta conclusão pode ser um problema. Assim, propõem-se nesta seção, além do $\operatorname{CoV}$, outras métricas de dispersão para a sequência descritora de fadiga obtida a partir de um indicador qualquer: uma baseada em ajustes polinomiais sucessivos, e outra baseada na derivada discreta. Ambas serão apresentadas a seguir.

\subsection{1 - Dispersão Polinomial}

Seja $p_{n}[i](i=1,2, \ldots, N)$ o polinômio de ordem $n$, em $N$ pontos (quantidade de ciclos ou segmentos do sinal EMG-S para o cálculo dos indicadores), que melhor aproxima a sequência descritora de fadiga $\boldsymbol{f}$ segundo o critério dos mínimos quadrados. Então a dispersão polinomial relativa de ordem $n=n_{0}$ é definida pela relação

$$
D_{P R n_{0}}=\sqrt{\frac{1}{N} \sum_{i=1}^{N} \frac{\left(p_{n_{0}}[i]-f[i]\right)^{2}}{\left(p_{n_{0}}[i]\right)^{2}}} .
$$

Isto é, $D_{P R_{0}}$ é a dispersão relativa de $\boldsymbol{f}$ em torno de sua média, $D_{P R_{1}}$ é a dispersão relativa em torno de seu ajuste linear, e assim por diante. Naturalmente, espera-se que

$$
m \geq n \Longrightarrow D_{P R_{m}} \leq D_{P R_{n}}
$$

Em último caso, para $n=N-1$, tem-se $p_{N-1}[i]=f[i] \forall k$. Desta maneira, se $\boldsymbol{f}$ é aproximação razoável para um polinômio de ordem $m, D_{P R_{n}} \approx 0 \forall n>m$. A partir da sequência de valores de dispersão relativa calculados em diferentes ordens $n \geq 0$, definese um vetor de dispersões polinomiais relativas

$$
\boldsymbol{D}_{\boldsymbol{P R}}=\left[D_{P R_{0}} D_{P R_{1}} D_{P R_{2}} D_{P R_{3}} \cdots\right]=\left\{D_{P R_{n}}\right\}_{n=0}^{n_{\max x}} .
$$


A dispersão polinomial $\left(I_{D_{p o l}}\right)$ é dada, portanto, segundo alguma norma \|.\| escolhida sobre $\boldsymbol{D}_{\boldsymbol{P} \boldsymbol{R}}$. De forma a obter um índice normalizado em relação ao comprimento de $\boldsymbol{D}_{\boldsymbol{P R}}$, e dado que $D_{P R_{n}} \geq 0(n=0,1,2, \ldots)$, será utilizado como norma o valor RMS da sequência $D_{P R}$, isto é:

$$
I_{D_{p o l}}=\left\|\boldsymbol{D}_{\boldsymbol{P R}}\right\|=\sqrt{\frac{1}{n_{\text {máx }}+1} \sum_{n=0}^{n_{\text {máx }}}\left(D_{P R n}\right)^{2}}
$$

$n_{\text {máx }}$ é a ordem máxima em que se calculou a dispersão relativa de $\boldsymbol{f}$. Note-se que, se $n_{\text {máx }}=0$, tem-se $I_{D_{\text {pol }}}=\operatorname{CoV}$.

Com este índice de dispersão, podem ser observadas as tendências polinomiais de diferentes ordens da sequência que define o parâmetro de fadiga, considerando-se os ajustes de ordens mais altas no cálculo da dispersão. A definição de um parâmetro de dispersão para $\boldsymbol{f}$ de acordo com outro ponto de vista é apresentada a seguir.

\subsection{2 - Dispersão Diferencial}

Para a definição da dispersão diferencial da sequência $\boldsymbol{f}$, utilizam-se as derivadas discretas de diferentes ordens de $\boldsymbol{f}$. Seja, portanto, $\boldsymbol{f}^{(\boldsymbol{n})}$ a derivada discreta normalizada de ordem $n$ da sequência $\boldsymbol{f}$, dada por:

$$
f^{(n)}[i]=\frac{1}{\sqrt{2}}\left(f^{(n-1)}[i]-f^{(n-1)}[i-1]\right),
$$

em que $\boldsymbol{f}^{(\mathbf{0})}=\boldsymbol{f}$. Esta normalização da derivada implica que sua resposta ao impulso tenha energia unitária. A dispersão diferencial relativa de ordem $n=n_{0}$ é definida como a raiz quadrada da razão entre as energias de $\boldsymbol{f}^{\left(\boldsymbol{n}_{\mathbf{0}}+\mathbf{1}\right)}$ e $\boldsymbol{f}^{\left(\boldsymbol{n}_{\mathbf{0}}\right)}$, isto é:

$$
D_{D R_{n_{0}}}=\sqrt{\frac{E_{f^{\left(n_{0}+1\right)}}}{E_{f^{\left(n_{0}\right)}}}} .
$$


Por convenção, se para $n=n_{0}$ tem-se $D_{D R_{n_{0}}}=0$, então $D_{D R_{n}}=0 \forall n>n_{0}$. Desta maneira, se a sequência $\boldsymbol{f}$ é um polinômio de ordem $m$, verifica-se que $D_{D R_{n}}=0 \forall n>m$. Por outro lado, $D_{D R_{n}}$ nunca se anula se $\boldsymbol{f}$ cresce exponencialmente. Assim como para o caso do índice de dispersão polinomial relativa, define-se o vetor de dispersões diferenciais relativas de diferentes ordens

$$
\boldsymbol{D}_{\boldsymbol{D R}}=\left[D_{D R_{0}} D_{D R_{1}} D_{D R_{2}} \cdots\right]=\left\{D_{D R_{n}}\right\}_{n=0}^{n_{\max x}}
$$

e calcula-se $I_{D_{\text {dif }}}$ pela expressão

$$
I_{D_{\text {dif }}}=\left\|\boldsymbol{D}_{\boldsymbol{D} \boldsymbol{R}}\right\|=\sqrt{\frac{1}{n_{\text {máx }}+1} \sum_{n=0}^{n_{\text {máx }}}\left(D_{D R_{n}}\right)^{2}}
$$

em que $n_{\text {máx }}$ é a ordem máxima considerada para as derivadas de $\boldsymbol{f}$. Fixada a ordem $n=n_{0}$ o parâmetro $D_{D R_{n_{0}}}$ assim definido - em termos das sequências $\boldsymbol{f}^{\left(\boldsymbol{n}_{\mathbf{0}}\right)}$ e $\boldsymbol{f}^{\left(\boldsymbol{n}_{\mathbf{0}}+\mathbf{1}\right)}$ depende, efetivamente, da sequência $\boldsymbol{f}^{\left(n_{0}\right)}$ e de sua autocorrelação $R_{f^{\left(n_{0}\right)}, f^{\left(n_{0}\right)}}[k]$. Isto é consequência de o parâmetro $D_{D R_{n_{0}}}$ permitir uma definição alternativa,

$$
D_{D R_{n_{0}}}=\sqrt{1-\frac{\frac{1}{2}\left(f^{\left(n_{0}\right)}[1]+f^{\left(n_{0}\right)}\left[N-n_{0}\right]\right)-R_{f\left(n_{0}\right), f\left(n_{0}\right)}[1]}{E_{f\left(n_{0}\right)}}},
$$

a qual fornece resultado numérico idêntico, sem envolver $f^{\left(n_{0}+1\right)}$ em seu cálculo. De fato:

$$
\begin{gathered}
E_{f^{\left(n_{0}+1\right)}}=\sum_{i=1}^{N-\left(n_{0}+1\right)}\left(f^{\left(n_{0}+1\right)}[i]\right)^{2}=\frac{1}{2} \sum_{i=2}^{N-n_{0}}\left(f^{\left(n_{0}\right)}[i]-f^{\left(n_{0}\right)}[i-1]\right)^{2}= \\
=\frac{1}{2}\left[\left(f^{\left(n_{0}\right)}[2]-f^{\left(n_{0}\right)}[1]\right)^{2}+\left(f^{\left(n_{0}\right)}[3]-f^{\left(n_{0}\right)}[2]\right)^{2}+\cdots\right. \\
\left.+\left(f^{\left(n_{0}\right)}\left[N-n_{0}\right]-f^{\left(n_{0}\right)}\left[N-n_{0}-1\right]\right)^{2}\right]=
\end{gathered}
$$




$$
=\frac{\left(f^{\left(n_{0}\right)}[1]\right)^{2}+\left(f^{\left(n_{0}\right)}\left[N-n_{0}\right]\right)^{2}}{2}+\sum_{i=2}^{N-n_{0}-1}\left(f^{\left(n_{0}\right)}[i]\right)^{2}-\sum_{i=2}^{N-n_{0}} f^{\left(n_{0}\right)}[i] f^{\left(n_{0}\right)}[i-1] .
$$

Então

$$
\begin{gathered}
\sum_{i=1}^{N-\left(n_{0}+1\right)}\left(f^{\left(n_{0}+1\right)}[i]\right)^{2}=\frac{\left(f^{\left(n_{0}\right)}[1]\right)^{2}+\left(f^{\left(n_{0}\right)}\left[N-n_{0}\right]\right)^{2}}{2}+ \\
+E_{\left\{f^{\left(n_{0}\right)}[i]\right\}_{i=2}^{N-n_{0}-1}}-\left\langle\left\{ f^{\left.\left(n_{0}\right)[i]\right\}_{i=2}^{N-n_{0}}} ;\left\{f^{\left.\left.\left(n_{0}\right)[i]\right\}_{i=1}^{N-n_{0}-1}\right\rangle,}\right.\right.\right.
\end{gathered}
$$

onde $\langle;\rangle$ denota a operação produto interno. Assim, reescreve-se $E_{f^{\left(n_{0}+1\right)}}$ na forma:

$$
E_{f^{\left(n_{0}+1\right)}}=\frac{\left(f^{\left(n_{0}\right)}[1]\right)^{2}+\left(f^{\left(n_{0}\right)}\left[N-n_{0}\right]\right)^{2}}{2}+E_{\left\{f^{\left(n_{0}\right)}[i]\right\}_{i=2}^{N-n_{0}-1}}-R_{f^{\left(n_{0}\right)}, f^{\left(n_{0}\right)}}[-1] .
$$

Como $\boldsymbol{f}^{\left(\boldsymbol{n}_{0}\right)}$ é uma sequência real:

$$
E_{f^{\left(n_{0}+1\right)}}=\frac{1}{2}\left[\left(f^{\left(n_{0}\right)}[1]\right)^{2}+\left(f^{\left(n_{0}\right)}\left[N-n_{0}\right]\right)^{2}\right]+E_{\left\{f^{\left(n_{0}\right)}[i]\right\}_{i=2}^{N-n_{0}-1}}-R_{f^{\left(n_{0}\right)}, f^{\left(n_{0}\right)}}[1]
$$

$\mathrm{Ou}$, equivalentemente

$$
E_{f^{\left(n_{0}+1\right)}}=E_{f^{\left(n_{0}\right)}}-\frac{\left(f^{\left(n_{0}\right)}[1]\right)^{2}+\left(f^{\left(n_{0}\right)}\left[N-n_{0}\right]\right)^{2}}{2}-R_{f\left(n_{0}\right), f^{\left(n_{0}\right)}}[1] .
$$

Portanto

$$
\sqrt{\frac{E_{f^{\left(n_{0}+1\right)}}}{E_{f\left(n_{0}\right)}}}=\sqrt{1-\frac{\frac{1}{2}\left(f^{\left(n_{0}\right)}[1]+f^{\left(n_{0}\right)}\left[N-n_{0}\right]\right)-R_{f\left(n_{0}\right), f^{\left(n_{0}\right)}[1]}}{E_{f\left(n_{0}\right)}}} .
$$

Assim, se $f^{\left(n_{0}\right)}[k]$ não apresenta autocorrelação significativa, tem-se 


$$
\left\langle\left\{f^{\left(n_{0}\right)}[i]\right\}_{i=2}^{N-n_{0}} ;\left\{f^{\left(n_{0}\right)}[i]\right\}_{i=1}^{N-n_{0}-1}\right\rangle=R_{f^{\left(n_{0}\right)}, f^{\left(n_{0}\right)}}[1] \cong 0
$$

e a razão entre $E_{f^{\left(n_{0}+1\right)}}$ e $E_{f\left(n_{0}\right)}$ tende a aumentar, obtendo-se maior dispersão diferencial relativa na ordem $n=n_{0}$.

Da maneira como foi definida, $I_{D_{\text {dif }}}$ deve fornecer uma estimativa percentual das variações locais dos indicadores de fadiga em relação ao seu valor absoluto. Assim, se indicadores obtidos em ciclos consecutivos forem significativamente correlacionados, $I_{D_{\text {dif }}}$ deve ser reduzida.

Considere-se agora, novamente, o exemplo da figura 5.10, situação em que a sequência $f_{1}[n]$ (relativamente mais dispersa) apresentava menor $\operatorname{CoV}$ do que $f_{2}[n]$. Com as medidas de dispersão aqui definidas, têm-se para as mesmas sequências $f_{1}[n]$ e $f_{2}[n]$ os valores na tabela 5.1 a seguir:

Tabela 5.1 - Dispersões das sequências de exemplo $f_{1}[n]$ e $f_{2}[n]$, de acordo com as

\begin{tabular}{|c|c|c|}
\multicolumn{3}{c}{ métricas $\operatorname{CoV}, I_{D_{\text {pol }}}$ e $I_{D_{\text {dif }}}}$. \\
\hline Métrica & $f_{1}[n]$ & $f_{2}[n]$ \\
\hline $\operatorname{CoV}$ & 0,5140 & 0,5475 \\
\hline$I_{D_{\text {pol }}}$ & 0,2960 & 0,2614 \\
\hline$I_{D_{\text {dif }}}$ & 0,1784 & 0,1102 \\
\hline
\end{tabular}

De acordo com as dispersões polinomial e diferencial, a sequência $f_{1}[n]$ mostra-se mais dispersa, em contraste com a conclusão obtida com o coeficiente de variação. Assim, verifica-se que as métricas $I_{D_{p o l}}$ e $I_{D_{d i f}}$ permitiram observar as dispersões destas sequências de acordo com a interpretação que se desejava.

\section{5 - CONSIDERAÇÕES FINAIS}

Neste capítulo foram apresentadas as propostas de indicadores eletromiográficos de fadiga muscular - explorando diferentes aspectos do eletromiograma no domínio do tempo e da frequência -, metodologias para sua aplicação, e as métricas de dispersão para a avaliação conjunta destes indicadores. No próximo capítulo são apresentados e discutidos 
os resultados experimentais obtidos para os indicadores de fadiga - e abordagens para sua aplicação - tratados nesta tese, aplicando-se as técnicas descritas aos sinais de EMG-S dos protocolos experimentais descritos no capítulo 3. 


\section{6 - ANÁLISE DOS INDICADORES DE FADIGA}

Neste capítulo os indicadores de fadiga definidos neste trabalho são discutidos em conjunto com os índices tradicionais encontrados na literatura. Primeiramente os indicadores foram validados experimentalmente em sinais de EMG-S de protocolo isométrico (Protocolo IV). Posteriormente, a validação foi realizada em protocolo dinâmico para os sinais de ciclismo. Para avaliação dos descritores eletromiográficos como indicadores de fadiga na atividade de ciclismo, foram utilizados os sinais dos músculos VL e VM dos voluntários participantes do Protocolo II (teste com carga e velocidade constantes), que constituem um conjunto mais significativo de sujeitos. Após a validação, os parâmetros dispersivos dos indicadores estudados são apresentados e discutidos. Posteriormente, os indicadores eletromiográficos são avaliados em conjunto nos testes de ciclismo a carga constante (CL) e crescente (IL) e nas abordagens isométrica e dinâmica.

Para o estudo do desempenho biomecânico em conjunto com a eletromiografia, são utilizados os sinais do Protocolo I, no qual se apresentou a instrumentação integrada. Os indicadores de fadiga serão também aplicados aos sinais do Protocolo III para seu estudo no contexto de exercícios de extensão isocinética de joelho. Para todos os testes estatísticos utilizados nas análises, o nível de significância adotado foi $\alpha=0,05$.

\section{1 - VALIDAÇÃO EXPERIMENTAL EM PROTOCOLO ISOMÉTRICO}

Nesta seção os parâmetros definidos neste trabalho são experimentalmente validados como indicadores de fadiga muscular em protocolo isométrico (Protocolo IV, seção 3.4). Para avaliação da fadiga, foram utilizados os índices discutidos no capítulo 4. Os índices clássicos aplicados foram: o valor RMS, a MDF e a MNF. Os índices definidos

na tese são: $K_{D E W}, K_{C E W}, K_{D E A}, K_{C E A}$, calculados no domínio da DWT; $s_{E}$, utilizando a DFT; e $d_{P E}$, no domínio do tempo. A dispersão dos indicadores também é discutida em conjunto neste protocolo, utilizando-a como métrica para comparação. Para o protocolo isométrico, avaliar-se-á, ainda, se a assimétrica do espectro do eletromiograma - dada pela razão entre MDF e MNF - apresenta algum padrão crescente ou decrescente com a ocorrência da fadiga muscular. 


\subsection{1 - Resultados e discussão}

\subsubsection{1 - Índices tradicionais e propostos}

Nesta subseção são apresentados e discutidos os índices - clássicos e propostos no trabalho - obtidos para os sinais de EMG-S de bíceps braquial em contrações isométricas (40\% MVC). Os indicadores foram aplicados a trechos de 1,0 s do sinal eletromiográfico. Recapitule-se que o índice de fadiga, para todos os indicadores, foi determinado como a razão entre o coeficiente de inclinação da reta obtida por ajuste linear - da sequência descritora de fadiga - e seu valor inicial, isto é, seu coeficiente de inclinação normalizado (ver capítulo 5).

A validação experimental é feita a partir dos índices obtidos para o conjunto de todos os voluntários, verificando se os indicadores eletromiográficos apresentam padrão crescente (média positiva dos índices) - ou decrescente, no caso das frequências média e mediana (média negativa). Para verificar que o conjunto de índices possui média não nula, foi aplicado o teste $t$ com a hipótese nula de que a média dos índices obtidos foi igual a zero. Ao saber-se de antemão que a tendência de um índice era crescente (ou decrescente), deu-se preferência ao uso da forma unicaudal à direita (ou à esquerda) do teste t. A hipótese nula de normalidade dos índices foi previamente verificada (Shapiro-Wilk, $p>0,05)$. Para os casos em que a normalidade não se verifica, utilizou-se o teste não paramétrico de Wilcoxon.

As tabelas 6.1, 6.2 e 6.3 a seguir apresentam os valores obtidos, respectivamente, para os indicadores definidos no domínio do tempo (RMS e $d_{P E}$ ), no domínio da frequência (MNF, MDF e $\left.s_{E}\right)$ e no domínio da DWT $\left(K_{D E W}, K_{C E W}, K_{D E A}\right.$ e $\left.K_{C E A}\right)$. Ao final de cada tabela constam os resultados dos testes estatísticos para validação (para normalidade dos dados e para média diferente de zero). 
Tabela 6.1 - Índices de fadiga definidos no domínio do tempo, valores $p$ do teste de Shapiro-Wilk e do teste t.

\begin{tabular}{|c|c|c|}
\hline Sujeito & RMS $\left(* 10^{-3}\right)$ & $d_{P E}\left(* 10^{-3}\right)$ \\
\hline S1 & 2,2705 & $-1,8845$ \\
\hline S2 & $-2,2715$ & $-3,4308$ \\
\hline S3 & 6,8311 & 2,7340 \\
\hline S4 & 2,1591 & 1,5861 \\
\hline S5 & 12,4827 & 7,2335 \\
\hline S6 & 14,8882 & 6,3936 \\
\hline S7 & 12,8465 & 10,6100 \\
\hline S8 & 12,7486 & 8,6012 \\
\hline$\mu \pm \sigma$ & $7,74 \pm 6,40$ & $3,98 \pm 5,05$ \\
\hline$p$ (Shapiro-Wilk) & 0,201896 & 0,699951 \\
\hline$p$ (teste t) & $<0,01$ & $<0,05$ \\
\hline
\end{tabular}

Tabela 6.2 - Índices de fadiga definidos no domínio da frequência, valores $p$ do teste de Shapiro-Wilk e do teste t.

\begin{tabular}{|c|c|c|c|}
\hline Sujeito & MNF $\left(* 10^{-3}\right)$ & MDF $\left(* 10^{-3}\right)$ & $S_{E}\left(* 10^{-4}\right)$ \\
\hline S1 & $-5,4110$ & $-4,8197$ & 2,7668 \\
\hline S2 & $-2,7795$ & $-2,5520$ & 3,6678 \\
\hline S3 & $-3,7262$ & $-3,4972$ & 4,3637 \\
\hline S4 & $-2,9710$ & $-2,8361$ & 1,9888 \\
\hline S5 & $-2,1257$ & $-2,0743$ & 2,7526 \\
\hline S6 & $-5,5016$ & $-5,8679$ & 7,4315 \\
\hline S7 & $-4,7422$ & $-4,5520$ & 6,8531 \\
\hline S8 & $-3,8936$ & $-3,4770$ & 3,3370 \\
\hline$\mu \pm \sigma$ & $3,89 \pm 1,25$ & $-3,71 \pm 1,28$ & $4,15 \pm 1,98$ \\
\hline$p$ (Shapiro-Wilk) & 0,613291 & 0,782002 & 0,142110 \\
\hline$p$ (teste t) & $<0,0001$ & $<0,0001$ & $<0,001$ \\
\hline
\end{tabular}

Tabela 6.3 - Índices de fadiga utilizando wavelets, valores $p$ do teste de Shapiro-Wilk e do teste t.

\begin{tabular}{|c|c|c|c|c|}
\hline Sujeito & $K_{D E W}\left(* 10^{-3}\right)$ & $K_{C E W}\left(* 10^{-4}\right)$ & $K_{D E A}\left(* 10^{-3}\right)$ & $K_{C E A}\left(* 10^{-4}\right)$ \\
\hline S1 & 6,0130 & 2,7971 & 3,6948 & 4,0201 \\
\hline S2 & 3,3758 & 1,2501 & 1,9904 & 3,0951 \\
\hline S3 & 0,9993 & 1,5166 & 3,6908 & 3,7522 \\
\hline S4 & 1,5695 & 1,0907 & 1,8689 & 1,6858 \\
\hline S5 & 6,3568 & 1,2069 & 1,8329 & 1,5141 \\
\hline S6 & 9,5236 & 2,9647 & 11,5732 & 5,1066 \\
\hline S7 & 5,3014 & 2,1151 & 4,3699 & 4,6920 \\
\hline S8 & 4,0796 & 1,7980 & 3,6177 & 2,7927 \\
\hline$\mu \pm \sigma$ & $4,65 \pm 2,77$ & $1,84 \pm 0,72$ & $4,08 \pm 3,19$ & $3,33 \pm 1,31$ \\
\hline$p$ (Shapiro-Wilk) & 0,863759 & 0,215695 & $\mathbf{0 , 0 0 1 6 0 9}$ & 0,703988 \\
\hline$p$ (teste t) & $<0,01$ & $<0,0001$ & - & $<0,0001$ \\
\hline
\end{tabular}

* Teste de Wilcoxon para $K_{D E A}: p<0,05$

Para o índice $K_{D E A}$, não se confirma a hipótese nula de normalidade (Shapiro-Wilk, 
$p<0,05)$. Portanto, utilizou-se o teste não paramétrico de Wilcoxon para verificar que apresenta tendência crescente com a indução da fadiga muscular $(p<0,05)$. A figura 6.1 mostra, para um dos sujeitos, as sequências descritoras de fadiga obtidas para cada indicador eletromiográfico.
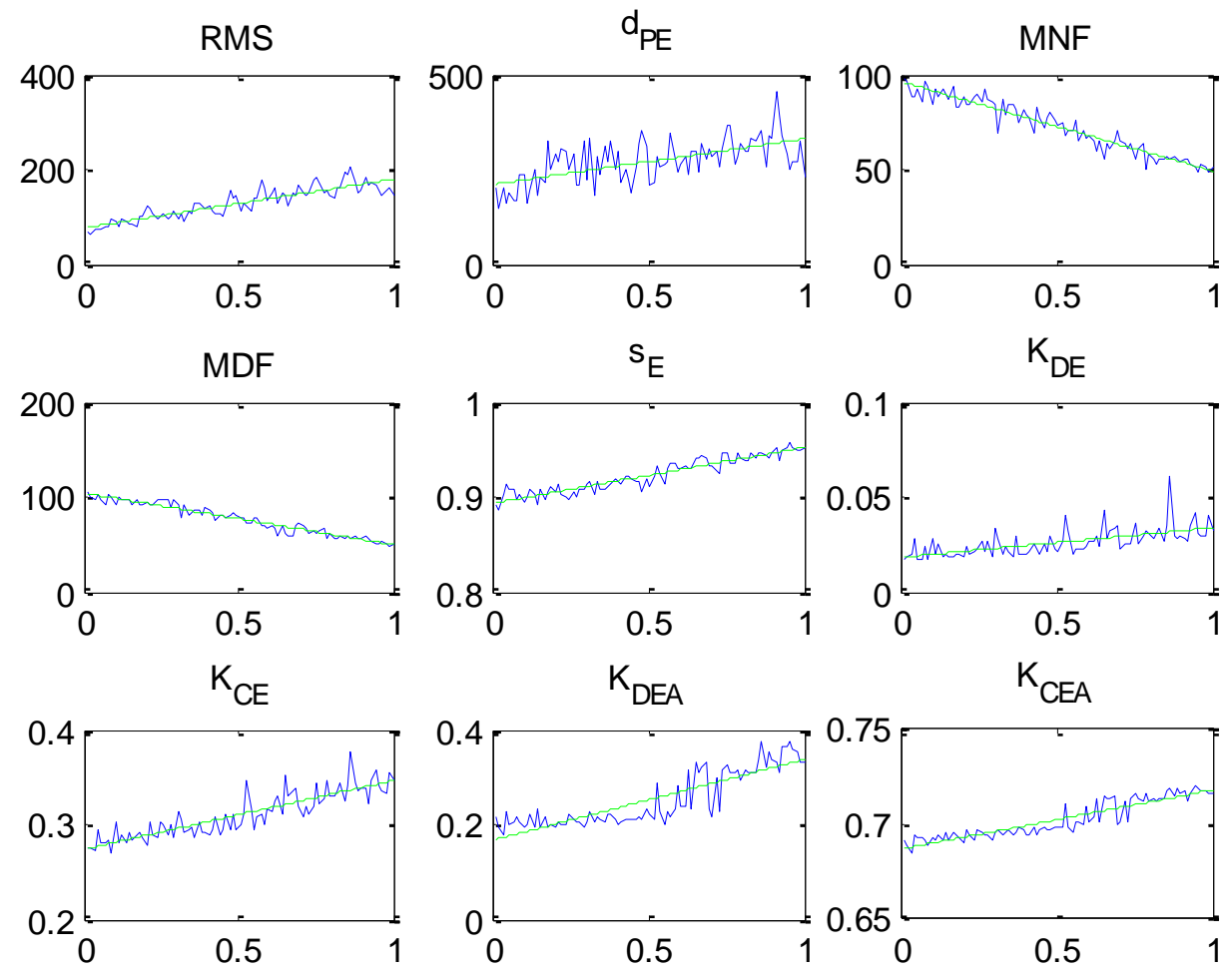

Figura 6.1: Sequências descritoras de fadiga obtidas para cada indicador eletromiográfico (em azul) e respectivos ajustes lineares (em verde). Exemplo dos resultados obtidos para um dos sujeitos $\left(n^{\circ} 6\right)$.

Estes resultados indicam que todos os indicadores - tradicionais e propostos apresentaram tendência crescente (decrescente, no caso da MNF e da MDF). Como os parâmetros RMS, MNF e MDF são consagrados na literatura como indicadores de fadiga, verifica-se que a fadiga muscular localizada foi efetivamente experimentada pelos voluntários na execução do protocolo proposto. Observa-se, portanto, que os parâmetros propostos nesta tese apresentaram o padrão esperado com o processo da fadiga muscular, tendo-se comportado como indicadores deste fenômeno em contrações isométricas prolongadas. Note-se que o parâmetro $d_{P E}$, mesmo tendo sido definido especificamente para o caso dinâmico, apresentou padrão significativamente crescente com a fadiga 
muscular no caso isométrico.

\subsubsection{2 - Dispersão dos indicadores}

Nesta subseção apresentam-se os valores de dispersão obtidos para os indicadores discutidos na subseção anterior. As métricas de dispersão aplicadas foram: o coeficiente de variação $(\mathrm{CoV})$ - parâmetro tradicionalmente utilizado - e os índices de dispersão polinomial e diferencial $\left(I_{D_{p o l}}\right.$ e $I_{D_{\text {dif }}}$ ), definidos nesta tese (ver seção 5.4). As tabelas 6.4, 6.5, e 6.6 a seguir, mostram os valores, obtidos para os indicadores temporais, no domínio da frequência e utilizando wavelets, respectivamente, para as três métricas de dispersão.

Tabela 6.4 - Dispersão para os indicadores de fadiga no domínio do tempo.

\begin{tabular}{|c|c|c|}
\hline Métrica & $\begin{array}{c}\text { RMS } \\
(\mu \pm \sigma)\end{array}$ & $\begin{array}{c}d_{P E} \\
(\mu \pm \sigma)\end{array}$ \\
\hline$C o V$ & $0,21 \pm 0,08$ & $0,23 \pm 0,05$ \\
\hline$I_{D_{\text {pol }}}$ & $0,16 \pm 0,06$ & $0,21 \pm 0,05$ \\
\hline$I_{D_{\text {dif }}}$ & $0,10 \pm 0,04$ & $0,17 \pm 0,04$ \\
\hline
\end{tabular}

Tabela 6.5 - Dispersão para os indicadores de fadiga no domínio da frequência.

\begin{tabular}{|c|c|c|c|}
\hline Métrica & $\begin{array}{c}\text { MNF } \\
(\mu \pm \sigma)\end{array}$ & $\begin{array}{c}\text { MDF } \\
(\mu \pm \sigma)\end{array}$ & $\begin{array}{c}S_{E} \\
(\mu \pm \sigma)\end{array}$ \\
\hline$C o V$ & $0,14 \pm 0,04$ & $0,14 \pm 0,05$ & $0,01 \pm 0,005$ \\
\hline$I_{D_{\text {pol }}}$ & $0,09 \pm 0,02$ & $0,09 \pm 0,02$ & $0,01 \pm 0,003$ \\
\hline$I_{D_{\text {dif }}}$ & $0,06 \pm 0,01$ & $0,05 \pm 0,01$ & $0,007 \pm 0,002$ \\
\hline
\end{tabular}

Tabela 6.6 - Dispersão para os indicadores de fadiga no domínio da DWT.

\begin{tabular}{|c|c|c|c|c|}
\hline Métrica & $\begin{array}{c}K_{D E W} \\
(\mu \pm \sigma)\end{array}$ & $\begin{array}{c}K_{C E W} \\
(\mu \pm \sigma)\end{array}$ & $\begin{array}{c}K_{D E A} \\
(\mu \pm \sigma)\end{array}$ & $\begin{array}{c}K_{C E A} \\
(\mu \pm \sigma)\end{array}$ \\
\hline$C o V$ & $0,42 \pm 0,14$ & $0,07 \pm 0,01$ & $0,13 \pm 0,05$ & $0,01 \pm 0,003$ \\
\hline$I_{D_{\text {pol }}}$ & $0,40 \pm 0,14$ & $0,06 \pm 0,01$ & $0,10 \pm 0,03$ & $0,009 \pm 0,002$ \\
\hline$I_{D_{\text {dif }}}$ & $0,93 \pm 0,56$ & $0,05 \pm 0,01$ & $0,09 \pm 0,02$ & $0,007 \pm 0,002$ \\
\hline
\end{tabular}

No domínio do tempo, o parâmetro RMS apresentou-se menos disperso do que $d_{P E}$ para todas as métricas consideradas. Uma das causas possíveis é a forma como o indicador $d_{P E}$ foi definido, a partir dos picos ocorridos no eletromiograma. Por sua natureza, o eletromiograma, quando registrado durante esforços exaustivos, apresenta picos de maneira relativamente imprevisível, dependendo sua ocorrência de diversos fatores 
fisiológicos e biomecânicos (Basmajian e DeLuca, 1985; Moritani et al., 2004).

Para os índices espectrais - utilizando a transformada de Fourier ou wavelets - os parâmetros definidos a partir da compressão do espectro $\left(s_{E}, K_{C E W}\right.$ e $\left.K_{C E A}\right)$ mostraram-se menos dispersos do que os definidos a partir de seu deslocamento (MNF, MDF, $K_{D E W}$ e $\left.K_{D E A}\right)$. Isto sugere que, para contrações isométricas fatigantes, a compressão (incluindo-se o estreitamento) do espectro de amplitude do eletromiograma seja um parâmetro mais previsível e reprodutível do que o deslocamento de seu centro.

Por fim, as três métricas de dispersão utilizadas apresentaram-se, em geral, semelhantes entre si na comparação de diferentes índices de fadiga. O parâmetro $\mathrm{CoV}$ apresentou-se maior do que as dispersões polinomial e diferencial. Especialmente para o valor RMS este parâmetro se destacou. Uma das possíveis razões consiste no fato de que este indicador depende puramente da amplitude do sinal que, em exercícios isométricos fatigantes acima de 30\% MVC, pode crescer acentuadamente (Moritani et al., 2004). Recapitule-se que o $\mathrm{CoV}$ consiste na razão entre desvio padrão e média - não levando em conta possíveis ajustes de ordem mais alta, como $I_{D_{p o l}}$. Assim, na ocorrência de acentuados aumentos percentuais ao longo da sequência indicadora de fadiga, esta métrica deve, necessariamente, apresentar valores mais altos de dispersão.

\subsubsection{3 - Outros parâmetros citados na literatura}

Nesta subseção mostram-se os resultados obtidos para a assimetria do espectro do eletromiograma, calculada como a razão $\mathrm{MDF} / \mathrm{MNF}$, ao longo dos testes de contração isométrica de bíceps. A figura 6.2 mostra a evolução da assimetria do espectro ao longo do tempo para todos os sujeitos e tabela 6.7 mostra os índices obtidos a partir das respectivas regressões lineares. Para o cálculo da sequência indicadora, utilizou-se o mesmo comprimento de janela $(1,0 \mathrm{~s})$ daquele utilizado nas subseções anteriores para os outros parâmetros. 

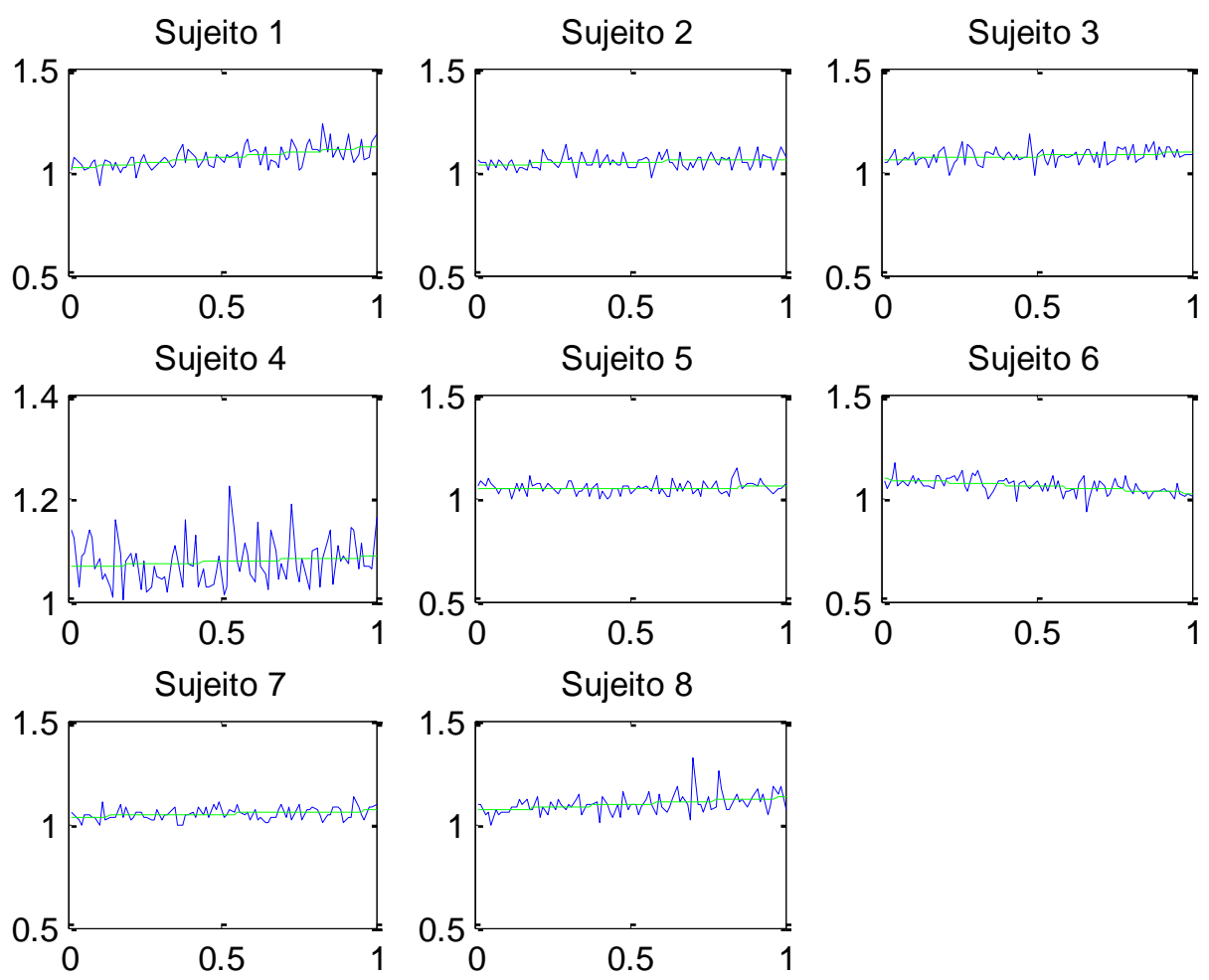

Figura 6.2: Assimetria do espectro de amplitude do eletromiograma ao longo do tempo (em azul) e respectivo ajuste linear (em verde). Todos os sujeitos. Eixo do tempo normalizado pela duração total do exercício.

Tabela 6.7 - Índices obtidos a partir da assimetria do espectro do eletromiograma em contrações isométricas.

\begin{tabular}{|c|c|}
\hline Sujeito & $\begin{array}{c}\text { Assimetria }(\mathrm{MDF} / \mathrm{MNF}) \\
\left(* 10^{-4}\right)\end{array}$ \\
\hline $\mathrm{S} 1$ & 11,4374 \\
\hline $\mathrm{S} 2$ & 3,1146 \\
\hline $\mathrm{S} 3$ & 3,3891 \\
\hline $\mathrm{S} 4$ & 2,0574 \\
\hline $\mathrm{S} 5$ & 0,7645 \\
\hline $\mathrm{S} 6$ & $-6,8113$ \\
\hline $\mathrm{S} 7$ & 3,2489 \\
\hline $\mathrm{S} 8$ & 6,7099 \\
\hline$\mu \pm \sigma$ & $2,99 \pm 5,17$ \\
\hline $\begin{array}{c}\text { Valor } p \\
(\text { Shapiro-Wilk) }\end{array}$ & 0,4711 \\
\hline $\begin{array}{c}\text { Valor } p \\
(\text { Teste t bicaudal) }\end{array}$ & 0,1462 \\
\hline $\begin{array}{c}\text { Valor } p \\
\text { (Teste t unicaudal à } \\
\text { direita }(\mu>0))\end{array}$ & 0,0731 \\
\hline
\end{tabular}


Como a média amostral dos índices é positiva, foram aplicadas as formas bicaudal e unicaudal (à direita) para o teste t. Apesar de no segundo caso o valor $p$ apresentar-se próximo ao nível de significância, os valores dos testes estatísticos indicam que a assimetria do espectro de amplitude do sinal de EMG-S não apresentou tendência crescente simultaneamente à instalação da fadiga. Neste sentido, os resultados apontam que este parâmetro não se comportou como um parâmetro indicador da fadiga muscular em teste isométrico.

\subsection{2 - Considerações finais}

Nesta seção todos os parâmetros propostos no trabalho foram validados experimentalmente como indicadores de fadiga muscular em protocolo isométrico, utilizando-se sinais de EMG-S de contração de bíceps braquial (cabeça curta) de oito sujeitos. Para que se confirmasse a ocorrência da fadiga muscular, indicadores tradicionais foram utilizados - RMS, MDF e MNF - atestando-se a indução da fadiga. Todos os sete parâmetros propostos $-d_{P E}, s_{E}, K_{D E W}, K_{C E W}, K_{D E A}$ e $K_{C E A}$ - atenderam a este propósito e, interessantemente, incluindo-se a distância entre picos e envoltória $\left(d_{P E}\right)$, que havia sido definida, a princípio, para protocolos dinâmicos.

Os indicadores também foram avaliados quanto à sua dispersão, a partir de três métricas: $\operatorname{CoV}, I_{D_{p o l}}$ e $I_{D_{d i f}}$. O $\mathrm{CoV}$ é tradicionalmente utilizado, e os dois últimos foram propostos neste trabalho. O parâmetro espectral $s_{E}$ apresentou-se significativamente menos disperso do que a MDF e MNF, que também são definidas no domínio da transformada de Fourier. Os parâmetros espectrais calculados no domínio da DWT ( $K_{D E W}, K_{C E W}, K_{D E A} \mathrm{e}$ $K_{C E A}$ ) também se mostraram coerentes como indicadores eletromiográficos de fadiga muscular, sendo as versões adaptativas $K_{D E A}$ e $K_{C E A}$ propostas com a finalidade de reduzir a dispersão. Ambas o satisfizeram, sendo o deslocamento espectral adaptativo $K_{D E A}$ menos disperso do que sua versão não adaptativa $K_{D E W}$, da mesma maneira que a compressão espectral adaptativa $K_{C E A}$ apresentou-se menos dispersa do que a não adaptativa $K_{C E W}$.

Em geral, todos os indicadores espectrais definidos a partir da compressão diminuição do suporte efetivo - do espectro de amplitude do eletromiograma $\left(s_{E}, K_{C E W} \mathrm{e}\right.$ $\left.K_{C E A}\right)$ mostraram-se menos dispersos do que os seus equivalentes que aferem a fadiga muscular a partir do deslocamento do centro do espectro para as baixas frequências (MDF, MNF, $K_{D E W}$ e $\left.K_{D E A}\right)$. Assim, sugere-se que, em testes nos quais a reprodutibilidade seja 
um aspecto importante, sejam utilizados, preferencialmente, indicadores com tais características.

Por fim, a assimetria do espectro do sinal eletromiográfico, calculado a partir da razão entre MDF e MNF, não se apresentou como um indicador de fadiga em protocolo isométrico, com o conjunto de voluntários participantes. Esta possibilidade será ainda avaliada em protocolo dinâmico. Na próxima seção, todos os indicadores agora discutidos serão aplicados aos sinais eletromiográficos de voluntários durante atividade de ciclismo.

\section{2 - VALIDAÇÃO EXPERIMENTAL EM PROTOCOLO DINÂMICO (CICLISMO - II): ABORDAGEM DINÂMICA}

Nesta seção são aplicados e validados experimentalmente os descritores eletromiográficos, definidos no quinto capítulo, como indicadores de fadiga muscular em contrações dinâmicas cíclicas. Apresentam-se também os resultados obtidos com as métricas de dispersão definidas no trabalho. A metodologia avaliada nesta seção é a abordagem dinâmica (ver capítulo 5). Além de todos os parâmetros abordados na seção 6.1, nesta seção avaliam-se também a variação do atraso da atividade mioelétrica e a variação da duração das bulhas ao longo dos ciclos, verificando-se a hipótese de apresentarem algum padrão com a ocorrência da fadiga muscular localizada. Portanto, os demais parâmetros propostos na literatura abordados nesta seção são: 1) assimetria espectral, 2) atraso da atividade mioelétrica e 3) duração das bulhas, nesta ordem. Todos os parâmetros foram calculados de acordo com a abordagem dinâmica, isto é, sobre cada ciclo, separadamente.

Para validação como indicadores de fadiga, os descritores foram aplicados aos sinais dos músculos vasto lateral (VL) e vasto medial (VM) dos 8 sujeitos voluntários do Protocolo II no teste com carga e velocidade constantes.

Os indicadores de fadiga são calculados sobre janelas de duração pouco superior a $500 \mathrm{~ms}$, de forma a incluir uma bulha completa de cada ciclo de pedalada, além de um trecho silencioso antes e depois. Assim, tem-se uma resolução espectral de cerca de 2,0 Hz. Como a bulha se anula nos extremos da janela considerada, minimizam-se naturalmente os efeitos de Gibbs e dispensa-se o uso de janelamento no domínio do tempo para o cálculo dos indicadores espectrais. Para os indicadores que utilizam wavelets, as bulhas são 
interpoladas para que ocupem aproximadamente toda a janela - de 1024 amostras -, de forma que a estimação seja diluída por toda a janela temporal dos coeficientes da DWT. Neste processo de reamostragem é utilizado um filtro anti-aliasing de 20 coeficientes com compensação de atraso. A figura 6.3 a seguir ilustra um segmento do eletromiograma obtido com este processo.

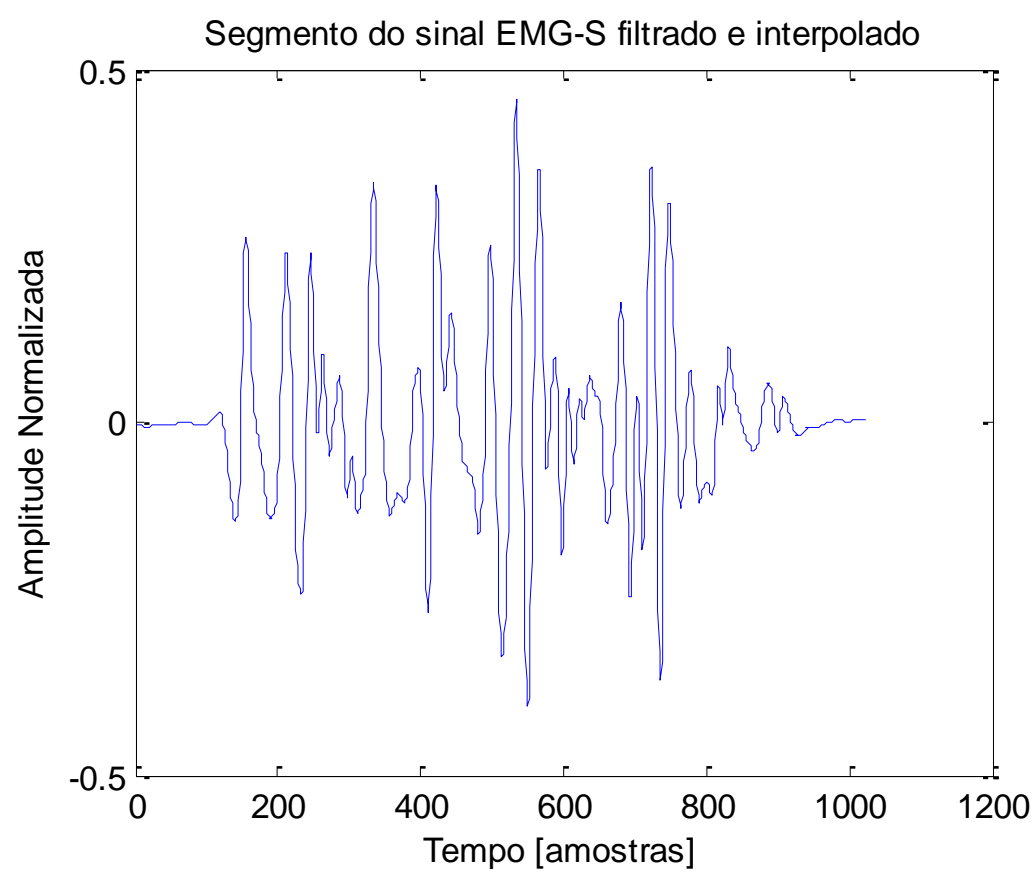

Figura 6.3: Exemplo de um ciclo do sinal EMG-S após pré-processamento, com 1024 amostras. A amplitude é normalizada pelo desvio padrão do sinal EMG-S completo.

Como índice de fadiga global, para todos os descritores, tomou-se o coeficiente de inclinação normalizado - divido pelo valor inicial - da reta obtida pela regressão linear da sequência indicadora de fadiga.

A assimetria espectral foi calculada com a mesma definição utilizada para o protocolo isométrico discutido na seção 6.1. Abordou-se, então, o atraso da atividade mioelétrica. A partir deste parâmetro, em conjunto com sinais de força, pode-se determinar o atraso eletromecânico, definido como o tempo decorrido entre a ativação neural e a ativação muscular. Este parâmetro é diversas vezes abordado na literatura e sugerido como possível indicador de fadiga muscular localizada, porém, em geral, esta hipótese não é avaliada experimentalmente. (Hodges e Rui, 1996; Bonato et al., 1998; Merlo et al., 2003; Lanyi e Adler, 2004; Vanozzi et al., 2010; Costa Filho et al., 2012).

Diversos trabalhos que abordam o ciclismo concluem que os músculos VL e VM 
apresentam padrões temporais similares de ativação, iniciando-se imediatamente antes do ponto morto superior e terminando em posição imediatamente após $90^{\circ}$ completados do ciclo de pedalada (Houtz e Fischer, 1959; Faria e Canavagh, 1978; Jorge e Hull, 1986; Dorel et al., 2008), como ilustrado na figura 6.4 .

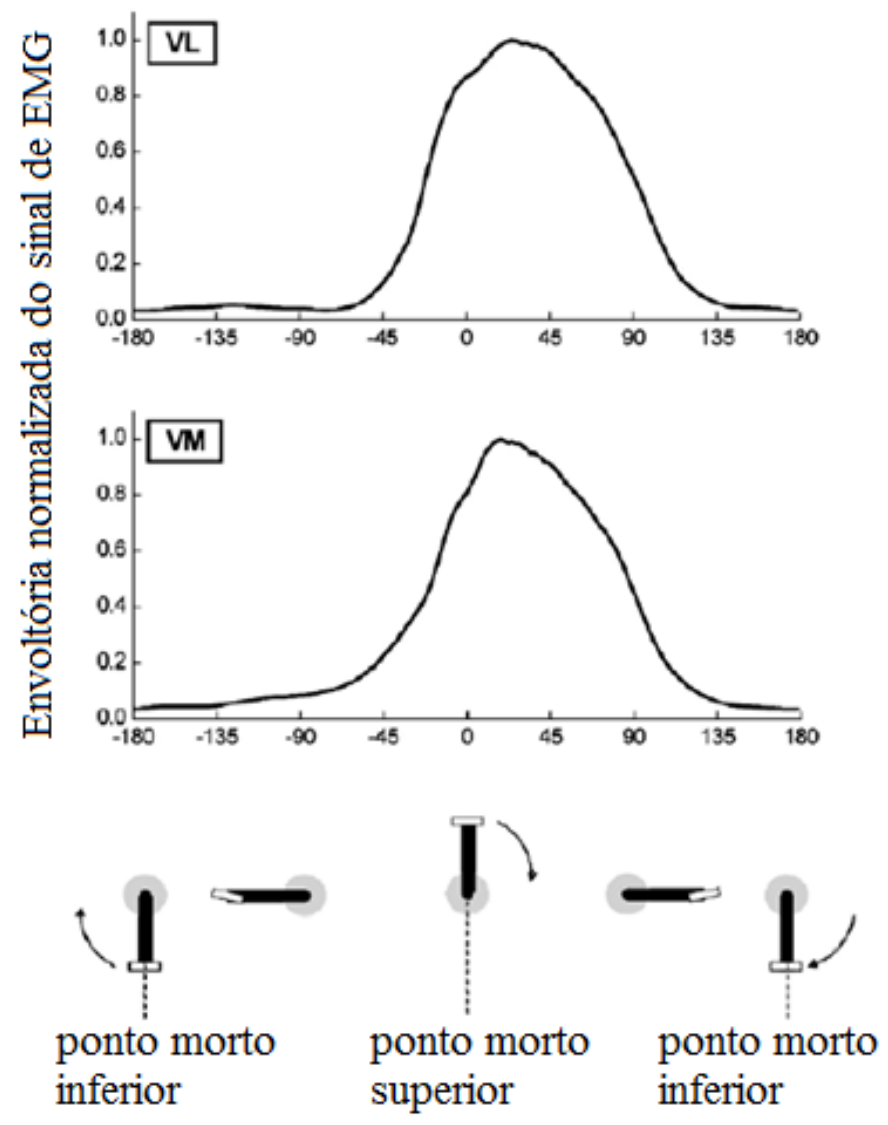

Ângulo do pedivela ao ponto morto superior $\left(^{\circ}\right)$

Figura 6.4: Padrão temporal de ativação muscular do VL e do VM. Adaptado de Hug e Dorel (2009).

Gregor et al. (1982) encontraram resultados contraditórios aos anteriores, reportando uma maior porcentagem do ciclo para a ativação do VM em relação ao VL. Em comum, conforme discutido, em nenhum destes trabalhos foi avaliada a possibilidade de utilizarem-se como indicadores de fadiga os parâmetros relacionados à ativação muscular ao longo dos ciclos de pedalada. É o que será feito ao final desta subseção do trabalho.

Por sua definição, este parâmetro somente se aplica ao caso de contrações dinâmicas, em que o sinal eletromiográfico apresenta padrões de ativação localizados temporalmente, em geral, na forma de bulhas. Este atraso foi calculado de duas maneiras 
distintas: atraso absoluto e atraso normalizado.

O atraso absoluto da atividade mioelétrica (AAM) foi calculado como a duração do intervalo de tempo $\Delta T$ decorrido entre o acionamento do trigger da bicicleta (localizado na extremidade superior que o pedal atinge no ciclo; ver seção 3.1.2.1) e a primeira amostra de um trecho - da bulha correspondente no eletromiograma - cuja energia correspondesse a $99 \%$ da energia total do sinal no ciclo completo. Em resumo, o AAM consiste no atraso ocorrido entre início do ciclo de pedalada e início da atividade mioelétrica significativa. A seguir, a figura 6.5 ilustra como este parâmetro é definido.

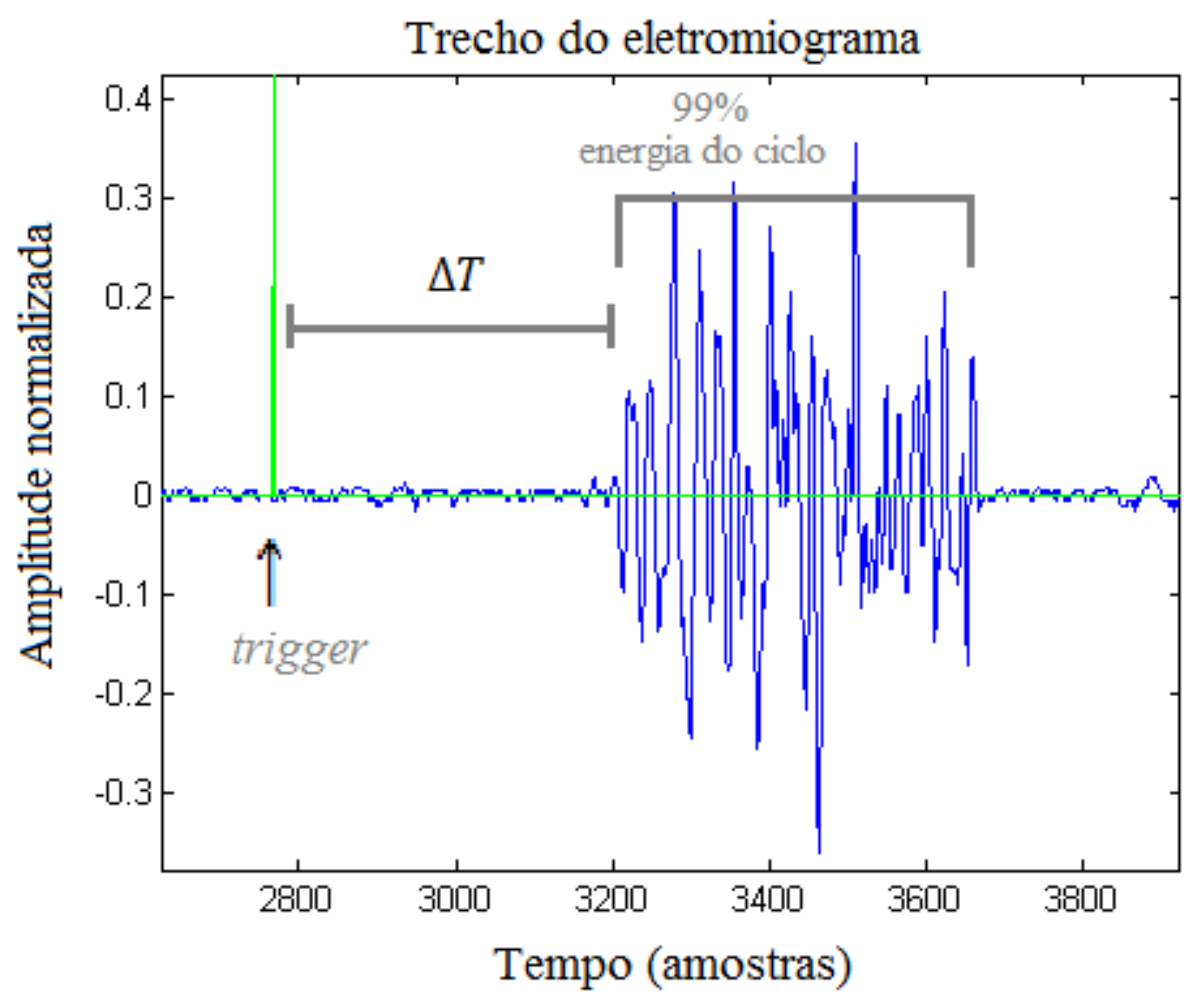

Figura 6.5: Atraso absoluto da atividade mioelétrica (AAM), definida como o intervalo $\Delta T$ indicado: tempo decorrido entre o acionamento do trigger (em verde) e início da atividade mioelétrica significativa no ciclo - definida como o trecho correspondente a $99 \%$ da energia do segmento do sinal eletromiográfico compreendido entre duas ativações consecutivas do trigger.

O atraso normalizado da atividade mioelétrica (ANM) foi definido como a razão entre o intervalo de tempo $\Delta T$ (isto é, a $\mathrm{AAM}$ ) e a duração do ciclo completo, que compreende o tempo decorrido entre dois acionamentos consecutivos do trigger. A aferição do parâmetro ANM motiva-se pela possibilidade de que as pequenas variações na cadência durante o teste influenciem no atraso medido e sua interpretação. Isto é, o ANM 
mede o atraso do início da bulha na forma de intervalo percentual, medida em relação à duração do ciclo completo de pedalada - fração do ciclo decorrida de seu início até o surgimento da bulha.

Os parâmetros AAM e ANM foram calculados para todos os ciclos do eletromiograma, a fim de se verificar se, em média, apresentam tendência - crescente ou decrescente - durante o teste a carga e velocidade constantes, com a indução da fadiga nos músculos VL e VM.

Finalmente, a duração das bulhas, assim como AAM e ANM, também foi aferida de duas maneiras: duração absoluta e duração normalizada das bulhas. A duração absoluta das bulhas foi calculada simplesmente como a duração do trecho que compreende $99 \%$ da energia do ciclo, conforme já indicado na Figura 6.4. Portanto, representa a duração, de fato, da bulha. O termo 'absoluta' visa diferenciar o outro tipo de duração aqui tratado: a duração normalizada das bulhas. A duração normalizada das bulhas foi calculada como a razão entre duração absoluta da bulha e a duração do ciclo completo. Assim, a duração normalizada representa a fração do ciclo de pedalada em que a atividade mioelétrica apresenta amplitude significativa.

Para todos os índices foi adotado o seguinte procedimento: para verificar se os dados obtidos apresentam média não nula, foi aplicado o teste $\mathrm{t}(\alpha=0,05)$ com a hipótese nula de que a média dos índices obtidos foi igual a zero. A normalidade dos dados (índices) obtidos foi previamente verificada (Shapiro-Wilk, $p>0,05$ ). Para os casos em que a normalidade não se verifica, utilizou-se o teste não paramétrico de Wilcoxon $(\alpha=0,05)$.

Como medida de variabilidade entre os sujeitos, calculou-se o coeficiente de variação $(\mathrm{CoV})$ para o conjunto de índices obtidos. Para avaliação da reprodutibilidade, foram aplicadas - às sequências descritoras de fadiga - as métricas de dispersão discutidas no capítulo $5\left(\operatorname{CoV}, I_{D_{\text {pol }}}\right.$ e $\left.I_{D_{d i f}}\right)$.

\subsection{1 - Resultados e discussão}

\subsubsection{1 - Índices tradicionais e propostos}

Nesta subseção serão mostrados e discutidos os índices, clássicos e propostos no trabalho, obtidos para os sinais do Protocolo II (músculos VL e VM, carga e velocidade 
constantes) utilizando a metodologia - envolvendo abordagem dinâmica - proposta na tese. Os índices clássicos aplicados foram: o valor RMS, a MDF e a MNF. Os índices definidos na tese são: $K_{D E W}, K_{C E W}, K_{D E A}, K_{C E A}$, calculados no domínio da DWT; $s_{E}$, utilizando a DFT; e $d_{P E}$, no domínio do tempo.

As tabelas 6.8, 6.9 e 6.10 a seguir apresentam, respectivamente, os valores obtidos para os indicadores (músculo VL) definidos no domínio do tempo, no domínio da frequência e no domínio da DWT. Ao final de cada tabela constam os resultados dos testes estatísticos para validação (para normalidade dos dados e para média diferente de zero).

Tabela 6.8 - Índices de fadiga (VL) definidos no domínio do tempo, valores $p$ do teste de Shapiro-Wilk e do teste t. Teste a carga constante e velocidade constante.

\begin{tabular}{|c|c|c|}
\hline Sujeito & RMS $\left(* 10^{-3}\right)$ & $d_{P E}\left(* 10^{-3}\right)$ \\
\hline $\mathrm{S} 1$ & 1,7819 & 1,2386 \\
\hline $\mathrm{S} 2$ & 1,0970 & 0,8733 \\
\hline $\mathrm{S} 3$ & 1,2357 & 0,8120 \\
\hline $\mathrm{S} 4$ & 2,4227 & 1,3049 \\
\hline $\mathrm{S} 5$ & 0,0253 & 0,0810 \\
\hline $\mathrm{S} 6$ & 1,3124 & 0,9325 \\
\hline $\mathrm{S} 7$ & 1,3501 & 1,4249 \\
\hline $\mathrm{S} 8$ & 1,2220 & 0,8713 \\
\hline$\mu \pm \sigma$ & $1,31 \pm 0,67$ & $0,94 \pm 0,42$ \\
\hline $\begin{array}{c}\text { Valor } p \\
\text { Shapiro-Wilk) }\end{array}$ & 0,319180 & 0,189669 \\
\hline $\begin{array}{c}\text { Valor } p \\
\text { (teste } \mathrm{t})\end{array}$ & $<0,001$ & $<0,001$ \\
\hline
\end{tabular}

Tabela 6.9 - Índices de fadiga (VL) definidos no domínio da frequência, valores $p$ do teste de Shapiro-Wilk e do teste t. Teste a carga constante e velocidade constante.

\begin{tabular}{|c|c|c|c|}
\hline Sujeito & MNF $\left(* 10^{-3}\right)$ & MDF $\left(* 10^{-3}\right)$ & $S_{E}\left(* 10^{-5}\right)$ \\
\hline S1 & $-0,3839$ & $-0,3080$ & 4,23 \\
\hline S2 & $-0,3448$ & $-0,2680$ & 1,57 \\
\hline S3 & $-0,6279$ & $-0,5795$ & 4,13 \\
\hline S4 & $-0,8595$ & $-0,8111$ & 11,68 \\
\hline S5 & $-0,2147$ & $-0,2097$ & 1,08 \\
\hline S6 & $-0,3184$ & $-0,3024$ & 2,62 \\
\hline S7 & $-0,3985$ & $-0,4793$ & 7,35 \\
\hline S8 & $-0,5783$ & $-0,5438$ & 6,45 \\
\hline$\mu \pm \sigma$ & $-0,47 \pm 0,21$ & $-0,44 \pm 0,20$ & $4,89 \pm 3,51$ \\
\hline $\begin{array}{c}\text { Valor } p \\
\text { Shapiro-Wilk) }\end{array}$ & 0,441037 & 0,407959 & 0,443531 \\
\hline $\begin{array}{c}\text { Valor } p \\
\text { (teste t) }\end{array}$ & $<0,001$ & $<0,001$ & $<0,01$ \\
\hline
\end{tabular}


Tabela 6.10 - Índices de fadiga (VL) utilizando wavelets, valores $p$ do teste de ShapiroWilk e do teste t. Teste a carga constante e velocidade constante.

\begin{tabular}{|c|c|c|c|c|}
\hline Sujeito & $K_{D E W} *\left(10^{-3}\right)$ & $K_{C E W}\left(* 10^{-4}\right)$ & $K_{D E A}\left(* 10^{-4}\right)$ & $K_{C E A}\left(* 10^{-5}\right)$ \\
\hline S1 & 0,4273 & 1,788 & $-0,413$ & 0,9811 \\
\hline S2 & 0,3775 & 1,352 & 2,283 & 1,3761 \\
\hline S3 & 1,6884 & 3,739 & 2,108 & 1,8419 \\
\hline S5 & 1,4089 & 3,994 & 5,273 & 3,8433 \\
\hline S6 & 0,2582 & 0,877 & 0,575 & 0,6488 \\
\hline S7 & 0,2762 & 0,988 & 0,904 & 0,9383 \\
\hline S8 & 0,5428 & 1,766 & 3,278 & 2,4803 \\
\hline$\mu \pm \sigma$ & $0,64 \pm 0,58$ & $1,90 \pm 1,28$ & $2,39 \pm 2,07$ & $1,86 \pm 1,10$ \\
\hline $\begin{array}{c}\text { Valor } p \\
\text { Shapiro-Wilk) }\end{array}$ & $\mathbf{0 , 0 1 8 1 6 4}$ & 0,055275 & 0,584291 & 0,483445 \\
\hline $\begin{array}{c}\text { Valor } p \\
\text { (teste t) }\end{array}$ & - & $<0,01$ & $<0,01$ & $<0,001$ \\
\hline
\end{tabular}

* Teste de Wilcoxon para $K_{D E W}: p<0,05$

Para o índice $K_{D E W}$, não se confirma a hipótese nula de normalidade $(p<0,05)$. Portanto, utilizou-se o teste não paramétrico de Wilcoxon para verificar que a distribuição dos índices possui média positiva $(p<0,05)$. As tabelas $6.11,6.12$ e 6.13 a seguir apresentam, respectivamente, os valores obtidos para os indicadores (músculo VM) definidos no domínio do tempo, no domínio da frequência e no domínio da DWT. Ao final de cada tabela constam os resultados dos testes estatísticos para validação (para normalidade dos dados e para média diferente de zero).

Tabela 6.11 - Índices de fadiga (VM) definidos no domínio do tempo, valores $p$ do teste de Shapiro-Wilk e do teste t. Teste a carga constante e velocidade constante.

\begin{tabular}{|c|c|c|}
\hline Sujeito & RMS $\left(* 10^{-3}\right)$ & $d_{P E}\left(* 10^{-3}\right)$ \\
\hline S1 & 2,9641 & 2,6675 \\
\hline S2 & 0,6320 & 0,4038 \\
\hline S3 & 1,3273 & 0,8299 \\
\hline S 5 & 3,9596 & 3,6810 \\
\hline S6 & 0,1034 & 0,1262 \\
\hline S7 & 1,0881 & 1,0175 \\
\hline S8 & 0,8723 & 0,7121 \\
\hline$\mu \pm \sigma$ & $1,46 \pm 1,31$ & 0,0494 \\
\hline $\begin{array}{c}\text { Valor } p \\
(\text { Shapiro-Wilk) }\end{array}$ & 0,078419 & $\mathbf{0 , 0 4 7 3 5 7}$ \\
\hline $\begin{array}{c}\text { Valor } p \\
\text { (teste } \mathrm{t})\end{array}$ & $<0,01$ & $*$ \\
\hline
\end{tabular}

* Teste de Wilcoxon para $d_{P E}: p<0,05$ 
Tabela 6.12 - Índices de fadiga (VM) definidos no domínio da frequência, valores $p$ do teste de Shapiro-Wilk e do teste t. Teste a carga constante e velocidade constante.

\begin{tabular}{|c|c|c|c|}
\hline Sujeito & MNF $\left(* 10^{-4}\right)$ & MDF $\left(* 10^{-4}\right)$ & $S_{E}\left(* 10^{-4}\right)$ \\
\hline S1 & $-6,0454$ & $-4,0934$ & 0,3142 \\
\hline S2 & $-0,6163$ & $-0,9881$ & 0,2179 \\
\hline S3 & $-9,2263$ & $-8,4385$ & 1,0185 \\
\hline S5 & $-4,4711$ & $-7,9055$ & 1,2142 \\
\hline S6 & 0,6575 & 0,8432 & $-0,0465$ \\
\hline S7 & 0,8391 & 0,9650 & 0,1345 \\
\hline S8 & $-1,6496$ & $-3,0249$ & 0,3395 \\
\hline$\mu \pm \sigma$ & $-3,38 \pm 3,7$ & $-3,58 \pm 3,70$ & $0,49 \pm 0,44$ \\
\hline $\begin{array}{c}\text { Valor } p \\
\text { Shapiro-Wilk) }\end{array}$ & 0,463667 & 0,451423 & 0,398224 \\
\hline $\begin{array}{c}\text { Valor } p \\
\text { (teste t) }\end{array}$ & $<0,05$ & $<0,05$ & $<0,01$ \\
\hline
\end{tabular}

Tabela 6.13 - Índices de fadiga (VM) utilizando wavelets, valores $p$ do teste de ShapiroWilk e do teste t. Teste a carga constante e velocidade constante.

\begin{tabular}{|c|c|c|c|c|}
\hline Sujeito & $K_{D E W}\left(* 10^{-3}\right)$ & $K_{C E W}\left(* 10^{-4}\right)$ & $K_{D E A}\left(* 10^{-4}\right)$ & $K_{C E A}\left(* 10^{-5}\right)$ \\
\hline S1 & 2,6525 & 5,5141 & 3,6252 & 2,5759 \\
\hline S2 & 0,4210 & 1,0104 & 1,4416 & 0,7369 \\
\hline S3 & 4,1193 & 7,2329 & 8,0658 & 4,3833 \\
\hline S4 & 0,5453 & 1,9935 & 5,0721 & 3,8288 \\
\hline S5 & 0,0224 & 0,0592 & $-0,5467$ & $-0,3112$ \\
\hline S6 & $-0,1283$ & $-0,5537$ & 0,0305 & $-0,1313$ \\
\hline S7 & 0,1798 & 0,4277 & 0,1867 & 0,3234 \\
\hline S8 & 0,4832 & 1,8487 & 3,5009 & 2,6434 \\
\hline$\mu \pm \sigma$ & $1,04 \pm 1,52$ & $2,19 \pm 2,76$ & $2,67 \pm 2,96$ & $1,76 \pm 1,83$ \\
\hline $\begin{array}{c}\text { Valor } p \\
\text { Shapiro-Wilk) }\end{array}$ & $\mathbf{0 , 0 0 7 1 6 5}$ & 0,116092 & 0,437069 & 0,279618 \\
\hline $\begin{array}{c}\text { Valor } p \\
\text { (teste t) }\end{array}$ & $*$ & $<0,05$ & $<0,05$ & $<0,05$ \\
\hline
\end{tabular}

* Teste de Wilcoxon para $K_{D E W}: p<0,05$

Não se confirmando a hipótese nula de normalidade (Shapiro-Wilk, $p<0,05$ ) para os índices $d_{P E}$ e $K_{D E W}$, utilizou-se o teste não paramétrico de Wilcoxon para verificar que suas distribuições apresentaram média positiva $(p<0,05)$.

Estes resultados indicam que todos os índices - tradicionais e propostos apresentaram o padrão esperado com o processo da fadiga muscular nos músculos VL e VM. Validam-se experimentalmente, portanto, como indicadores deste fenômeno em ciclismo utilizando-se a abordagem dinâmica. Apesar de os testes estatísticos fornecerem resultados mais significativos para o músculo VL (comparar os valores $p$ dos testes de 
média), ambos os músculos experimentaram a fadiga muscular localizada neste protocolo. Mais adiante, são abordadas em maiores detalhes as correlações observadas entre a fadiga localizada no VL e no VM em ciclismo. As figuras 6.6 e 6.7 a seguir mostram, para os sinais do VL e do VM de um dos sujeitos, as sequências descritoras de fadiga obtidas para cada indicador eletromiográfico.
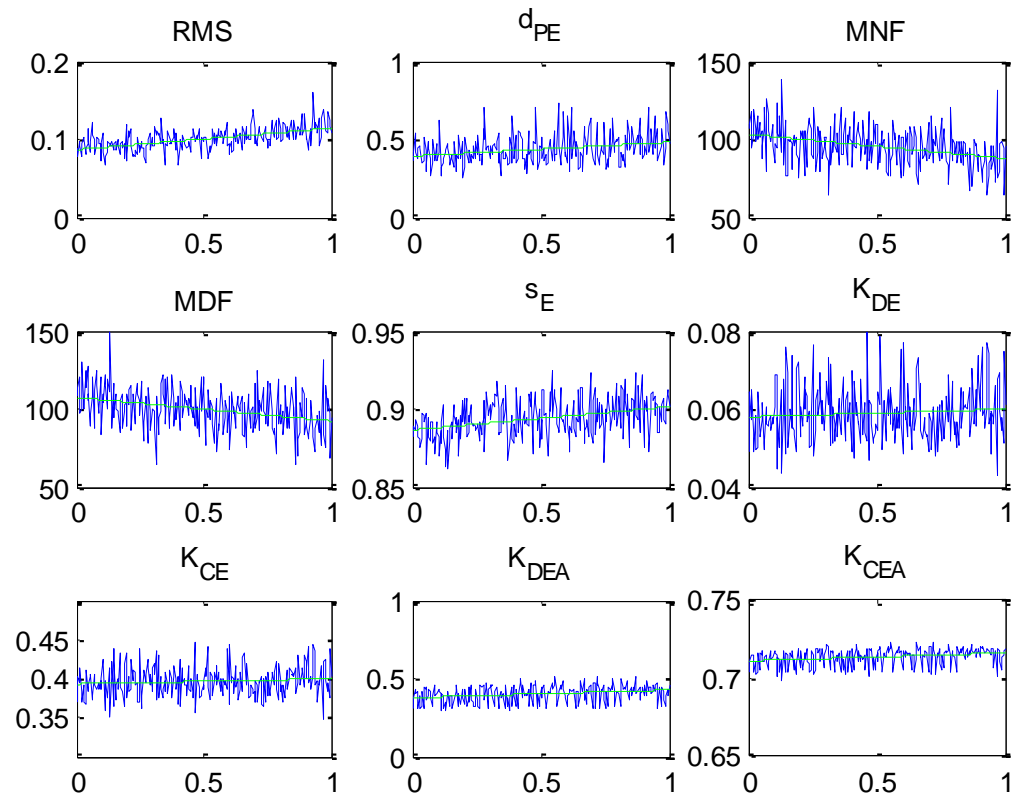

Figura 6.6: Sequências descritoras de fadiga do músculo VL obtidas para cada indicador eletromiográfico (em azul) e respectivos ajustes lineares (em verde). Exemplo dos resultados obtidos para um dos sujeitos $\left(n^{\circ} 8\right)$. 

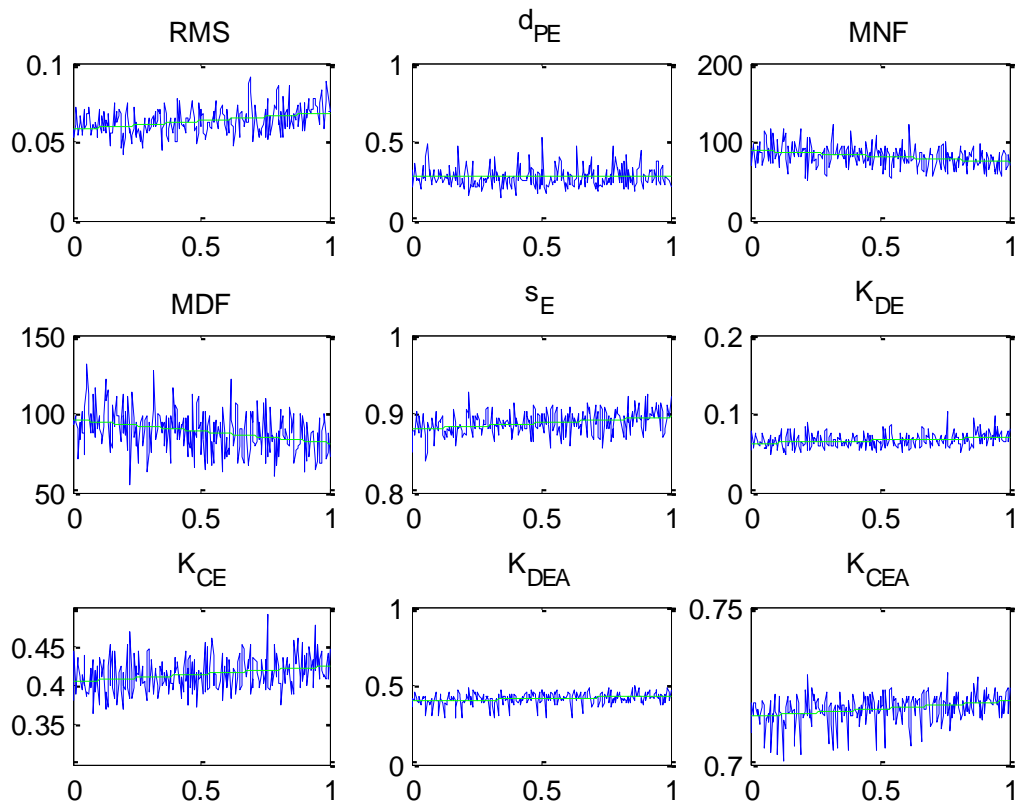

Figura 6.7: Sequências descritoras de fadiga do músculo VL obtidas para cada indicador eletromiográfico (em azul) e respectivos ajustes lineares (em verde). Exemplo dos resultados obtidos para um dos sujeitos $\left(\mathrm{n}^{\mathrm{o}} 8\right)$.

A seguir, a tabela 6.14 apresenta a variabilidade dos índices para o grupo de voluntários participantes do experimento para os músculos VL e VM. A variabilidade foi calculada como a razão entre o desvio padrão e a média dos dados obtidos para o conjunto dos oito sujeitos.

Tabela 6.14 - Variabilidade dos índices (para VL e VM) obtidos para o conjunto dos sujeitos. Teste a carga constante e velocidade constante.

\begin{tabular}{|c|c|c|}
\hline Índices & $\begin{array}{c}\text { Variabilidade } \\
\operatorname{VL}(\sigma / \mu)\end{array}$ & $\begin{array}{c}\text { Variabilidade } \\
\text { VM }(\sigma / \mu)\end{array}$ \\
\hline RMS & 0,51542 & 0,90124 \\
\hline$d_{P E}$ & 0,44319 & 1,096 \\
\hline MNF & 0,44789 & 1,1018 \\
\hline MDF & 0,46374 & 1,0328 \\
\hline$S_{E}$ & 0,71893 & 0,91671 \\
\hline$K_{D E W}$ & 0,9071 & 1,4654 \\
\hline$K_{C E W}$ & 0,67643 & 1,2579 \\
\hline$K_{D E A}$ & 0,86607 & 1,1091 \\
\hline$K_{C E A}$ & 0,5914 & 0,90124 \\
\hline$\sigma \pm \mu$ & $0,63 \pm 0,18$ & $1,09 \pm 0,19$ \\
\hline$p$ (Shapiro-Wilk) & 0,205220 & 0,175546 \\
\hline
\end{tabular}

As diferenças obtidas para a variabilidade entre sujeitos em cada índice sugerem que cada 
indicador afere uma manifestação mioelétrica de forma distinta - entre os músculos VL e VM - relacionada à fadiga muscular. Verifica-se (teste $\mathrm{t} ; p<0,001$ ) que, em geral, a variabilidade obtida para o vasto medial foi significativamente superior à do vasto lateral com o uso da abordagem dinâmica.

\subsubsection{2 - Dispersão dos indicadores}

Nesta subseção apresentam-se os valores de dispersão ( $\operatorname{CoV}, I_{D_{p o l}}$ e $\left.I_{D_{\text {dif }}}\right)$ obtidos para os indicadores de fadiga em ciclismo utilizando a abordagem dinâmica com carga e velocidade constantes, para os músculos VL e VM. As tabelas 6.15, 6.16, e 6.17 a seguir mostram os valores obtidos para os indicadores temporais no músculo VL, para os indicadores temporais, no domínio da frequência e da DWT, respectivamente.

Tabela 6.15 - Dispersão para os indicadores de fadiga no domínio do tempo (VL). Teste a carga constante e velocidade constante.

\begin{tabular}{|c|c|c|}
\hline Métrica & $\begin{array}{c}\text { RMS } \\
(\mu \pm \sigma)\end{array}$ & $\begin{array}{c}d_{P E} \\
(\mu \pm \sigma)\end{array}$ \\
\hline$C o V$ & $0,17 \pm 0,02$ & $0,23 \pm 0,02$ \\
\hline$I_{D_{\text {pol }}}$ & $0,15 \pm 0,01$ & $0,23 \pm 0,03$ \\
\hline$I_{D_{\text {dif }}}$ & $0,14 \pm 0,02$ & $0,22 \pm 0,02$ \\
\hline
\end{tabular}

Tabela 6.16 - Dispersão para os indicadores de fadiga no domínio da frequência (VL).

Teste a carga constante e velocidade constante.

\begin{tabular}{|c|c|c|c|}
\hline Métrica & $\begin{array}{c}\text { MNF } \\
(\mu \pm \sigma)\end{array}$ & $\begin{array}{c}\text { MDF } \\
(\mu \pm \sigma)\end{array}$ & $\begin{array}{c}s_{E} \\
(\mu \pm \sigma)\end{array}$ \\
\hline $\operatorname{CoV}$ & $0,13 \pm 0,02$ & $0,13 \pm 0,03$ & $0,01 \pm 0,002$ \\
\hline$I_{D_{\text {pol }}}$ & $0,13 \pm 0,02$ & $0,13 \pm 0,03$ & $0,01 \pm 0,002$ \\
\hline$I_{D_{\text {dif }}}$ & $0,13 \pm 0,02$ & $0,13 \pm 0,03$ & $0,01 \pm 0,001$ \\
\hline
\end{tabular}

Tabela 6.17 - Dispersão para os indicadores de fadiga no domínio da DWT (VL). Teste a carga constante e velocidade constante.

\begin{tabular}{|c|c|c|c|c|}
\hline Métrica & $\begin{array}{c}K_{D E W} \\
(\mu \pm \sigma)\end{array}$ & $\begin{array}{c}K_{C E W} \\
(\mu \pm \sigma)\end{array}$ & $\begin{array}{c}K_{D E A} \\
(\mu \pm \sigma)\end{array}$ & $\begin{array}{c}K_{C E A} \\
(\mu \pm \sigma)\end{array}$ \\
\hline$C o V$ & $0,15 \pm 0,05$ & $0,05 \pm 0,006$ & $0,09 \pm 0,03$ & $0,005 \pm 0,002$ \\
\hline$I_{D_{\text {pol }}}$ & $0,15 \pm 0,05$ & $0,05 \pm 0,006$ & $0,08 \pm 0,03$ & $0,005 \pm 0,002$ \\
\hline$I_{D_{\text {dif }}}$ & $0,15 \pm 0,05$ & $0,05 \pm 0,006$ & $0,08 \pm 0,03$ & $0,005 \pm 0,002$ \\
\hline
\end{tabular}

Para o músculo VL, todos os indicadores espectrais - utilizando DWT ou DFT - propostos 
neste trabalho apresentaram-se menos dispersos do que os tradicionais (MNF e MDF), à exceção de $K_{D E W}$, que apresentou valores semelhantes. Nota-se ainda que, neste protocolo dinâmico com abordagem dinâmica, as três métricas de dispersão resultaram valores muito próximos para cada indicador espectral. Uma observação interessante é que as dispersões polinomiais e diferenciais, apesar de definidas de maneiras bastante distintas, forneceram resultados sempre iguais, a menos de três casas decimais. Observações semelhantes podem ser feitas para o VM. As tabelas 6.18, 6.19, e 6.20 a seguir mostram os valores obtidos para os indicadores temporais no músculo VM, para os indicadores temporais, no domínio da frequência e da DWT, respectivamente.

Tabela 6.18 - Dispersão para os indicadores de fadiga no domínio do tempo (VM). Teste a carga constante e velocidade constante.

\begin{tabular}{|c|c|c|}
\hline Métrica & $\begin{array}{c}\text { RMS } \\
(\mu \pm \sigma)\end{array}$ & $\begin{array}{c}d_{P E} \\
(\mu \pm \sigma)\end{array}$ \\
\hline$C o V$ & $0,18 \pm 0,03$ & $0,27 \pm 0,04$ \\
\hline$I_{D_{\text {pol }}}$ & $0,17 \pm 0,02$ & $0,26 \pm 0,03$ \\
\hline$I_{D_{\text {dif }}}$ & $0,15 \pm 0,02$ & $0,38 \pm 0,40$ \\
\hline
\end{tabular}

Tabela 6.19 - Dispersão para os indicadores de fadiga no domínio da frequência (VM).

Teste a carga constante e velocidade constante.

\begin{tabular}{|c|c|c|c|}
\hline Métrica & $\begin{array}{c}\text { MNF } \\
(\mu \pm \sigma)\end{array}$ & $\begin{array}{c}\text { MDF } \\
(\mu \pm \sigma)\end{array}$ & $\begin{array}{c}S_{E} \\
(\mu \pm \sigma)\end{array}$ \\
\hline$C o V$ & $0,15 \pm 0,016$ & $0,14 \pm 0,014$ & $0,013 \pm 0,0024$ \\
\hline$I_{D_{\text {pol }}}$ & $0,15 \pm 0,015$ & $0,14 \pm 0,014$ & $0,013 \pm 0,0023$ \\
\hline$I_{D_{\text {dif }}}$ & $0,14 \pm 0,015$ & $0,14 \pm 0,016$ & $0,013 \pm 0,0023$ \\
\hline
\end{tabular}

Tabela 6.20 - Dispersão para os indicadores de fadiga no domínio da DWT (VM). Teste a carga constante e velocidade constante.

\begin{tabular}{|c|c|c|c|c|}
\hline Métrica & $\begin{array}{c}K_{D E W} \\
(\mu \pm \sigma)\end{array}$ & $\begin{array}{c}K_{C E W} \\
(\mu \pm \sigma)\end{array}$ & $\begin{array}{c}K_{D E A} \\
(\mu \pm \sigma)\end{array}$ & $\begin{array}{c}K_{C E A} \\
(\mu \pm \sigma)\end{array}$ \\
\hline $\operatorname{CoV}$ & $0,19 \pm 0,089$ & $0,056 \pm 0,0087$ & $0,097 \pm 0,022$ & $0,0057 \pm 0,0013$ \\
\hline$I_{D_{\text {pol }}}$ & $0,18 \pm 0,075$ & $0,054 \pm 0,0069$ & $0,095 \pm 0,022$ & $0,0056 \pm 0,0013$ \\
\hline$I_{D_{\text {dif }}}$ & $0,17 \pm 0,063$ & $0,052 \pm 0,0047$ & $0,095 \pm 0,022$ & $0,0056 \pm 0,0014$ \\
\hline
\end{tabular}

Novamente, os indicadores espectrais propostos neste trabalho apresentaram-se menos dispersos do que os tradicionais, à exceção de $K_{D E W}$. No caso do músculo VM, $K_{D E W}$ apresentou dispersão comparável à do parâmetro temporal RMS. Assim como para o VL, as três métricas de dispersão resultaram valores muito próximos entre si para cada indicador espectral, especialmente dispersões polinomiais e diferenciais, apesar de 
definidas de maneiras bastante distintas. Em geral, as métricas de dispersão dos indicadores apresentaram resultados semelhantes entre VL e VM.

Em ambos os protocolos experimentais utilizados para validação dos índices (contração isométrica de bíceps e VL e VM em ciclismo), os parâmetros espectrais que aferem a compressão (e estreitamento) do espectro apresentaram-se significativamente menos dispersos do que aqueles que aferem deslocamento espectral. Assim, sugere-se que seu uso apresente utilidade na elaboração de métodos reprodutíveis para monitoração e avaliação da fadiga muscular localizada. Note-se que na literatura disponível, a grande maioria dos estudos envolvendo a observação da fadiga muscular no domínio da frequência utiliza as frequências média, mediana e demais percentis. Por fim, verifica-se que as versões adaptativas dos indicadores baseados em wavelets obtiveram dispersões significativamente menores do que suas versões não adaptativas. Assim, a possibilidade de adaptar-se a decomposição do eletromiograma no banco de filtros às características locais do sinal - simultaneamente ao cálculo do valor da sequência descritora de fadiga mostrou-se útil na avaliação de fadiga muscular.

\subsubsection{3 - Outros parâmetros citados na literatura}

Nesta subseção avaliam-se os demais parâmetros abordados - para verificação da hipótese de que apresentem padrão com a fadiga muscular, 1) a assimetria do espectro de amplitude, 2) a variação do atraso da atividade mioelétrica e 3) variação da duração das bulhas ao longo dos ciclos de contração (pedaladas). Os resultados de assimetria espectral são mostrados nas figuras 6.8 e 6.9 e na tabela 6.21 a seguir. 

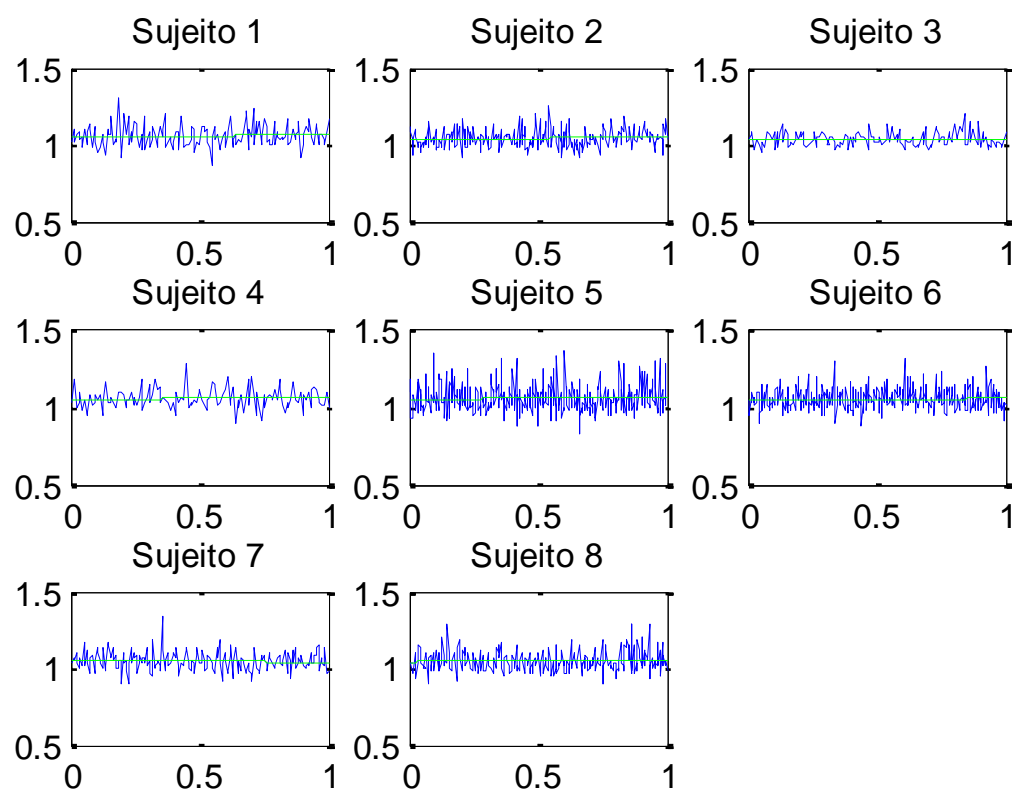

Figura 6.8: Assimetria do espectro de amplitude do eletromiograma ao longo do tempo (em azul) e respectivo ajuste linear (em verde). Sinais do músculo vasto lateral em teste a carga e velocidade constantes. Todos os sujeitos. Eixo do tempo normalizado pela duração total do exercício.
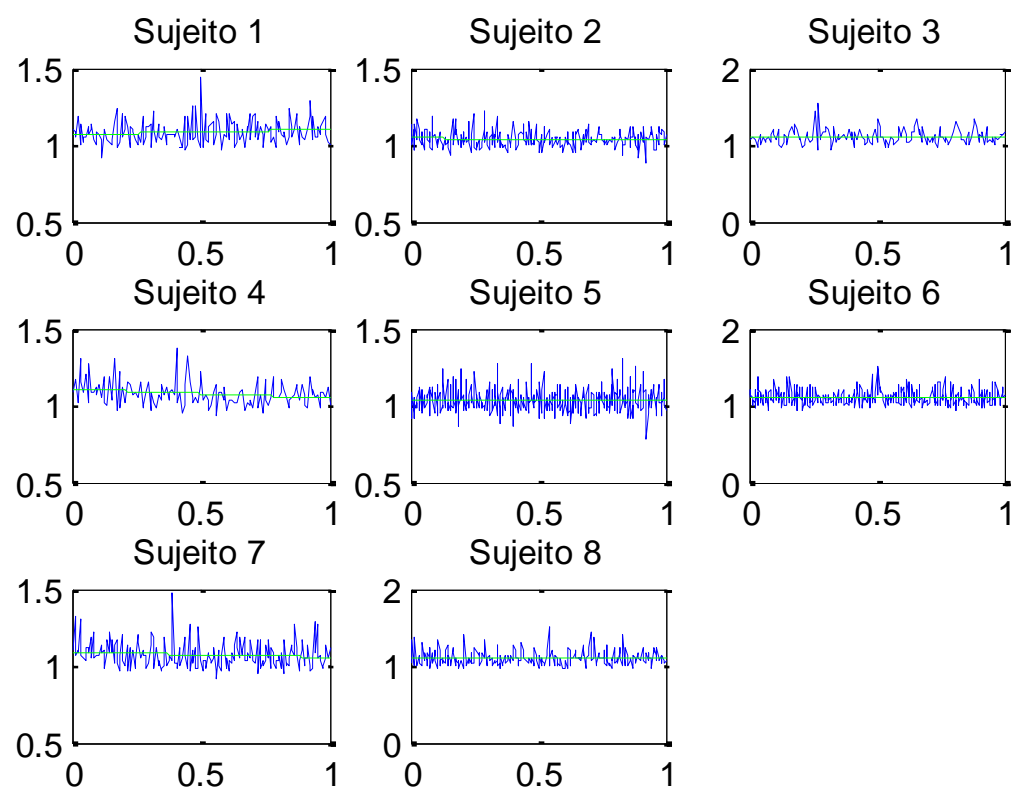

Figura 6.9: Assimetria do espectro de amplitude do eletromiograma ao longo do tempo (em azul) e respectivo ajuste linear (em verde). Sinais do músculo vasto medial em teste a carga e velocidade constantes. Todos os sujeitos. Eixo do tempo normalizado pela duração total do exercício. 
Tabela 6.21 - Índices obtidos a partir da assimetria espectral do sinal de EMG-S em ciclismo (teste com carga e velocidade constantes) para os músculos VL e VM.

\begin{tabular}{|c|c|c|}
\hline Sujeitos & VL & VM \\
\hline $\mathrm{S} 1$ & 7.8689 & 1.9550 \\
\hline $\mathrm{S} 2$ & 8.3435 & -0.3998 \\
\hline $\mathrm{S} 3$ & 5.4369 & 0.8798 \\
\hline $\mathrm{S} 4$ & 4.9017 & -4.1132 \\
\hline $\mathrm{S} 5$ & 0.8517 & 0.1995 \\
\hline $\mathrm{S} 6$ & 1.7646 & 0.1617 \\
\hline $\mathrm{S} 7$ & -7.7427 & -1.5352 \\
\hline $\mathrm{S} 8$ & 3.4876 & 0.4298 \\
\hline $\begin{array}{c}\text { Valor } p \\
\text { (Shapiro-Wilk) }\end{array}$ & 0,1709 & 0,2438 \\
\hline $\begin{array}{c}\text { Valor } p \\
\text { (Teste t bicaudal) }\end{array}$ & 0,1291 & 0,6547 \\
\hline $\begin{array}{c}\text { Valor } p \\
\text { (Teste t unicaudal } \\
\text { à direita) }\end{array}$ & 0,0645 & 0,6726 \\
\hline $\begin{array}{c}\text { Valor } p \\
\text { (Teste t unicaudal } \\
\text { à esquerda) }\end{array}$ & 0,9355 & 0,3274 \\
\hline
\end{tabular}

Os dados para VL e VM confirmam a hipótese nula de normalidade (Shapiro-Wilk, $p>0,05)$. Como se observam - especialmente para o VM - índices positivos e negativos, $\mathrm{o}$ teste $\mathrm{t}$ foi aplicado em suas três formas básicas. Apesar de o resultado do teste $\mathrm{t}$ unicaudal à direita para o VL aproximar-se do nível de significância, os resultados aqui verificados, em conjunto com o que se observou na seção 6.1.1.3, sugerem que a assimetria do espectro do sinal de EMG-S não constitui um parâmetro indicador de fadiga em contrações isométricas nem em contrações cíclicas com carga e velocidade constantes. Isto indica que o espectro de amplitude do eletromiograma, durante a indução da fadiga, em média, não apresenta aumento relativo entre sua cauda à direita (altas frequências) ou à esquerda (baixas frequências). Isto é, sua forma inicialmente observada não sofre significativas variações ao longo do teste até o ponto de ruptura. Além de não se comportarem como indicadores de fadiga em ciclismo nestas condições, os índices obtidos para VL e VM não diferem significativamente (Anova, $p>0,05$ ), conforme ilustra a figura 6.10 a seguir. 


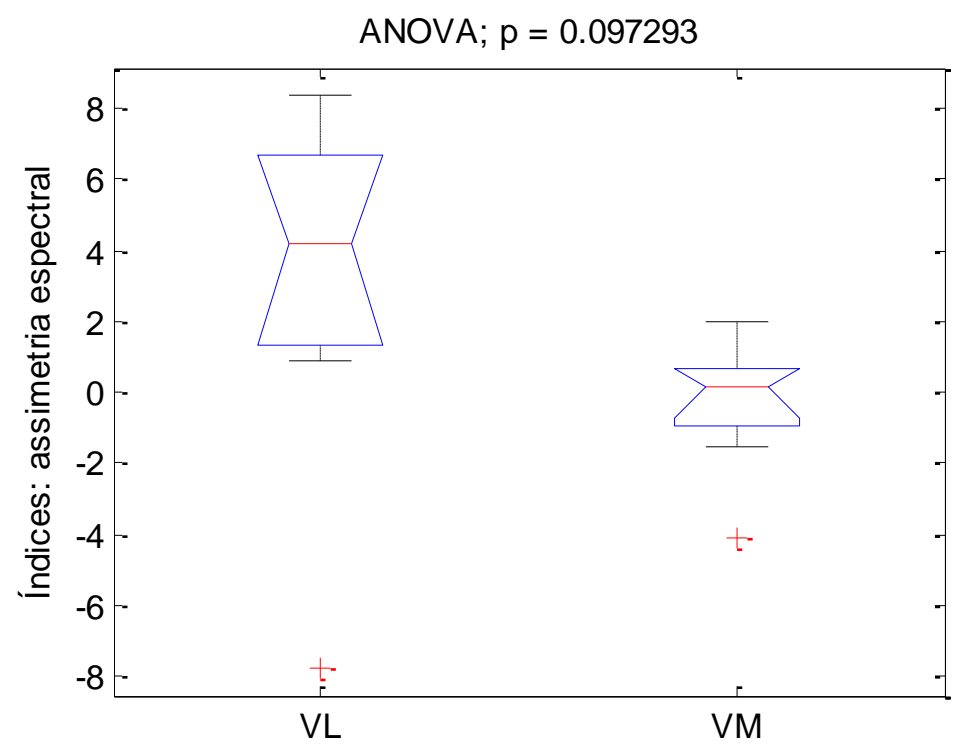

Figura 6.10: Comparação (Anova, $\alpha=0,05$ ) entre os dados obtidos para o VL e o VM para a variação da assimetria do espectro ao longo do teste. Não se observam diferenças significativas $(p>0,05)$ a partir destes resultados.

A seguir apresentam-se os resultados obtidos para o atraso da atividade mioelétrica. As figuras 6.11 e 6.12 apresentam os resultados obtidos para o atraso absoluto da atividade mioelétrica, para todos os sujeitos, para os músculos VL e VM, respectivamente.
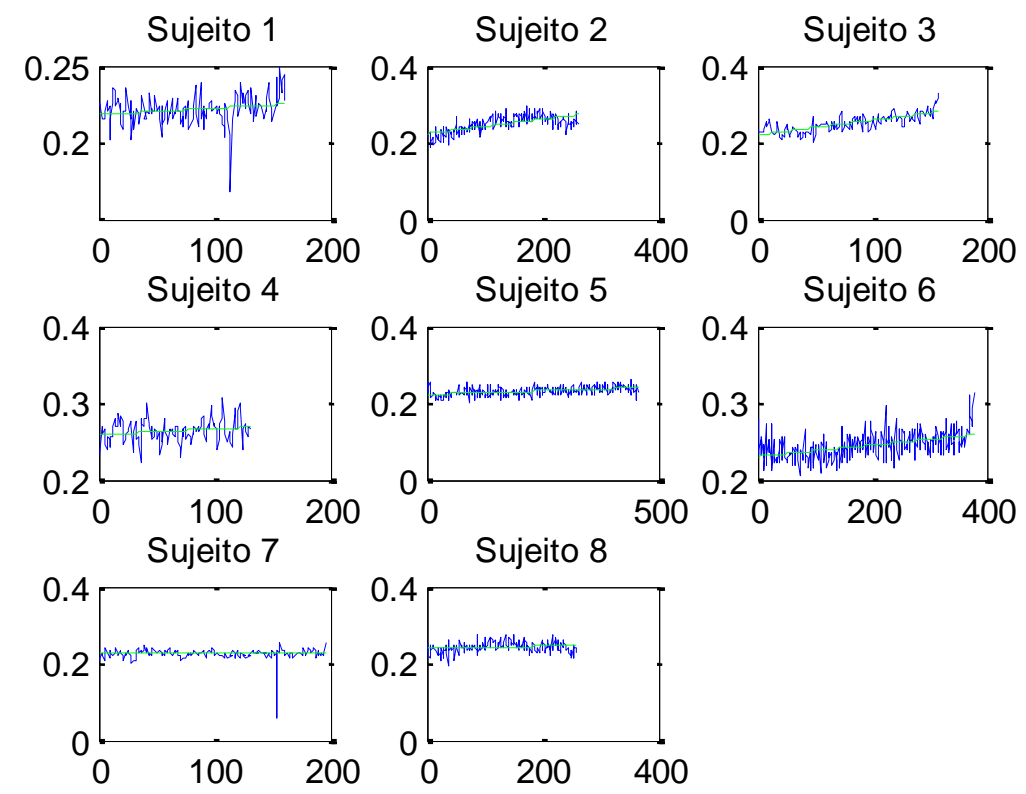

Figura 6.11: Atraso absoluto da atividade mioelétrica ao longo dos ciclos (em azul) e respectivo ajuste linear (em verde). Sinais do músculo vasto lateral em teste a carga e velocidade constantes. Todos os sujeitos. 

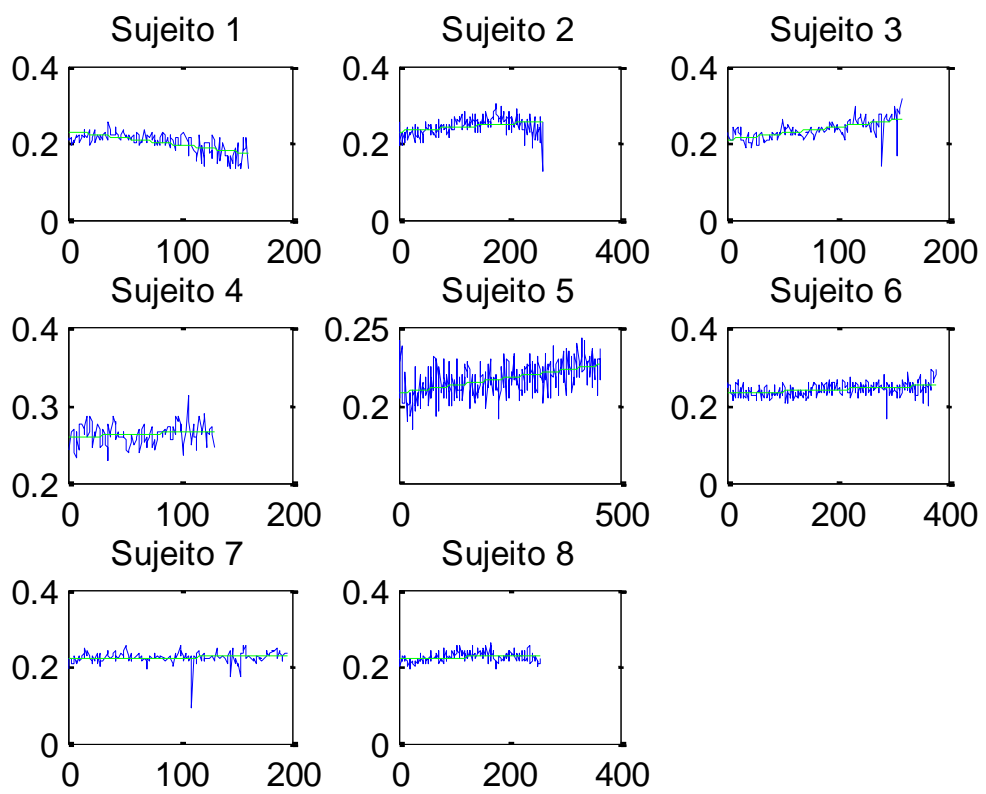

Figura 6.12: Atraso absoluto da atividade mioelétrica ao longo dos ciclos (em azul) e respectivo ajuste linear (em verde). Sinais do músculo vasto medial em teste a carga e velocidade constantes. Todos os sujeitos.

Note-se que, em alguns casos (e.g. sujeito 7) pequenas descontinuidades são observadas. Estas descontinuidades podem ser decorrentes de interferências pontuais em um dos ciclos do sinal de EMG-S, com amplitude tal que o método do cálculo de atraso da atividade mioelétrica as inclua na parcela correspondente a $99 \%$ da energia do ciclo. Isto implicaria um falso positivo para a detecção de bulha no sinal de EMG-S. Outros possíveis fatores que causam estas variações no atraso são os artefatos de movimento do eletrodo, que configuram não-estacionariedades rápidas no sinal eletromiográfico. Como tais ocorrências não se dão em quantidade suficiente para alterar o índice obtido por ajuste linear (inclinações das retas; ver figura 6.12), nenhum tratamento especial lhes foi dado. A figura 6.13 mostra as retas normalizadas (com inclinação dividida pelo valor inicial) de todos os sujeitos sobrepostas, para os músculos VL e VM, separadamente. 

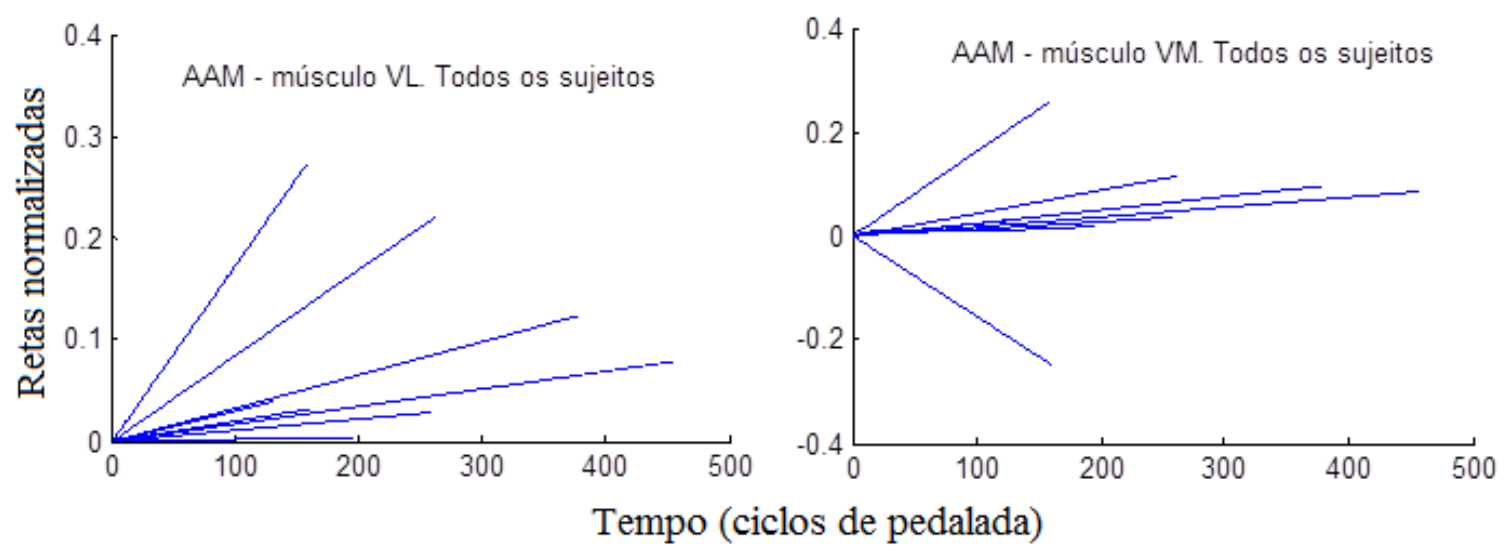

Figura 6.13: Atraso absoluto da atividade mioelétrica ao longo dos ciclos. Retas normalizadas (com inclinação dividida pelo valor inicial) de todos os sujeitos sobrepostas, para os músculos VL (à esquerda) e VM (à direita).

Visualizando-se os dados desta forma - a partir das retas normalizadas - coloca-se a hipótese de que somente os resultados de atraso obtidos para o VL apresentem média positiva. A tabela 6.22 apresenta estes dados e confirma tal hipótese.

Tabela 6.22 - Índices obtidos a partir do atraso absoluto da atividade mioelétrica em ciclismo (teste com carga e velocidade constantes) para os músculos VL e VM.

\begin{tabular}{|c|c|c|}
\hline Sujeitos & VL & VM \\
\hline S1 & 19,9372 & $-154,8637$ \\
\hline S2 & 84,4518 & 44,6693 \\
\hline S3 & 173,3489 & 162,5643 \\
\hline S4 & 30,0456 & 25,0755 \\
\hline S5 & 17,2462 & 19,0626 \\
\hline S6 & 32,7028 & 25,8285 \\
\hline S7 & 2,1256 & 10,3165 \\
\hline S8 & 11,0692 & 14,6041 \\
\hline $\begin{array}{c}\text { Valor } p \\
\text { (Shapiro- } \\
\text { Wilk) }\end{array}$ & 0,006828 & 0,041470 \\
\hline $\begin{array}{c}\text { Valor } p \\
\text { (Wilcoxon) }\end{array}$ & 0,011719 & 0,123485 \\
\hline
\end{tabular}

Para nenhum dos músculos a normalidade dos dados foi confirmada. Utilizou-se, portanto, o teste não paramétrico de Wilcoxon para avaliar se o atraso absoluto da atividade mioelétrica apresentou comportamento crescente ao longo do teste. Os resultados indicam $(p<0,05)$ que este parâmetro, somente para o eletromiograma obtido do músculo VL, apresentou esta tendência. Os resultados obtidos para o atraso normalizado da atividade mioelétrica levam às mesmas conclusões - de que o atraso da atividade 
mioelétrica apresente padrão crescente ao longo do teste somente para o músculo VL -, conforme mostra a tabela 6.23 .

Tabela 6.23 - Índices obtidos a partir do atraso normalizado da atividade mioelétrica em ciclismo (teste com carga e velocidade constantes) para os músculos VL e VM.

\begin{tabular}{|c|c|c|}
\hline Sujeitos & VL & VM \\
\hline S1 & 18,2348 & $-155,6846$ \\
\hline S2 3 & 79,9852 & 40,0410 \\
\hline S3 & 64,2433 & 55,9191 \\
\hline S5 & $-6,0145$ & $-10,3463$ \\
\hline S6 & 15,7083 & 17,4994 \\
\hline S7 & 22,1489 & 15,5748 \\
\hline S8 & 14,5469 & 22,7527 \\
\hline $\begin{array}{c}\text { Valor } p \\
\text { (Shapiro-Wilk) }\end{array}$ & 5,7632 & 9,1552 \\
\hline $\begin{array}{c}\text { Valor } p \\
\text { (Wilcoxon) }\end{array}$ & 0,089786 & 0,002904 \\
\hline $\begin{array}{c}\text { Valor } p \\
\text { (Teste t unicaudal à direita) }\end{array}$ & 0,018596 & - \\
\hline
\end{tabular}

Neste caso, somente os dados obtidos para o VL apresentaram-se normalmente distribuídos (Shapiro-Wilk, $p>0,05$ ). Optou-se, portanto, por aplicar o teste de Wilcoxon aos dados obtidos de ambos os músculos e o teste t aos dados do VL para confirmar - com todos os testes - que somente o VL apresentou padrão crescente para atraso da atividade mioelétrica durante a instalação da fadiga localizada. Neste sentido, verificam-se diferentes manifestações de fadiga localizada em cada músculo a partir deste padrão temporal.

Observe-se que estes resultados não implicam que, em média, os padrões de ativação do VL e do VM em ciclismo sejam significativamente distintos. Apenas sugerem que a variação deste padrão de ativação no VL seja suficientemente acentuada, de forma que somente este músculo apresente padrão significativamente crescente ao longo da atividade. De fato, o teste não paramétrico de Kruskal-Wallis não aponta diferenças significativas $(p>0,05)$ entre os dados obtidos para os músculos VL e VM, para os índices AAM e ANM, conforme mostram as figuras 6.14 e 6.15 . 


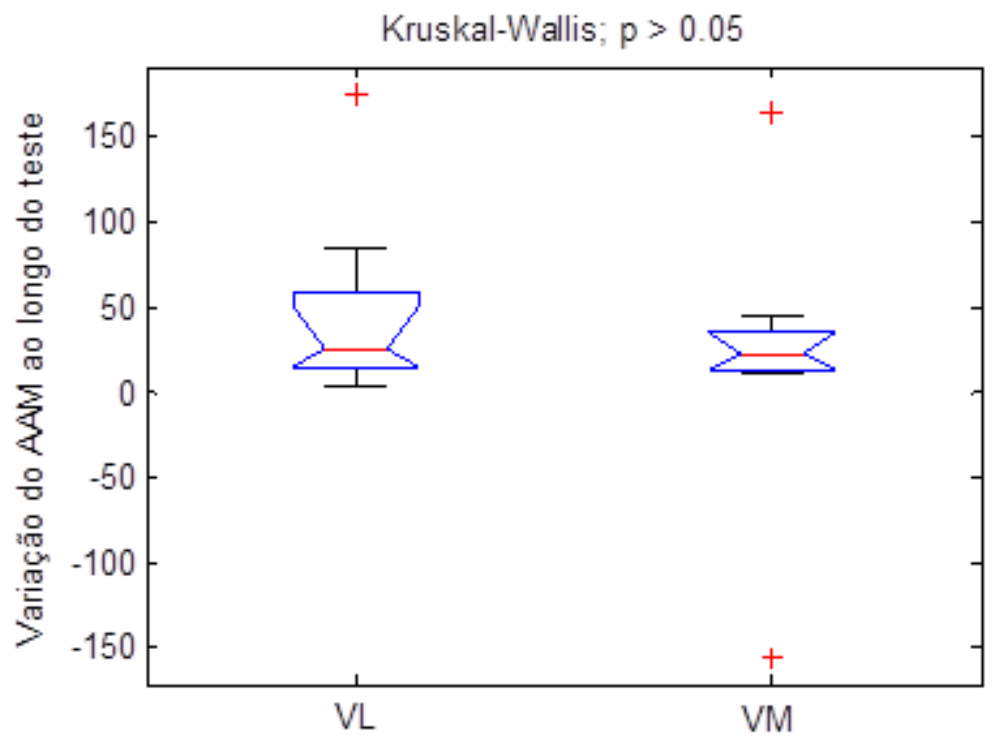

Figura 6.14: Comparação (Kruskal-Wallis, $\alpha=0,05$ ) entre os dados obtidos para o VL e o VM para a variação do atraso absoluto da atividade mioelétrica ao longo do teste. Não se observam diferenças significativas a partir destes resultados.

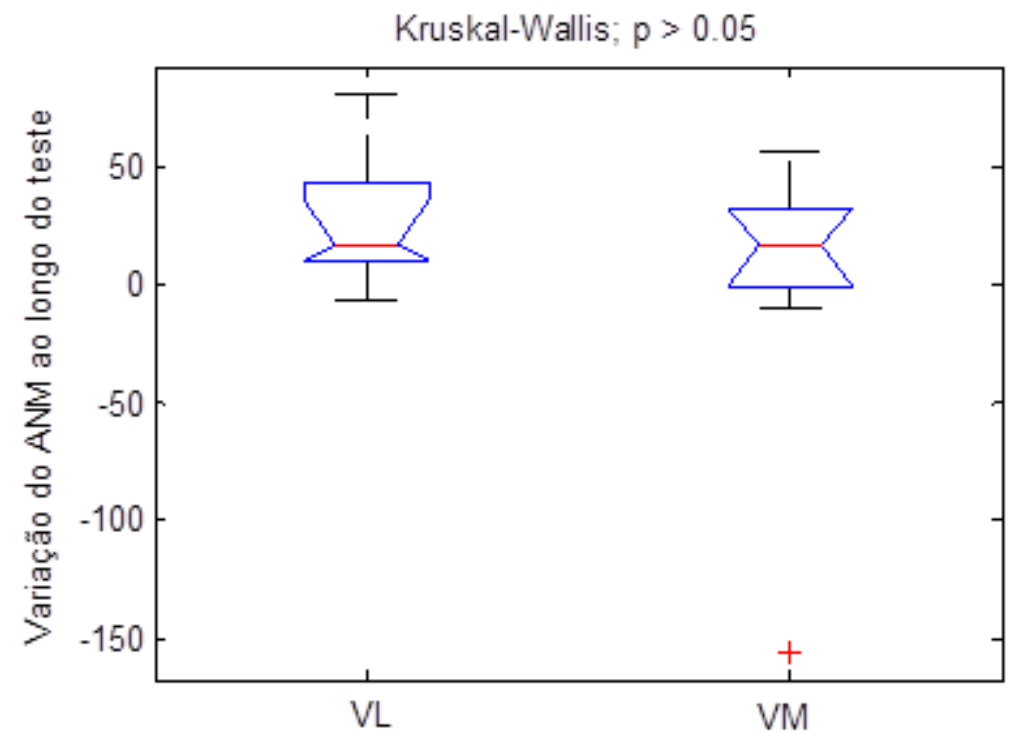

Figura 6.15: Comparação (Kruskal-Wallis, $\alpha=0,05$ ) entre os dados obtidos para o VL e o VM para a variação do atraso normalizado da atividade mioelétrica ao longo do teste. Não se observam diferenças significativas a partir destes resultados.

Estes resultados estão de acordo com diversos trabalhos científicos encontrados na literatura que concluem que os músculos VL e VM apresentam padrões temporais similares de ativação, iniciando-se imediatamente antes do ponto morto superior e terminando em posição imediatamente após o ponto morto inferior (Houtz e Fischer, 1959; Faria e Cavanagh, 1978; Jorge e Hull, 1986; Dorel et al., 2008).

Uma possível razão para o fato de que somente o músculo VL tenha apresentado 
aumento significativo no atraso da ativação mioelétrica pode estar relacionada às diferenças na composição destes músculos, no que compreende à fração de fibras tipo I e tipo II que cada um apresenta. Por exemplo, Johnson et al. (1973) mostraram que o músculo VL apresenta maiores proporções de fibras do tipo II se comparado ao músculo VM. Estes resultados conduzem naturalmente à hipótese de que estes músculos possam apresentar respostas distintas, para algum parâmetro adequadamente escolhido. Esta verificação está possivelmente relacionada ao fato de que fibras do tipo II são mais adaptadas a contrações mais intensas e rápidas, caso semelhante à atividade de ciclismo com indução de fadiga (Fleck e Kraemer, 2004). Como fibras tipo II apresentam potenciais de ação mais breves e são recrutadas, em geral, após as fibras tipo I (Moritani et al., 2004), é possível que ocorra a compensação no padrão temporal de ativação, de modo que as unidades motoras com fibras tipo II possam ser recrutadas mais tardiamente ao longo do ciclo sem prejuízo à ação motora, por possuírem resposta mais rápida.

Por fim, são apresentados a seguir os resultados obtidos para a duração (absoluta e normalizada) das bulhas ao longo do teste com velocidade e carga constantes, para os músculos VL e VM. A tabela 6.24 a seguir mostra os resultados obtidos para a variação da duração absoluta das bulhas.

Tabela 6.24 - Índices obtidos a partir da duração absoluta das bulhas em ciclismo (teste com carga e velocidade constantes) para os músculos VL e VM.

\begin{tabular}{|c|c|c|}
\hline Sujeitos & VL & VM \\
\hline S1 & $-76,6915$ & 112,4647 \\
\hline S2 3 & $-72,6893$ & $-14,8611$ \\
\hline S4 & 56,4105 & 107,4542 \\
\hline S5 & $-1,4742$ & $-32,8303$ \\
\hline S6 & $-42,7401$ & $-37,2317$ \\
\hline S7 8 & $-1,9476$ & 3,2871 \\
\hline Valor $p$ & $-56,5087$ & $-78,2433$ \\
\hline $\begin{array}{c}\text { (Shapiro-Wilk) } \\
\text { Valor } p\end{array}$ & $-18,1158$ & $-5,0683$ \\
\hline $\begin{array}{c}\text { (Teste t bicaudal) } \\
\text { Valor } p\end{array}$ & 0,13487313 & 0,133074 \\
\hline (Teste t unicaudal à esquerda) & 0,0674 & 0,7842 \\
\hline $\begin{array}{c}\text { Valor } p \\
\text { (Teste t unicaudal à direita) }\end{array}$ & 0,9326 & 0,3921 \\
\hline
\end{tabular}

Todos os testes indicam que os dados obtidos para ambos os músculos apresentam média 
nula. Portanto, a duração absoluta das bulhas não apresentou padrão significativamente crescente nem decrescente ao longo da atividade, apesar do valor $p$ próximo ao nível de significância no teste t unicaudal à esquerda para o VL. Entretanto, ao se considerar a duração normalizada das bulhas, os dados obtidos para o VL indicam padrão decrescente durante a indução da fadiga, conforme mostra a tabela 6.25 a seguir.

Tabela 6.25 - Índices obtidos a partir da duração normalizada das bulhas em ciclismo (teste com carga e velocidade constantes) para os músculos VL e VM.

\begin{tabular}{|c|c|c|}
\hline Sujeitos & VL & VM \\
\hline S1 & $-77,7002$ & 110,9427 \\
\hline S2 & $-76,6715$ & $-18,7908$ \\
\hline S4 & $-36,1978$ & 6,6149 \\
\hline S5 & $-35,3739$ & $-66,3604$ \\
\hline S6 & $-43,7152$ & $-38,0763$ \\
\hline S7 & $-10,9396$ & $-5,9051$ \\
\hline S & $-45,8029$ & $-67,7237$ \\
\hline $\begin{array}{c}\text { Valor } p \\
\text { (Shapiro-Wilk) }\end{array}$ & $-23,2067$ & $-10,2316$ \\
\hline $\begin{array}{c}\text { Valor } p \\
\text { (Teste t bicaudal) }\end{array}$ & 0,408949 & 0,086850 \\
\hline $\begin{array}{c}\text { Valor } p \\
\text { (Teste t unicaudal à esquerda) }\end{array}$ & $<0,0012$ & 0,5923 \\
\hline $\begin{array}{c}\text { Valor } p \\
\text { (Teste t unicaudal à direita) }\end{array}$ & - & 0,7039 \\
\hline
\end{tabular}

Os testes $\mathrm{t}$ (unicaudal à esquerda e bicaudal) indicam que o VL exibiu padrão decrescente para a duração normalizada das bulhas. Para o VM, todos os testes confirmaram a hipótese nula. Portanto, em média, não foram verificadas variações significativas na duração normalizada das bulhas do sinal de EMG-S do VM. A apresentação destes índices na forma de retas normalizadas (figuras 6.16 e 6.17) permite razoável visualização destes resultados. 


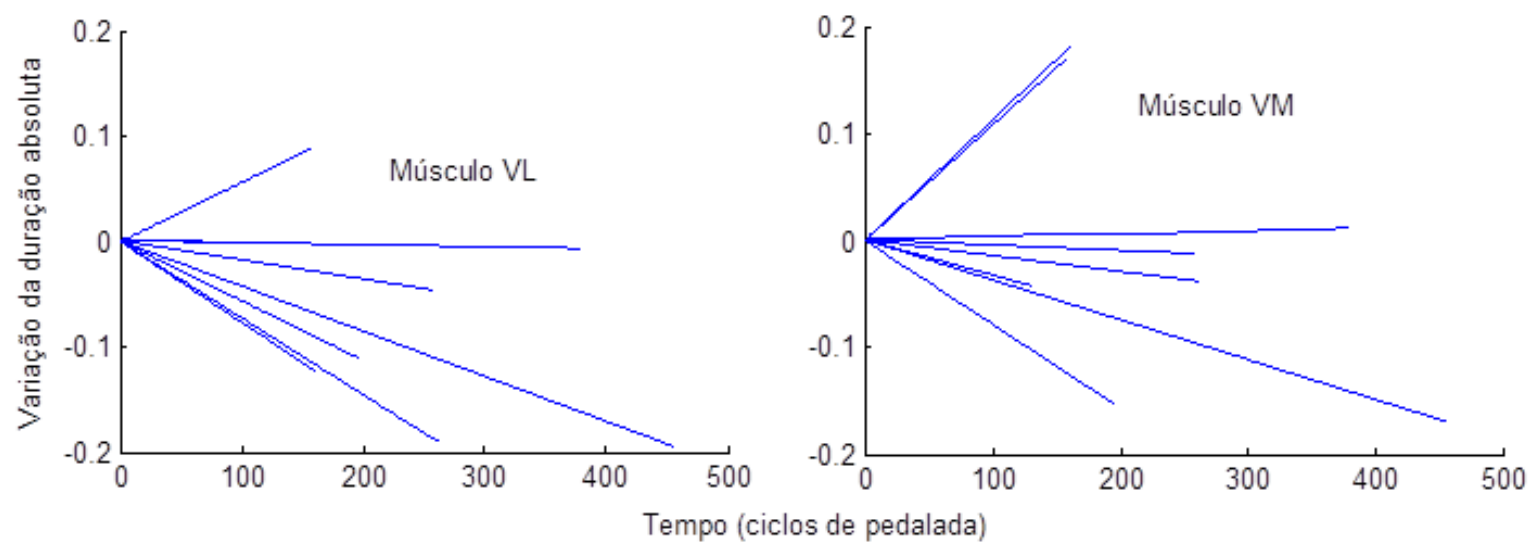

Figura 6.16: Duração absoluta das bulhas ao longo dos ciclos. Retas normalizadas (com inclinação dividida pelo valor inicial) de todos os sujeitos sobrepostas, para os músculos

VL (à esquerda) e VM (à direita).

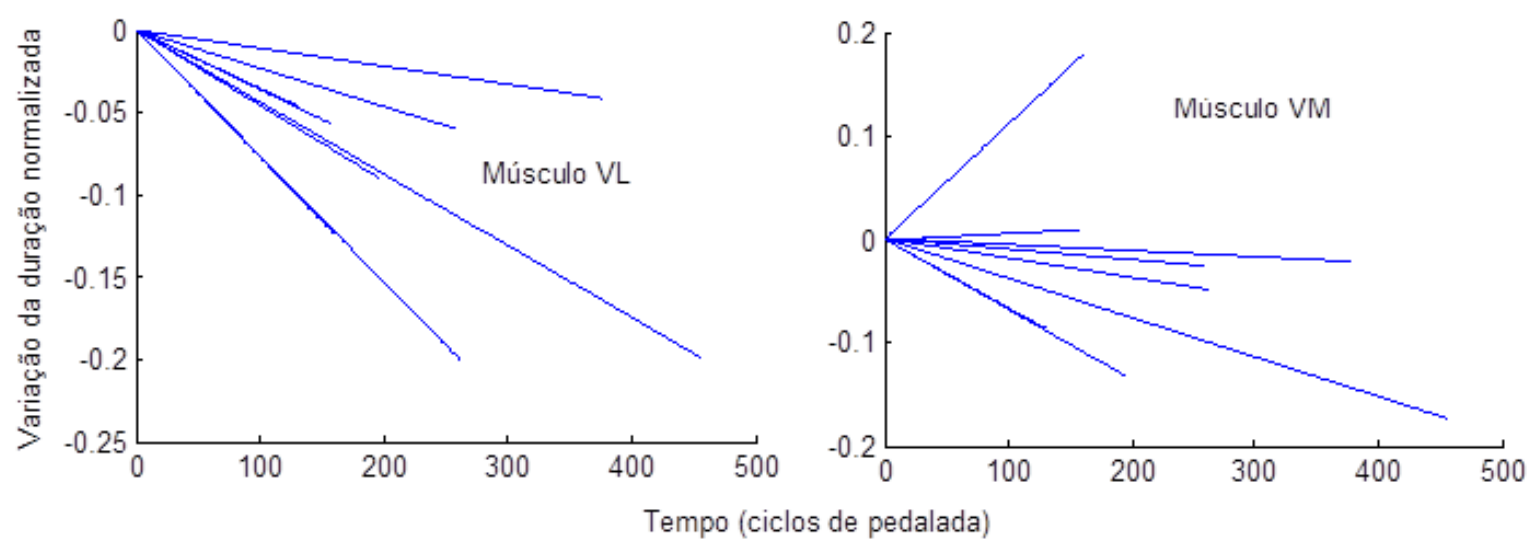

Figura 6.17: Duração normalizada das bulhas ao longo dos ciclos. Retas normalizadas (com inclinação dividida pelo valor inicial) de todos os sujeitos sobrepostas, para os músculos VL (à esquerda) e VM (à direita).

Observações semelhantes às do atraso da atividade mioelétrica se fazem neste caso. Possivelmente, a contribuição do aumento relativo de fibras tipo II - nas quais potenciais de ação possuem menor duração -, decorrente de seu recrutamento com a ocorrência da fadiga, deve colaborar para uma bulha também de menor duração para o VL, que possui maior parcela de tais fibras. A modificação dos resultados obtidos entre a duração absoluta e a normalizada evidencia as influências que as pequenas variações da cadência ao longo do teste podem impor às interpretações.

\subsection{2 - Considerações finais}

Nesta seção foram apresentados e discutidos os resultados obtidos para a validação experimental dos parâmetros - como indicadores de fadiga muscular - em protocolo 
dinâmico de contrações cíclicas (atividade em bicicleta ergométrica). Todos os parâmetros propostos neste trabalho apresentaram o padrão esperado com a ocorrência da fadiga muscular. Em geral (à exceção de $K_{D E W}$ ) os indicadores espectrais propostos baseados em wavelets mostraram-se menos dispersos do que as tradicionais MNF e MDF. Da mesma maneira, o indicador calculado no domínio da frequência $\left(s_{E}\right)$ apresentou-se menos disperso do que as frequências média e mediana. Verificou-se que, em geral, os indicadores espectrais que exploram o fenômeno da compressão (ou estreitamento) do espectro de amplitude do eletromiograma - i.e., a diminuição de sua largura de banda ao longo do tempo - apresentaram dispersões significativamente menores do que os indicadores baseados no deslocamento do centro espectro. Assim, é possível que esta abordagem espectral seja mais adequada a protocolos experimentais fatigantes em que a reprodutibilidade dos parâmetros eletromiográficos seja um fator essencial.

Assim como no caso isométrico, não se observaram padrões significativos crescente nem decrescente - na assimetria espectral do eletromiograma em protocolo dinâmico. Assim, sugere-se a princípio que tal parâmetro não seja significativamente sensível à fadiga muscular, não se recomendando seu uso para esta finalidade nos protocolos experimentais abordados.

$\mathrm{O}$ atraso da atividade mioelétrica e sua duração - percentual dentro do ciclo mostraram, respectivamente, padrões significativamente crescente e decrescente com a ocorrência da fadiga muscular localizada no vasto lateral. Para o músculo vasto medial, neste sentido, não se observaram padrões com os resultados obtidos. Assim, ao serem abordados os padrões temporais de ativação muscular para monitoração da fadiga em ciclismo, sugere-se utilizar o sinal eletromiográfico do músculo vasto lateral. Para os demais indicadores de fadiga, ambos os músculos podem ser utilizados como referência para avaliação da fadiga em ciclismo.

Por fim, a abordagem dinâmica - observando-se as bulhas como fenômenos separados - mostrou-se adequada à avaliação da fadiga, visto que os parâmetros tradicionais (RMS, MDF e MNF) se comportaram de acordo com o esperado para indicação da fadiga muscular. Desta maneira, os padrões observados para os demais parâmetros, previamente validados em protocolo isométrico, são validados também nesta abordagem. Na próxima seção, os indicadores de fadiga muscular serão estudados sob a influência da variação da carga e do janelamento em abordagem isométrica, avaliando-se possíveis padrões e diferenças entre VL e VM. 


\section{3 - PROTOCOLO DINÂMICO (CICLISMO - II): VARIAÇÃO DA CARGA E DA}

ABORDAGEM

Nesta seção investiga-se a sensibilidade dos indicadores eletromiográficos de fadiga muscular em ciclismo. Por sensibilidade dos índices entende-se alguma variação significativa em função da modalidade de exercício, do músculo avaliado e do método para cálculo dos indicadores eletromiográficos.

Diferentemente de modalidades como natação e atletismo, a modalidade do ciclismo envolve uma dinâmica relativamente padronizada em função das restrições dos movimentos dos membros inferiores (Hug e Dorel, 2009). Entretanto, os padrões de ativação dos músculos destes membros podem ser relativamente complexos (Jorge e Hull, 1986; Hug e Dorel, 2009; Hug et al., 2013). Assim, para a proposição de métodos de reabilitação e desempenho em ciclismo, é desejável o conhecimento dos padrões de ativação muscular ao longo dos ciclos de pedalada (Hug e Dorel, 2009). Desta maneira justifica-se a importância do estudo da sensibilidade dos descritores eletromiográficos às características particulares de cada músculo e aos protocolos experimentais utilizados em ciclismo.

Em vários trabalhos envolvendo ciclismo, verifica-se que a amplitude do eletromiograma apresenta comportamento crescente em função da carga (resistência imposta pelo cicloergômetro) em atividades realizadas até a exaustão (Bigland-Ritchie e Woods, 1974; Taylor e Bronks, 1994; Lucia et al., 1997; Hug et al., 2003; Hug et al., 2006a,b). Como os exercícios nesses protocolos experimentais foram, em geral, realizados até a exaustão, a interpretação dos resultados torna-se limitada em função da dificuldade em dissociar os efeitos do aumento da carga das manifestações da fadiga muscular (Hug e Dorel, 2009). Contudo, em geral não são abordadas variáveis no domínio da frequência para verificar os efeitos da variação da resistência imposta.

Ericson (1986) relatou um aumento na amplitude do sinal de EMG dos principais músculos dos membros inferiores (GMax, VL, RF, VM, BF, ST, GM) em função da carga em exercícios divididos em etapas a carga constante, para várias intensidades (de 120 a 240 W, a 60 RPM), adotando-se períodos de recuperação - entre diferentes intensidades suficientes para descartar os efeitos da fadiga. Em seu estudo, verificou que os principais músculos atuantes no movimento da pedalada são os extensores do joelho. Em especial, os vastos lateral e medial são responsáveis por 39\% do trabalho mecânico (positivo) total, em 
comparação com $27 \%$ para os músculos extensores do quadril. Um aspecto ainda não avaliado na literatura disponível é a correlação entre os indicadores eletromiográficos variáveis temporais e espectrais - para os músculos VL e VM no ciclismo em função da carga. Neste sentido, deve-se avaliar a hipótese de que o comportamento dessas variáveis para o VL e o VM se torne mais próximo, refletindo uma semelhança funcional destes músculos com o aumento da carga.

Sarre et al. (2003) mostraram haver dependência da amplitude do eletromiograma em relação à carga para os três músculos extensores do joelho (vastos lateral e medial e reto femoral) em diferentes porcentagens $(60,80$ e 100\%) da potência aeróbica máxima, obtendo resultados significativamente distintos para cada porcentagem. Porém, não foi avaliada a influência da carga sobre variáveis espectrais do sinal eletromiográfico. Rainoldi et al. (2008) concluem, ainda, que a EMG-S pode ser utilizada como método não invasivo para diferenciação funcional dos músculos VL e VM e entre porções longa e oblíqua do VM.

Para os músculos do quadríceps, o aumento na amplitude do eletromiograma durante atividades de ciclismo à carga constante foi relatado em diversos estudos (Petrofsky, 1979; Housh et al., 2000; Saunders et al., 2000; Sarre e Lepers, 2005), verificando-se a diminuição da capacidade de gerar torque próximo à exaustão e concluindo-se que o aumento na amplitude - dos sinais obtidos dos músculos VL e BF - é consistente com a localização da fadiga periférica.

Apesar de atribuído ao recrutamento de unidades motoras adicionais, o aumento na amplitude do eletromiograma em contrações fatigantes também poderia ser atribuído a modificações - induzidas pela fadiga - na coordenação dos músculos dos membros inferiores. Assim, a dissociação entre os efeitos da fadiga neuromuscular e as modificações nos padrões de coordenação desses músculos envolvidos torna-se uma tarefa complexa (Hug e Dorel, 2009).

Sadoyama et al. (1988) reportaram, para o músculo VL, uma correlação positiva entre velocidade de condução e porcentagem de fibras do tipo II (contração rápida) em atletas velocistas e de resistência. Verificaram não haver correlação significativa entre velocidade de condução e o diâmetro das fibras. As membranas destas fibras apresentam maior potencial de repouso e potenciais de ação com maior amplitude e menor duração em comparação com as fibras do tipo I (contração lenta) (Hanson, 1974). Assim, a correlação entre velocidade de condução e composição das fibras pode ser atribuída às diferenças na 
excitabilidade das membranas das fibras dos tipos I e II.

Por fim, Johnson et al. (1973) mostraram que o músculo VL apresenta maiores proporções de fibras do tipo II se comparado ao músculo VM. Estes resultados conduzem naturalmente à hipótese de que estes músculos possam apresentar respostas distintas, para alguma variável - espectral ou de amplitude - em exercícios de ciclismo com indução de fadiga. Fleck e Kraemer (2004) colaboram com esta hipótese, constatando a adaptabilidade das fibras do tipo II a contrações mais intensas e de curta duração, caso semelhante ao de uma pedalada à alta carga resistida. Além disso, as diferentes proporções de fibras dos tipos I e II nos músculos VL e VM sugerem que, possivelmente, diferentes protocolos experimentais - à carga constante ou crescente - possam permitir a distinção de padrões dos sinais destes músculos a partir de algum descritor eletromiográfico adequadamente escolhido.

Ainda, vários autores concluem que a EMG-S pode ser utilizada para diferenciação funcional dos músculos e avaliação de suas propriedades intrínsecas (Sadoyama et al., 1988; Rainoldi et al., 2008; Hug et al., 2013).

Portanto, nesta seção, a fadiga muscular é estudada explorando-se tais lacunas encontradas na literatura científica disponível, avaliando-se a sensibilidade dos indicadores definidos neste trabalho. Assim, os indicadores eletromiográficos são estudados nas abordagens isométrica e dinâmica, nas modalidades de carga constante (CL) e crescente (IL). Assim, procurou-se responder às seguintes perguntas:

- Entre as abordagens estudadas - dinâmica e isométrica (ver seção 5.1) com diferentes durações de trechos - alguma delas apresenta maior semelhança entre os indicadores de fadiga do VL e do VM?

- Entre os indicadores estudados, algum apresenta sensibilidade à carga, de forma que os conjuntos de índices calculados difiram significativamente entre CL e IL?

- Em qual das modalidades (CL ou IL) se observa maior semelhança - caso exista entre os indicadores calculados sobre os sinais eletromiográficos do VL e do VM?

- Entre os indicadores estudados, algum apresenta valores significativamente maiores de correlação entre VL e VM? Isto é, há diferenças significativas entre o quanto cada indicador eletromiográfico distingue a atividade em cada músculo?

Portanto, quer-se verificar se, entre os indicadores estudados, algum apresenta diferenças significativas para os coeficientes de correlação entre as sequências descritoras de fadiga de todos os sujeitos - quando calculadas para o VL e para o VM - em função do 
janelamento utilizado - i.e. duração dos trechos do sinal de EMG-S - para cálculo do índice. Avalia-se com isto a possibilidade de que as sequências descritoras de fadiga se tornem mais (ou menos) semelhantes ao, por exemplo, aumentar a duração das janelas. Estes resultados devem sugerir, por exemplo, quais dos indicadores estudados melhor dissociam a atividade mioelétrica do VL e do VM e em que situações.

Buscou-se responder a estas perguntas da seguinte maneira (e nesta ordem): comparando-se os conjuntos de índices obtidos (comparação entre VL e o VM) para todos os sujeitos em cada modalidade, CL e IL; calculando-se o coeficiente de correlação normalizado (coeficiente de Pearson) entre as sequências descritoras de fadiga do VL e do VM em cada situação (diferentes abordagens para as modalidades CL e IL) e avaliando a existência de diferenças significativas nos perfis de correlação entre estas sequências em função do janelamento; e, por fim, comparando-se os índices obtidos de todos os voluntários (entre as modalidades CL e IL) para cada músculo. Em todos os casos, utilizou-se o teste Anova para os dados normalmente distribuídos, e de Kruskal-Wallis para os demais, sempre com nível de significância $\alpha=0,05$.

Para a avaliação da correlação entre as sequências descritoras de fadiga do VL e do VM, os parâmetros foram aplicados em abordagem dinâmica e isométrica nas modalidades CL e IL, em ambos os músculos, VL e VM. Em abordagem isométrica, as sequências descritoras de fadiga foram calculadas para trechos de $500 \mathrm{~ms}$ a $2000 \mathrm{~ms}$ para avaliar a existência de padrões para a correlação entre estas sequências em função do janelamento. Para este estudo, os sinais do Protocolo II (ver capítulo 3) foram utilizados.

\subsection{1 - Resultados e discussão}

As figuras 6.18, 6.19 e 6.20 a seguir mostram os resultados dos testes estatísticos comparando os índices obtidos para os músculos VL e VM na modalidade CL em abordagem dinâmica, isométrica com trechos de $500 \mathrm{~ms}$ e isométrica com trechos de 2,0 s, respectivamente. Logo após, as figuras 6.21, 6.22 e 6.23 mostram essa mesma comparação para a modalidade IL. 

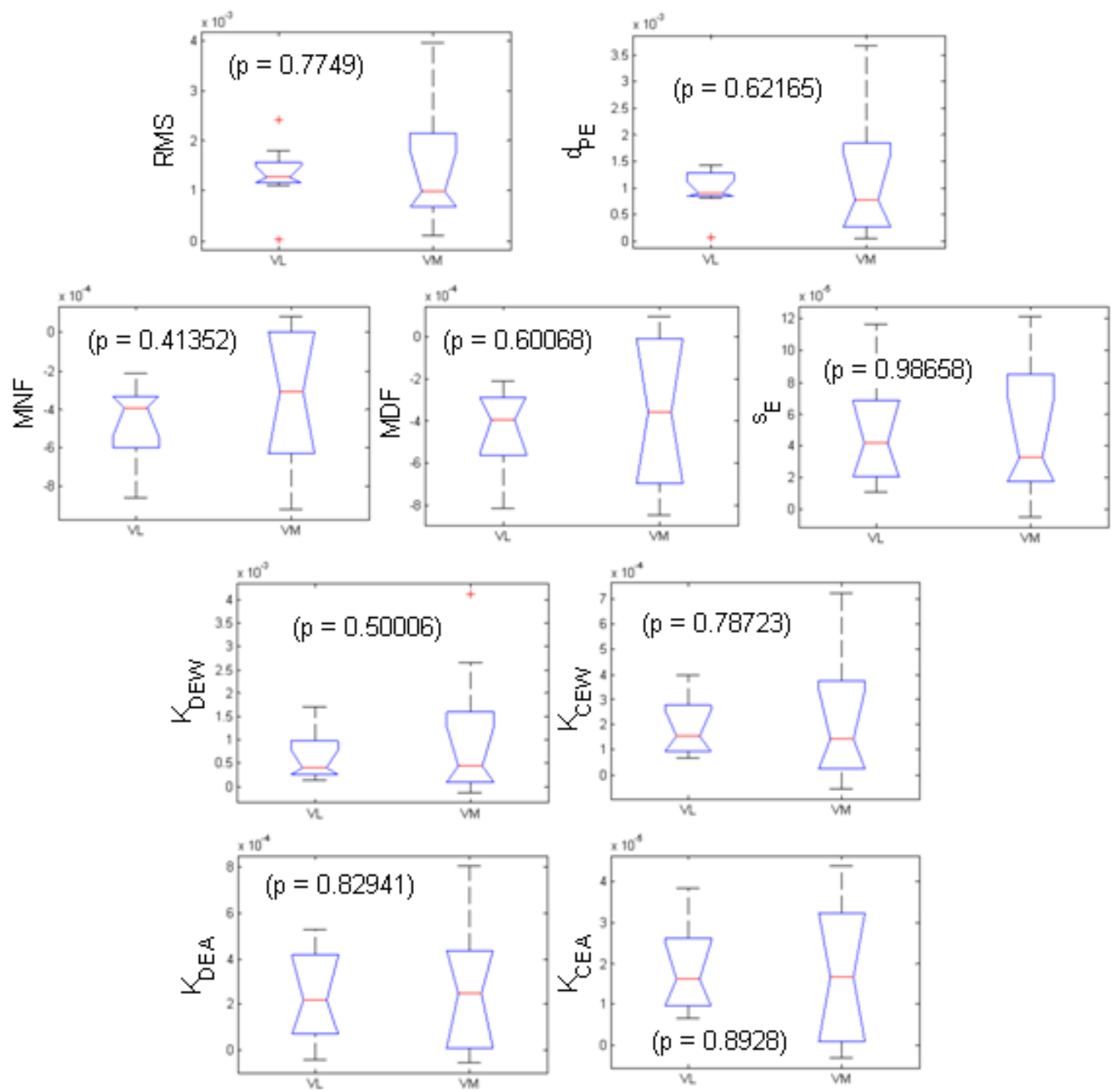

Figura 6.18: Comparação dos índices: VL versus VM em abordagem dinâmica, modalidade CL. 

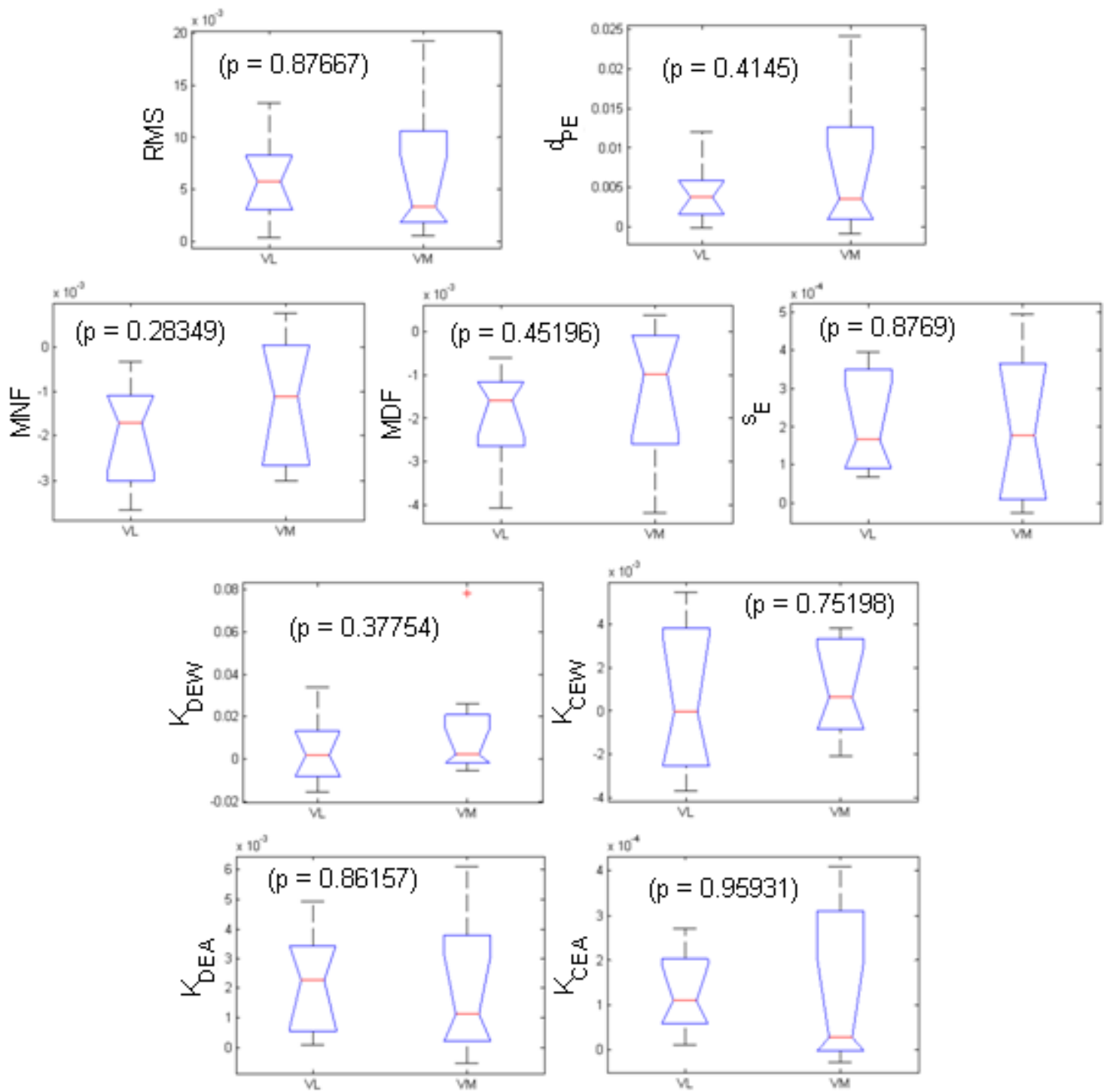

Figura 6.19: Comparação dos índices: VL versus VM em abordagem isométrica (trechos de $500 \mathrm{~ms}$ ), modalidade CL. 

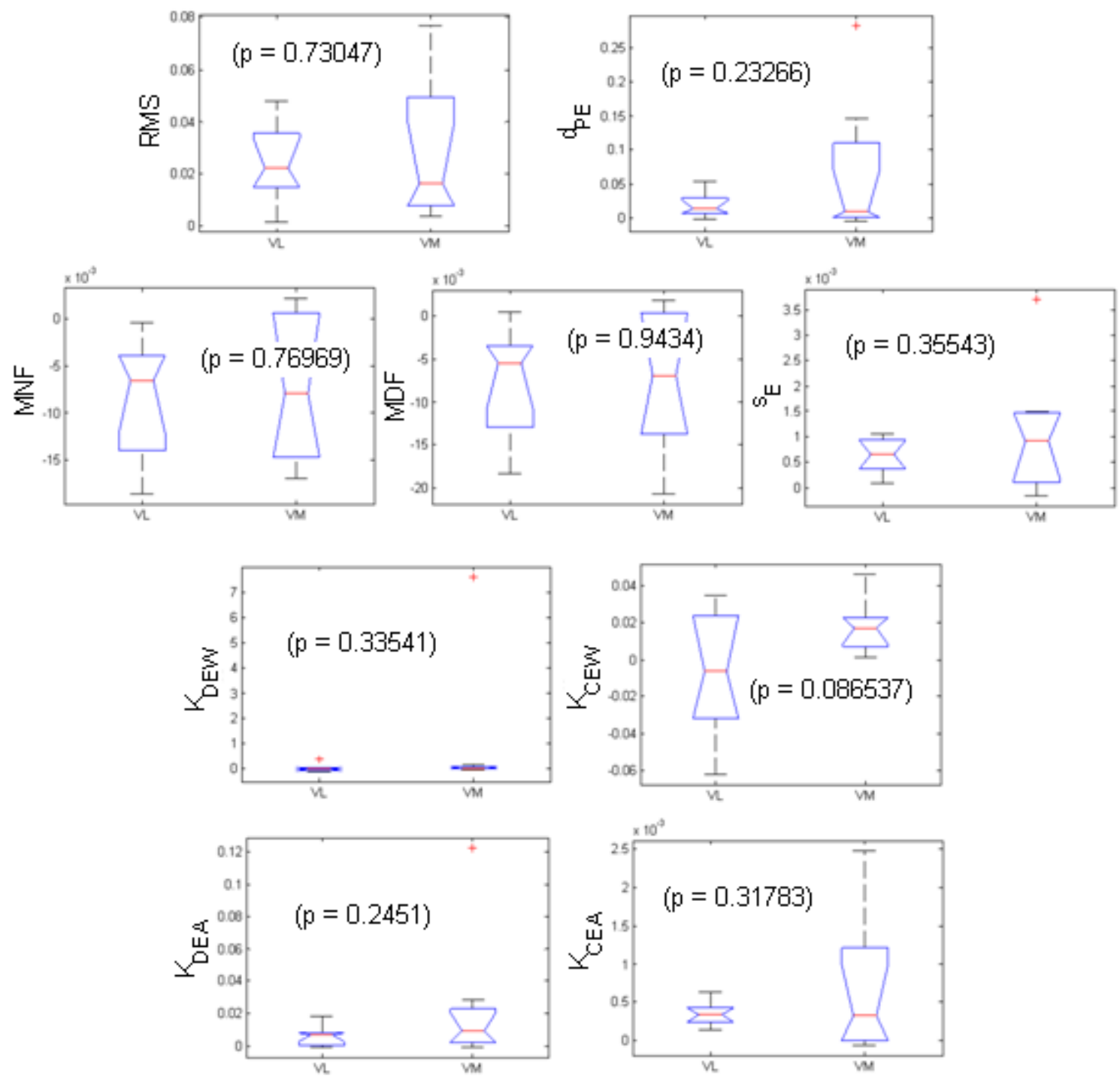

Figura 6.20: Comparação dos índices: VL versus VM em abordagem isométrica (trechos de 2,0 s), modalidade CL.

Verifica-se que, para um protocolo e abordagem fixos, não há diferenças significativas (em geral, $p \gg 0,05$ ) entre os índices obtidos para o VL e para o VM. Situação semelhante se verificará para a modalidade IL, como mostrado nas figuras as figuras $6.21,6.22$ e 6.23 . 

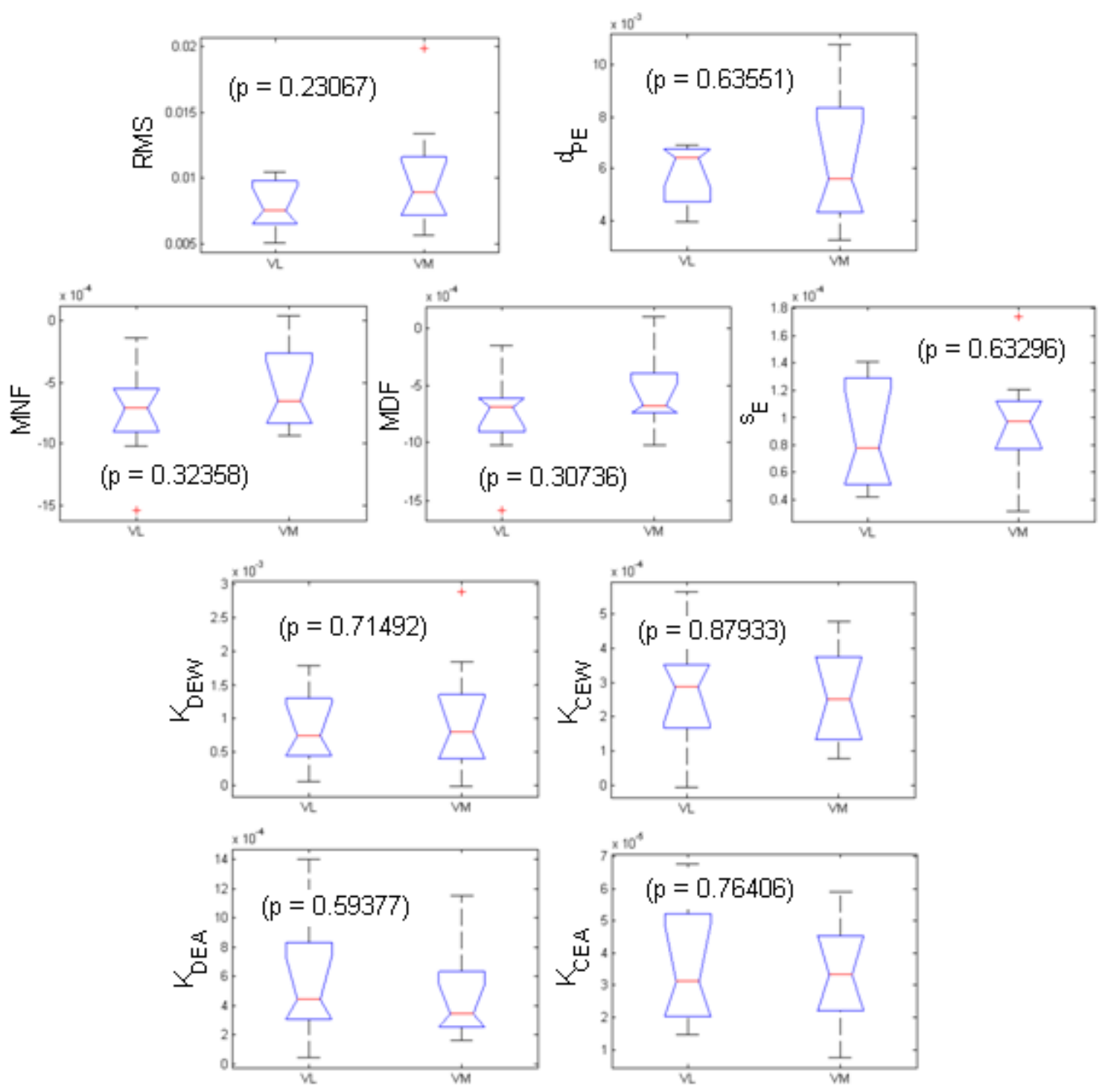

Figura 6.21: Comparação dos índices: VL versus VM em abordagem dinâmica, modalidade IL. 

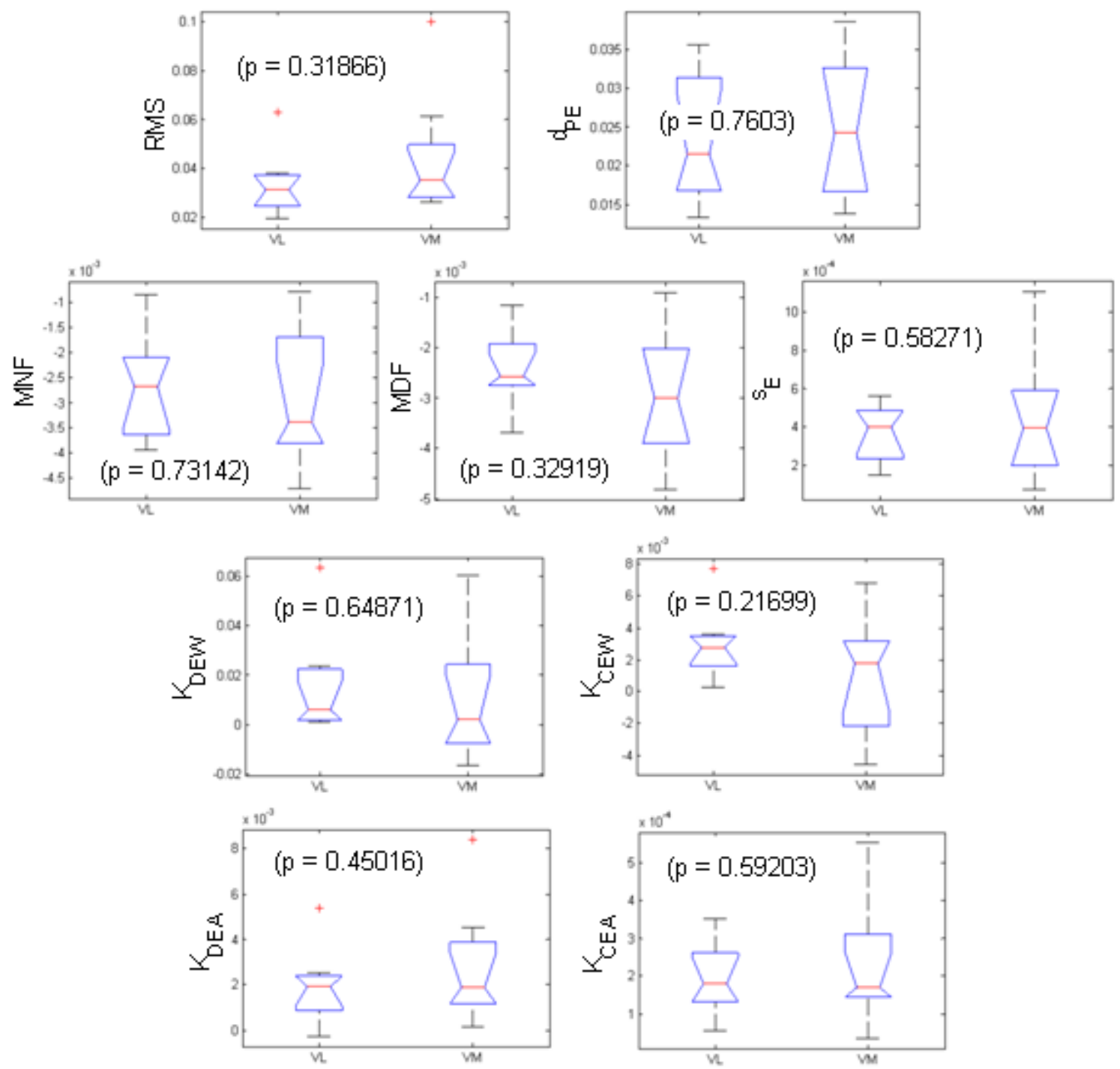

Figura 6.22: Comparação dos índices: VL versus VM em abordagem isométrica (trechos de $500 \mathrm{~ms}$ ), modalidade IL. 


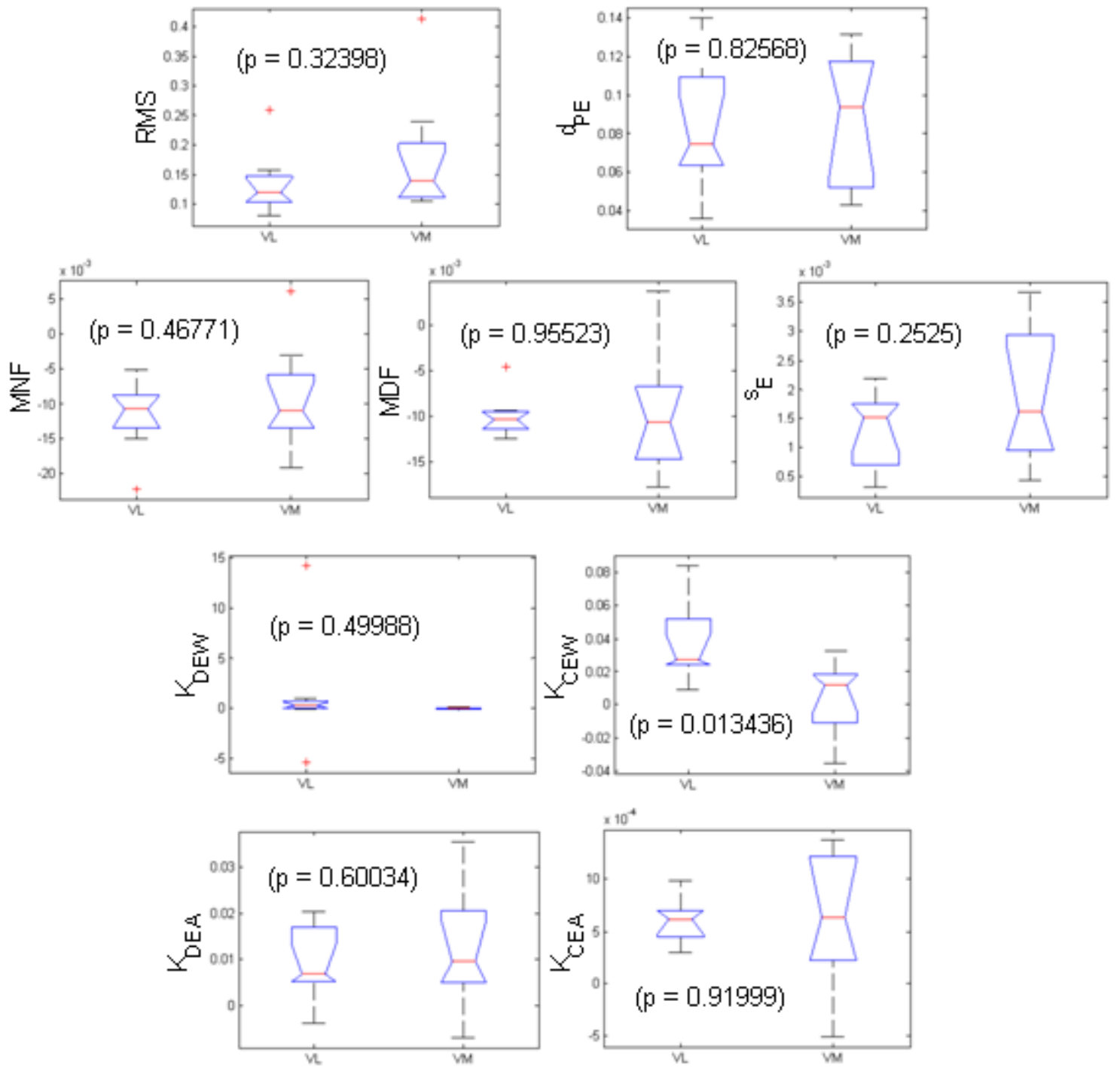

Figura 6.23: Comparação dos índices: VL versus VM em abordagem isométrica (trechos de 2,0 s), modalidade IL.

Verifica-se novamente que, fixando-se modalidade de exercício e abordagem para cálculo dos indicadores, nenhum conjunto de índices - de todos os voluntários - apresenta resultados significativamente distintos entre VL e VM, à exceção de $K_{C E W}(p \cong 0,013)$. Note-se que, na modalidade CL, também para janelas de 2,0 s, este parâmetro apresentou o valor $p$ mais próximo do nível de significância $(p \cong 0,0865)$. Portanto, é possível que esta não seja uma observação isolada e que, de fato, a compressão espectral utilizando wavelets, $K_{C E W}$, envolva em sua definição características do sinal de EMG-S que diferenciem a atividade mioelétrica dos músculos VL e VM, ao considerarem-se longos trechos do eletromiograma.

Assim, no caso geral, quando não há interesse em observar efeitos de variação da carga ou da abordagem, esses resultados indicam que, aparentemente, não há diferenças 
entre o músculo escolhido - VL ou VM - para aferição da fadiga em ciclismo. Portanto, fixando-se a abordagem e a modalidade de exercício, a fadiga muscular localizada no VL e no VM não deve mostrar diferenças significativas. Ainda, tanto a abordagem dinâmica quanto a isométrica - com qualquer dos janelamentos abordados - permitem a aferição objetiva da fadiga muscular localizada no VL e no VM $(p<0,05$; testes Anova e de Wilcoxon para os dados não normalmente distribuídos).

Os resultados a seguir apresentam os efeitos sobre o coeficiente de correlação entre as sequências descritoras de fadiga para cada janelamento utilizado na abordagem isométrica. As figuras 6.24, 6.25 e 6.26 apresentam os valores médios de correlação - para o conjunto dos sujeitos - em função da duração dos trechos para cálculo dos indicadores, respectivamente, no domínio do tempo, da frequência e da DWT.
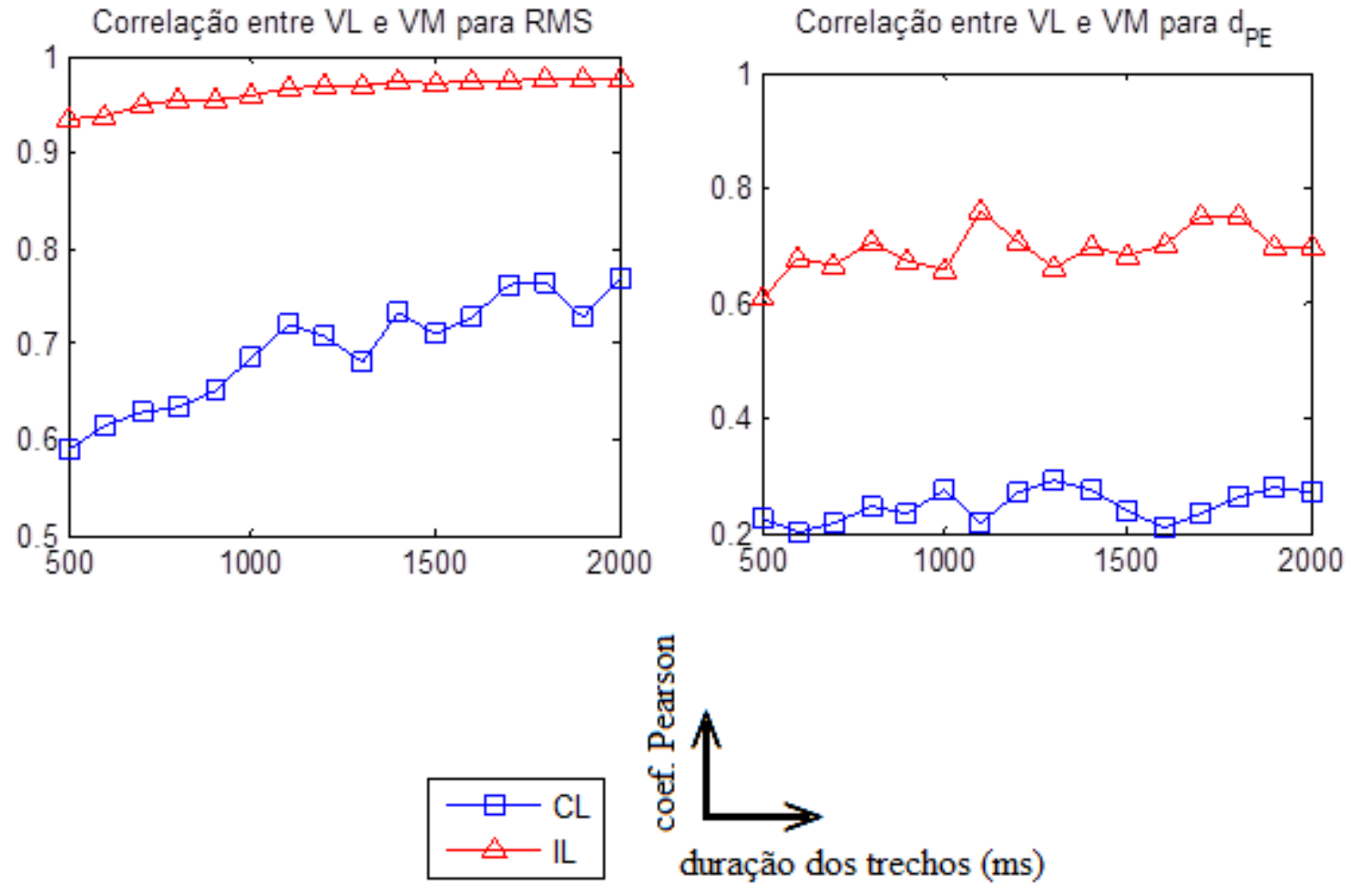

Figura 6.24: Correlação média (coeficiente de Pearson) entre sequências descritoras de fadiga dos voluntários para o VL e VM. Indicadores no domínio do tempo. Carga constante (azul) e carga crescente (vermelho). 
Correlação entre VL e VM para MNF

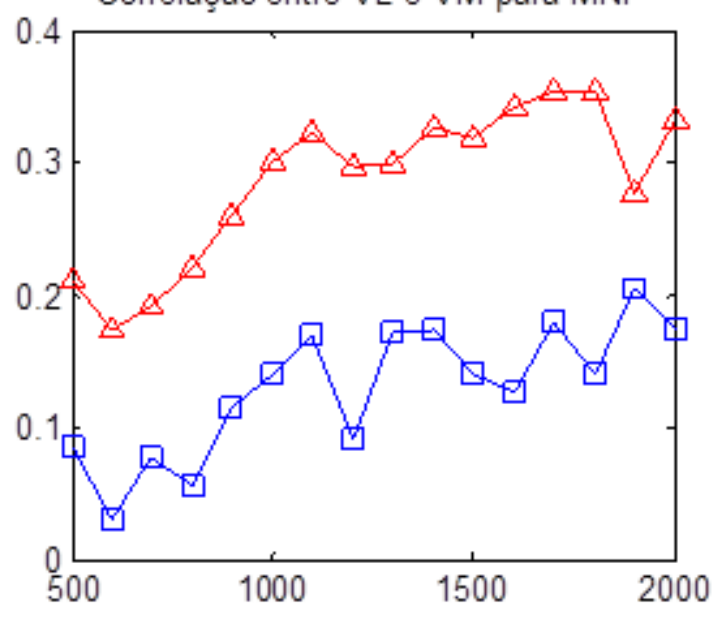

Correlação entre VL e VM para MDF

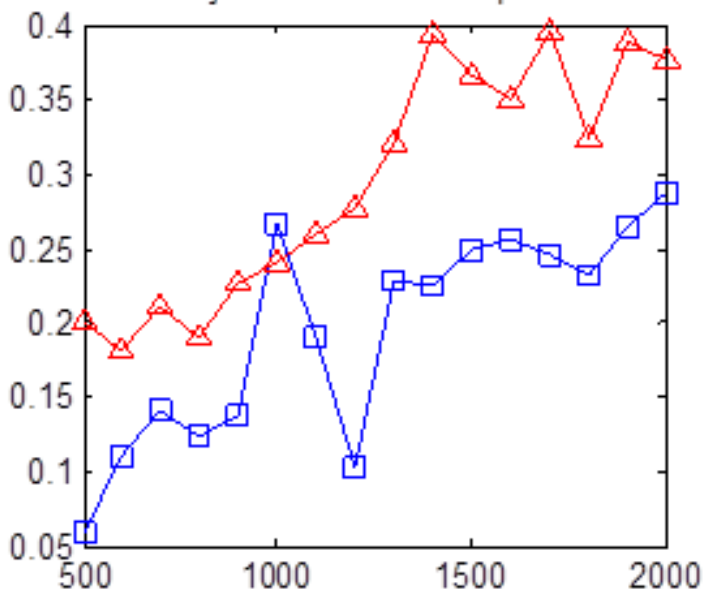

Correlação entre VL e VM para $s_{E}$
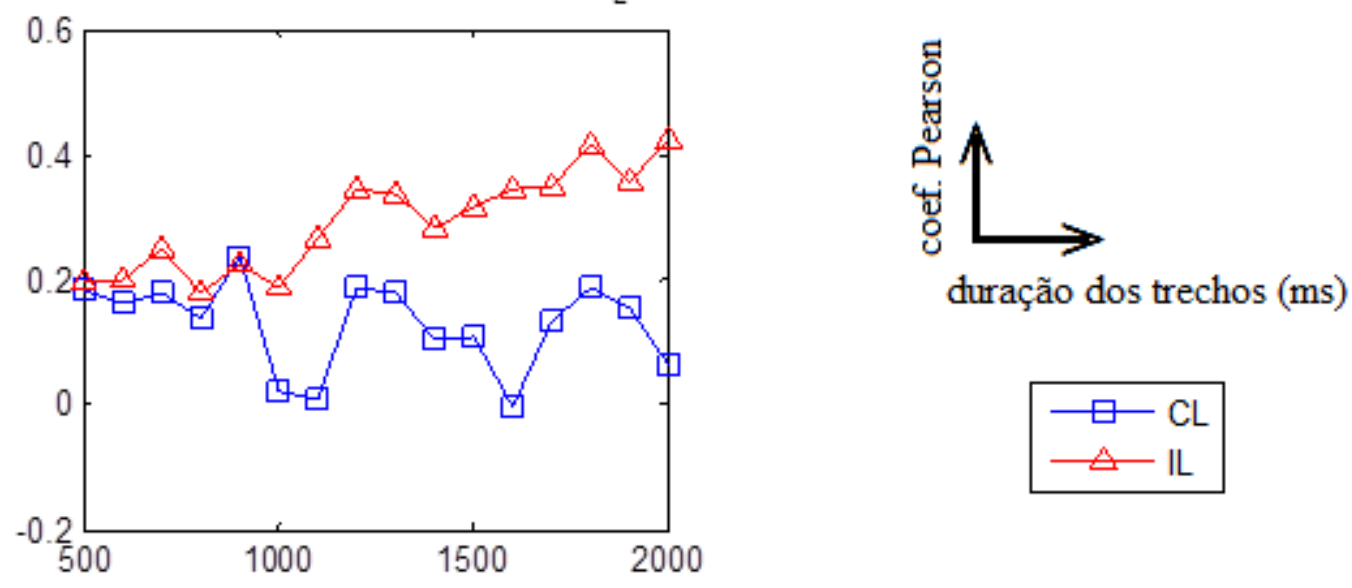

Figura 6.25: Correlação média (coeficiente de Pearson) entre sequências descritoras de fadiga dos voluntários para o VL e VM. Indicadores no domínio da frequência. Carga constante (azul) e carga crescente (vermelho). 
Correlação entre VL e VM para $K_{\mathrm{DEW}}$

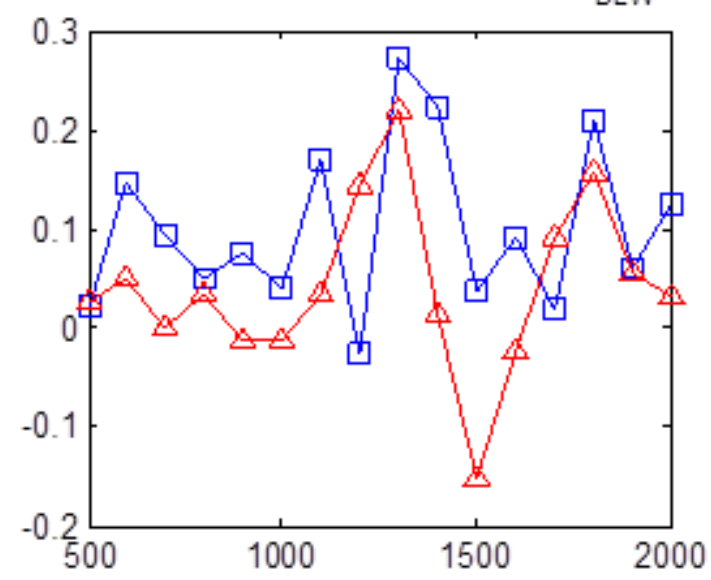

Correlação entre VL e VM para $\mathrm{K}_{\mathrm{DEA}}$

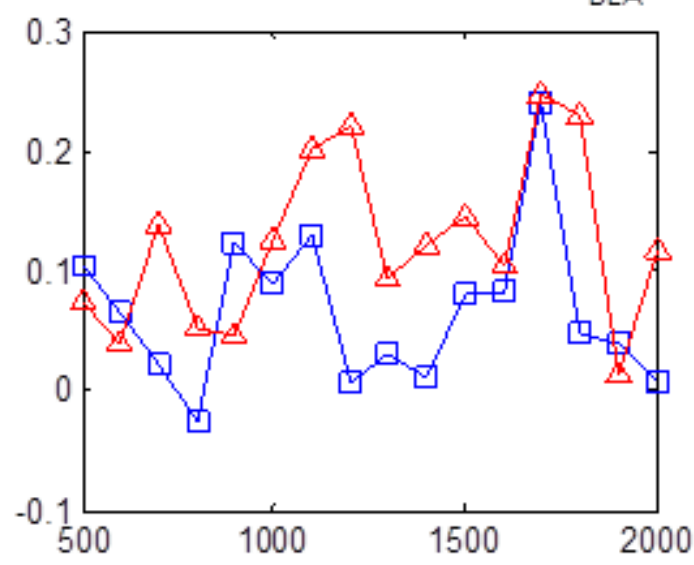

Correlação entre VL e VM para $\mathrm{K}_{\mathrm{CEW}}$

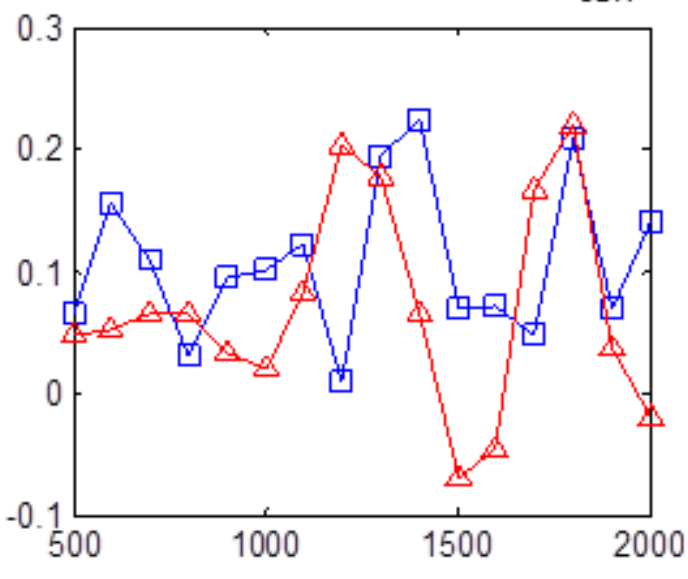

Correlação entre VL e VM para $\mathrm{K}_{\mathrm{CEA}}$

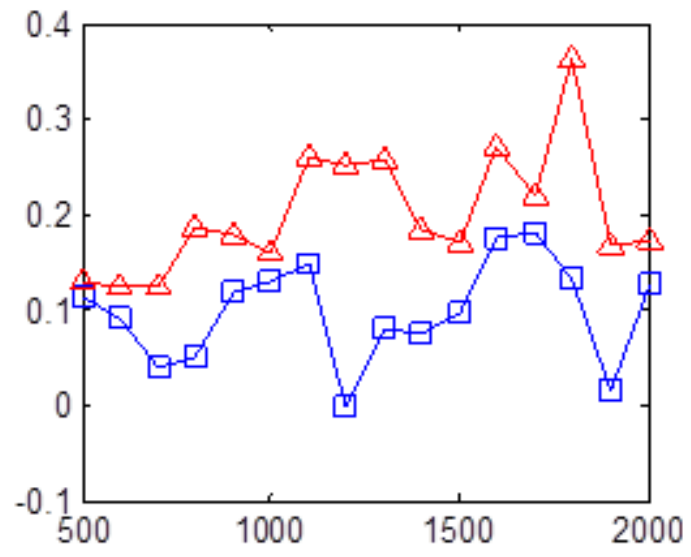

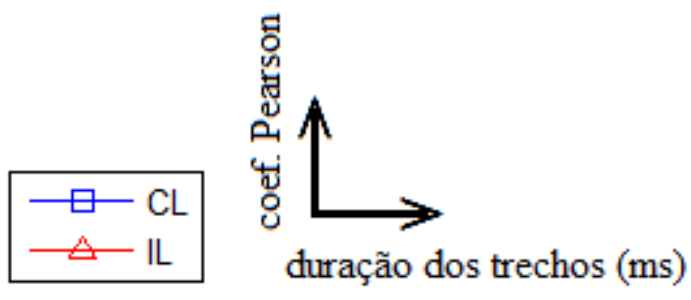

Figura 6.26: Correlação média (coeficiente de Pearson) entre sequências descritoras de fadiga dos voluntários para o VL e VM. Indicadores no domínio da DWT. Carga constante (azul) e carga crescente (vermelho).

Os resultados obtidos para os indicadores no domínio do tempo sugerem padrão, em média, crescente para a correlação entre VL e VM em função da duração dos trechos. Neste sentido, com maiores janelas para análise, os indicadores dissociam menos a atividade mioelétrica do VL e do VM no domínio do tempo, em que se considera, essencialmente, a amplitude do sinal. Ainda para esses indicadores, as curvas de correlação evidenciam a maior semelhança entre a atividade mioelétrica do VL e do VM na modalidade IL, no qual foi imposto um aumento linear da carga (50 W a cada $30 \mathrm{~s}$ ). Estas observações corroboram com as conclusões de Sarre et al. (2003), que verificaram haver 
dependência da amplitude do eletromiograma em função da carga imposta em bicicleta ergométrica para os músculos extensores do joelho (VL, VM e RF).

Os parâmetros definidos no domínio da frequência também apresentaram padrão crescente de correlação entre VL e VM em função da duração dos segmentos do eletromiograma para cálculo dos indicadores, à exceção do estreitamento do espectro $\left(s_{E}\right)$ em carga constante, situação em que, aparentemente, não sofreu variações significativas com o janelamento. Semelhantemente aos indicadores definidos no domínio do tempo, estes parâmetros em geral sugerem o aumento na similaridade funcional dos vastos lateral e medial ao submetê-los ao aumento gradual da carga resistida.

Os parâmetros de deslocamento e compressão espectral definidos no domínio da DWT, em sua versão não adaptativa $-K_{D E W}$ e $K_{C E W}$-, não apresentaram, de forma clara, distintos graus de dissociação entre VL e VM, entre diferentes durações de janela nem entre as modalidades CL e IL. Suas versões adaptativas, $K_{D E A}$ e $K_{C E A}$, parecem refletir o comportamento crescente na similaridade funcional dos músculos com o aumento da carga, assim como os outros indicadores previamente discutidos. $\mathrm{O}$ comportamento aparentemente oscilatório do perfil de correlação para os indicadores baseados em wavelets pode estar associado à relação entre comprimento das janelas do sinal e comprimento das wavelets utilizadas (Daubechies-4), de forma que características transitórias do eletromiograma sejam incluídas por completo - em regiões da distribuição tempo-escala no cálculo dos indicadores para determinados comprimentos de janela, mas não para outros, problema intrínseco ao uso da DWT. São vários os fatores reportados na literatura que afetam diferentes estimativas espectrais do eletromiograma, sendo, em geral, estabelecer relações de causalidade uma difícil tarefa, o que torna pouco frequente chegarse a conclusões que suportem afirmações categóricas (Lindström e Petersén, 1981; Solomonow et al., 1990; Masuda et al., 1996 e 1999; Farina et al., 2002; Waly et al., 2003; Dimitrova e Dimitrov, 2003).

Para aferir mais objetivamente as observações aqui discutidas, mostram-se a seguir os resultados de testes Anova para avaliar se houve diferenças de fato significativas entre as modalidades CL e IL, para as correlações obtidas entre indicadores calculados para o VL e para o VM. As figuras 6.27, 6.28 e 6.29 mostram os resultados destes testes para os parâmetros no domínio do tempo, da frequência e da DWT, respectivamente. 

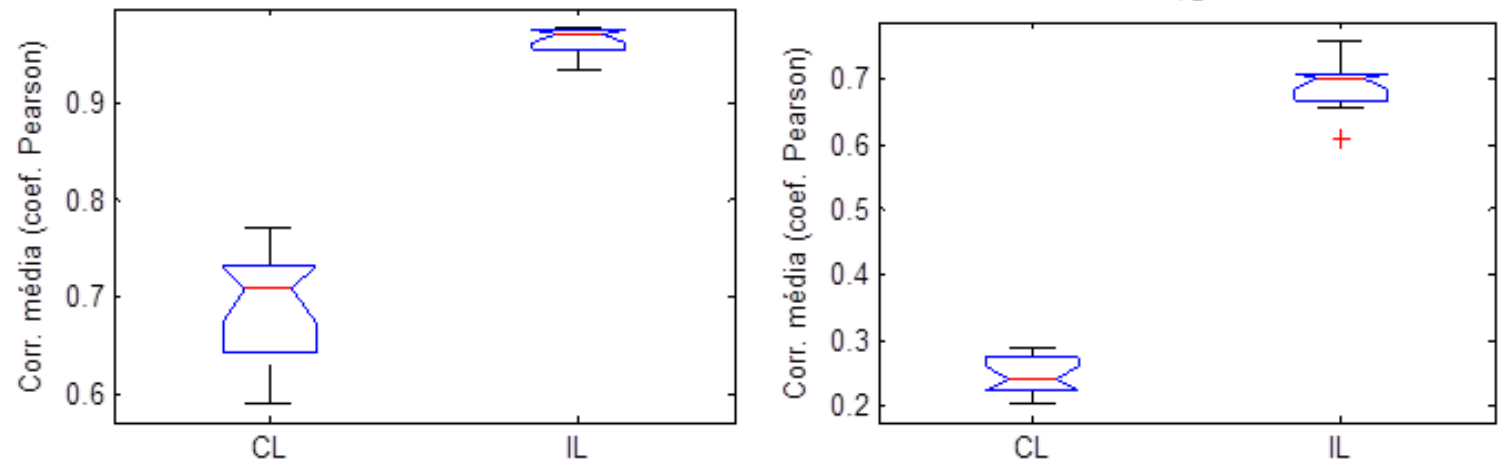

Figura 6.27: Comparação (teste Anova) entre os valores médios de correlação entre VL e VM nas modalidades CL e IL. Indicadores no domínio do tempo.

Cor. entre VL e VM para MNF: $C L$ versus IL; $p=4.0769$ e-009 Cor. entre VL e VM para MDF: $C L$ versus IL; $p=0.00085203$
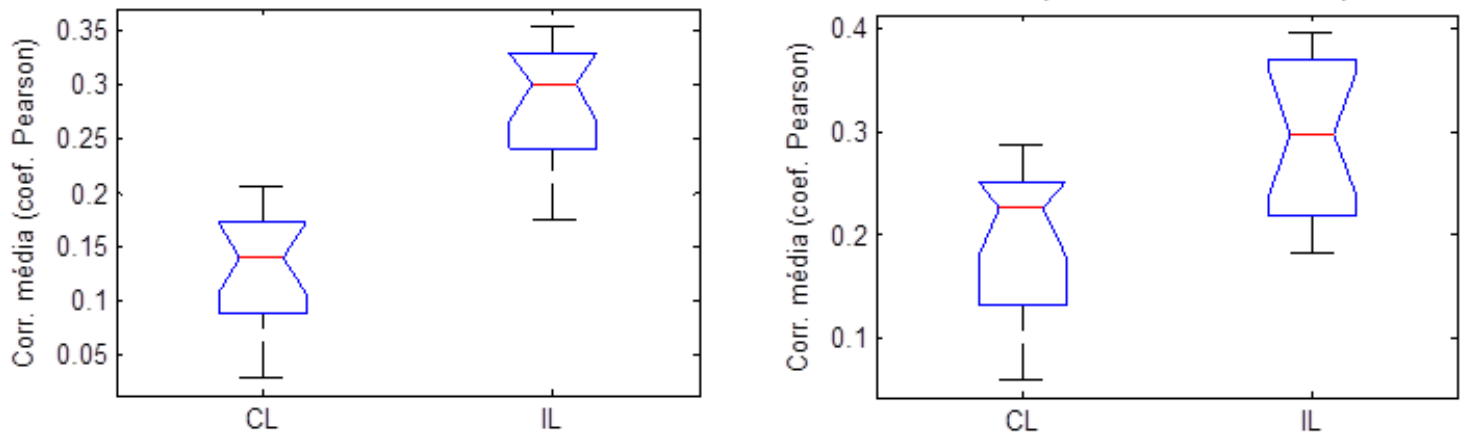

Cor. entre VL e VM para $s_{E}: C L$ versus IL; $p=1.0231 \mathrm{e}-006$

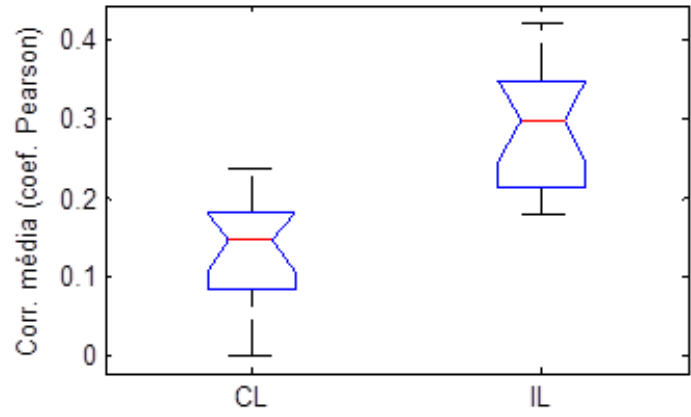

Figura 6.28: Comparação (teste Anova) entre os valores médios de correlação entre VL e VM nas modalidades CL e IL. Indicadores no domínio da frequência. 

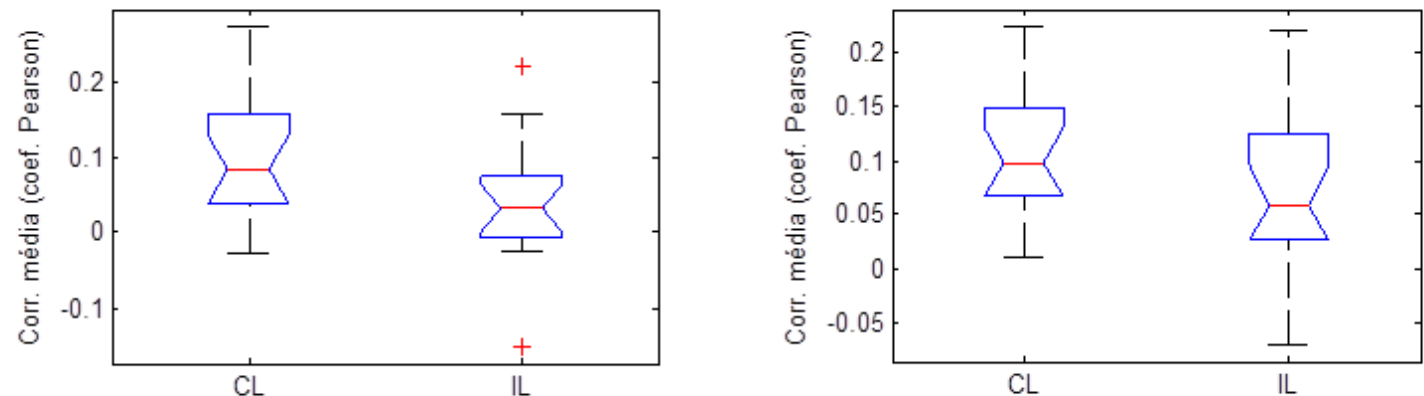

Correlação entre VL e VM para $\mathrm{K}_{\mathrm{DEA}}: \mathrm{CL}$ versus IL; $p=0.024364$

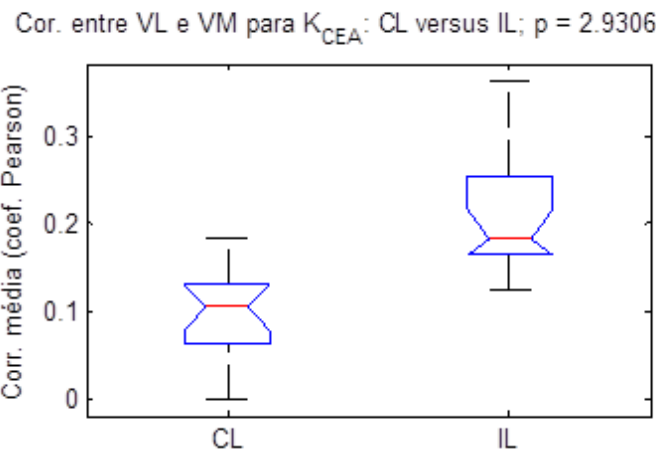

Figura 6.29: Comparação (teste Anova) entre os valores médios de correlação entre VL e VM nas modalidades CL e IL. Indicadores no domínio da DWT.

Estes resultados atestam o que foi anteriormente sugerido: os únicos parâmetros que não refletiram a influência da modalidade - CL ou IL - sobre a semelhança entre a atividade muscular do VL da do VM foram os indicadores $K_{D E W}$ e $K_{C E W}$. Neste sentido, estes indicadores não refletem as diferenças entre a atividade mioelétrica do VL da do VM de forma mais significativa quando se varia a carga da maneira proposta neste protocolo experimental. Note-se que, dado o caráter estatístico destas aferições, tal asserção não equivale à constatação de que estes indicadores mensurem a fadiga da mesma forma em ambas as modalidades, não sendo, portanto, imediata tal conclusão. As figuras 6.30 e 6.31 a seguir melhor ilustram as diferenças de correlação obtidas entre todos os indicadores (teste Anova) estudados neste trabalho, em carga constante e crescente, respectivamente. Note-se a discrepância entre indicadores de amplitude - no domínio do tempo - e espectrais - no domínio da frequência e da DWT. 
Correlação entre VL e VM - todos os indicadores Carga Constante
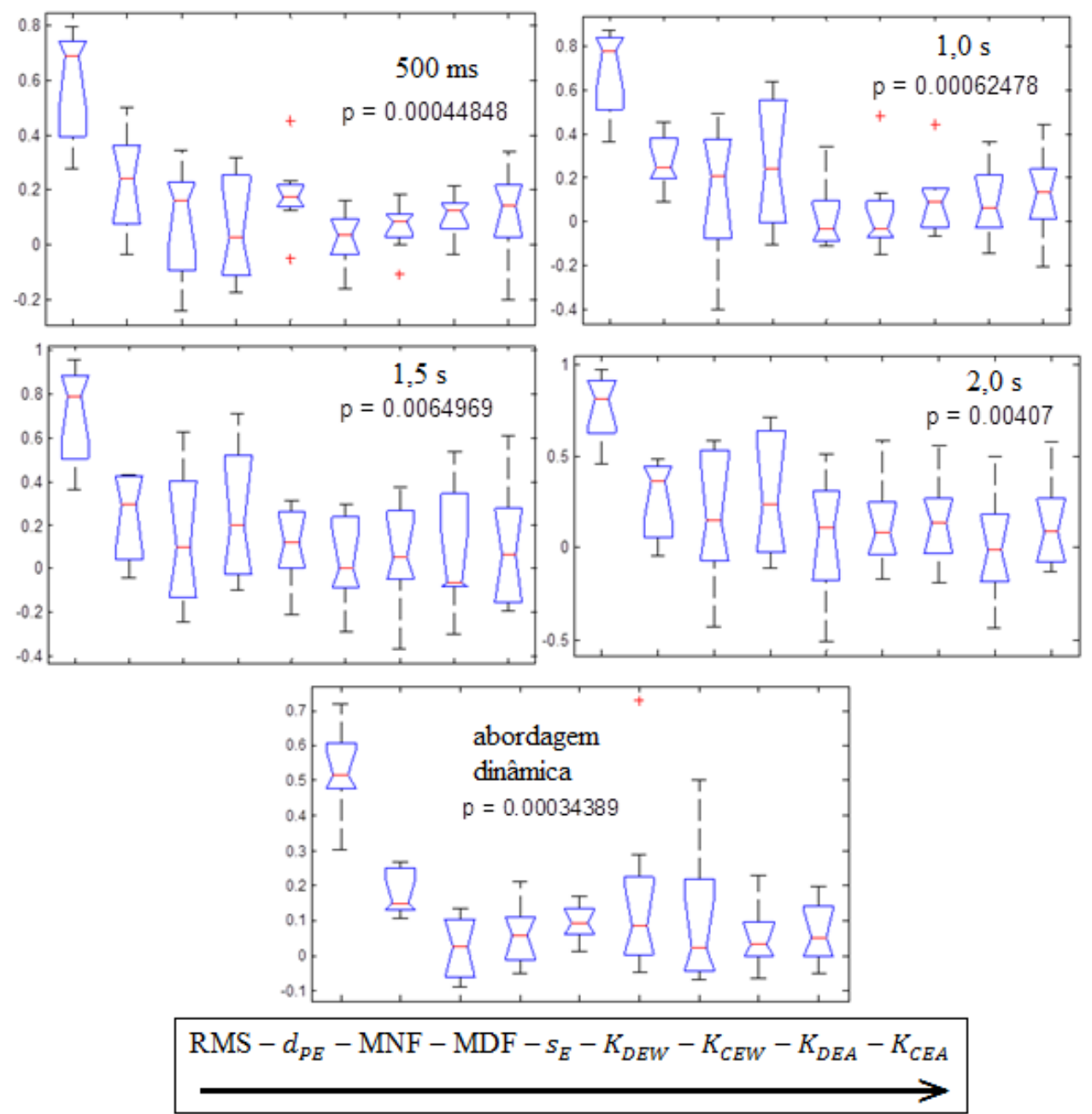

Figura 6.30: Correlações médias entre VL e VM observadas para todos os indicadores em carga constante. 

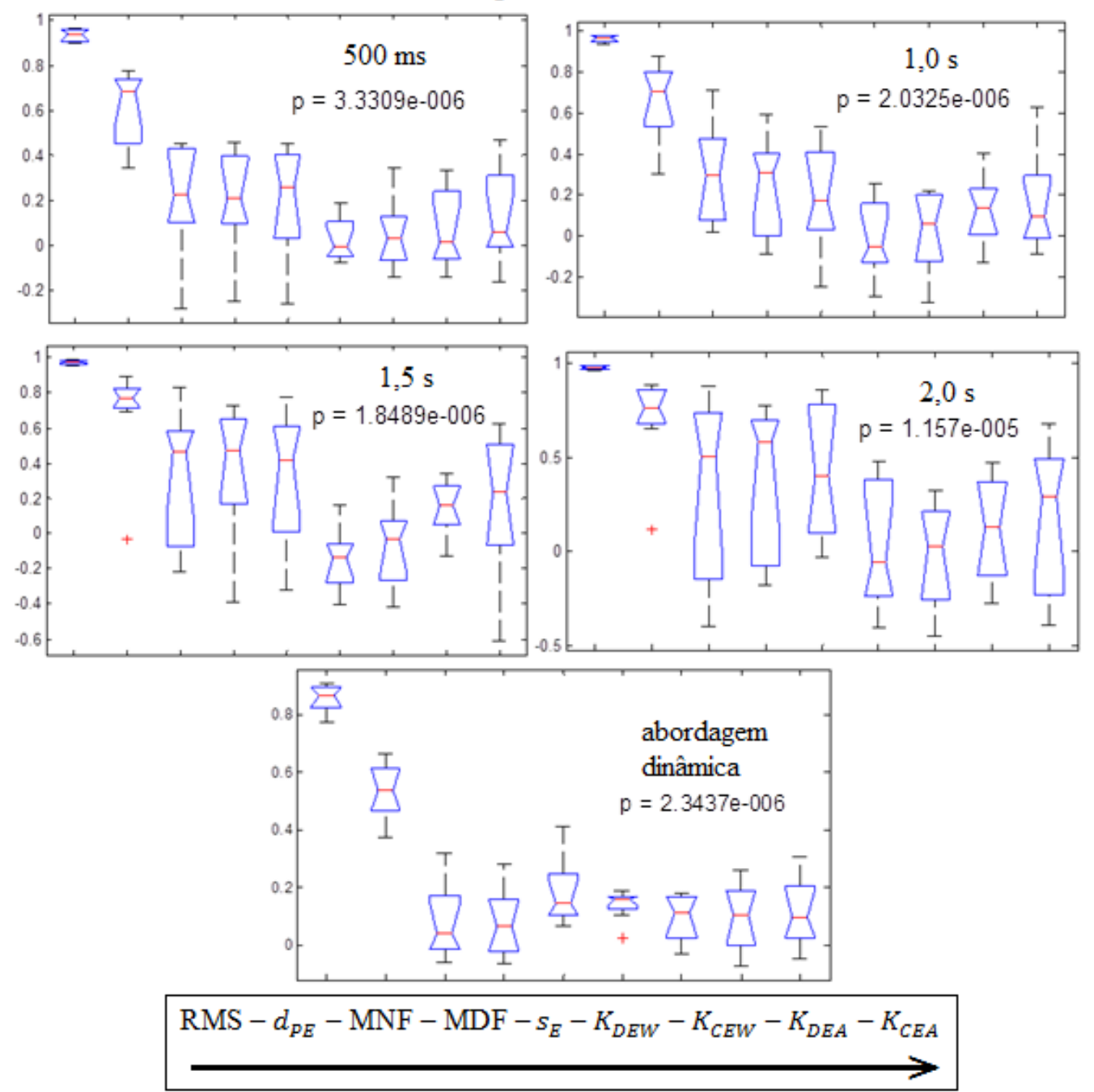

Figura 6.31: Correlações médias entre VL e VM observadas para todos os indicadores em carga crescente.

Os valores $p$ obtidos mostram que em geral as correlações médias entre os indicadores do VL e do VM foram, de fato, distintas em ambas as modalidades. Além disso, verifica-se na modalidade IL um interessante fato: o indicador $d_{P E}$ apresentou perfil intermediário de correlação entre VL e VM, situando-se entre o indicador temporal (RMS) e os demais, que exploram o espectro do eletromiograma (a partir da transformada de Fourier ou de wavelets). Isto possivelmente se deve à maneira como se definiu $d_{P E}$, explorando a distância entre os picos do sinal de EMG-S e sua envoltória. Tal definição aborda características temporais - visto que o surgimento de picos mais acentuados e em maior quantidade no sinal eletromiográfico está relacionado ao gradual aumento de sua amplitude - e características espectrais - já que estes picos mais acentuados e de menor 
duração correspondem a um espalhamento no espectro do sinal. $O$ fato de que esta observação é feita especialmente na modalidade IL deve relacionar-se com o recrutamento adicional - com o aumento da carga - de fibras do tipo II, que tendem a apresentar tais características, com maiores limiares de ativação e velocidades de condução, conforme verificado por Fleck e Kraemer (2004), que concluíram que essas fibras são mais adaptadas a contrações voluntárias mais intensas, devendo ser recrutadas em maior proporção em protocolos experimentais que envolvem esta situação, como, por exemplo, em ciclismo a uma alta carga resistida.

Por fim, a tabela 6.26 e a figura 6.32 mostram, dentre todos os valores obtidos para a correlação entre VL e VM, que, a semelhança observada entre a sequência indicadora de fadiga obtida para cada um destes músculos, apresentou - além do perfil crescente em função da janela de observação do eletromiograma - diferenças significativas entre as modalidades CL e IL (Kruskal-Wallis, $p<0,05$ ). Desta maneira, a tabela 6.26 mostra os valores de correlação geral entre VL e VM - considerando-se todos os indicadores - em cada situação, e a figura 6.32 atesta que há diferenças significativas entre os resultados obtidos em cada modalidade de exercício (colunas da tabela 6.26).

Tabela 6.26 - Correlação média geral - para todos os indicadores de todos os sujeitos - nas modalidades CL e IL, em função da abordagem.

\begin{tabular}{|c|c|c|}
\hline Abordagem & Carga constante & Carga crescente \\
\hline Dinâmica & 0,16303 & 0,25341 \\
\hline Isométrica (0,5 s) & 0,20505 & 0,31887 \\
\hline Isométrica (1,0 s) & 0,25161 & 0,34732 \\
\hline Isométrica (1,5 s) & 0,27697 & 0,43727 \\
\hline Isométrica (2,0 s) & 0,31261 & 0,46998 \\
\hline
\end{tabular}

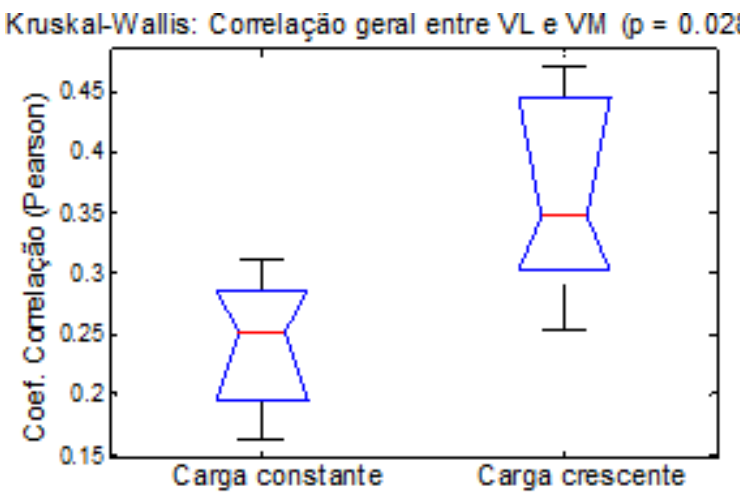

Figura 6.32: Diferenças significativas observadas para a correlação média geral entre os músculos VL e VM - para todos os indicadores de todos os sujeitos - obtida na modalidade CL e na modalidade IL. 
Estes resultados reforçam as observações de que, na exigência crescente de torque, os músculos VL e VM têm suas características funcionais aproximadas. Esta constatação complementa as feitas por Ericson (1986), que concluiu que os músculos VL e VM são responsáveis pela maior parte do trabalho mecânico positivo total em ciclismo. Está-se também de acordo com as conclusões de Ryan e Gregor (1992), que também utilizaram EMG-S, verificando que os músculos monoarticulares - dentre estes o VL e o VM desempenham, em geral, funções semelhantes ao gerar torque em maiores intensidades, em contraste com os músculos biarticulares, que apresentam maior variabilidade entre si (Ryan e Gregor, 1992; Hug et al., 2004a).

Os resultados agora vistos indicam que a variação da abordagem pode afetar significativamente a aferição da fadiga muscular. Em abordagem dinâmica, a correlação média entre indicadores do VL e do VM apresentou-se inferior à observada em abordagem isométrica. Isto sugere que, em abordagem dinâmica, os indicadores sofrem maiores influências das particularidades dos vastos lateral e medial. Isto está possivelmente relacionado às observações da seção 6.2.1.3, onde se verificou que os padrões de ativação do VL - mas não os do VM - variaram significativamente com a fadiga muscular. Note-se que, da forma como se define a abordagem isométrica, desconsideram-se os trechos correspondentes à ativação muscular (início das bulhas) para posterior concatenação, de forma a obter um sinal eletromiográfico de perfil próximo ao do caso isométrico. Assim, os padrões de ativação muscular devem influenciar majoritariamente os resultados obtidos com uso da abordagem dinâmica.

Em abordagem isométrica, o efeito da variação da duração dos trechos para cálculo dos indicadores sobre as correlações entre VL e VM em cada modalidade - quando observada separadamente - foi avaliado com o teste de Friedman. Este foi aplicado, para cada indicador eletromiográfico, aos conjuntos de correlações obtidos de todos os sujeitos, separados por duração adotada para cálculo. A tabela 6.27 mostra os valores $p$ obtidos com o teste. Seus resultados sugerem que, na modalidade IL, a correlação entre os indicadores do VL e do VM talvez seja mais influenciada pela duração do trecho escolhida do que na modalidade CL. 
Tabela 6.27 - Resultados do teste de Friedman. Comparação entre as correlações observadas - entre VL e VM - variando a duração do segmento do eletromiograma para cálculo dos indicadores (diferenças significativas destacadas em negrito).

\begin{tabular}{|c|c|c|}
\hline Indicador & Valor $p(\mathrm{CL})$ & Valor $p$ (IL) \\
\hline RMS & $\mathbf{4 , 5 1 8 5 . 1 0}^{-7}$ & $\mathbf{1 , 0 0 3 8 . 1 0}^{-\mathbf{6}}$ \\
\hline$d_{P E}$ & 0,8480 & $\mathbf{0 , 0 1 7 2}$ \\
\hline $\mathrm{MNF}$ & 0,2556 & 0,3605 \\
\hline $\mathrm{MDF}$ & $\mathbf{0 , 0 3 1 1}$ & $\mathbf{0 , 0 1 1 8}$ \\
\hline$S_{E}$ & 0,1308 & $\mathbf{0 , 0 3 3 0}$ \\
\hline$K_{D E W}$ & 0,8155 & 0,1925 \\
\hline$K_{C E W}$ & 0,8604 & 0,4113 \\
\hline$K_{D E A}$ & 0,7249 & 0,6960 \\
\hline$K_{C E A}$ & 0,5669 & 0,0941 \\
\hline
\end{tabular}

Estes resultados indicam que a correlação entre VL e VM, especialmente quando observada a partir do parâmetro RMS, é significativamente influenciada pela duração dos trechos em ambas as modalidades. O mesmo se verifica para a MDF. A correlação entre a distância entre picos e envoltória do sinal de EMG-S obtido do VL e do VM mostrou-se significativamente influenciada pela duração dos trechos somente em carga crescente. A mesma verificação se faz para o estreitamento do espectro $s_{E}$. As correlações entre VL e VM observadas a partir dos demais indicadores não apresentaram significativas variações em função da duração das janelas. O aumento das correlações médias entre indicadores para VL e VM observadas - em função da duração dos trechos - pode encontrar suporte no fato de que, ao calcular os indicadores sobre trechos mais longos do eletromiograma com perfil isométrico, fenômenos transientes sejam diluídos no processo, influenciando menos os valores obtidos nas sequências descritoras de fadiga, ao contrário de trechos mais curtos, em que variações abruptas nas características do sinal podem representar significativa parcela da energia do trecho.

Finalmente, os resultados referentes à avaliação sobre qual músculo - e, a partir de qual indicador eletromiográfico - deve apresentar diferenças significativas para a fadiga localizada nas modalidades CL e IL são mostrados a seguir. A tabela 6.28 mostra os resultados das comparações de todos os índices entre as modalidades CL e IL para o VL. A tabela 6.29 apresenta os resultados das mesmas comparações para o VM. Os resultados foram obtidos aplicando-se aos os índices de fadiga para as modalidades CL e IL - para cada indicador - o teste Anova, em caso de ambos os conjuntos (índices para CL e IL) estarem normalmente distribuídos, e o teste de Kruskal-Wallis, no caso de algum conjunto de índices obtidos não se apresentar normalmente distribuído. Os resultados são mostrados 
para a abordagem dinâmica e para abordagem isométrica com janelas de 500, 1000, 1500 e $2000 \mathrm{~ms}$.

Tabela 6.28 - Valores $p$ obtidos para as comparações entre os conjuntos de índices obtidos em CL e IL (diferenças significativas destacadas em negrito). Músculo VL.

\begin{tabular}{|c|c|c|c|c|c|c|c|c|c|}
\hline $\begin{array}{c}\text { Duração } \\
\text { das janelas } \\
(\mathrm{ms})\end{array}$ & $\mathrm{RMS}$ & $d_{P E}$ & $\mathrm{MNF}$ & $\mathrm{MDF}$ & $S_{E}$ & $K_{D E W}$ & $K_{C E W}$ & $K_{D E A}$ & $K_{C E A}$ \\
\hline 500 & $<\mathbf{1 0}^{-4}$ & $<\mathbf{1 0}^{-4}$ & $>0,05$ & $>0,05$ & $<\mathbf{0 , 0 5}$ & $>0,05$ & $>0,05$ & $>0,05$ & $>0,05$ \\
\hline 1000 & $<\mathbf{1 0}^{-4}$ & $<\mathbf{1 0}^{-4}$ & $>0,05$ & $>0,05$ & $>0,05$ & $>0,05$ & $>0,05$ & $>0,05$ & $>0,05$ \\
\hline 1500 & $<\mathbf{1 0}^{-3}$ & $<\mathbf{1 0}^{-3}$ & $>0,05$ & $>0,05$ & $<\mathbf{0 , 0 5}$ & $>0,05$ & $>0,05$ & $>0,05$ & $>0,05$ \\
\hline 2000 & $<\mathbf{1 0}^{-4}$ & $<\mathbf{1 0}^{-3}$ & $>0,05$ & $>0,05$ & $<\mathbf{0 , 0 5}$ & $>0,05$ & $<\mathbf{0 , 0 5}$ & $>0,05$ & $<\mathbf{0 , 0 5}$ \\
\hline $\begin{array}{c}\text { Abordagem } \\
\text { dinâmica }\end{array}$ & $<\mathbf{1 0}^{-\mathbf{6}}$ & $<\mathbf{1 0}^{-\mathbf{6}}$ & $>0,05$ & $>0,05$ & $>0,05$ & $>0,05$ & $>0,05$ & $>0,05$ & $<\mathbf{0 , 0 5}$ \\
\hline
\end{tabular}

Tabela 6.29 - Valores $p$ obtidos para as comparações entre os conjuntos de índices obtidos em CL e IL (diferenças significativas destacadas em negrito). Músculo VM.

\begin{tabular}{|c|c|c|c|c|c|c|c|c|c|}
\hline $\begin{array}{c}\text { Duração } \\
\text { das janelas } \\
(\mathrm{ms})\end{array}$ & $\mathrm{RMS}$ & $d_{P E}$ & $\mathrm{MNF}$ & $\mathrm{MDF}$ & $S_{E}$ & $K_{D E W}$ & $K_{C E W}$ & $K_{D E A}$ & $K_{C E A}$ \\
\hline 500 & $<\mathbf{1 0}^{-3}$ & $<\mathbf{0 , 0 1}$ & $<\mathbf{0 , 0 5}$ & $>0,05$ & $>0,05$ & $>0,05$ & $>0,05$ & $>0,05$ & $>0,05$ \\
\hline 1000 & $<\mathbf{1 0}^{-3}$ & $<\mathbf{0 , 0 5}$ & $>0,05$ & $>0,05$ & $>0,05$ & $>0,05$ & $>0,05$ & $>0,05$ & $>0,05$ \\
\hline 1500 & $<\mathbf{1 0}^{-3}$ & $<\mathbf{0 , 0 5}$ & $>0,05$ & $>0,05$ & $>0,05$ & $>0,05$ & $>0,05$ & $>0,05$ & $>0,05$ \\
\hline 2000 & $<\mathbf{1 0}^{-3}$ & $>0,05$ & $>0,05$ & $>0,05$ & $>0,05$ & $>0,05$ & $>0,05$ & $>0,05$ & $>0,05$ \\
\hline $\begin{array}{c}\text { Abordagem } \\
\text { dinâmica }\end{array}$ & $<\mathbf{1 0}^{-3}$ & $<\mathbf{0 , 0 1}$ & $>0,05$ & $>0,05$ & $<\mathbf{0 , 0 5}$ & $>0,05$ & $>0,05$ & $>0,05$ & $>0,05$ \\
\hline
\end{tabular}

Os resultados apontam que os parâmetros relacionados à amplitude do sinal de EMG-S (RMS e $d_{P E}$ ) de ambos os músculos distinguem significativamente a situação à carga constante da situação em que o incremento gradual da carga é imposto ao voluntário. Na maioria dos casos observados, os parâmetros espectrais tradicionais (MNF e MDF) não apresentaram distinção entre uma situação e outra, o que indica que estes indicadores não sejam significativamente sensíveis aos efeitos do aumento da carga. $\mathrm{O}$ estreitamento do espectro do eletromiograma para o músculo VL aparentemente foi mais sensível a estes efeitos. De fato, é uma expectativa razoável a de que o aumento da carga induza um processo de fadiga muscular mais intenso, sendo tendo sido o parâmetro $s_{E}$ proposto neste trabalho o único dos indicadores, entre aqueles definidos no domínio da frequência, a mostrar-se relativamente associado a isto. Em geral, as variáveis espectrais apresentaramse mais sensíveis aos efeitos do incremento da carga para o músculo VL do que para o VM. 
Um dos possíveis fatores que devem diminuir a sensibilidade dos indicadores espectrais que se baseiam na localização e deslocamento do centro do espectro do sinal eletromiográfico é o aumento da frequência central do sinal em função da carga, fato verificado por Moritani et al. (2004). Note-se que esses autores não avaliaram os efeitos da carga sobre a largura de banda do sinal eletromiográfico.

Uma interessante constatação é que, à exceção da MNF - quando calculada sobre trechos de $500 \mathrm{~ms}$ para o $\mathrm{VM}$-, todos os indicadores espectrais que eventualmente distinguiram a modalidade CL da IL foram aqueles definidos a partir da compressão - ou estreitamento - do espectro de amplitude do sinal eletromiográfico, e não em função da localização ou deslocamento de sua frequência central. Neste sentido, os efeitos da fadiga mais intensa que seriam verificados em carga crescente - que se observariam na forma de um decréscimo mais acentuado na frequência central do eletromiograma - devem ser compensados pelos efeitos do aumento da carga, que geram um deslocamento desta frequência central no sentido contrário, provocando seu aumento (Moritani et al., 2004). Assim, sugere-se que nessas situações e protocolos experimentais, em que se exige o incremento do torque, parâmetros espectrais associados à largura de banda do eletromiograma sejam mais adequados à aferição da fadiga muscular localizada.

Por fim, os resultados sugerem que os padrões eletromiográficos para o VL e o VM apresentem maior semelhança no domínio do tempo, independentemente de a carga ser linearmente incrementada ou mantida constante. A semelhança observada entre VL e VM para o aumento da amplitude do eletromiograma está de acordo com trabalhos prévios em que se avaliam os padrões temporais de ativação destes músculos (Houtz e Fischer, 1959; Faria e Cavanagh, 1978; Jorge e Hull, 1986; Dorel et al., 2008). A semelhança maior entre os parâmetros de amplitude - se comparada aos espectrais - para o VL e VM também pode estar relacionada à maior dependência dos parâmetros espectrais em relação à forma e duração dos Muaps, os quais não necessariamente devem apresentar significativas semelhanças entre os músculos.

O aumento significativamente mais acentuado da amplitude do eletromiograma verificado com o aumento da carga é coerente com a literatura (Bigland-Ritchie e Woods, 1974; Taylor e Bronks, 1994; Lucia et al., 1997; Hug et al., 2003; Hug et al., 2006a,b). Esta diferença significativa observada entre os índices de fadiga baseados na amplitude do eletromiograma - obtidos para carga constante e crescente - sugerem que estes são mais suscetíveis ao aumento da carga, somando-se os efeitos deste aumento aos efeitos da fadiga 
muscular. Desta maneira, recomenda-se que, para a aferição da fadiga em ciclismo à carga crescente, sejam utilizados índices de fadiga baseados em parâmetros espectrais, os quais não apresentaram diferenças significativas com o aumento da carga. Estas observações e sugestões encontram suporte no trabalho de Hug e Dorel (2009), que, com o gradual incremento da carga, relataram dificuldade em associar o aumento de amplitude do eletromiograma à fadiga ou ao aumento da carga. Sugere-se que na modalidade IL o aumento da amplitude do sinal de EMG-S possa ser parcialmente atribuído ao aumento da carga, já que: 1) neste protocolo, o indicador de fadiga baseado na amplitude do eletromiograma teve seu aumento intensificado se comparado à modalidade CL; e 2) o fator em comum é a fadiga localizada. Esta observação também é apoiada nos resultados obtidos por Ericson (1986), que relatou este aumento na amplitude do sinal em função da carga, minimizando os efeitos relativos da fadiga muscular. Assim, reforça-se a verificação de que a carga resistida, além da manifestação da fadiga (Petrofsky, 1979; Housh et al., 2000; Saunders et al., 2000; Sarre e Lepers, 2005), influencia significativamente a amplitude do sinal em atividades de ciclismo. Portanto, para avaliação da fadiga como parâmetro isolado e resistência em ciclismo, recomendam-se exercícios à carga constante ou, na necessidade de se variar a carga, o uso de parâmetros espectrais.

Observa-se também que, em geral, a correlação entre os parâmetros calculados para o VL e para o VM se apresentou maior em abordagem isométrica, especialmente para janelas de maior duração. É possível, portanto, que os parâmetros espectrais estejam mais relacionados com as possíveis diferenças funcionais entre estes músculos.

O aumento da correlação verificada entre os indicadores calculados para cada músculo com o aumento da carga pode estar relacionado ao padrão de recrutamento de unidades motoras com limiares de ativação gradativamente mais altos (Moritani et al., 2004). Assim, o recrutamento extra de unidades motoras deve tornar a atividade mioelétrica nos músculos VL e VM significativamente mais correlacionada. O aumento desta semelhança funcional entre os músculos com o incremento da carga deve relacionarse com o aumento da exigência de ambos para atuação conjunta, de modo a cumprir com o exercício proposto. Fisiologicamente, uma possibilidade é que este aumento da correlação entre VL e VM que se verificou na modalidade à carga crescente esteja relacionado ao aumento gradual de fibras do tipo II recrutadas em ambos os músculos, diminuindo-se a diferença entre o percentual destas fibras ativas (fibras do tipo II / total de fibras) observada entre o VL e o VM. Em condições normais - de carga relativamente baixa e sem 
manifestações significativas da fadiga - é possível que esta diferença entre as proporções de fibras do tipo II ativas em cada músculo seja mais evidente (Johnson et al., 1973), sem o recrutamento adicional de unidades motoras com limiar de ativação mais alto, que apresentam CV mais alta e potenciais de ação com menor duração. Estas observações colaboram com Tesch e Karlsson (1985), que concluíram que fibras tipo II apresentam maiores concentrações de metabólitos em atividades exaustivas. Desta maneira, um processo mais intenso de fadiga deve equalizar as influências sobre os parâmetros eletrofisiológicos dos músculos estudados neste trabalho.

\subsection{2 - Considerações finais}

Nesta seção, os indicadores tratados neste trabalho foram avaliados em protocolo dinâmico de ciclismo, envolvendo duas modalidades: CL e IL, no qual a carga era gradualmente incrementada (50 W / 30 s). Em ambas a modalidades os voluntários pedalavam a velocidade constante. Duas abordagens para cálculo dos indicadores foram empregadas: dinâmica, que considera ciclos completos do sinal; e isométrica, que concatena trechos de cada ciclo, obtendo-se um eletromiograma com perfil isométrico. Nesta última abordagem, os indicadores foram calculados para diferentes durações de janela, observando-se suas influências sobre a similaridade entre indicadores do VL e do VM.

Verifica-se que, ao fixar uma modalidade de exercício e abordagem para cálculo dos indicadores, não houve diferenças significativas entre os índices obtidos para o VL e para o VM, à exceção de $K_{C E W}$ na modalidade IL para janelas de maior duração.

Assim, quando não há interesse em observar efeitos de variação da carga ou da abordagem, esses resultados indicam que, aparentemente, não há diferenças entre o músculo escolhido - VL ou VM - para aferição da fadiga em ciclismo. Ainda, tanto a abordagem dinâmica quanto a isométrica - com quaisquer dos janelamentos abordados permitiram a aferição objetiva da fadiga muscular localizada no VL e no VM.

Em abordagem isométrica observou-se um padrão, em média, crescente para a correlação entre as sequências descritoras de fadiga do VL e do VM em função da duração dos trechos. Neste sentido, sugere-se que, quanto maiores forem as janelas consideradas para análise, menos os indicadores eletromiográficos de amplitude deverão dissociar a atividade mioelétrica do VL e do VM. 
Uma possível causa é que, ao calcular os indicadores sobre trechos mais longos do eletromiograma com perfil isométrico, os fenômenos transientes particulares dos sinais de EMG-S de cada músculo sejam diluídos no processo.

Ainda para esses indicadores, as curvas de correlação obtidas evidenciaram a maior semelhança entre a atividade mioelétrica do VL e do VM ao exigir-lhes torque crescente, o que sugere uma aproximação funcional destes músculos nesta situação.

Os parâmetros definidos no domínio da frequência também apresentaram padrão crescente em função da duração dos segmentos do eletromiograma para cálculo dos indicadores, à exceção do estreitamento do espectro $\left(s_{E}\right)$ em carga constante, que, não sofreu variações significativas com o janelamento. Semelhantemente ao domínio do tempo, estes parâmetros sugerem o aumento na similaridade funcional dos músculos VL e VM ao submetê-los ao aumento gradual da carga resistida.

Os indicadores $K_{D E W}$ e $K_{C E W}$, ao contrário de suas versões adaptativas, não apresentaram significativo aumento ou diminuição da correlação entre seus valores para o VL e para o VM em função da duração da janela em abordagem isométrica, tampouco sua correlação variou significativamente entre as modalidades CL e IL. Neste sentido, estes indicadores não refletem maiores diferenças entre a atividade muscular do VL da do VM ao submetê-los a um esforço gradativamente crescente.

Os indicadores temporais - dependentes da amplitude - do eletromiograma apresentaram maior similaridade entre o VL e o VM. Desta maneira, ao intencionar-se diferenciar a atividade mioelétrica destes músculos, sugere-se o uso de parâmetros espectrais, em vez de temporais. Ainda, os indicadores de amplitude mostraram-se significativamente mais sensíveis ao aumento da carga. Assim, se a intenção é diferenciar a atividade muscular observada na modalidade CL da observada na modalidade IL, recomenda-se o uso destes indicadores. Por outro lado, se o objeto de estudo é a avaliação objetiva da fadiga muscular, sem que se incluam as influências do aumento da carga no eletromiograma, indica-se o uso de indicadores espectrais.

Em abordagem isométrica, os indicadores calculados para o VL e para o VM apresentaram maior semelhança, se comparada à abordagem dinâmica. Isto pode estar relacionado aos fenômenos transientes que ocorrem no momento da ativação muscular no início das bulhas -, que são desconsiderados ao empregar-se a abordagem isométrica. Observou-se ainda que, na modalidade IL, a correlação entre os indicadores do VL e do VM sofreu maior influência pela duração do trecho escolhida do que na modalidade CL. 
Contudo, os indicadores baseados em wavelets parecem ser igualmente correlacionados em ambas as situações.

Finalmente, os resultados sugerem que o músculo VL seja mais sensível ao aumento da carga, se comparado ao VM. Estas constatações se fazem especialmente com os indicadores temporais. Os indicadores espectrais baseados na compressão do espectro de amplitude do sinal de EMG-S apresentaram-se, em geral, mais sensíveis à modalidade se comparados àqueles que mensuram a fadiga a partir da posição do centro do espectro do sinal. Recapitule-se que os parâmetros $s_{E}, K_{C E W}$ e $K_{C E A}$, propostos neste trabalho, são os parâmetros que exploram este fenômeno no espectro. Assim, para a diferenciação entre modalidades a partir de parâmetros espectrais, recomenda-se a aferição da compressão do espectro do eletromiograma - em vez do deslocamento de seu centro.

Um passo adiante no entendimento destas questões é, por exemplo, a avaliação desta sensibilidade definindo-se como parâmetros adicionais de estudo a postura e posição ao pedalar, considerando-se as formas neutra, aduzida e abduzida. Tendo-se maior ciência de tais tópicos, poder-se-iam recomendar atividades associadas a posturas que mais se adéquem à ativação, em particular, de cada um destes músculos extensores do joelho. Na próxima seção apresenta-se o último estudo de caso deste trabalho envolvendo ciclismo.

\section{4 - PROTOCOLO DINÂMICO (CICLISMO - I): ELETROMIOGRAFIA E DESEMPENHO BIOMECÂNICO}

Nesta seção apresentam-se os resultados obtidos para o Protocolo I - apresentado na seção 3.1 -, que envolve instrumentação integrada para aquisição de sinais biomecânicos e eletromiográficos.

Como medida de desempenho fisiológico, tomou-se a razão entre o índice de fadiga e o tempo total - medido pela quantidade de ciclos - antes do ponto de quebra, em que o voluntário não se mostrou mais apto a manter o exercício proposto. Esta medida de desempenho fisiológico, para cada indicador eletromiográfico considerado, foi comparada ao desempenho biomecânico global (média de $f_{d}$ ao longo de todo o teste) utilizando-se o coeficiente de correlação de Pearson para avaliar possíveis semelhanças entre esses descritores. 


\subsection{1 - Resultados e discussão}

A figura 6.33 mostra a evolução ao longo do teste de cada indicador eletromiográfico (i.e. seus ajustes lineares) para os quatro voluntários que participaram do experimento.
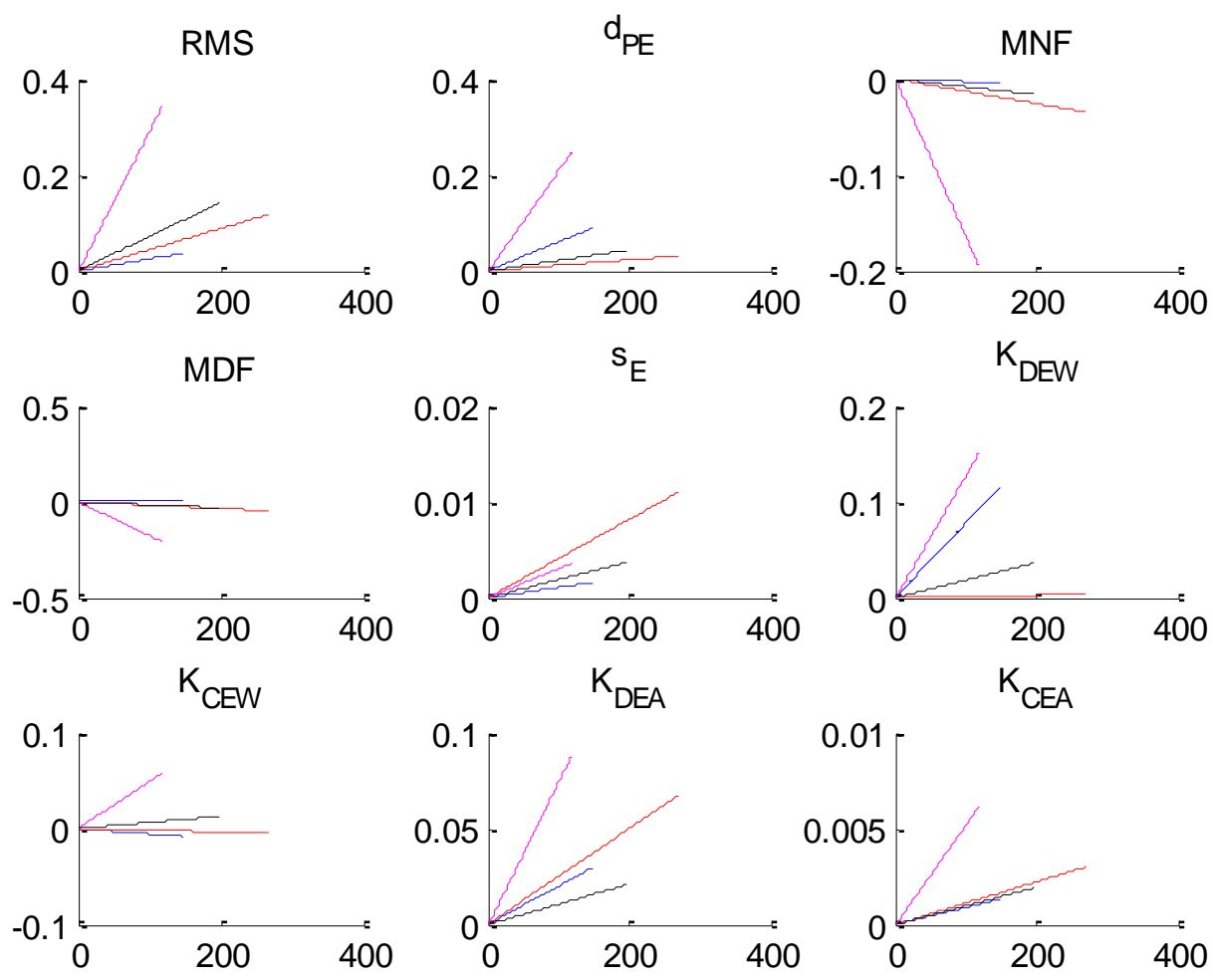

Figura 6.33: Comportamento dos indicadores eletromiográficos ao longo do teste - em função dos ciclos de pedalada - para todos os sujeitos. (Sujeitos 1, 2, 3 e 4 em azul, vermelho, preto e lilás, respectivamente.)

No total, houve três ajustes fora do esperado: um ajuste crescente para a MDF e dois ajustes decrescentes para $K_{C E W}$. Em geral, as causas dessas ocorrências observadas no eletromiograma são de difícil dissociação, sendo vários os possíveis fatores que lhes impõem modificações transitórias no espectro, afetando os descritores espectrais (Lindström e Petersén, 1981; Solomonow et al., 1990; Masuda et al., 1996 e 1999; Farina et al., 2002; Waly et al., 2003; Dimitrova e Dimitrov, 2003).

As tabelas 6.30, 6.31 e 6.32 a seguir mostram os valores de desempenho fisiológico - conforme definido nesta seção -, respectivamente, para os indicadores definidos no 
domínio do tempo (RMS e $d_{P E}$ ), no domínio da frequência (MNF, MDF e $s_{E}$ ) e no domínio da DWT ( $K_{D E W}, K_{C E W}, K_{D E A}$ e $\left.K_{C E A}\right)$. O desempenho biomecânico global de cada sujeito é mostrado na tabela 6.33, em conjunto com sua variação global ao longo do exercício. A variação global de $f_{d}$ foi calculada a partir do ajuste linear de $f_{d}$, dividindo-se o termo linear pelo valor inicial, obtendo-se a variação percentual média ao longo do teste - relativa ao valor inicial de $f_{d}$.

Tabela 6.30 - Desempenho fisiológico para os indicadores eletromiográficos no domínio do tempo.

\begin{tabular}{|c|c|c|}
\hline Sujeito & RMS $\left(* 10^{-5}\right)$ & $d_{P E}\left(* 10^{-5}\right)$ \\
\hline 1 & 0,1695 & 0,4083 \\
\hline 2 & 0,1647 & 0,0429 \\
\hline 3 & 0,3614 & 0,1104 \\
\hline 4 & 2,4872 & 1,7784 \\
\hline
\end{tabular}

Tabela 6.31 - Desempenho fisiológico para os indicadores eletromiográficos no domínio da frequência.

\begin{tabular}{|c|c|c|c|}
\hline Sujeito & MNF $\left(* 10^{-6}\right)$ & MDF $\left(* 10^{-6}\right)$ & $S_{E}\left(* 10^{-6}\right)$ \\
\hline 1 & $-0,1901$ & 0,2887 & 0,0723 \\
\hline 2 & $-0,4784$ & $-0,6498$ & 0,1519 \\
\hline 3 & $-0,4126$ & $-0,7943$ & 0,0953 \\
\hline 4 & $-14,0224$ & $-14,8588$ & 0,2550 \\
\hline
\end{tabular}

Tabela 6.32 - Desempenho fisiológico para os indicadores eletromiográficos no domínio da DWT.

\begin{tabular}{|c|c|c|c|c|}
\hline Sujeito & $K_{D E W}\left(* 10^{-6}\right)$ & $K_{C E W}\left(* 10^{-6}\right)$ & $K_{D E A}\left(* 10^{-6}\right)$ & $K_{C E A}\left(* 10^{-7}\right)$ \\
\hline 1 & 5,2511 & $-0,3420$ & 1,3548 & 0,6034 \\
\hline 2 & 0,0496 & $-0,0626$ & 0,9338 & 0,4164 \\
\hline 3 & 0,9219 & 0,3266 & 0,5359 & 0,4910 \\
\hline 4 & 10,8659 & 4,1574 & 6,3269 & 4,4231 \\
\hline
\end{tabular}

Tabela 6.33 - Desempenho biomecânico global (valor médio de $f_{d}$ ) e variação média de $f_{d}$ ao longo do teste em função de seu valor inicial. Todos os sujeitos.

\begin{tabular}{|c|c|c|}
\hline Sujeito & $f_{d}$ global & $\begin{array}{c}\text { Variação global de } f_{d} \\
(\%)\end{array}$ \\
\hline 1 & 0,2325 & 0,19 \\
\hline 2 & 0,3149 & 0,07 \\
\hline 3 & 0,1807 & 0,32 \\
\hline 4 & 0,3831 & 0,33 \\
\hline
\end{tabular}

Note-se que todos os sujeitos apresentaram variações inferiores a 1,0\% do desempenho no início da execução do exercício. Esta constatação sugere que ciclistas 
treinados não devem, em geral, apresentar significativas variações na forma de pedalar ao longo de um teste fatigante (Milhomem et al., 2014d). A figura 6.34 a seguir mostra a evolução de $f_{d}$ ao longo dos ciclos de pedalada do exercício completo para todos os sujeitos.
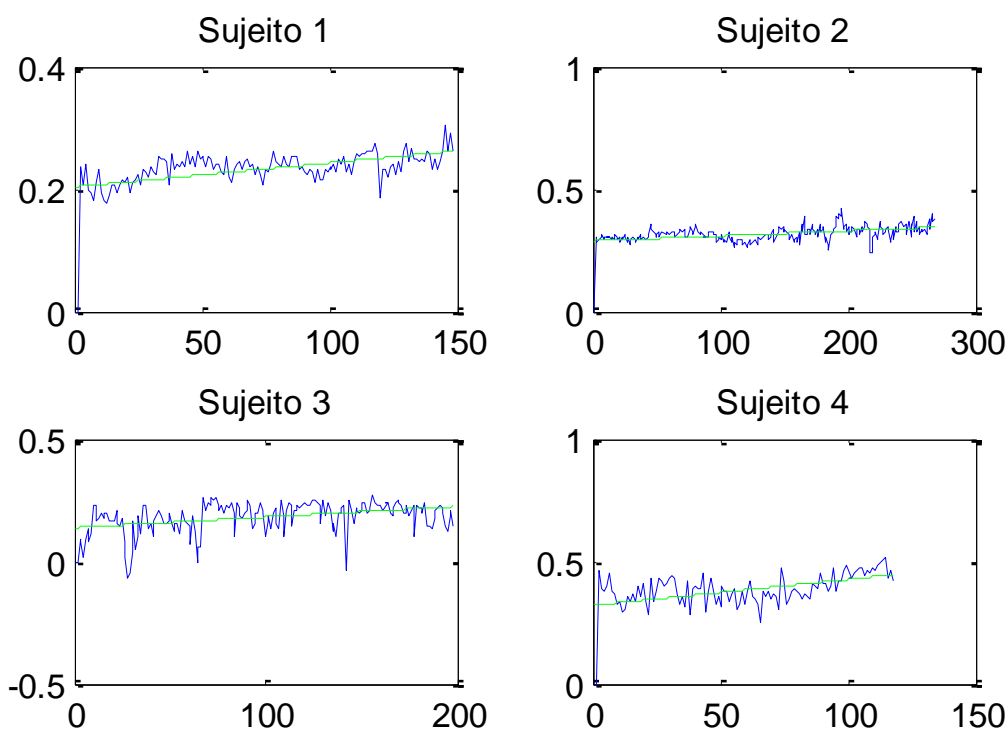

Figura 6.34: Evolução de $f_{d}$ (azul) e respectivos ajustes lineares (verde) ao longo dos ciclos de pedalada do exercício completo para todos os sujeitos.

Esses gráficos ilustram mais detalhadamente que o sujeito 4 apresentou maior $f_{d}$ ao longo do exercício proposto, conforme apresentado anteriormente na tabela 6.33. Perfis típicos de torque efetivo e fator de desempenho biomecânico ao longo de um ciclo de pedalada são mostrados nas figuras 6.35 e 6.36, respectivamente. Note-se que o uso de dois potenciômetros fixados de forma diametralmente oposta evitou regiões demasiadamente ruidosas, situações típicas observadas ao utilizar um goniômetro simples em função do gap contido na trilha resistiva. 


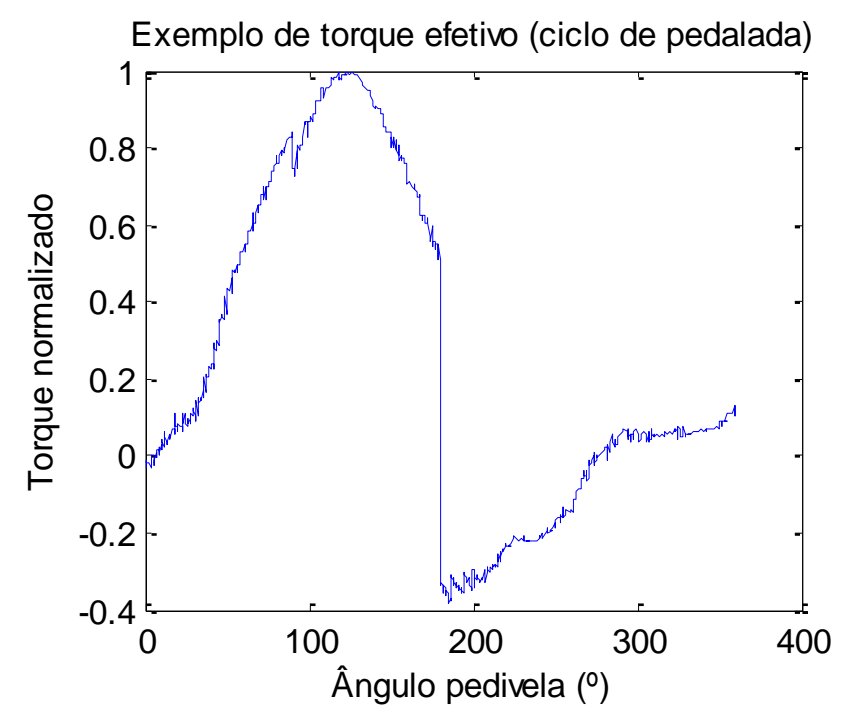

Figura 6.35: Exemplo de torque efetivo num ciclo de pedalada completo (suj. 2).

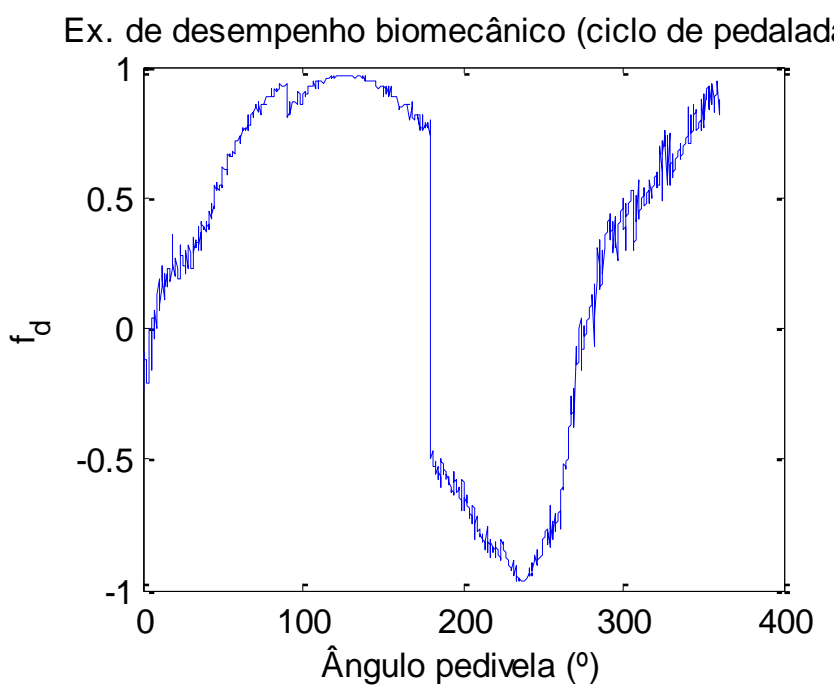

Figura 6.36: Exemplo de $f_{d}$ num ciclo de pedalada completo (suj. 2).

Constata-se que a maior parte da contribuição ao giro do pedivela é feita durante a fase de potência (primeira metade do ciclo de pedalada). Em geral, durante a fase de recuperação (segunda metade do ciclo de pedalada), a contribuição líquida ao giro do pedivela é negativa, sendo a força produtiva exercida sobre o outro pedal, com defasagem de $180^{\circ}$ entre os perfis de torque efetivo e $f_{d}$. A descontinuidade observada para os sinais de torque efetivo e de $f_{d}$ entre as fases de potência e de recuperação é esperada, visto que, logo após o ponto morto inferior do pedal, o sentido de aplicação da força sobre o pedal (em geral, para baixo) imediatamente deixa de corresponder a uma contribuição líquida positiva para o giro do pedivela (Milhomem et al., 2012). 
Além da pouca variação na técnica de pedalar, observa-se que nenhum dos voluntários obteve um fator de desempenho global superior a 0,4 , ou de $40 \%$ de aproveitamento das forças totais aplicadas. Tais limitações parecem ser características de ciclistas em geral, incluindo-se os treinados (Milhomem et al., 2012 e 2014d).

O sujeito 4, que apresentou maior fator de desempenho biomecânico global, também apresentou índices de fadiga mais acentuados, como mostraram as tabelas 6.30, 6.31 e 6.32. Os índices correspondentes à fadiga muscular menos intensa foram observados para os sujeitos 1, 2 e 3 de forma alternada, dependendo do índice utilizado para mensurála. Coloca-se, portanto, a hipótese de que ciclistas cuja postura e técnica de pedalar promovam um desempenho biomecânico mais alto estejam mais aptos a experimentar um processo de fadiga relativamente mais intenso. Esta hipótese é reforçada pelos resultados mostrados nas tabelas 6.34 e 6.35, que apresentam os coeficientes de correlação entre os índices de fadiga e desempenho biomecânico global (para o grupo dos quatro sujeitos) e entre desempenho fisiológico e desempenho biomecânico global, respectivamente.

Tabela 6.34 - Coeficientes de correlação entre valores de índice de fadiga e desempenho biomecânico global para o conjunto de todos os sujeitos.

\begin{tabular}{|c|c|}
\hline Índice & $\begin{array}{c}\text { Correlação } \\
\text { com } f_{d} \text { global }\end{array}$ \\
\hline RMS & 0,7317 \\
\hline$d_{P E}$ & 0,7186 \\
\hline $\mathrm{MNF}$ & $-0,8034$ \\
\hline $\mathrm{MDF}$ & $-0,7950$ \\
\hline$S_{E}$ & 0,6726 \\
\hline$K_{D E W}$ & 0,5312 \\
\hline$K_{C E W}$ & 0,7012 \\
\hline$K_{D E A}$ & 0,8915 \\
\hline$K_{C E A}$ & 0,8049 \\
\hline
\end{tabular}

Tabela 6.35 - Coeficientes de correlação entre valores de desempenho fisiológico e desempenho biomecânico global para o conjunto de todos os sujeitos.

\begin{tabular}{|c|c|}
\hline Índice & $\begin{array}{c}\text { Correlação } \\
\text { com } f_{d} \text { global }\end{array}$ \\
\hline RMS & 0,7430 \\
\hline$d_{P E}$ & 0,7344 \\
\hline $\mathrm{MNF}$ & $-0,7897$ \\
\hline $\mathrm{MDF}$ & $-0,7845$ \\
\hline$S_{E}$ & 0,9147 \\
\hline$K_{D E W}$ & 0,6174 \\
\hline$K_{C E W}$ & 0,7418 \\
\hline$K_{D E A}$ & 0,8080 \\
\hline$K_{C E A}$ & 0,7729 \\
\hline
\end{tabular}


Observa-se que, à exceção de $K_{D E W}$, os valores de correlação obtidos, em módulo, foram próximos ou superiores a 0,7 , com destaque para o desempenho fisiológico medido a partir do estreitamento espectral $s_{E}$, corroborando com a relação observada entre eficiência biomecânica e intensidade da fadiga experimentada, sugerindo-se que ciclistas mais treinados possivelmente se sintam mais confortáveis para realizar o protocolo próximo ao limite de sua capacidade.

Notem-se as limitações das conclusões que aqui podem ser feitas, vista a pequena quantidade de voluntários avaliados. Desta maneira, estes resultados devem ser interpretados como hipóteses colocadas para trabalhos futuros que empreguem metodologia semelhante envolvendo instrumentação para avaliação conjunta de parâmetros biomecânicos e fisiológicos dos ciclistas.

As limitações ao desempenho biomecânico também devem ser observadas. A geração de torque efetivo, durante os ciclos de pedalada, está em geral limitada a regiões específicas da fase de potência (Hug e Dorel, 2009). Outras formas de promover aumento de eficiência na pedalada podem envolver, por exemplo, a proposição de coroas de diferentes formatos, de forma que se as adaptem aos perfis típicos de pedalada e de curvas de força sobre os pedais de cada ciclista (Carmo, 2003; Milhomem 2011; Milhomem et al., 2012).

\subsection{2 - Considerações finais}

Nesta seção os parâmetros objetivos para avaliação de desempenho biomecânico em ciclismo - definidos no capítulo 3 - foram estudados. Em conjunto, definiu-se um parâmetro de desempenho fisiológico, a partir da razão entre o índice de fadiga e a duração total do experimento, até a ocorrência do ponto de ruptura em função da fadiga localizada.

Conforme verificação quantitativa, em geral menos de $40 \%$ do total das forças medidas sobre os pedais são geradoras de torque efetivo e, aparentemente, ciclistas treinados não devem apresentar variações significativas em seu desempenho biomecânico com a ocorrência da fadiga muscular ao longo do exercício. Sugere-se que ciclistas treinados que, além do conhecimento das próprias limitações, apresentam postura e técnica de pedalar que promovam valores mais altos de desempenho biomecânico, estejam mais aptos a experimentar um processo relativamente mais intenso de fadiga.

As relações entre desempenho fisiológico e biomecânico observadas neste trabalho 
devem ser observadas à luz da limitação do conjunto de voluntários. Assim, estes resultados devem ser avaliados como geradores de hipóteses, conduzindo à proposição de novos experimentos a partir de metodologias semelhantes de avaliação conjunta entre sinais eletromiográficos e biomecânicos.

Por fim, a instrumentação integrada definida para a avaliação conjunta de parâmetros eletromiográficos e biomecânicos permitiu a condução adequada do experimento, atendendo à demanda satisfatoriamente. A seguir, apresenta-se o último estudo de caso deste trabalho, envolvendo o uso de dinamometria isocinética para exercícios de extensão de joelho.

\section{5 - PROTOCOLO DINÂMICO (ISOCINÉTICO)}

Nesta seção a fadiga muscular é estudada em exercícios de extensão de joelho em dinamometria isocinética, a partir de sinais de EMG-S do músculo VL coletado de 7 (sete) voluntários. Adotou-se um protocolo tradicional, em que o voluntário executava 6 (seis) séries de 10 (dez) contrações, a 60 \% na fase concêntrica e a $180 \%$ s na fase excêntrica.

A primeira hipótese a ser avaliada é a de que a fase concêntrica do exercício - no qual o dinamômetro impõe uma carga resistida de forma a manter a velocidade constante (fase isocinética) - seja a mais adequada para avaliação da fadiga muscular. Esta hipótese motiva-se em razão do maior grau de não-estacionariedade do sinal de EMG-S fora desta fase, em que se observa variação significativa da velocidade angular no dinamômetro, conforme verificado por Schwartz (2010) e Schwartz et al. (2012). Nesses trabalhos os autores avaliaram a estacionariedade do sinal eletromiográfico nas regiões de carga - em que o equipamento busca manter o protocolo isocinético - e de oscilação da velocidade angular.

No caso específico de dinamometria isocinética, recomenda-se, para a redução dos efeitos das não-estacionariedades, descartar as fases onde há oscilação da velocidade, no início da região de carga, em que o membro em aceleração é conduzido pelo aparelho à velocidade constante (Schwartz, 2010). Sugere-se, portanto, que a análise do sinal EMG-S se limite a intervalos cíclicos, em que fatores biomecânicos se repetem periodicamente.

Contudo, uma questão ainda não avaliada na literatura científica disponível é o efeito do cálculo dos indicadores de fadiga nas diferentes fases (Milhomem et al., 2014e). 
Foram consideradas as fases concêntrica (FC), excêntrica e de aceleração (FA). A figura 6.37 ilustra estas fases do exercício, identificadas a partir do sinal de velocidade angular.

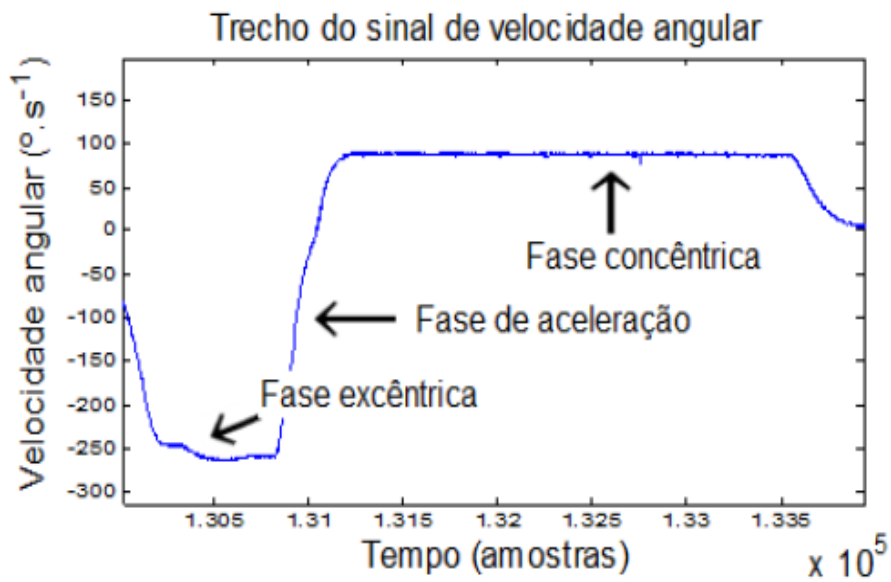

Figura 6.37: Fases concêntrica (FC), excêntrica (FE) e de aceleração (FA) em dinamometria isocinética (adaptado de Milhomem et al., 2014e).

Para a avaliação da fadiga, nas três fases, utilizou-se abordagem isométrica. Para a FC, foram concatenados segmentos de $300 \mathrm{~ms}$ do sinal de EMG-S de cada contração, calculando-se os indicadores sobre trechos sucessivos de $500 \mathrm{~ms}$ do sinal concatenado com perfil isométrico. Como se observa na figura 6.37, a FE e a FA são mais curtas do que a FC. Assim, nestas fases, concatenaram-se segmentos de $150 \mathrm{~ms}$ do sinal de EMG-S de cada contração, calculando-se os indicadores sobre trechos sucessivos de $250 \mathrm{~ms}$ do sinal concatenado, de forma a obter quantidade de pontos comparável à da FC para avaliação da fadiga a partir das regressões lineares em cada série de dez contrações. O trecho isocinético da FC foi determinado como o segmento que se inicia na primeira amostra do sinal de velocidade angular a atingir $95 \%$ do valor máximo, terminando na última amostra do sinal com amplitude igual ou superior a 95\% do valor máximo. Outros autores, como Wilk et al. (1992), também utilizam esta definição para delimitar a fase isocinética. Para a FE, aplicou-se procedimento semelhante, porém considerando o valor mínimo, pois a velocidade angular medida pelo equipamento na FE é negativa. A FA foi considerada como toda a região compreendida entre os instantes imediatamente após o fim da FE e imediatamente antes do início da FC. Para todos os procedimentos de identificação dos ciclos, segmentação, concatenação - dos sinais de EMG-S, torque, velocidade e posição angular -, identificação de pico de torque, e cálculo de parâmetros sobre os sinais eletromiográficos e biomecânicos, foram desenvolvidas rotinas específicas em Matlab. 
A segunda questão a ser avaliada é o padrão apresentado pela eficiência neuromuscular (ENM) com a indução da fadiga muscular no VL. Tais parâmetros quantificadores de eficiência, em conjunto com a mensuração de resistência e fadiga muscular, são necessários para a avaliação objetiva de pacientes com disfunções neuromusculares, visto que a perda em longo prazo da capacidade de gerar torque e a fadiga crônica estão entre seus principais sintomas (Milner-Brown et al., 1986). Seu cálculo se baseará na definição clássica de ENM dada por Milner-Brown et al. (1986), que a define como a razão entre força e amplitude do eletromiograma. Uma das implicações deste parâmetro assim definido é que em contrações isotônicas prolongadas, por exemplo, a ENM deve apresentar um decréscimo gradual, devido ao aumento da amplitude do eletromiograma em função da fadiga muscular para que se mantenha a mesma força solicitada. Porém, em protocolo isocinético, conforme verificado por Gerdle et al. (2000), durante a fase de fadiga a amplitude do eletromiograma decresce simultaneamente ao torque. Notem-se, além disso, os resultados controversos encontrados para a amplitude do eletromiograma - padrões significativamente crescentes, significativamente decrescentes, ou, ainda, sem variações significativas (Gerdle et al., 1987; Gerdle e Langström, 1987; Gerdle e Elert, 1989; Wretling et al., 1997).

A ENM será aqui calculada - a partir do sinal de torque $T(t)$ e do sinal eletromiográfico $x(t)$-, para um trecho entre os instantes $t_{\text {inicial }}$ e $t_{\text {final }}$ do exercício, como:

$$
E N M_{\left[t_{\text {inicial }}, t_{\text {final }}\right]}=\frac{\max _{t \in\left[t_{\text {inicial }}, t_{\text {final }}\right]}\{T(t)\}}{x_{R M S}\left[t_{\text {inicial }}, t_{\text {final }}\right]} .
$$

Isto é, dado um intervalo $t_{\text {inicial }} \leq t \leq t_{\text {final }}$ do exercício, a ENM é dada pela razão entre o pico de torque observado neste intervalo e o valor RMS do sinal eletromiográfico, também neste intervalo. Os valores de ENM serão calculados na FC, fase na qual, em cada ciclo completo de contração, os picos de torque são observados, como mostra a figura 6.38. 
Velocidade angular normalizada (azul) e Torque normalizado (verde)

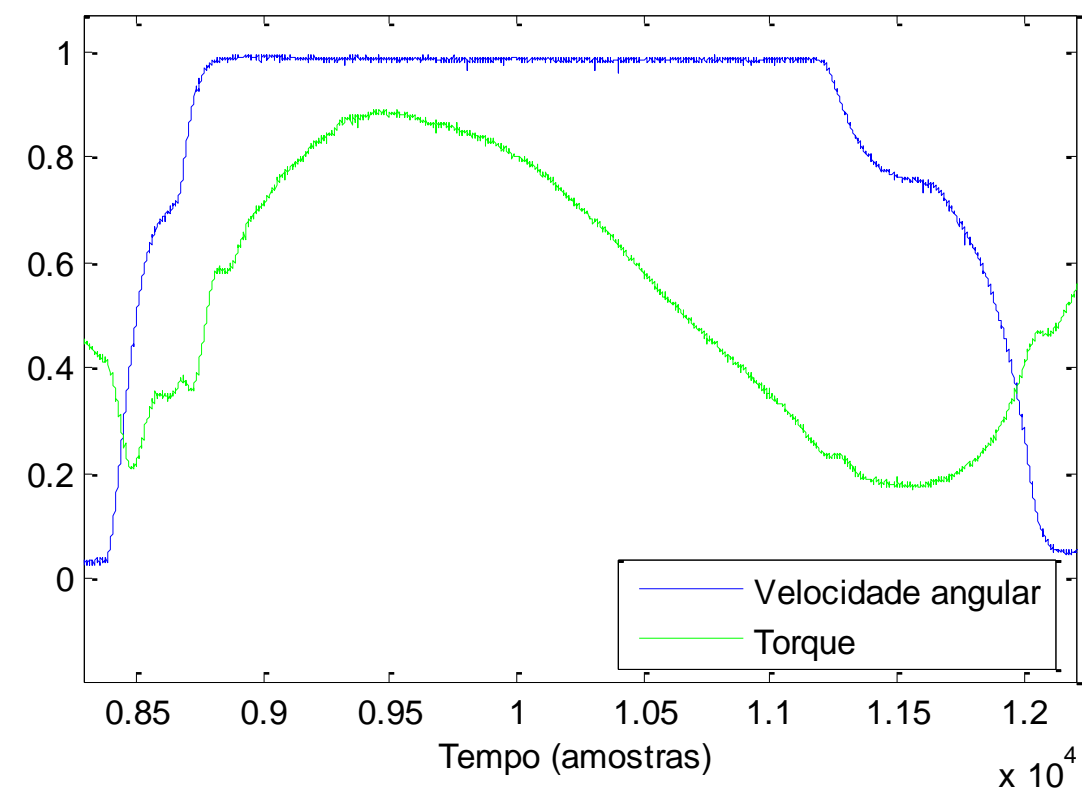

Figura 6.38: Representação da velocidade angular normalizada (azul) e torque normalizado (verde) em um ciclo de contração durante a FC. Observa-se que o pico de torque ocorre durante esta fase, na região em que o exercício é mantido isocinético com imposição da carga pelo dinamômetro. Trecho dos sinais de um dos voluntários.

Verifica-se que o pico de torque ocorre durante a FC, fase na qual a extensão de joelho ocorre a velocidade constante. O cálculo da ENM foi considerado para janelas de $150,200,250$ e $300 \mathrm{~ms}$.

A terceira e última questão a ser abordada é se os índices de fadiga apresentam algum padrão ao longo das seis séries de contração. Busca-se saber, portanto, se o índice de fadiga da maneira como foi definido - razão entre inclinação da reta obtida pelo ajuste linear da sequência descritora de fadiga e seu valor inicial - é sensível ao acúmulo da fadiga ao longo das séries. Assim, aos índices parciais obtidos por série de contração, aplica-se um novo ajuste linear, obtendo-se um índice total por sujeito. Desta maneira a existência de padrões será aqui avaliada a partir de testes aplicados aos índices totais. Ao longo desta seção, para os dados normalmente distribuídos, foi utilizado o teste t para avaliar a hipótese nula de que a média dos dados seja igual a zero. Rejeitando-se a hipótese de normalidade, utilizou-se o teste não paramétrico de Kruskal-Wallis para avaliar se a mediana do conjunto de dados é significativamente diferente de zero. A hipótese de normalidade foi avaliada com o teste de Lilliefors. Para todos os testes o nível de significância adotado foi $\alpha=0,05$. 


\subsection{1 - Resultados e discussão}

Às exceções da MNF, de $s_{E}$ e de $K_{D E A}$, todos os índices obtidos para a FC apresentaram-se normalmente distribuídos (teste de Lilliefors; $p>0,05$ ). Para estes três índices, o teste de Kruskal-Wallis indica que apresentaram o comportamento esperado MNF decrescente, e $s_{E}$ e $K_{D E A}$ crescentes $(p<0,05)$. Para os demais índices, o teste $\mathrm{t}$ indica que o valor RMS, $d_{P E}$ e a MDF apresentaram comportamento decrescente, enquanto $K_{D E W}, K_{C E W}$ e $K_{C E A}$ apresentaram padrão crescente com a fadiga muscular, conforme esperado $(p<0,05)$. Assim, a avaliação da fadiga na FC se mostrou de acordo com o esperado para todos os indicadores eletromiográficos abordados. As figuras 6.39, $6.40 \mathrm{e}$ 6.41 mostram as sequências descritoras de fadiga por série de contração para um dos voluntários, para os indicadores no domínio do tempo, da frequência e da DWT, respectivamente.

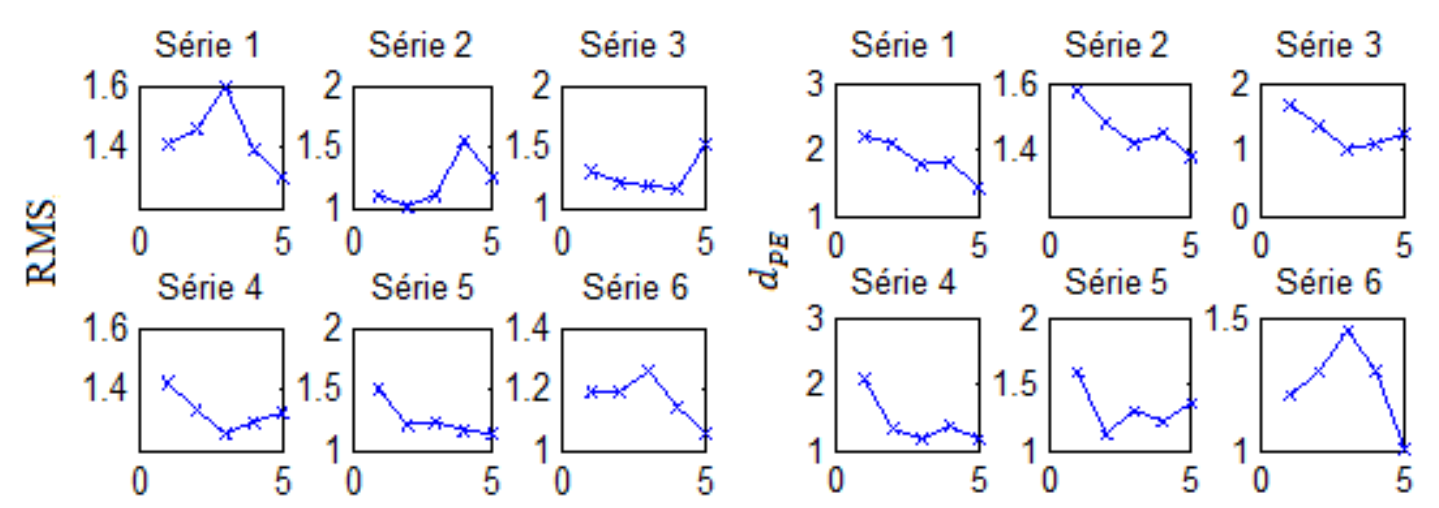

Figura 6.39: Sequências descritoras de fadiga por série de contração. Sujeito 1. Indicadores no domínio do tempo. 

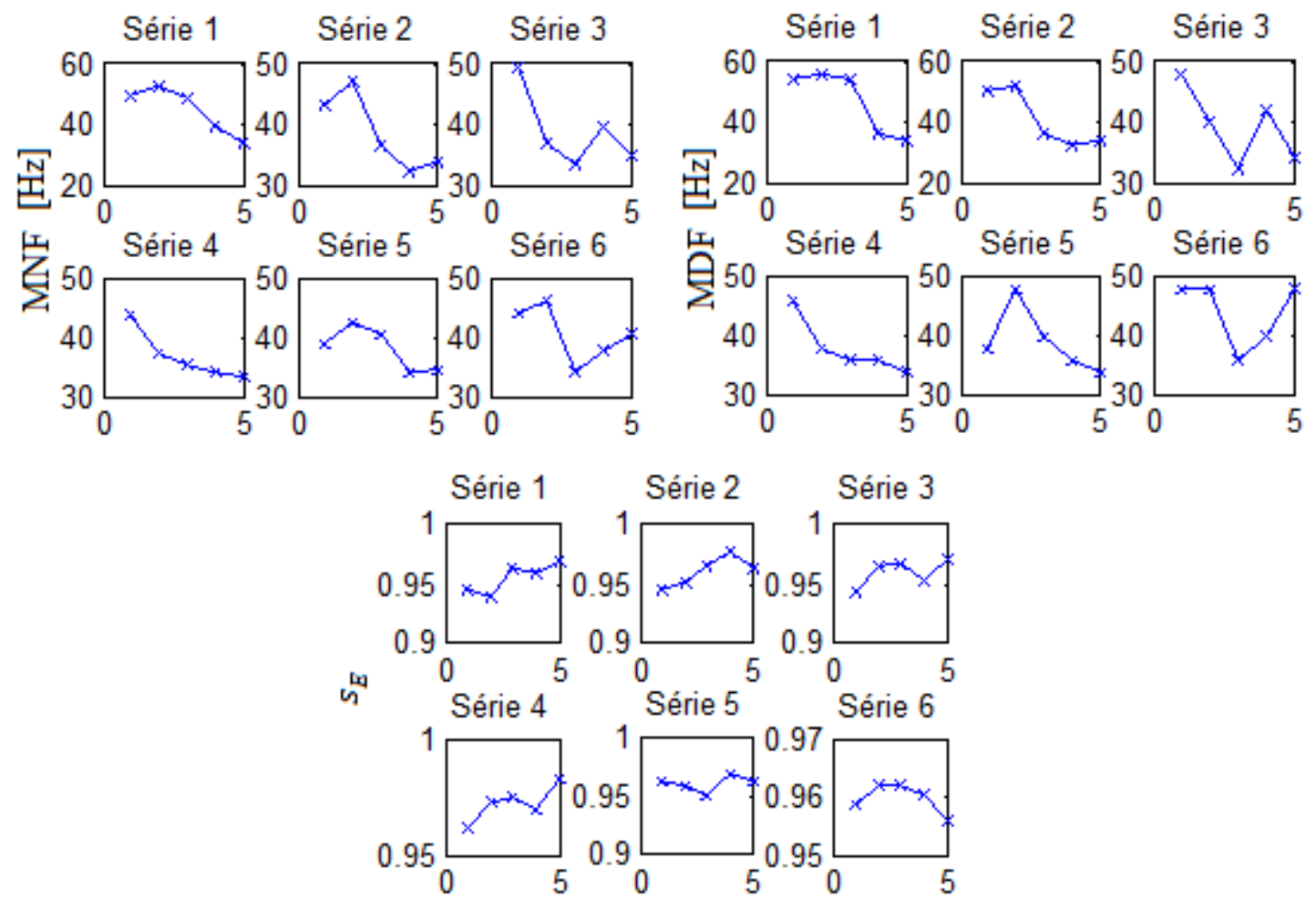

Figura 6.40: Sequências descritoras de fadiga por série de contração. Sujeito 1. Indicadores no domínio da frequência.
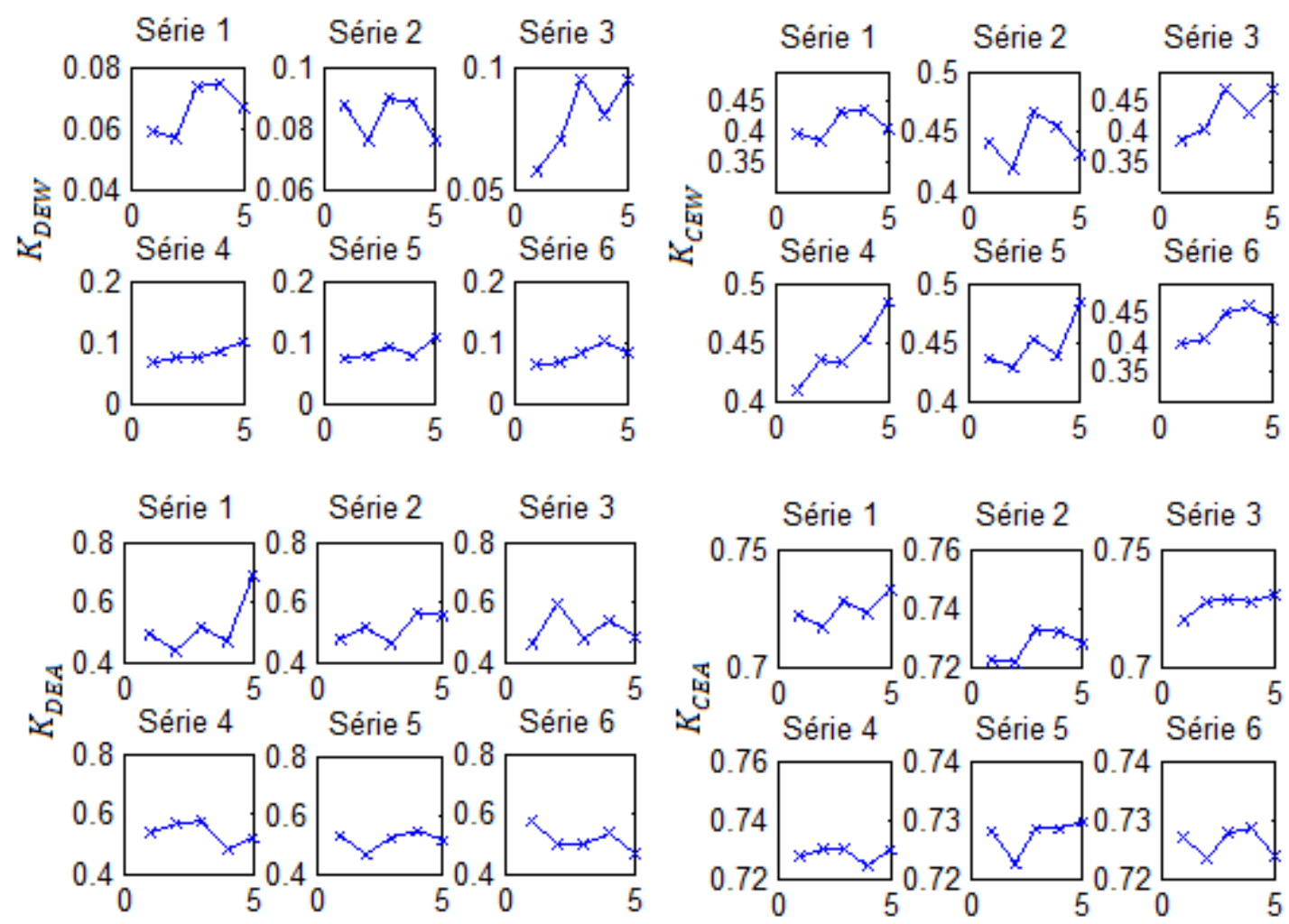

Figura 6.41: Sequências descritoras de fadiga por série de contração. Sujeito 1. Indicadores no domínio da DWT. 
$\mathrm{Na}$ FE somente os conjuntos de índices obtidos para RMS, $d_{P E}$ e MNF não se apresentaram normalmente distribuídos. Nesta fase nenhum dos índices apresentou padrão esperado, à exceção da MNF (Kruskal-Wallis; $p<0,05$ ). Para o restante dos indicadores, não se observou padrão crescente nem decrescente com a indução da fadiga.

$\mathrm{Na} F A$ os conjuntos de índices obtidos para RMS, $d_{P E}$, MNF e MDF não se mostraram normalmente distribuídos. Uma constatação interessante foi que, dentre todos os indicadores, somente os temporais - RMS e $d_{P E}$ - apresentaram o padrão esperado com a fadiga muscular na FA, refletindo a diminuição da amplitude do sinal de EMG. $O$ indicador $S_{E}$ mostrou padrão oposto ao esperado, apresentando decréscimo significativo na FA (teste $\mathrm{t}$ unicaudal à esquerda; $p<0,05$ ). Esta constatação para os indicadores temporais pode encontrar respaldo nos resultados de Grabiner e Owings (2003), que verificaram que, quando um indivíduo realiza uma contração voluntária máxima concêntrica ou excêntrica - e uma resistência mecânica lhe é imposta, então o trecho do sinal de EMG-S correspondente à fase isométrica imediatamente antes do início desta contração reflete a intensidade com que o indivíduo intencionava realizá-la. Como a FA ocorre imediatamente antes da FC - e, ao avaliar os indicadores RMS e $d_{P E}$ nesta última fase, observou-se para estes parâmetros um padrão significativamente decrescente -, sugere-se que estes resultados aqui observados estejam, em parte, relacionados àqueles de Grabiner e Owings (2003) e ao atraso eletromecânico que se observa em contrações dinâmicas. De fato, como mostra a figura 6.42, a região do ciclo mais semelhante ao caso isométrico é aquela em torno da qual a posição do músculo varia menos rapidamente, isto é, quando a velocidade angular cruza o zero - trecho cuja posição angular apresenta concavidade para cima - no qual, portanto, a aceleração é máxima. Assim, a região que mais aproxima o caso isométrico situa-se em torno da posição angular mínima - desde que considerada uma vizinhança deste instante com duração suficientemente pequena -, região contida na FA. Esta é uma das possíveis explicações para o padrão significativamente decrescente das variáveis RMS e $d_{P E}$ que se observa na FA. Note-se ainda que esta fase é a que precede o pico de torque observado no ciclo, que reflete a intensidade com que o voluntário intenciona realizar a contração. 


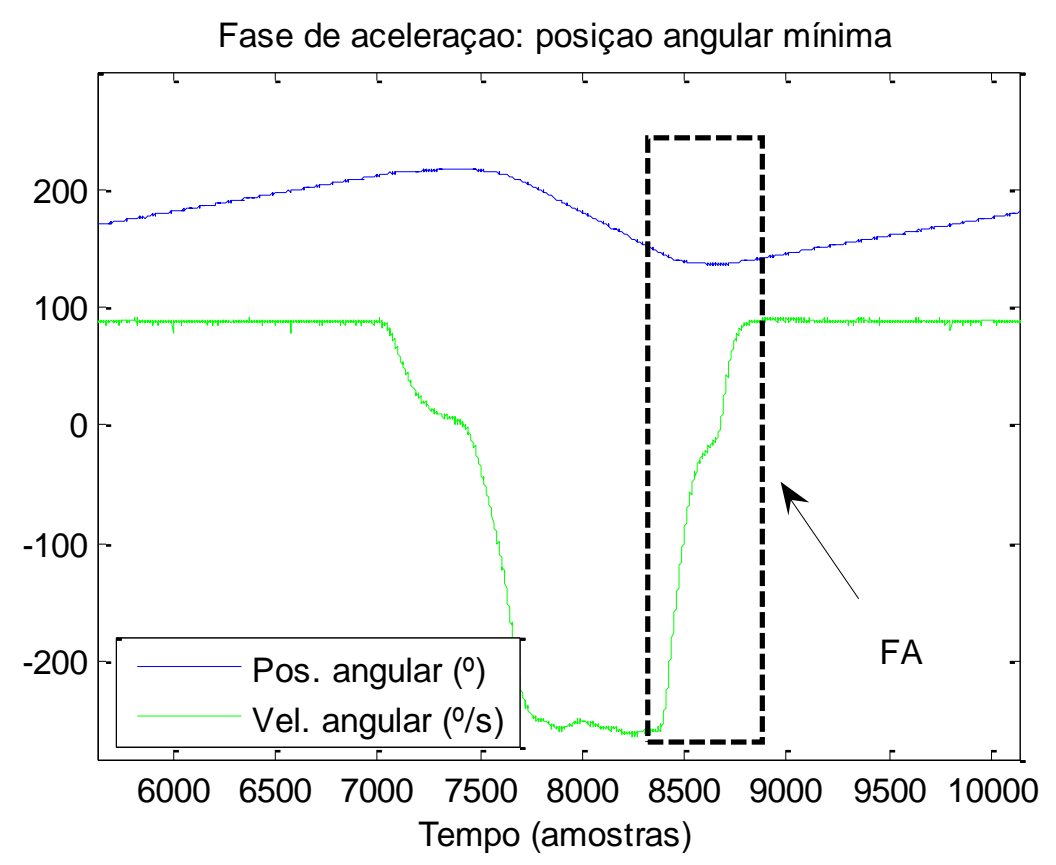

Figura 6.42: Fase do exercício em torno da posição angular mínima: região contida na FA.

Especialmente para os descritores espectrais, sugere-se que a FA não seja adequada para avaliar a fadiga muscular. Entre os possíveis fatores que contribuem para a inadequação à avaliação de fadiga observada na FA a partir de parâmetros espectrais, estão, além da variação abrupta na posição dos eletrodos, a rápida variação do esforço muscular (Bilodeau et al., 1990) e a correspondente variação no comprimento das fibras musculares (Inbar et al., 1987), fatores que afetam significativamente o espectro de frequências do eletromiograma (Bilodeau et al., 1990; Inbar et al., 1987). A restrição a curtas regiões cicloestacionárias contidas na FC mostrou-se mais interessante à avaliação da fadiga, pois, nestas regiões do exercício, as fibras musculares apresentam comprimento praticamente idêntico, preservando as características biomecânicas entre ciclos distintos de contração (Bonato et al., 2001).

Os valores de ENM obtidos não apresentaram tendência significativamente crescente nem decrescente (teste $\mathrm{t} ; p>0,05$ ). Para reforçar esta verificação, foram testadas janelas de 150, 200, 250 e 300 ms das porções dos ciclos de contração contidas na FC. Possivelmente, a dinamometria isocinética não seja a técnica experimental mais adequada para avaliar objetivamente a ENM em função das características intrínsecas que definem este exercício, no qual o dinamômetro mantém o membro involuntariamente à velocidade constante na fase concêntrica, em que ocorre o pico de torque. Estas verificações estão de acordo com os resultados de Komi e Tesch (1979) e Gerdle e Fugl- 
Meyer (1992), que concluíram que a fase de fadiga em exercício isocinético ocorre, em média, durante as 40-60 primeiras contrações - fase do exercício no qual as manifestações da fadiga muscular se apresentam acentuadamente -, sendo o voluntário conduzido, então, à fase de recuperação, na qual as manifestações biomecânicas da fadiga gradativamente cessam (note-se que, no protocolo experimental adotado neste trabalho, o sujeito deve realizar, ao todo, 60 contrações isocinéticas). Conforme verificado por Miler-Brown et al. (1986), a NME, em esforços isométricos, recupera gradativamente seu valor inicial na fase de recuperação. Sugere-se, portanto, que o protocolo experimental mais adequado para avaliar objetivamente a ENM deva envolver contrações isométricas ou isotônicas prolongadas, em que a intensidade da contração é mantida de forma voluntária. Assim, obtêm-se as informações de controle para possível análise comparativa ao abordar protocolos envolvendo contrações auxotônicas, em que se permite a variação da carga.

Ao avaliar os possíveis efeitos acumulados da fadiga muscular ao longo das séries de contrações, os índices de fadiga baseados no valor RMS apresentaram padrão crescente ao longo das séries e os índices baseados nos parâmetros MNF, $s_{E}$ e $K_{D E W}$ apresentaram padrão decrescente (teste t para RMS e $s_{E}$ e teste de Kruskal-Wallis para MNF e $K_{D E W}$; $p<0,05)$. Os demais não apresentaram padrão crescente nem decrescente. Note-se que, como padrão esperado em função da fadiga induzida em exercício isocinético, esperam-se índices negativos para RMS e MNF, de forma que uma eventual intensificação da fadiga parcial em cada série do exercício implique, sucessivamente, na observação de índices negativos de maior valor absoluto para estes parâmetros ao longo das séries. Assim, para os parâmetros RMS, $s_{E}$ e $K_{D E W}$, os resultados sugerem que a fadiga muscular - segundo a definição utilizada neste trabalho - experimentada nas primeiras séries de contração seja mais acentuada, ao contrário do que sugere a MNF, que, para indicar este mesmo fato, deveria apresentar comportamento crescente. Uma das causas destes resultados contraditórios para diferentes índices pode consistir nas diferenças de duração da fase de fadiga de cada voluntário que participou do experimento, além da forma distinta como cada indicador possivelmente deve responder ao início da fase de recuperação.

Esta mesma conclusão é obtida ao agrupar os dados de todos os sujeitos por séries de contrações, em vez de se considerar a regressão linear dos conjuntos de índices de cada sujeito. Ao avaliar os dados por séries, pode-se verificar que o teste não paramétrico de Kruskal-Wallis não aponta diferenças significativas entre os conjuntos de índices obtidos $(p>0,05)$ (Milhomem et al., 2014b). Sugere-se, para futuros estudos neste sentido, que 
previamente sejam identificadas as fases de fadiga e de recuperação de cada sujeito, restringindo-se esta análise à fase de fadiga.

\subsection{2 - Considerações finais}

Nesta seção fez-se um estudo envolvendo extensões isocinéticas de joelho. Propôsse realizar a avaliação da fadiga muscular localizada no VL nas fases concêntrica, excêntrica e de aceleração. Todos os indicadores eletromiográficos se comportaram de acordo com o esperado na FC. Na FE nenhum dos indicadores apresentou o padrão esperado com a fadiga e, na FA, somente os indicadores temporais apresentaram o comportamento esperado. Isto pode estar relacionado ao fato de ser o protocolo isocinético e ao atraso da ativação muscular, em que a amplitude do sinal de EMG-S logo antes da contração reflete a intensidade com que o voluntário pretende realizá-la. Sugere-se, portanto, que este fenômeno não seja adequadamente observado a partir de parâmetros espectrais do sinal eletromiográfico, que são significativamente influenciados pela rápida variação do esforço muscular e a correspondente variação no comprimento das fibras musculares. Assim, sugere-se que a avaliação de fadiga em dinamometria isocinética seja feita na FC.

Neste estudo não se observou nenhum padrão específico para a ENM - que, em contrações isotônicas prolongadas, deve apresentar comportamento decrescente. Sugere-se que outros protocolos sejam mais adequados à aferição deste parâmetro. Note-se que, em dinamometria isocinética, não há o caráter isotônico devido à resistência variável imposta pelo equipamento, de forma a manter a contração a velocidade constante.

Para a avaliação da intensidade relativa da fadiga experimentada pelo voluntário ao longo de cada série de contração, sugere-se a prévia identificação da fase de fadiga de cada sujeito, restringindo-se a análise a esta fase. 


\section{7 - CONCLUSÕES E RECOMENDAÇÕES}

Neste trabalho apresentou-se um estudo de parâmetros objetivos indicadores eletromiográficos de fadiga muscular. Seis novos indicadores foram propostos: um calculado no domínio do tempo, um no domínio da frequência e quatro utilizando wavelets. Estes foram utilizados e discutidos em conjunto com os parâmetros tradicionais RMS, MNF e MDF. Para análise comparativa dos indicadores, utilizaram-se três métricas de dispersão, duas destas definidas neste trabalho. Também foram avaliados três outros parâmetros eletromiográficos como possíveis indicadores de fadiga: a assimetria de seu espectro de amplitude, o atraso da atividade mioelétrica e sua duração. A validação experimental dos parâmetros eletromiográficos foi realizada primeiramente em protocolo isométrico (contração de bíceps) e, então, em protocolo dinâmico (ciclismo à velocidade constante e carga constante). Após validação experimental, os indicadores foram avaliados quando aplicados aos sinais de EMG-S dos vastos lateral e medial em atividade de ciclismo com carga constante e crescente na qual se induz a fadiga. Ainda em ciclismo, os indicadores eletromiográficos do vasto lateral foram avaliados em conjunto com o desempenho biomecânico que, juntamente à instrumentação dedicada, se propôs neste trabalho. Os indicadores eletromiográficos foram, por fim, avaliados em exercício isocinético de extensão de joelho para os sinais de EMG-S do vasto lateral. Finalmente, um conjunto de técnicas de pré-processamento - baseadas em wavelets - foi proposto para o tratamento dos sinais de EMG-S.

Os resultados obtidos mostram que as técnicas de pré-processamento propostas apresentaram desempenho satisfatório, reduzindo significativamente as interferências da rede elétrica no sinal de EMG-S - nas frequências de $60 \mathrm{~Hz}$ e harmônicos -, além do ruído branco, a partir do método proposto para estimativa da potência deste ruído. Trabalhos futuros devem abordar a sistematização dos procedimentos de pré-processamento, apresentando uma visão mais geral e crítica destes aspectos no contexto da eletromiografia.

Todos os indicadores de fadiga propostos apresentaram o padrão esperado com a fadiga muscular. Os indicadores espectrais propostos que estimam a compressão do espectro de amplitude do eletromiograma propostos nesta tese $\left(s_{E}, K_{C E W}\right.$ e $\left.K_{C E A}\right)$ apresentaram-se menos dispersos do que os demais - que estimam o deslocamento do centro de seu espectro -, incluindo-se as tradicionais MNF e MDF. As versões adaptativas dos indicadores utilizando wavelets $K_{D E A}$ e $K_{C E A}$ permitiram obter valores 
significativamente menores de dispersão do que suas versões não adaptativas $K_{D E W}$ e $K_{C E W}$ para avaliação da fadiga. A mesma constatação se faz para o $s_{E}$ ao compará-lo às frequências média e mediana. Entre os demais parâmetros citados na literatura, a assimetria do espectro de amplitude do sinal eletromiográfico não apresentou padrão crescente nem decrescente com a fadiga muscular, nem para o caso isométrico nem para o dinâmico. No caso dinâmico, o atraso da atividade mioelétrica e sua duração apresentaram padrão com a fadiga muscular localizada no músculo vasto lateral, mas não no vasto medial. Sugere-se que tais diferenças estejam relacionadas às distintas proporções de cada tipo de fibra muscular encontradas nestes músculos e, possivelmente, a pequenas diferenças funcionais.

Ao comparar as modalidades CL e IL, em cada situação (dada uma modalidade de exercício e uma abordagem para cálculo dos indicadores), em geral, não houve diferenças significativas entre os índices obtidos para o VL e para o VM.

Portanto, não havendo interesse em observar efeitos de variação da carga ou da abordagem, aparentemente, não há diferenças significativas entre o músculo escolhido VL ou VM - para aferição da fadiga em ciclismo. Ambas as abordagens, dinâmica e isométrica - esta com quaisquer dos janelamentos utilizados - permitiram a aferição objetiva da fadiga muscular localizada no VL e no VM.

Em abordagem isométrica observou-se um padrão crescente para a correlação entre as sequências descritoras de fadiga do VL e do VM em função da duração dos trechos. Neste sentido, recomenda-se que, para diferenciar a atividade mioelétrica destes músculos, seja utilizada abordagem dinâmica ou isométrica com janelas de menor duração.

As curvas de correlação entre VL e VM obtidas, especialmente para os indicadores temporais, mostraram semelhança significativamente maior entre a atividade mioelétrica do VL e do VM ao exigir-lhes torque crescente, indicando uma possível aproximação funcional destes músculos nesta situação.

Os parâmetros definidos no domínio da frequência também apresentaram padrão crescente em função da duração dos segmentos do eletromiograma para cálculo dos indicadores, à exceção do estreitamento do espectro na modalidade CL, que, não sofreu variações significativas em função do janelamento. De forma semelhante aos indicadores no domínio do tempo, estes parâmetros sugerem o aumento na similaridade funcional dos músculos VL e VM ao submetê-los ao aumento gradual da carga resistida em bicicleta ergométrica.

Em todos os casos, os indicadores temporais - dependentes da amplitude - dos 
sinais de EMG-S do VL e do VM apresentaram maior correlação entre a atividade destes músculos se comparados aos indicadores espectrais. Desta maneira, ao intencionar-se distinguir a atividade mioelétrica destes músculos, recomenda-se o uso de parâmetros espectrais em vez de temporais. Verificou-se, além disso, que os indicadores de amplitude se mostraram significativamente mais sensíveis ao aumento da carga. Portanto, se a intenção é diferenciar a atividade muscular observada na modalidade CL da observada na modalidade IL, recomenda-se o uso dos indicadores no domínio do tempo. Por outro lado, se o objetivo é a avaliação objetiva da fadiga muscular, reduzindo-se parcialmente as influências do aumento da carga durante a execução do exercício, recomendam-se os indicadores espectrais.

Os indicadores calculados para o VL e para o VM apresentaram maior semelhança ao empregar abordagem isométrica. Isto se verificou, possivelmente, por desconsideraremse nesta abordagem os trechos de ativação e desativação muscular. Observou-se ainda que, na modalidade IL, a correlação entre os indicadores do VL e do VM sofreu maior influência pela duração do trecho escolhida do que na modalidade CL. Entretanto, os indicadores baseados em wavelets mostraram-se correlacionados de maneira não significativamente distinta em ambas as situações.

Os resultados sugerem que, possivelmente, em ciclismo, o músculo VL seja mais sensível ao aumento da carga, se comparado ao VM, especialmente ao utilizar indicadores temporais. Um passo adiante no entendimento deste tópico consiste em avaliar esta sensibilidade incluindo-se como um dos aspectos específicos do protocolo experimental o controle da postura e posição: neutra, aduzida e abduzida.

Os indicadores espectrais baseados na compressão do espectro de amplitude do sinal de EMG-S apresentaram-se, em geral, mais sensíveis à modalidade - CL ou IL - se comparados àqueles que mensuram a fadiga a partir da posição do centro do espectro do sinal. Assim, para a diferenciação entre modalidades a partir de parâmetros espectrais, recomenda-se a aferição da compressão do espectro (ou diminuição da largura de banda) do eletromiograma - em vez do deslocamento de seu centro. Todavia, almejando-se minimizar os efeitos do aumento da carga ao avaliar objetivamente a fadiga, utilizem-se os parâmetros dependentes do deslocamento do conteúdo espectral do sinal. É oportuno relembrar que, apesar destas recomendações, em geral, todos os indicadores deverão sofrer alguma influência - mesmo que não completamente conhecida - da variação da carga (ver Cap. 2). 
Ainda, em ciclismo, os resultados sugerem que indivíduos treinados não devem apresentar variações significativas em seu desempenho biomecânico com a indução de fadiga ao longo do exercício. Uma hipótese posta é que ciclistas cujas postura e técnica de pedalar promovam valores mais altos de desempenho biomecânico estejam mais aptos a experimentar um processo relativamente mais intenso de fadiga, tendo-se razoável conhecimento das próprias limitações. Estas observações devem ser avaliadas como possibilidades apresentadas, vista a limitação dada pela quantidade de voluntários (quatro) no experimento. Recomenda-se para trabalhos futuros a proposição novos experimentos a partir de metodologias semelhantes de avaliação conjunta entre sinais eletromiográficos e biomecânicos. A instrumentação dedicada apresentada neste trabalho atendeu satisfatoriamente aos objetivos definidos, dando o suporte necessário à aplicação da metodologia para avaliação conjunta de parâmetros objetivos - biomecânicos e eletromiográficos - que se propôs.

No estudo de caso envolvendo dinamometria isocinética, todos os indicadores eletromiográficos comportaram-se de acordo com o esperado na FC. Ao serem avaliados na FE, nenhum dos indicadores apresentou o padrão esperado com a fadiga. Na FA somente os indicadores temporais apresentaram o comportamento esperado. Para avaliação de fadiga em protocolo isocinético sugere-se, portanto, que seja feita na fase concêntrica, na qual o dinamômetro impõe a carga, região em que se observa o pico de torque.

Nenhum padrão específico com a fadiga muscular localizada foi observado para a ENM em dinamometria isocinética. Sugere-se que outros protocolos sejam mais adequados à aferição deste parâmetro, por exemplo, em contrações isométricas ou isotônicas prolongadas, em que a intensidade da contração é mantida de forma voluntária. Para a avaliação de fadiga parcial em protocolos envolvendo séries múltiplas, trabalhos futuros devem levar em consideração a duração da fase de fadiga de cada indivíduo.

São diversas as possibilidades de trabalhos futuros que podem ser propostas a partir das discussões desta tese. Em futuras pesquisas envolvendo a fadiga muscular em ciclismo, a postura e a posição - abduzida, neutra e aduzida - ao pedalar também podem ser estudadas quanto às suas influências sobre o desempenho biomecânico e fisiológico, a partir de metodologias semelhantes envolvendo instrumentação integrada para aquisição de sinais biomecânicos e eletromiográficos. O parâmetro de desempenho biomecânico pode, ainda, ser avaliado com o uso de coroas modificadas ou personalizadas - em geral, com formato não circular - e em função do protocolo experimental - ao variar a carga resistida, 
por exemplo. Uma avaliação mais cuidadosa - do que aquelas já encontradas na literatura - relativa ao janelamento do eletromiograma para o cálculo de parâmetros no domínio da frequência também deve ser futuramente considerada; são diversas as opções a serem utilizadas para as estimativas espectrais. Como demais recomendações gerais para trabalhos futuros, a avaliação da fadiga muscular a partir do eletromiograma pode ser feita utilizando-se outras abordagens e metodologias não utilizadas aqui. A avaliação objetiva da fadiga muscular a partir do sinal de EMG-S - em situações relativamente simples e corriqueiras - pode ainda apresentar muitos pontos controvérsia, e não se pretende, com este trabalho, suprimi-los todos. Finalmente, maior atenção deve ser dada à assinatura de cada indivíduo durante a fadiga muscular, explorando-se com maior rigor aspectos relativos à reprodutibilidade e à variância temporal dos parâmetros e procedimentos para aferição da fadiga localizada. 


\section{REFERÊNCIAS BIBLIOGRÁFICAS}

Adrian ED, Bronk DW (1929). "The discharge of impulses in motor nerve fibers II: The frequency of discharge in reflex and voluntary contractions," J Physiol, vol. 67, pp. $119-151$.

Al-Mulla MR, Sepulveda F, Colley M. (2011a) "An autonomous wearable system for predicting and detecting localised muscle fatigue." Sensors (Basel), 11(2):1542-57.

Al-Mulla MR, Sepulveda F, Colley M. (2011b) “A review of non-invasive techniques to detect and predict localised muscle fatigue." Sensors (Basel), 11(4):3545-94.

Allen PJ, Josephs O, Turner R. (2000). "A Method for Removing Imaging Artifact from Continuous EEG Recorded during Functional MRI.” NeuroImage v. 12, pp. 230-239.

Ament W, Bonga GJJ, Hof AL, Verkerke GJ. (1996) "Electromyogram median power frequency in dynamic exercise at medium exercise intensities." Eur $\mathrm{J}$ Appl Physiol 1996;74:180-6.

Andrade MM, DoCarmo JC, Nascimento FAO, Camapum JF, dos Santos I, Mochizuki L, da Rocha AF (2006). "Evaluation of Techniques for the Study of Electromyographic Signals" IEEE - The 28th Annual International Conference of the IEEE Engineering in Medicine and Biology Society, 2006, New York, p. 1-4.

Andrade MM (2006). "Análise tempo-freqüência de sinais eletromiográficos para a avaliação de fadiga muscular em cicloergômetro." Tese de Doutorado, Publicação 013/06, Departamento de Engenharia Elétrica, Universidade de Brasília, Brasília.

Andrade AO, Kyberd P, Nasuto SJ, (2008). "The application of the Hilbert spectrum to the analysis of electromyographic signals", Information Sciences 178, p. 2176-2193.

Antoniadis A, Oppenheim G (1995). "Wavelets and Statistics". Em: Springer New York.

Arendt-Nielsen L, Mills KR, (1985). "The relationship between mean power frequency of the EMG spectrum and muscle fibre conduction velocity," Electroencephalogr Clin Neurophysiol, vol. 60, pp. 130-134.

Arendt-Nielsen L, Mills KR, (1988). "Muscle fiber conduction velocity, mean power frequency, mean EMG voltage and force during submaximal fatiguing contractions of human quadriceps," Eur J Appl Physiol, vol. 58, pp. 20-25.

Arnall FA, Koumantakis GA, Oldham JA, Cooper RG (2002). "Between-days reliability of electromyographic measures of paraspinal muscle fatigue at 40,50 and $60 \%$ levels of maximal voluntary contractile force." Clin Rehabil. 2002 Nov;16(7):761-71.

Arabadzhiev TI, Dimitrov VG, Dimitrova NA, Dimitrov GV (2010). "Interpretation of EMG integral or RMS and estimates of "neuromuscular efficiency" can be misleading 
in fatiguing contraction." Journal of Electromyography and Kinesiology 20 (2010) $223-232$.

Balestra G, Knaflitz M, Merletti R (1988). "Comparison between myoelectric signal mean and median ferquency estimates." Proc. of the 10th Int. Conf. of the IEEE Eng. in Med. and Biol. Soc., New Orleans, 1988.

Basmajian JV (1978). "Muscles alive: their functions revealed by electromyography." 3. ed. Baltimore: Williams and Wilkins, 1978.

Basmajian J, DeLuca CJ. (1985). "Muscles Alive”, Baltimore, MD: Williams \& Wilkins.

Bear MF, Connors BW, Paradiso MA, (2008). "Neurociências: Desvendando o sistema nervoso." Williams \& Wilkins, 3 ed, Artmed.

Berger PA, Nascimento FAO, Carmo JC, Rocha AF (2006). "Compression of EMG signals with wavelet transform and artificial neural networks." Physiological Measurement, v. 27, pp. 457-465.

Bigland-Ritchie B, Woods JJ (1974). "Integrated EMG and oxygen uptake during dynamic contractions of human muscles.” J Appl Physiol 1974;36:475-9.

Bilodeau M, Arsenault AB, Gravel D, Bourbonnais D (1990). "The influence of an increase in the level of force on the EMG power spectrum of elbow extensors." European Journal of Applied Physiology. 1990;61(5-6):461-6.

Bilodeau M, Cincera M, Arsenault AB, Gravel D (1997). "Normality and stationarity of EMG signals of elbow flexor muscles during ramp and step isometric contractions." J Electromyogr Kinesiol 1997;7:87-96.

Biodex MS (1998). "Biodex System 3 Pro Manual (\#835-000) Applications/Operations", Biodex Medical Systems Inc, Shirley, NY.

Bonato P, Gagliati G, Knaflitz M, (1996). "Analysis of myoelectric signals recorded during dynamic contractions," Engineering in Medicine and Bio. Magazine, IEEE, v. 15, n. 6, p. $102-11$.

Bonato P, D'Alessia T, Knatlita M. (1998). "A statistical method for the measurement of muscle activation intervals from surface myoelectric signal during gait", IEEE Trans. Biomed. Eng., MI. vol. 45, pp. 287-299.

Bonato P, Roy SH, Knaflitz M, deLuca CJ, (2001). "Time-frequency parameters of de surface myoelectric signal for assessing muscle fatigue during cyclic dynamic contractions." IEEE Transactions on Biomedical Engineering, vol. 48, $\mathrm{n}^{\circ}$ 7, pp. 745753.

Bontempo HA, Macêdo WB, Carmo JC, Nascimento FAO. (1997) "Projeto de pedal para aquisição de forças em ciclistas." Anais do VII Congresso Brasileiro de Biomecânica. Campinas, SP, 1997. 
Bottaro M, Ernesto C, Celes R, Farinatti PTV, Brown LE, Oliveira RJ. (2010) "Effects of Age and Rest Interval on Strength Recovery." International Journal of Sports Medicine 2010; 31(1):22-25.

Bottas R, Linnamo V, Nicol C, Komi PV (2005). "Repeated maximal eccentric actions causes long-lasting disturbances in movement control." Eur J Appl Physiol. 2005 May;94(1-2):62-9.

Boyas S, Remaud A, Rivers E, Bilodeau M (2013). "Fatiguing exercise intensity influences the relationship between parameters reflecting neuromuscular function and postural control variables." PLoS One. 2013 Aug 26;8(8).

Broker JP, Gregor RJ (1996). "Cycling biomechnics in High-tech Cycling.” Burke, E. R. (Ed). Champaign, Illinois: Human Kinetics.

Brown WF (1984). "The Physiological and Technical Basis of Electromyography", Butterworth Publishers.

Brown DA, Kautz SA, Dairaghi CA (1996). "Muscle activity patterns altered during pedaling at different body orientations." J Biomechanics, vol. 29, n. 10, pp. 13491356.

Bouissou P, Estrade PY, Goubel F, Guezennec CY, Serrurier B (1989). "Surface EMG power spectrum and intramuscular $\mathrm{pH}$ in human vastus lateralis muscle during dynamic exercise.” J Appl Physiol 1989;67:1245-9.

Burden A, Bartlett R (1999). "Normalisation of EMG amplitude: an evaluation and comparison of old and new methods." Med Eng Phys 1999;21:247-57.

Burke RE (1981). "Motor units: Anatomy, physiology and Functional organization," in V. B. Brooks, ed., Handbook of physiology: The nervous system, American Physiological Society, Bethesda, pp. 345-422.

Burrus CS, Gopinath RA, Guo H (1998). "Introduction to Wavelets and Wavelet Transforms: A Primer.”, Prentice Hall.

Cao H, Dib IEH, Antoni J, Marque C, (2007). "Analysis of Muscular Fatigue during Cyclic Dynamic Movement", Proceedings of the 29th Annual International Conference of the IEEE EMBS, Cité Internationale, Lyon, France, August 23-26, 2007.

Carmo JC, Nascimento FAO, Rocha AP (1998). "Sistema de pedais para transdução de sinais de forças em bicicletas." Anais do IV Fórum Nacional de Ciências e Tecnologia em Saúde. Curitiba, PR, 1998.

Carmo JC, Nascimento FAO, Costa JC e Rocha, AP (2001). "Instrumentação para aquisição e avaliação das forças exercidas nos pedais por ciclistas." Revista Brasileira de Biomecânica. Ano 2, nº 3. Novembro, 2001. 
Carmo JC (2003). "Desenvolvimento de Instrumentação Dedicada e Proposta de Técnica de Análise de Fadiga em Ciclistas Utilizando Transformada de Wavelets." Tese de Doutorado, Departamento de Engenharia Elétrica, Universidade de Brasília.

Carmo JC, Telles F, Milhomem TR, Rocha Junior VA (2014). "The Influence Of The Feet Position In Rehabilitation Observing Force And Torque Curves During Cycling." In: 61th Annual Meeting and 3rd World Congress on Exercise is Medicine of the American College of Sports Medicine, 2014, Orlando - Flórida. ACSM's Annual Meeting, 2014.

Cechetto AD, Parker PA, Scott RN (2001). "The effects of four time-varying factors on the mean frequency of a myoelectric signal." Journal of Electromyography and Kinesiology, vol. 11, pp. 347-354.

Ceriani L, Verme P (2011). "The origins of the Gini index: extracts from Variabilità e Mutabilità (1912) by Corrado Gini.” The Journal of Economic Inequality. Vol. 10, no 3, pp. 421-443.

Chaffin DB (1973). "Localized muscle fatigue: Definition and measurement," J. Occup. Med., vol. 15, pp. 346-354.

Chapman AR, Vicenzino B, Blanch P, Knox JJ, Hodges PW (2006). "Leg muscle recruitment in highly trained cyclists." J Sport Sci 2006;24:115-24.

Chapman AR, Vicenzino B, Blanch P, Hodges PW (2007). "Patterns of leg muscle recruitment vary between novice and highly trained cyclists." J Electromyogr Kinesiol. 2008 Jun;18(3):359-71.

Choi HI, Williams WJ (1989) "Improved time-frequency signal representations of multicomponent signals using exponential kernel", IEE Trans Acoust Speech, Signal Processing, vol. 37, pp. 862-871.

Christensen H, Søgaard K, Jensen BR, Finsen L, Sjøgaard G (1995). "Intramuscular and surface EMG power spectrum from dynamic and static contractions," J. Electromyograph. Kines., v. 5 n.1, pp. 27-36.

Cifrek M, Medved V, Tonković S, Ostojić S (2009). "Surface EMG based muscle fatigue evaluation in biomechanics." Clin Biomech (Bristol, Avon). 2009 May;24(4):327-40.

Clancy EA, Hogan N (1994). "Single site electromyograph amplitude estimation." IEEE Trans Biomed Eng 1994;41:159-67.

Clancy EA, Hogan N (1999). "Probability density of the surface electromyogram and its relation to amplitude detectors." IEEE Trans Biomed Eng 1999;46(6):730-9.

Clancy EA, Morin EL, Merletti R (2002). "Sampling, noise-reduction and amplitude estimation issues in surface electromyography." Journal of Electromyography and Kinesiology 2002;12:1-16. 
Clancy EA, Farina D, Filligoi G, (2004). "Single-channel techniques for information extraction from the surface EMG signal," Em: Electromyography: Physiology, Engineering, and Noninvasive Applications, R. Merletti and P. A. Parker, Eds. Hobooken, New Jersey: JohnWiley \& Sons, 2004, ch. 6, pp. 133-168.

Clancy EA, Farina D, Merletti R (2005). "Cross-comparison of time- and frequencydomain methods for monitoring the myoelectric signal during a cyclic, force-varying, fatiguing hand-grip task." Journal of Electromyography and Kinesiology 15 (2005) $256-265$.

Clark BC, Collier SR, Manini TM, Ploutz-Snyder LL (2005). "Sex differences in muscle fatigability and activation patterns of the human quadriceps femoris." Eur J Appl Physiol. 2005 May;94(1-2):196-206.

Coifman RR, Donoho DL (1995). “Translation-Invariant De-Noising”. Em: "Wavelets and Statistics”. Antoniadis A, Oppenheim G, Eds. Springer New York; 1995; pp. 125-150.

Coorevits P, Danneels L, Cambier D, Ramon H, Druyts H, Karlsson JS, De Moor G, Vanderstraeten G, (2008). "Correlations between short-time Fourier- and continuous wavelet transforms in the analysis of localized back and hip muscle fatigue during isometric contractions", Journal of Electromyography and Kinesiology 18, p. 637-644.

Costa Filho WL, Milhomem TR, Telles F, Braga M, Carmo JC, Schwartz FP, Nascimento FAO (2012). "Algoritmo Automático de Detecção da Ativação Muscular em S-EMG." In: XXIII Congresso Brasileiro de Engenharia Biomédica - CBEB 2012, 2012, Ipojuca. Anais do CBEB - 2012, vol. 1. pp. 2061-2065.

Cram JR (2004). "Biofeedback applications" Em: Electromyography: Physiology, Engineering, and Noninvasive Applications, R. Merletti and P. A. Parker, Eds. Hobooken, New Jersey: JohnWiley \& Sons, 2004, ch. 17, pp. 435-452.

Daubechies I (1988). “Orthonormal bases of compactly supported wavelets”, Comm. Pure \& Appl. Math., 41 (7), pp. 909-996.

Daubechies I (1989). "Orthonormal bases of wavelets with finite support - connection with discrete filters", Proceedings of the 1987 International Workshop on Wavelets and Applications, Marseille, France, eds. J.M. Combes, A. Grossmann, and Ph. Tchamitchian, Springer, Berlin, 1989.

Daubechies I (1990). "The wavelet transform, time-frequency localization and signal analysis" IEEE Trans. Inf. Theory, 36 (5), pp. 961-1005.

Davies MR, Reisman SS (1994). "Time frequency analysis of the electromyogram during fatigue." Proceedings of the 1994 20th Annual Northeast Bioengineering Conference, IEEE, pp. 93-95.

David P, Mora I, Pérot C (2008). "Neuromuscular efficiency of the rectus abdominis differs with gender and sport practice." J Strength Cond Res 22(6): 1855-1861. 
DeLuca CJ (1979). "Physiology and Mathematics of Myoelectric signal," IEEE Trans. Biom. Eng., v. 26, n 6, pp. 313-25.

DeLuca CJ (1984). "Myoelectrical Manifestations of Localized Muscular Fatigue in Humans", Crit. Rev. Biomed. Eng. (1984), v. 11, n. 4, pp. 251-79.

DeLuca CJ (1997). "The use of surface electromyography in biomechanics", Journal of Applied Biomechanics, 13 (2): 135-163.

DeLuca CJ, Gilmore LD, Kuznetsov M, Serge H, Roy SH, (2010). "Filtering the surface EMG signal: Movement artifact and baseline noise contamination." Journal of Biomechanics $n^{\circ}$ 43, pp. 1573-1579.

Dimitrov GV, Dimitrova NA (1974): "Extracellular potential field of a single striated muscle fibre immersed in anisotropic volume conductor", Electromyogr Clin Neurophysiol, vol. 14, pp. 423-436.

Dimitrova NA (1974). "Model of the extracellular potential field of a single striated muscle fiber” Electromyogr Clin Neurophysiol, vol. 14, pp. 53-66 (1974).

Dimitrova NA, Dimitrov GV (2003). "Interpretation of EMG changes with fatigue: facts, pitfalls, and fallacies.” J Electromyogr Kinesiol. 2003 Feb;13(1):13-36.

Dimitrova NA, Arabadzhiev TI, Hogrel JY, Dimitrov GV, (2009) "Fatigue analysis of interference EMG signals obtained from biceps brachii during isometric voluntary contraction at various force levels", Journal of Electromyography and Kinesiology 19, pp. 252-258.

Donoho DL. (1995) "De-noising by soft-thresholding". IEEE Trans Info Theory, May, v. 41, issue 3, pp. 613-627.

Dorel S, Couturier A, Hug F (2008). "Intra-session repeatability of lower limb muscles activation pattern during pedaling." J Electromyogr Kinesiol. 2008 Oct;18(5):857-65.

Duc S, Bertucci W, Pernin JN, Grappe F (2008). "Muscular activity during uphill cycling: effect of slope, posture, hand grip position and constrained bicycle lateral sways." J Electromyogr Kinesiol. 2008 Feb;18(1):116-27.

Duchene J, Goubel F (1990). "EMG spectral shift as an indicator of fatigability in an heterogeneous muscle group.” Eur J Appl Physiol 1990;61:81-7.

Duchene J, Goubel F (1993). "Surface electromyogram during voluntary contraction: processing tools and relation to physiological events." Crit Rev Biomed Eng 1993;21:313-97.

Dumitru D. (2000) "Physiologic basis of potentials recorded in electromyography." Muscle \& Nerve 23: 1667-1685. 
Edwards RHT (1981). "Human Muscle Function and Fatigue," in R. Porter, and J. Whelan, eds., Human muscle fatigue: Physiological mechanisms, Pitman Medical, London.

Ericson M. "On the biomechanics of cycling. A study of joint and muscle load during exercise on the bicycle ergometer." Scand J Rehabil Med Suppl 1986;16:1-43.

Faria IE, Cavanagh PR (1978). "The Physiology and Biomechanics of Cycling." John Wiley, New York.

Farina D, Merletti R. (2001). "A novel approach for precise simulation of the EMG signal detected by surface electrodes.", IEEE Transactions on Biomedical Engineering, Vol. 48, $\mathrm{N}^{\mathrm{o}}$ 6, pp. 637-646.

Farina D, Fosci M, Merletti R. (2002) "Motor unit recruitment strategies investigated by surface EMG variables.” J Appl Physiol 92:235-247.

Farina D, Merletti R. (2004) "Methods for estimating muscle fibre conduction velocity from surface electromyographic signals." Med Biol Eng Comput, 2004, vol. 42, pp. 432-445.

Farina D, Merletti R, Stegeman DF. (2004) "Biophysics of the generation of EMG signals". Em: Electromyography: Physiology, Engineering, and Noninvasive Applications, R. Merletti and P. A. Parker, Eds. Hobooken, New Jersey: JohnWiley \& Sons, 2004, ch. 4, pp. 81-105.

Farina D, Pozzo M, Merlo E, Bottin A, Merletti R, (2004) "Assessment of Average Muscle Fiber Conduction Velocity From Surface EMG Signals During Fatiguing Dynamic Contractions", IEEE Transactions on Biomedical Engineering, v. 51, n. 8, p. 13831393.

Felici F. (2004) "Applications in exercise physiology" Em: Electromyography: Physiology, Engineering, and Noninvasive Applications, R. Merletti and P. A. Parker, Eds. Hobooken, New Jersey: JohnWiley \& Sons, 2004, ch. 14, pp. 365-380.

Fleck SJ, Kraemer WJ. (2004) "Designing Resistance Training Programs", $3^{\text {a }}$ edição, 392 pp, Ed. Human Kinetics.

Frigo C, Shiavi R. (2004) "Applications in movement and gait analysis" Em: Electromyography: Physiology, Engineering, and Noninvasive Applications, R. Merletti and P. A. Parker, Eds. Hobooken, New Jersey: JohnWiley \& Sons, 2004, ch. 15, pp. 381-402.

Fugl-Meyer AR, Gerdle B, Eriksson B-E, Jonsson B. (1985) "Isokinetic plantar flexion endurance.” Scand J Rehabil Med 1985;17:47-52.

Gamet D, Duchene J, Garaponbar C, and Goubel F. (1993) "Surface Electromyogram power spectrum in human quadriceps muscle during incremental exercise," J. Appl. Physiol., v. 74, n. 6, pp. 2704-10. 
Georgakis A, Stergioulas LK, Glakas G. (2003) "Fatigue Analysis of the Surface EMG Signal in Isometric Constant Force Contractions Using the Averaged Instantaneous Frequency," IEEE Trans. Biomed. Eng., v. 50, n. 2, pp. 262-5.

Gerdle B, Langström M. (1987) "Repeated isokinetic plantar flexions at different angular velocities.” Acta Physiol Scand 1987;130:495-500.

Gerdle B, Hedberg R, Jonsson B, Fugl-Meyer A. (1987) "Mean power frequency and integrated electromyogram of repeated isokinetic plantar flexions." Acta Physiol Scand 1987;130:501-6.

Gerdle B, Elert J, Henriksson-Larsén K. (1989) "Muscular fatigue during repeated isokinetic shoulder forward flexions in young females." Eur $J$ Appl Physiol 1989;58:666-73.

Gerdle B, Fugl-Meyer A. (1992) "Is the mean power frequency shift of the EMG a selective indicator of fatigue of the fast twitch motor units?" Acta Physiol Scand 1992;145:129-38.

Gerdle B, Larsson B, Karlsson S (2000). "Criterion validation of surface EMG variables as fatigue indicators using peak torque: A study of repetitive maximum isokinetic knee extensions.” Journal of Electromyography and Kinesiology, vol. 10, pp. 225-232.

Gini C. (1921) "Measurement of Inequality of Incomes." The Economic Journal. vol. 31, no. 121 , pp. 124-126.

Giroux B, Lamontagne M. (1990) "Comparisons between surface electrodes and intramuscular wire electrodes in isometric and dynamic conditions", Electromyogr. Clin. Neurophysiol., vol. 30, pp. 397-405.

Grabiner MD, Owings TM (2003). "Intent-Related Differences in Surface EMG of Maximum Eccentric and Concentric Contractions", Journal of Applied Biomechanics, v. 19, pp. 99-105.

Graps A (1995). “An Introduction to Wavelets." IEEE Computational Science and Engineering, Summer 1995, vol. 2, num. 2, published by the IEEE Computer Society.

Gregor RJ, Green D e Garhammer JJ (1982). "An electromyographic analysis of selected muscle ativity in elite competitive cyclists." Biomechanics VII, pp. 537-541. University ParkPress, Maltimore.

Gydikov A, Gerilovsky L, Dimitrov GV (1976a). "Volume conducted motor unit potentials in human triceps surae", Electromyogr Clin Neurophysiol, vol. 16, pp. 569-586.

Gydikov A, Dimitrov GV, Kosarov D, Dimitrova N (1976b). "Functional differentiation of motor units in human opponens pollicis muscle", Ex Neurol, vol. 50, pp. 36-47. 
Gydikov A, Kosarov D, Dimitrov GV (1979). "Length of the summated depolarized area and duration of the depolarizing and repolarizing processes in the motor unit under different conditions", Electromyogr Clin Neurophysiol, vol. 19, pp. 229-248.

Hägg GM, Melin B, Kadefors R. (2004) "Applications in ergonomics" Em: Electromyography: Physiology, Engineering, and Noninvasive Applications, R. Merletti and P. A. Parker, Eds. Hobooken, New Jersey: JohnWiley \& Sons, 2004, ch. 13, pp. 343-364.

Hanson J (1974). "The effects of repetitive stimulation on the action potential and the twitch of rat muscle." Acta Physiol Scand 90:387-400.

Hassani A, Patikas D, Bassa E, Hatzikotoulas K, Kellis E, Kotzamanidis C. (2006) "Agonist and antagonist muscle activation during maximal and submaximal isokinetic fatigue tests of the knee extensors." J Electromyogr Kinesiol. 2006 Dec;16(6):661-8.

Hedayatpour N, Arendt-Nielsen L, Farina D, (2008). "Non-uniform electromyographic activity during fatigue and recovery of the vastus medialis and lateralis muscles", Journal of Electromyography and Kinesiology 18, pp. 390-396.

Hermens HJ, van Bruggen TAM (1988). "Simulation of fatigue related changes in spectral parameters of surface EMG" Engineering in Medicine and Biology Society, 1988. Proceedings of the Annual International Conference of the IEEE, 4-7 Nov. 1988, vol. 4, pp. 1706-1707.

Hermens HJ, Freriks B, Disselhorst-Klug C, Rau G (2000). "Development of recommendations for SEMG sensors and sensor placement procedures." Journal of Electromyography and Kinesiology. 2000; 10(5):361-74.

Hodges P, Bui B. (1996) "A comparison of computer-based methods for the determination of onset of muscle contraction using electromyography," Electroenc. Clin. Neurophysiol., vol. 101, pp. 511-519.

Hodgkin AL, Huxley AF (1952). "A quantitative description of membrane current and its application to conduction and excitation in nerve," J Physiol, vol. 117, pp. 500-544.

Hollman JH, Hohl JM, Kraft JL, Strauss JD, Traver KJ (2013). "Does the fast Fourier transformation window length affect the slope of an electromyogram's median frequency plot during a fatiguing isometric contraction?" Gait \& Posture 38 (2013) $161-164$.

Houtz SJ, Fischer FJ (1959). "An analysis of muscle action and joint excursion during exercise on a stationary bicycle." J Bone Joint Surg Am 1959;41-A:123-31.

Housh TJ, Perry SR, Bull AJ, Johnson GO, Ebersole KT, Housh DJ, deVries HA (2000) "Mechanomyographic and electromyographic responses during submaximal cycle ergometry." Eur J Appl Physiol. 2000 Nov;83(4 -5):381-7. 
Hug F, Bendahan D, Le Fur Y, Cozzone PJ, Grelot L (2004a). "Heterogeneity of muscle recruitment pattern during pedaling in professional road cyclists: a magnetic resonance imaging and electromyography study." Eur J Appl Physiol 2004a;92:334-42.

Hug F, Faucher M, Marqueste T, Guillot C, Kipson N, Jammes Y (2004b). "Electromyographic signs of neuromuscular fatigue are concomitant with further increase in ventilation during static handgrip." Clin Physiol Funct Imag 2004b;24:2532.

Hug F, Laplaud D, Lucia A, Grelot L (2006a). "EMG threshold determination in eight lower limb muscles during cycling exercise: a pilot study." Int J Sport Med 2006a;27:456-62.

Hug F, Marqueste T, Le Fur Y, Cozzone PJ, Grelot L, Bendahan D (2006b). "Selective training-induced thigh muscles hypertrophy in professional road cyclists." Eur J Appl Physiol 2006b;97:591-7.

Hug F, Dorel S. (2009) "Electromyographic analysis of pedaling: A review" Journal of Electromyography and Kinesiology 19 (2009) 182-198.

Hunter IW, Kearney RE, Jones LA (1987). "Estimation of the conduction velocity of muscle action potentials using phase and impulse response function techniques." Med Bio Eng Comput 1987;25:121-6.

Hunter AM, St Clair Gibson A, Lambert M, Noakes TD. "Electromyographic (EMG) normalization method for cycle fatigue protocols." Med Sci Sport Exerc 2002;34:85761.

Hussain MS, Reaz MBI, Mohd-Yasin F, Ibrahimy MI (2009). "Electromyography signal analysis using wavelet transform and higher order statistics to determine muscle contraction." Expert Systems, vol. 26, no. 1, pp. 35-48.

Hussain MS, Mamun Md (2012) "Wavelet Denoising and Surface Electromyography Analysis". Research Journal of Applied Sciences, Engineering and Technology 4(15): 2372-2374.

Inbar GF, Noujaim AE (1984) "On surface EMG spectral characterization and its application to diagnostic classification", IEEE Trans. Biomed. Eng. 31 (9) (1984) 597604.

Inbar GF, Allin J, Kranz H. (1987) "Surface EMG spectral changes with muscle length." Medical and Biological Engineering and Computing. 1987; 25(6):683-9.

Ismail AR, Asfour SS (1998). "Continuous wavelet transform application to EMG signals during human gait" Conference Record of the Thirty-Second Asilomar Conference on Signals, Systems \&amp; Computers, 1-4 Nov. 1998, vol. 1, pp. 325-329. 
Jansen R, Ament W, Verkerke GJ, Hof AL. (1997) "Median power frequency of the surface electromyogram and blood lactate concentration in incremental cycle ergometry,” Eur. J. Appl. Physiol. Occup. Physiol. v. 75 , n .2, pp. 102-8.

Jiang N, Falla D, d'Avella A, Graimann B, Farina D. (2010) "Myoelectric control in neurorehabilitation.” Crit Rev Biomed Eng. 2010;38(4):381-91.

Jonsson B, Bagga UE (1968). "Displacement, deformaand and fracture of wire electrodes for electromyography”, Electromyography 8 (1968) 328-347.

Johnson MA, Polgar J, Weightman D, Appleton D (1973). "Data on the distribution of fibre types in thirty-six human muscles. An autopsy study." J Neurol Sci 1973;18(1):111-29.

Jorge M, Hull ML. (1986) "Analysys of EMG measurements during bicycle pedalling". J Biomechanics, Vol 19, n. 9, pp. 683-694.

Jung-Yong K, Myung-Chul J, Haight JM. (2005) “The sensitivity of autoregressive model coefficient in quantification of trunk muscle fatigue during a sustained isometric contraction.” International Journal of Industrial Ergonomics, vol. 35, pp. 321-330.

Kamen G, Gabriel DA (2010). "Essentials of electromyography", Human Kinetics.

Karlsson S, Yu J, Akay M. (2000) "Time-frequency analysis of myoelectric signal during dynamic contractions: A comparative study," IEEE Trans BME v. 47, pp. 228-238.

Karlsson S, Gerdle B. (2001) "Mean frequency and signal amplitude of the surface EMG of the quadriceps muscles increase with increasing torque - a study using the continuous wavelet transform." Journal of Electromyography and Kinesiology, vol. 11, pp. 131-140.

Kay D, St Clair Gibson A, Mitchell MJ, Lambert MI, Noakes TD. (2000) "Different neuromuscular recruitment patterns during eccentric, concentric and isometric contractions". J Electromyogr Kinesiol. 2000 Dec;10(6):425-31.

Kiryu T, Takahashi K, Saitoh Y, (1995) "Evaluation of Muscular Fatigue during Bicycle Ergometer Exercise using the Propotion Time-Series of Principal Components", IEEEEMBC and CMBEC Theme 5: Neuromuscular Systems/Biomechanics.

Kiryu T, Morishiata M, Yamada H, Okada M, (1998) "A Muscular Fatigue Index Based on the Relationships Between Superimposed $M$ Wave and Preceding Background Activity", IEEE Trans. Biomed. Eng., v. 45, v. 10, pp. 1194-1204.

Knaflitz M, Bonato P (1999). "Time-frequency methods applied to muscle fatigue assessment during dynamic contractions." Journal of Electromyography and Kinesiology, vol. 9, pp. 337-350. 
Komi PV, Buskirk ER. (1970) "Reproducibility of electromyographic measurements with inserted wire electrodes and surface electrodes", Electromyography 10 (1970) 357367.

Komi PA, Tesch P. (1979) "EMG frequency spectrum, muscle structure and fatigue during dynamic contractions in man.” Eur J Appl Physiol 1979;42:41-50.

Korosec D. (2000) "Parametric estimation of the continuous non-stationary spectrum and its dynamics in surface EMG studies." International Journal of Medical Informatics 58-59 (2000) 59-69.

Krivickas LS, Nadler SF, Davies MR, Petroski GF, Feinberg JH. (1996) "Spectral analysis during fatigue, Surface and fine wire electrode comparison", Am. J. Phys. Med. Rehabil. 75 (1996) 15-20.

Kukulka, CG, Clamann HP (1981). "Comparison of the recruitment and discharge properties of motor units in human brachial biceps and adductor pollicis during isometric contractions" Brain Res, vol. 219, pp. 45-55.

Lanyi X, Adler A. (2004) "An improved method for muscle activation detection during gait", In: Canadian Conference of Electrical and Computer Engineering 2004, Canadá, pp. 357-360.

Laplaud D, Hug F, Grelot L (2006). "Reproducibility of eight lower limb muscles activity level in the course of an incremental pedaling exercise." J Electromyogr Kinesiol 2006;16:158-66.

Larivière C, Arsenault AB, Gravel D, Gagnon D, Loisel P. (2002) "Evaluation of measurement strategies to increase the reliability of EMG indices to assess back muscle fatigue and recovery.” J Electromyogr Kinesiol. 2002 Apr;12(2):91-102.

Larivière C, Gagnon D, Gravel D, Bertrand Arsenault A. (2008) "The assessment of back muscle capacity using intermittent static contractions. Part I - Validity and reliability of electromyographic indices of fatigue." J Electromyogr Kinesiol. 2008 Dec;18(6):100619.

Larivière C, Gravel D, Gagnon D, Arsenault AB. (2009) "Toward the development of predictive equations of back muscle capacity based on frequency- and temporaldomain electromyographic indices computed from intermittent static contractions." Spine J. 2009 Jan-Feb;9(1):87-95.

Larsson B, Mansson B, Karlberg C, Syvertsson P, Elert J, Gerdle B. (1999) "Reproducibility of surface EMG variables and Peak torque during three sets of ten dynamic contractions." J Electromyogr Kinesiol 1999;9:351-7.

LeFever RS, DeLuca CJ (1982a) "A procedure for decomposing the myoelectric signal into its constituent action potentials: I. Technique, theory and implementation," IEEE Trans BME 29(3);149-157. 
LeFever RS, DeLuca CJ (1982b) "A procedure for decomposing the myoelectric signal into its constituent action potentials: II execution and test of accuracy," IEEE Trans BME 29(3);158-164.

Li L, Caldwell GE (1999). "Coefficient of cross correlation and the time domain correspondence." J Electromyogr Kinesiol 1999;9:385-9.

Lindström L. (1970). "On the frequency spectrum of EMG signals." Thesis, Research Laboratories for Medical Electronics, Goteborg.

Lindström L, Magnusson R, Petersén I (1970). "Muscular fatigue and action potential conduction velocity changes studied with frequency analysis of EMG signals", Electromyography, vol. 10, pp. 341-356.

Lindström L, Magnusson R, Petersén I (1971). "The 'dip phenomenon' in power spectra of EMG signals", Electroencephalogr Clin Neurophysiol, vol. 30, pp. 259-260.

Lindström L, Magnusson R, Petersén I (1977). "An electromyographic index for localized muscle fatigue", J Appl Physiol, vol. 43, pp. 750-754.

Lindström L, Magnusson R (1977). "Interpretation of myoelectric power spectra: a model and its applications", Proc IEEE, vol. 65, pp. 653-662.

Lindström L, Petersén I (1981). "Power spectra of myoelectric signals: motor unit activity and muscle fatigue." In Neurology, vol. 1, Clinical Neurophyeiology, pp. 66-87. London: Butterworths.

Lo Conte LR, Merletti R, Sandri GV (1994). "Hermite expansions of compact support waveforms: applications to myoelectric signals", IEEE Trans Biomed Eng, vol. 41, pp. 1147-1159.

Lo Conte LR, Merletti R (1996). "Estimating EMG spectral compression: comparison of four indices." 18th Annual International Conference of the IEEE Engineering in Medicine and Biology Society, Amsterdam 1996, pp. 1472-1473.

Loeb GE, Gans C. (1986). "Electromyography for experimentalists." Chicago: University of Chicago Press.

Lowery M, Vaughan C, Nolan P, O'Malley M, (2000). "Spectral Compression of the Electromyographic Signal due to Decreasing Muscle Fiber Conduction Velocity", IEEE Transactions on Rehabilitation Engineering, v. 8, n. 3, pp. 353-361.

Lowery M, Nolan P, O’Malley M, (2002). "Electromyogram median frequency, spectral compression and muscle fibre conduction velocity during sustained sub-maximal contraction of the brachioradialis muscle", Journal of Electromyography and Kinesiology 12, pp. 111-118. 
Lucía A, Vaquero AF, Pérez M, Sánchez O, Sánchez V, Gómez MA, Chicharro JL (1997). "Electromyographic response to exercise in cardiac transplant patients: a new method for anaerobic threshold determination?" Chest. 1997 Jun;111(6):1571-6.

Maïsettia O, Guével A, Legrosd P, Hogrela JY, (2002). "SEMG power spectrum changes during a sustained 50\% Maximum Voluntary Isometric Torque do not depend upon the prior knowledge of the exercise duration", Journal of Electromyography and Kinesiology 12, pp. 103-109.

Mallat SA (2009). "Wavelet Tour of Signal Processing - The Sparse Way.”, Elsevier.

Marsh AP, Martin PE (1995). "The relationship between cadence and lower extremity EMG in cyclists and noncyclists." Med Sci Sport Exerc 1995;27:217-25.

Masuda T, Miyano H, Sadoyama T (1985): "The position of innervation zones in the biceps brachii investigated by surface electromyography", IEEE Trans Biomed Eng, vol. 32, pp. 36-42.

Masuda T, Sadoyama T, e Shiraishi M. (1996) "Dependence of average muscle fiber conduction velocity on voluntary contraction force." J Electromyogr Kinesiol 6: 267276.

Masuda K, Masuda T, Sadoyama T, Inaki M, Katsuta S (1999). "Changes in surface EMG parameters during static and dynamic fatiguing contractions", Journal of Electromyography and Kinesiology 9, pp. 39-46.

McGill K C, Cummins KL, Dorfman LJ (1985) "Automatic decomposition of the clinical electromyogram,” IEEE Trans BME vol. 32, n. 7, pp. 470-477.

McGill S, Juker D, Kropf P. (1996) "Appropriately placed surface EMG electrodes reflect deep muscle activity (psoas, quadratus lumborum, abdominal wall) in the lumbar spine.” J Biomechanics, v. 29, n. 11, pp. 1503-1507.

Medbo JI, Tabata I. (1993) "Anaerobic energy release in working muscle during $30 \mathrm{~s}$ to 3 min of exhausting bicycling." Journal of Applied Physiology, 75(4):1654-60.

Melchiorri G, Rainoldi A (2011) "Muscle fatigue induced by two different resistances: Elastic tubing versus weight machines", Journal of Electromyography and Kinesiology 21, p. 954-959.

Merletti R, Sabbahi MA, DeLuca CJ (1984) "Median frequency of the myoelectric signal: Effect of muscle ischemia and cooling," Eur J Appl Physiol, vol. 52, pp. 258-265.

Merletti R, Balestra G, Knaflitz M (1989) "Effect of FFT based algorithms on estimation of myoelectric signal spectral parameters" Proceedings of the Annual International Conference of the IEEE Engineering in Engineering in Medicine and Biology Society, 1989. Images of the Twenty-First Century., 09-12 Nov 1989, Seattle USA, vol. 3, pp. 1022-1023. 
Merletti R, Knaflitz M, DeLuca CJ, (1990) "Myoelectric manifestations of fatigue in volunatry and electrically elicited contractions," J Appl Physiol, vol. 68, pp. 16571667.

Merletti R, DiTorino P, (1999) "Standards for reporting EMG data," J Electromyograph Kinesiol, vol. 9, n. 1, p. III-IV.

Merletti R (2000) "Surface electromyography: The SENIAM project"; Europa Medicophysica 36, pp. 167-169.

Merletti R, Hermens H (2000) "Introduction to the special issue on the SENIAM European Concerted Action” J Electrom Kinesiol 10, pp. 283-286.

Merletti R, Parker PA (2004) "Electromyography, physiology, engineering, and noninvasive applications", New Jersey: John Wiley \& Sons, Inc.

Merletti R, Hermens H (2004) "Detection and conditioning of the surface EMG signal" Em: Electromyography: Physiology, Engineering, and Noninvasive Applications, R. Merletti and P. A. Parker, Eds. Hobooken, New Jersey: JohnWiley \& Sons, 2004, ch. 5, pp. 107-132.

Merletti R, Rainoldi A, Farina D. (2004) "Myoelectric manifestations of muscle fatigue" Em: Electromyography: Physiology, Engineering, and Noninvasive Applications, R. Merletti and P. A. Parker, Eds. Hobooken, New Jersey: JohnWiley \& Sons, 2004, ch. 9, pp. 233-258.

Merlo A, Dario D, Merletti R.(2003) "A Fast and Reliable Technique for Muscle Activity Detection From Surface EMG Signals", IEEE Transactions on Biomedical Engineering, vol. 50, n. 3, pp. 316-323.

Mesin L, Merletti R, Rainoldi A, (2009) "Surface EMG: The issue of electrode location", Journal of Electromyography and Kinesiology 19, pp. 719-726.

Mewett DT, Nazeran H, Reynolds KJ. (2001). "Removing Power Line Noise from Recorded EMG." 23rd Annual Conference - IEEE/EMBS Oct.25-28, 2001, Istanbul, TURKEY.

Milhomem TR. (2011) "Avaliação do Desempenho de Ciclistas em Exercício Isocinético com Produção de Fadiga: Instrumentação, Biomecânica e Eletromiografia." Dissertação de Mestrado, publicação 461/11, Universidade de Brasília, Brasília, 2011, $68 \mathrm{p}$.

Milhomem TR, Costa Filho WL, Telles FS, Braga M, Carmo JC, Schwartz FP, Nascimento FAO. (2012) "Instrumentação Para Avaliação de Desempenho de Ciclistas em Protocolo Dinâmico Com Produção de Fadiga." In: XXIII Congresso Brasileiro de Engenharia Biomédica - CBEB 2012, 2012, Ipojuca. Anais do CBEB - 2012, 2012. v. 1. pp. $1546-1550$. 
Milhomem TR, Rocha Junior VA, Ferreira Junior JB, Bottaro M, Carmo JC, Nascimento FAO. (2014a) "Fadiga em Dinamometria Isocinética: Frequência de Potência Mediana em Diferentes Fases do Exercício.” In: VII Simpósio em Engenharia Biomédica, 2014, Uberlândia. Anais do VII SEB - Tecnologia a Favor da Vida, v. 7. pp. 33-38.

Milhomem TR, Rocha Junior VA, Ferreira Junior JB, Bottaro M, Carmo JC, Nascimento FAO. (2014b) "Avaliação do Comportamento de Índices Eletromiográficos com o Acúmulo de Fadiga em Séries Múltiplas de Exercício Isocinético.” In: VII Simpósio em Engenharia Biomédica, 2014, Uberlândia. Anais do VII SEB - Tecnologia a Favor da Vida, 2014. v. 7. pp. 39-44.

Milhomem TR, Rocha Junior VA, Andrade MM, Carmo JC, Nascimento FAO. (2014c) "Redução da Interferência de Rede Elétrica em Sinais Eletromiográficos Usando DWT.” In: XX Congresso Brasileiro de Automática, 2014, Belo Horizonte. Anais do XX Congresso Brasileiro de Automática, 2014, v. 20. pp. 2881-2885.

Milhomem TR, Rocha Junior VA, Carmo JC, Nascimento FAO. (2014d) "Desempenho em Ciclismo: Instrumentação e Parâmetros Biomecânicos e Eletromiográficos." In: XXIV Congresso Brasileiro de Engenharia Biomédica, 2014, Uberlândia. Anais do XXIV CBEB, v. 24. pp. 809-812.

Milhomem TR, Rocha Junior VA, Ferreira Junior JB, Carmo JC, Nascimento FAO. (2014e) "Descritores de EMG-S em Dinamometria Isocinética: Índices Espectrais em Diferentes Fases do Exercício." In: XXIV Congresso Brasileiro de Engenharia Biomédica, 2014, Uberlândia. Anais do XXIV CBEB, v. 24. pp. 829-832.

Mills KR. (1982) "Power Spectral Analysis of Electromyogram and Compound Muscle Action Potential During Muscle Fatigue and Recovery.” J. Physiol., 326, pp. 401-409.

Milner-Brown HS, Stein RB, Yemm R (1973). "Changes in firing rate of human motor units during linearly changing voluntary contractions" J Physiol (Lond), vol. 230, pp. 371-390.

Milner-Brown HS, Stein RB. (1975). "The relation between the surface electromyogram and muscular force." J Physiol 1975;246:549-69.

Milner-Brown HS, Mellenthin M, Miller RG (1986). "Quantifying human muscle strength, endurance and fatigue." Arch Phys Med Rehabil. 1986 Aug;67(8):530-5.

Mirka GA (1991). "The quantification of EMG normalization error." Ergonomics 1991;34:343-52.

Molina RM, Galan AT, Garcia MSM. (1997). "Spectral electromyographic changes during a muscular strengthening training based on electrical stimulation." Electromyogr Clin Neurophysiol. 1997 Aug;37(5):287-95.

Moritani T, Muro M, Nagata A, (1986). "Intramuscular and Surface Eletromyogram Changes During Muscle Fatigue,” J. Appl. Physiol. v. 60, p. 1179-85. 
Moritani T, Muro M (1987). "Motor unit activity and surface electromyogram power spectrum during increasing force of contraction” Eur J Appl Physiol vol. 56, pp. 260265.

Moritani T, Stegeman D, Merletti R, (2004). "Basic physiology and biophysics of EMG signal generation" Em: Electromyography: Physiology, Engineering, and Noninvasive Applications, R. Merletti and P. A. Parker, Eds. Hobooken, New Jersey: JohnWiley \& Sons, 2004, ch. 1, pp. 1-26.

Moshou D, Hostens I, Papaioannou G, Ramon H. (2005) "Dynamic muscle fatigue detection using self-organizing maps.” Applied Soft Computing 5 (2005) 391-398.

Muhammad W, Meste O, Rix H, Farina D (2003). "A pseudojoint estimation of time delay and scale factor for M-wave analysis", IEEE Trans Biomed Eng, vol. 50, pp. 459-468.

Neptune RR, KautzSA, Zajac FE. (2000) "Muscle contributions to specific biomechanical functions do not change in forward versus backward pedaling." Journal of Biomechanics v. 33 pp. 155-164, 2000.

Neto CD, Schmidt G, Candotti CT, Loss JF, Zaro MA, Cervieri AE, Guimarães ACS. (2001) "Desenvolvimento de uma plataforma de força em pedal de ciclismo." Revista Brasileira de Biomecânica. Ano 2, nº 3 Novembro, 2001.

Nobrega JAM, Manzano GM. (2013) "Eletroneuromiografia: bases e aplicações." Em: "Propedêutica Ortopédica e Traumatológica", R. G. Bañolas, Ed. Artmed, 2013, cap. 5, pp. 63-71.

Öberg T, Sandsjö L, Kadefors R (1992) “Arm movement and EMG power frequency in the trapezius muscle: A comparison between surface and intramuscular recording techniques." Electromyogr Clin Neurophysiol, vol. 32, pp. 87-96.

Ogino K, Kozak W. (1983) "Spectrum analysis of surface electromyogram (EMG)" IEEE International Conference on Acoustics, Speech, and Signal Processing, ICASSP '83 (Apr 1983), vol. 8, pp. 1114 -1117.

Ollivier K, Portero P, Olivier Maïsetti O, Hogrel JY, (2005) "Repeatability of surface EMG parameters at various isometric contraction levels and during fatigue using bipolar and Laplacian electrode configurations", Journal of Electromyography and Kinesiology 15, pp. 466-473.

Parker PA, Englehart KB, Hudgins BS (2004) "Control of powered upper limb prostheses" Em: Electromyography: Physiology, Engineering, and Noninvasive Applications, R. Merletti and P. A. Parker, Eds. Hobooken, New Jersey: JohnWiley \& Sons, 2004, ch. 18, pp. 453-476.

Petrofsky JS (1979). "Frequency and amplitude analysis of the EMG during exercise on the bicycle ergometer." Eur J Appl Physiol Occup Physiol 1979;41:1-15. 
Phinyomark A, Phukpattaranont P, Limsakul C. (2011) "Wavelet-based denoising algorithm for robust EMG pattern recognition." Fluctuation and Noise Letters, vol. 10, No. 2, pp. 157-167.

Piper H (1912) “Elektrophysiologie Menschlicher Muskeln”, Berlin: Springer Verlag.

Potvin JR. (1997) "Effects of muscle kinematics on surface EMG amplitude and frequency during fatiguing dynamic contractions." J Appl Physiol 1997;82:144-51.

Quotb A, Bornat Y, Renaud S (2011). "Wavelet transform for real-time detection of action potentials in neural signals.” Frontiers in Neuroengineering, July 2011, vol. 4, article 7.

Rainoldi A, Galardi G, Maderna L, Comi G, LoConte L, Merletti R (1999). "Repeatability of surface EMG variables during voluntary isometric contractions of the biceps brachii muscle.” J Electromyogr Kinesiol. 1999 Apr;9(2):105-19.

Rainoldi A, Casale R, Hodges P, Jull G (2004). "Applications in rehabilitation medicine and related fields" Em: Electromyography: Physiology, Engineering, and Noninvasive Applications, R. Merletti and P. A. Parker, Eds. Hobooken, New Jersey: JohnWiley \& Sons, 2004, ch. 16, pp. 403-434.

Rainoldi A, Falla D, Mellor R, Bennell K, Hodges P (2008). "Myoelectric manifestations of fatigue in vastus lateralis, medialis obliquus and medialis longus muscles." Journal of Electromyography and Kinesiology, vol. 18, pp. 1032-1037.

Ranniger C, Akin D (1997). "EMG Mean Power Frequency Determination Using Wavelet Analysis", Proceedings - 19th International Conference - IEEE/EMBS Oct. 30 - Nov. 2, Chicago, IL. USA.

Roesler H (1974). "Statistical analysis and evaluation of myoelectric signals for proportional control." In: Herberts P, Kadefors R, Magnusson R, Petersen I, editors. "The control of upper-extremity prostheses and orthoses." Springfield, IL: Charles C. Thomas Publisher, 1974, pp. 44-53.

Roman-Liu D, Konarska M, (2009). "Characteristics of power spectrum density function of EMG during muscle contraction below 30\%MVC", Journal of Electromyography and Kinesiology 19, p. 864-874.

Rouffet DM, Hautier CA (2008). "EMG normalization to study muscle activation in cycling." J Electromyogr Kinesiol. 2008 Oct;18(5):866-78.

Ryan MM, Gregor RJ (1992). "EMG profiles of lower extremity muscles during cycling at constant workload and cadence." J Electromyogr Kinesiol 1992;2:69-80.

Sadoyama T, Masuda T, Miyano T (1985). "Optimal conditions for the measurement of muscle fiber conduction velocity using surface electrode arrays", Med Biol Eng Comput, vol. 23, pp. 339-342. 
Sadoyama T, Masuda M, Miyata H, Katsuta S (1988). "Fibre conduction velocity and fibre composition in human vastus lateralis.” Eur J Appl Physiol 1988;57:767-71.

Sakurai T, Toda M, Sakurazawa S, Akita J, Kondo K, Nakamura Y, (2010) "Detection of Muscle Fatigue by the Surface Electromyogram and its Application", 9th IEEE/ACIS International Conference on Computer and Information Science, IEEE Computer Society.

Salomoni S (2008). "Efeito das Diferenças entre Gêneros e do Ciclo Menstrual Feminino da Fadiga e seus Reflexos nas Variáveis do Sinal Eletromiográfico de Superfície." Dissertação de Mestrado em Engenharia Elétrica, publicação 340/08, Departamento de Engenharia Elétrica, Universidade de Brasília, Brasília, 85 p.

Sarre G, Lepers R, Maffiuletti N, Millet G, Martin A (2003). "Influence of cycling cadence on neuromuscular activity of the knee extensors in humans." Eur J Appl Physiol 2003;88:476-9.

Sarre G, Lepers R (2005) "Neuromuscular function during prolonged pedaling exercise at different cadences." Acta Physiol Scand 2005;185:321-8.

Saunders MJ, Evans EM, Arngrimsson SA, Allison JD, Warren GL, Cureton KJ (2000) "Muscle activation and the slow component rise in oxygen uptake during cycling." Med Sci Sport Exerc 2000;32:2040-5.

Sbriccoli P, Bazzucchi I, Rosponi A, Bernardi M, DeVito G, Felici F, (2003) "Amplitude and spectral characteristics of biceps Brachii sEMG depend upon speed of isometric force generation", Journal of Electromyography and Kinesiology 13, p. 139-147.

Shaw D, Huang CR, (2010) "Assessing Muscle Fatigue by measuring the EMG of Biceps Brachii", 3rd International Conference on Biomedical Engineering and Informatics (BMEI 2010).

Schwartz FP (2010). "Análise do comportamento dos descritores biomecânicos e eletromiográficos de superfície em exercício resistido por dinamometria isocinética com produção de fadiga." Tese de Doutorado, Publicação 053/10, Departamento de Engenharia Elétrica, Universidade de Brasília, Brasília.

Schwartz FP, Celes RS, Pereira MCC, Milhomem TR, Costa Filho WL, Souza ACF, Carmo JC, Nascimento FAO. (2012) "How to Avoid The Impacts of Velocity Overshoot on The Estimation of Torque and Velocity Development Rates." In: XXIII Congresso Brasileiro de Engenharia Biomédica - CBEB 2012, 2012, Ipojuca. Anais do CBEB - 2012. v. 1. p. 282-285.

Silbernagl S, Despopoulos A. (2003) "Fisiologia - texto e atlas". 5a ed, Porto Alegre, Artmed.

Soares FA (2007). "Estudo do Comportamento das Variáveis Eletromiográficas ao Longo do Ciclo Menstrual." Dissertação de Mestrado em Engenharia Elétrica, publicação 318/07, Departamento de Engenharia Elétrica, Universidade de Brasília, Brasília, 75 p. 
Soares WC, Vieira Filho J, Duarte MAQ, Villarreal F (2008). "Análise de Métodos de Redução de Ruído por Limiar no Domínio Wavelet" TEMA Tend. Mat. Apl. Comput., vol. 9, No. 3, 471-480.

Søgaard K, Blangsted AK, Jørgensen LV, Madeleine P, Sjøgaard G (2003). "Evidence of long term muscle fatigue following prolonged intermittent contractions based on mechano- and electromyograms." J Electromyogr Kinesiol. 2003 Oct;13(5):441-50.

Solomonow M, Baten C, Smith J, Baratta R, Hermens H, D'Ambrosia R, and Shoji H (1990). "Electromyogram power spectra frequencies associated with motor unit recruitment strategies.” J Appl Physiol, vol. 68, pp. 1177-1185.

Sparto PJ, Parnianpour M, Barria EA, Jagadeesh JM, (2000). "Wavelet and Short-Time Fourier Transform Analysis of Electromyography for Detection of Back Muscle Fatigue", IEEE Transactions on Rehabilitation Engineering, vol. 8, n. 3, p. 433-436.

Spinelli E, Felice CJ, Mayosky M, Politti JC, Valentinuzzi ME (2001). "Propagation velocity measurement: autocorrelation technique applied to the electromyogram", Med Biol Eng Cornput, vol. 39, pp. 590-593.

Stulen FB, DeLuca CJ (1981). "Frequency parameters of the myoelectric signal as a measure of muscle conduction velocity," IEEE Trans. Biomed. Eng., vol. 28, pp. 512 522.

Stulen FB, DeLuca CJ (1982). "Muscle fatigue monitor: a non invasive device for observing localized muscular fatigue," IEEE Trans. Biomed. Eng., vol. 29, pp. 760769.

Takaishi T, Yamamoto T, Ono T, Ito T, Moritani T. (1998) "Neuromuscular, metabolic, and kinetic adaptations for skilled pedaling performance in cyclists." Med Sci Sport Exerc, vol. 30, pp. 442-9.

Taylor AD, Bronks R. (1994) "Electromyographic correlates of the transition from aerobic to anaerobic metabolism in treadmill running." Eur J Appl Physiol Occup Physiol, vol. 69 , pp. 508-515.

Tesch P, Karlsson J (1985) "Muscle fiber types and size in trained and untrained muscles of elite athletes." J Appl Physiol 59:1716-1720.

Telles F, Braga M, Milhomem TR, Costa Filho WL, Carmo JC. (2012) "Identificação de Posturas Indesejadas ao Pedalar Através das Curvas de Forças Aplicadas em Pedais." In: 64 ${ }^{\mathrm{a}}$ Reunião Anual da SBPC, 2012, São Luís, MA. Anais da $64^{\mathrm{a}}$ Reunião Anual da SBPC, v. 1.

Thiebaud RS, Yasuda T, Loenneke JP, Abe T. (2013) "Effects of low-intensity concentric and eccentric exercise combined with blood flow restriction on indices of exerciseinduced muscle damage.” Interv Med Appl Sci. Jun;5(2):53-9. 
Thongpanja S, Phinyomark A, Phukpattaranont P, Limsakul C, (2012) "A Feasibility Study of Fatigue and Muscle Contraction Indices Based on EMG Time-dependent Spectral Analysis", Procedia Engineering 32, p. 239-245.

Trontelj JV, Jabre J, Mihelin M (2004) "Needle and wire detection techniques" Em: Electromyography: Physiology, Engineering, and Noninvasive Applications, R. Merletti and P. A. Parker, Eds. Hobooken, New Jersey: JohnWiley \& Sons, 2004, ch. 2, pp. 27-46.

Ullah K, Cescon C, Afsharipour B, Merletti R (2014). "Automatic detection of motor unit innervation zones of the external anal sphincter by multichannel surface EMG." J Electromyogr Kinesiol. Dec;24(6):860-67.

Vannozzi G, Conforto S, D'Alessio T. (2010) “Automatic detection of surface EMG activation timing using a wavelet transform based method", Journal of Electromyography and Kinesiology, vol. 20, pp. 767-772.

Vollestad NK (1997). "Measurement of Human Muscle Fatigue.” J. Neuro. Meth., v. 74, n. 2, p. 219-27.

Waly SM, Asfour SS, Khalil TM. (2003) "Effects of window size and load on estimated myoelectric signal power spectrum.” Computers \& Industrial Engineering 44, 595-610.

Wilk KE, Arrigo CA e Andrews JR (1992) "Isokinetic Testing of the Shoulder Abductors and Adductors: Windowed vs. Nonwindowed Data Collection", Journal of Orthopedic and Sports Physical Therapy, v. 15, n. 2, pp. 107-112.

Wittek A, Ono K, Kajzer J, Ortengren R, Inami S (2001) "Analysis and comparison of reflex times and electromyogram of cervicalmuscles under impact loading using surface and fine-wire electrodes" IEEE Transactions on Biomedical Engineering, vol. 48, n. 2, pp. 143-153.

Wretling M-L, Henriksson-Larsén K, Gerdle B (1997) "Inter-relationship between muscle morphology, mechanical output and electromyographic activity during fatiguing dynamic knee-extensions in untrained females.” Eur J Appl Physiol 1997;76:483-90.

Yacoub S, Raoof K, (2008). "Noise Removal from Surface Respiratory EMG Signal." World Academy of Science, Engineering and Technology, Vol. 14, pp. 580-587.

Yochum M, Bakir T, Lepers R, Binczak S, (2012) "Estimation of Muscular Fatigue Under Electromyostimulation Using CWT", IEEE Transactions on Biomedical Engineering, v. 59, n. 12, p. 3372-3378.

Zaman SA, Ferdjallah M, Khamayseh A, (2005) "Muscle Fatigue Analysis For Healthy Adults Using TVAR Model With Instantaneous Frequency Estimation", Proceedings of the 38th Southeastern Symposium on System Theory, Tennessee Technological University, Cookeville, TN, USA, March 5-7, 2006. 
Zaman, SA, MacIsaac, DT, Parker, PA, (2011) "Repeatability of surface EMG-based Single Parameter Muscle Fatigue Assessment Strategies in Static and Cyclic Contractions", 33rd Annual International Conference of the IEEE EMBS.

Zazula D, Karlsson S, Doncarli C. (2004) "Advanced signal processing techniques" Em: Electromyography: Physiology, Engineering, and Noninvasive Applications, R. Merletti and P. A. Parker, Eds. Hobooken, New Jersey: JohnWiley \& Sons, 2004, ch. 12, pp. 259-304.

Zuniga E, Truong X, Simons D. (1970) "Effect of skin electrode position on averaged electromyographic potential.” Arch, Phys. Med. Rehabil, V. 50: p. 264-72.

Zwarts MJ, Stegeman DF, van Dijk JG. (2004) "Surface EMG applications in neurology" Em: Electromyography: Physiology, Engineering, and Noninvasive Applications, R. Merletti and P. A. Parker, Eds. Hobooken, New Jersey: JohnWiley \& Sons, ch. 12, pp. $323-342$. 